\title{
Paediatric drug utilization in Europe
}

Citation for published version (APA):

Italia, S. (2016). Paediatric drug utilization in Europe: prevalence and socioeconomic aspects of use. [Doctoral Thesis, Maastricht University]. Datawyse / Universitaire Pers Maastricht.

https://doi.org/10.26481/dis.20161020si

Document status and date:

Published: 01/01/2016

DOI:

10.26481/dis.20161020si

Document Version:

Publisher's PDF, also known as Version of record

\section{Please check the document version of this publication:}

- A submitted manuscript is the version of the article upon submission and before peer-review. There can be important differences between the submitted version and the official published version of record.

People interested in the research are advised to contact the author for the final version of the publication, or visit the DOI to the publisher's website.

- The final author version and the galley proof are versions of the publication after peer review.

- The final published version features the final layout of the paper including the volume, issue and page numbers.

Link to publication

\footnotetext{
General rights rights.

- You may freely distribute the URL identifying the publication in the public portal. please follow below link for the End User Agreement:

www.umlib.nl/taverne-license

Take down policy

If you believe that this document breaches copyright please contact us at:

repository@maastrichtuniversity.nl

providing details and we will investigate your claim.
}

Copyright and moral rights for the publications made accessible in the public portal are retained by the authors and/or other copyright owners and it is a condition of accessing publications that users recognise and abide by the legal requirements associated with these

- Users may download and print one copy of any publication from the public portal for the purpose of private study or research.

- You may not further distribute the material or use it for any profit-making activity or commercial gain

If the publication is distributed under the terms of Article $25 \mathrm{fa}$ of the Dutch Copyright Act, indicated by the "Taverne" license above, 


\section{Paediatric drug utilization in Europe}

\section{Prevalence and socioeconomic aspects of use}

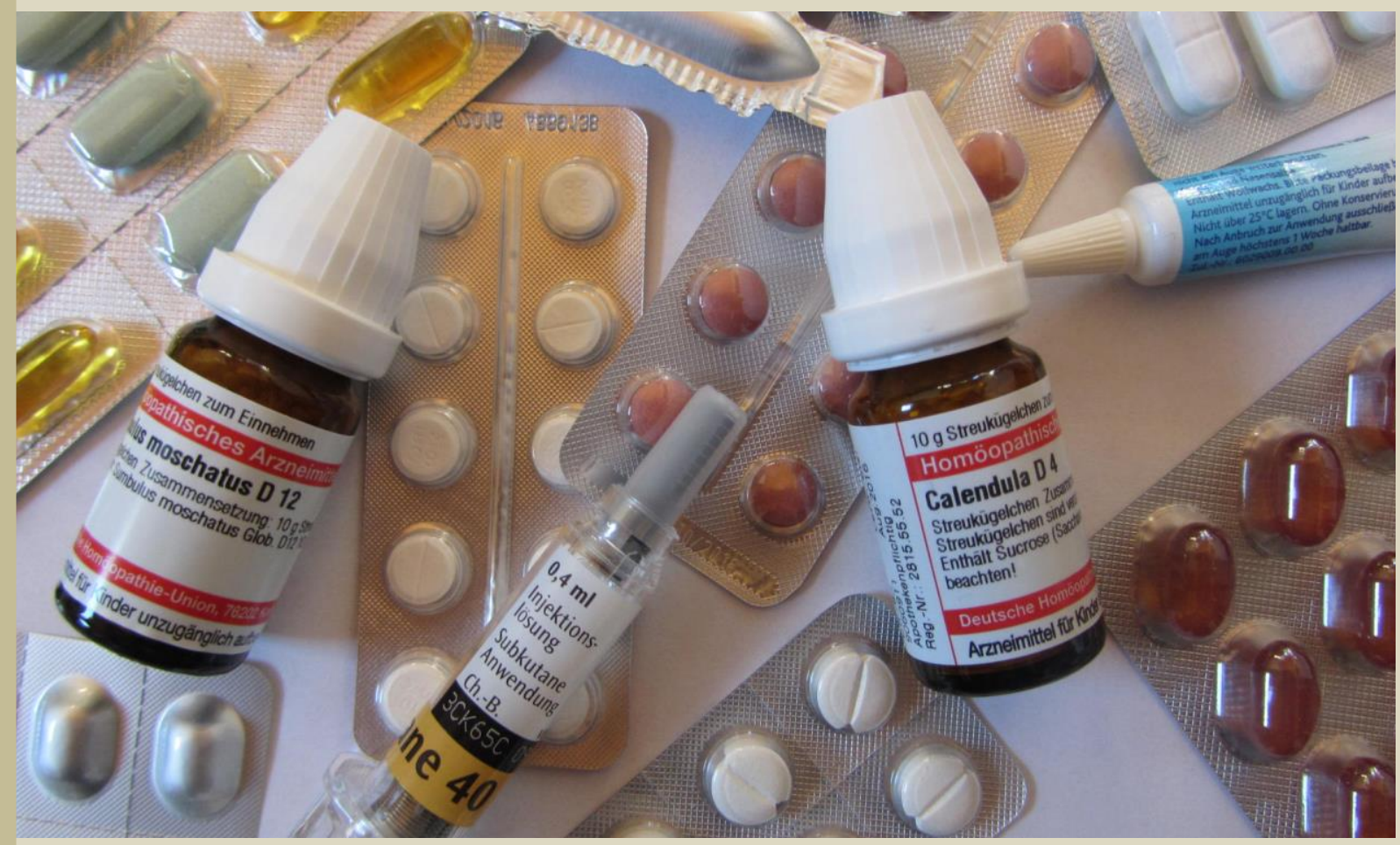

Salvatore Italia 


\section{Colophon}

The research presented in this thesis was conducted at the Department of International Health within the School for Public Health and Primary Care (CAPHRI), Faculty of Health, Medicine, and Life Sciences, Maastricht University, which participates in the Netherlands School for Primary Care Research (CaRe) and is acknowledged by the Royal Dutch Academy of Science (KNAW).

Part of the work for this thesis was conducted at the Helmholtz Zentrum München, German Research Center for Environmental Health, Institute of Health Economics and Health Care Management, Neuherberg, Germany.

Dissertation: Paediatric drug utilization in Europe - Prevalence and socioeconomic aspects of use. Author: Salvatore Italia

Cover design: Nicole Tanja Haas and Salvatore Italia

ISBN: 9789461595935

Printing: Datawyse | Universitaire Pers Maastricht

C Copyright: S. Italia, Maastricht 2016. All rights reserved. No part of this publication may be reproduced without permission of the copyright owner. 


\title{
Paediatric drug utilization in Europe
}

\section{Prevalence and socioeconomic aspects of use}

\author{
DISSERTATION \\ to obtain the degree of Doctor at Maastricht University, \\ on the authority of the Rector Magnificus, Prof. dr. Rianne M. Letschert \\ in accordance with the decision of the Board of Deans, \\ to be defended in public \\ on Thursday, 20 October 2016, at 12.00 hours
}

by

Salvatore Italia

born on 7 July 1967 in Ulm, Germany 


\section{Supervisor}

Prof. dr. Helmut Brand

\section{Co-supervisor}

Dr. Silke B. Wolfenstetter, Ludwig-Maximilians-Universität München, Germany

\section{Assessment Committee}

Prof. dr. Leopold M. G. Curfs (chairman)

Prof. dr. Joerg Hasford, Ludwig-Maximilians-Universität München, Germany

Prof. dr. Jacques Scheres, National Institute of Public Health NIZP, Warsaw, Poland

Prof. dr. Matty P. Weijenberg

\section{Acknowledgement of funding:}

The GINIplus study was mainly supported for the first 3 years by the Federal Ministry for Education, Science, Research and Technology (interventional arm) and Helmholtz Zentrum Munich (former GSF) (observational arm). The 4 year, 6 year, 10 year and 15 year follow-up examinations of the GINIplus study were covered from the respective budgets of the 5 study centres (Helmholtz Zentrum Munich (former GSF), Research Institute at Marien-Hospital Wesel, LMU Munich, TU Munich and from 6 years onwards also from IUF - Leibniz Research-Institute for Environmental Medicine at the University of Düsseldorf) and a grant from the Federal Ministry for Environment (IUF Düsseldorf, FKZ 20462296). The LISAplus study was mainly supported by grants from the Federal Ministry for Education, Science, Research and Technology and in addition from Helmholtz Zentrum Munich (former GSF), Helmholtz Centre for Environmental Research - UFZ, Leipzig, Research Institute at Marien-Hospital Wesel, Pediatric Practice, Bad Honnef for the first 2 years. The 4 year, 6 year, 10 year and 15 year follow-up examinations of the LISAplus study were covered from the respective budgets of the involved partners (Helmholtz Zentrum Munich (former GSF), Helmholtz Centre for Environmental Research - UFZ, Leipzig, Research Institute at Marien-Hospital Wesel, Pediatric Practice, Bad Honnef, IUF - Leibniz-Research Institute for Environmental Medicine at the University of Düsseldorf) and in addition by a grant from the Federal Ministry for Environment (IUF Düsseldorf, FKZ 20462296). Further, the 15 year follow-up examination of the GINIplus and LISAplus studies was supported by the Commission of the European Communities, the $7^{\text {th }}$ Framework Program: MeDALL project. The 15 year follow-up examination of the GINIplus study was additionally supported by the Mead Johnson and Nestlé companies.

This work was also supported by the German Competence Network Obesity ('Kompetenznetz Adipositas') funded by the German Federal Ministry of Education and Research (BMBF) as part of the 'Core Domain Health Economics' (Grant No. 01GI1127). The specific analysis on drug use among children from the German GINIplus and LISAplus birth cohorts was additionally funded by the Helmholtz Zentrum Munich. 


\section{CONTENTS}

Chapter 1 Introduction

Chapter 2 Patterns of complementary and alternative medicine (CAM) use in children: a systematic review.

Chapter 3 Complementary and alternative medicine (CAM) use among chronically ill adolescents from two German birth cohorts.

Chapter 4 Utilization of complementary and alternative medicine (CAM) among children from a German birth cohort (GINIplus): patterns, costs, and trends of use.

Chapter 5 Utilization of self-medication and prescription drugs among 15year-old children from the German GINIplus birth cohort.

Chapter 6 A longitudinal comparison of drug use among 10-year-old children and 15-year-old adolescents from the German GINIplus and LISAplus birth cohorts.

Chapter 7 Prices of over-the-counter-drugs used by adolescents in Germany and their association with socioeconomic factors.

Chapter 8 Status of emergency contraceptives in Europe one year after the European Medicines Agency's recommendation to switch ulipristal acetate to non-prescription status.

Chapter 9 General Discussion

Annex

Valorisation

Summary - Samenvatting - Zusammenfassung - Riassunto

Contributing authors

Annotations

Abbreviations

Acknowledgements

Curriculum vitae

International workshops/conferences/presentations

Public Health related publications 
The important thing is not to stop questioning. Curiosity has its own reason for existence.

Albert Einstein

American physicist born in Ulm, Germany 


\title{
CHAPTER 1
}

\author{
Introduction
}

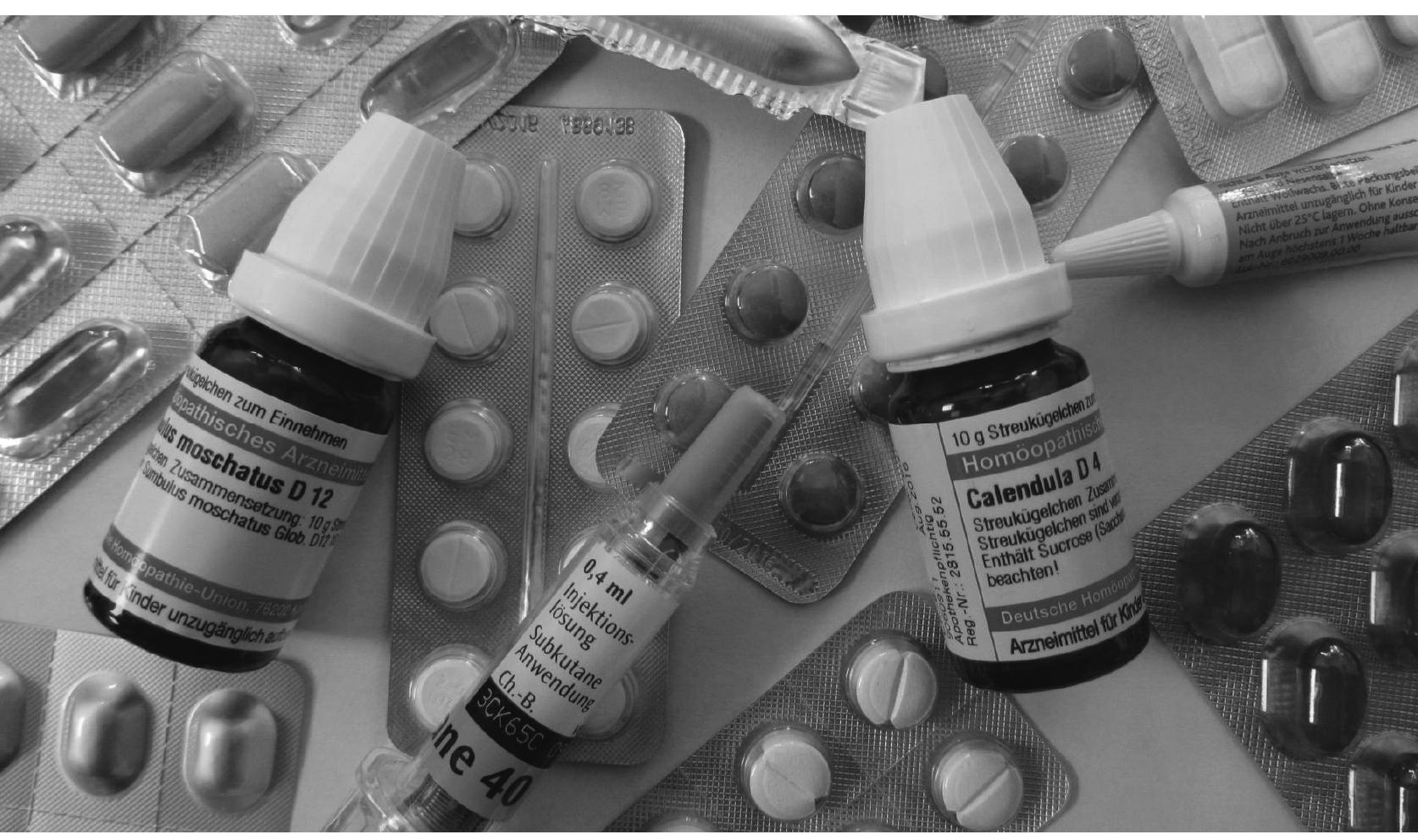




\section{Introduction}

\section{Background information}

Pharmaceutical products play a relevant role in the European health care systems, both in medical terms as well as from an economic point of view. Undoubtedly, pharmaceuticals can contribute substantially to the treatment of various severe diseases such as asthma or diabetes and, of course, scientific progress regarding the development of new drugs should be further fostered. Pharmaceuticals can also play a fundamental role in the prevention of diseases (e.g. vaccines for diseases such as measles, cervical cancer, etc.) which, from a public health view, may be their most important and efficient task. Some of the greatest achievements in public health are based on preventive measures with vaccines, for instance the eradication of smallpox [1] or the elimination of poliomyelitis from most countries, including the whole World Health Organization (WHO) European Region [2,3]. The importance of pharmaceutical products in health care is further reflected by the essential medicines list that is updated every 2 years by the WHO and is compiled for adults and children separately as well [4]. Last but not least, for several life-threatening diseases such as the acquired immune deficiency syndrome, treatment with pharmaceuticals is at present the only medical option.

The economic importance of pharmaceuticals in Europe is illustrated by the number of people employed in the pharmaceutical industry, which was estimated at about 690,000 (figure for the European Union (EU), Switzerland, and Turkey) for 2012 [5], and also by the turnover in pharmaceutical products, which amounted to roughly 190 billion euros in 2013 for the EU [6]. Depending on the source, six to nine European companies rank among the world's 15 largest pharmaceutical companies [7-9]. In 2012, expenditures on pharmaceutical products accounted for about $1.5 \%$ of the gross domestic product (GDP) of the European Union, compared with about $8.7 \%$ of GDP for total expenditure on health [10]. Pharmaceuticals are also a relevant item for health insurance companies as, e.g., expenditure on drugs accounts for approximately $16 \%$ of the statutory health insurance companies' expenditure in Germany [6].

Evidently, the population seeking medical health by means of pharmaceutical products is, probably without being conscious of it, confronted with strong (and opposed) economic interests. As in other branches of public service, the public health care sector also has to deal with increasingly limited financial resources. Therefore, in Germany and many other European countries, the health sector (and the pharmaceutical sector as a part of it as well) experienced major changes at the turn of the new millennium, such as the deregulation of the pharmacy market, the liberalization of drug sales, or cuts and price reductions regarding the reimbursement of prescribed drugs [11-17]. For instance, freely available drugs (over-the-counter drugs), which account for a sub- 
stantial part of all drugs utilized by adults and children $[10,18]$, were gradually removed from the list of reimbursable drugs and, hence, have to be paid for out-of-pocket by the consumers or patients themselves $[19,20]$. This implies that, as a consequence, a higher financial burden is imposed on every consumer/patient. Furthermore, the administrations have partly moved the responsibility for proper and safe drug use from physicians to those who use self-medicated drugs, highlighting the growing importance of pharmaceutical advice in community pharmacies. By quantity of drug packages used in Europe, prescribed drugs and self-medicated drugs are roughly at the same level, although the turnover in self-medicated drugs may account for about $15 \%$ of total drug sales in the European Union [21]. The market in self-medication with over-the-counter drugs that are not covered by statutory health insurance companies was estimated at 27 billion euros for the European Union in 2011 [21] and can normally be promoted (with some restrictions) by the pharmaceutical companies with advertising materials $[22,23]$. In this context, inequalities with regard to health literacy, accessibility to drugs, and affordability of drugs are important aspects that have to be considered carefully by the decision makers within the health sector to ensure that the phenomena of underor oversupply of drugs in various population strata are avoided or at least minimized.

\section{Aims and objectives}

The objective of this dissertation is to analyse the patterns of paediatric drug use with regard to the prevalence of use and the socioeconomic predictors of drug utilization. Children represent the future of every society. Like elderly or chronically ill people, children belong to a particularly vulnerable group in the population, as they normally do not take their own decisions on (self-) medication but have to rely on the correct decisions taken for them by other involved persons. This, of course, may gradually change during the transition from childhood to adolescence.

In a first step (chapter 2), a systematic review of the use of complementary and alternative medicine (CAM) among children in Europe was performed in comparison with paediatric CAM utilization outside Europe. The authors anticipated that CAM use would be significantly higher in children with chronic conditions such as cancer, diabetes, or allergies. Therefore, studies analysing CAM use exclusively among children with chronic conditions (which were the majority of available studies on paediatric CAM use) were excluded from the review to estimate CAM use among the general paediatric population in European and non-European countries.

Chapter $\mathbf{3}$ analyses CAM use among chronically ill adolescents and is an addendum to the systematic review on CAM use presented in chapter 2 . The results imply that, compared with the general adolescent population, the prevalence of CAM use is higher among adolescents with chronic conditions. Thus, the exclusion of studies conducted 
exclusively among children/adolescents suffering from any kind of chronic condition from the systematic review presented in chapter $\mathbf{2}$ may have yielded more unbiased estimates for CAM use among the general paediatric population in Europe.

Chapter 4 presents an updated view on paediatric CAM use based on data from a large German birth cohort (GINIplus). Furthermore, the results on CAM use among 15year-old adolescents were compared with the results for 10-year-old children from the 10-year follow-up of the same birth cohort to detect trends in CAM use.

Chapter 5 focuses on the utilization of pharmaceutical products among 15-year-old adolescents from the German GINIplus birth cohort. The research primarily addressed the comparison of self-medicated drugs with prescription drugs and investigated the differences regarding prevalence and the socioeconomic predictors of use.

A comprehensive longitudinal analysis of drug use based on data for 10-year-old children and 15-year-old adolescents from the German GINIplus and LISAplus birth cohorts was performed in chapter $\mathbf{6}$. Among other things, chapter 6 also analysed the association of drug use in adolescence with previous drug use during childhood.

The research question treated in chapter 7 is whether the prices of over-thecounter drugs used by adolescents are associated with socioeconomic factors such as parental educational background or parental income.

The final chapter $\mathbf{8}$ is devoted to the current issue of emergency contraceptives. The European Medicines Agency (EMA) recommended switching ulipristal acetate to non-prescription status throughout the European Union in November 2014. This drug class is used by girls mainly during adolescence and young adulthood [24]. The use of emergency contraceptives, which is known to be predicted by socioeconomic variables [24], may have been influenced by the switch to non-prescription status. 
The GINIplus and LISAplus birth cohorts contributed data for several parts of the present thesis (Figure 1). Therefore, further information not given in the following chapters 2-7 is briefly presented at this point.

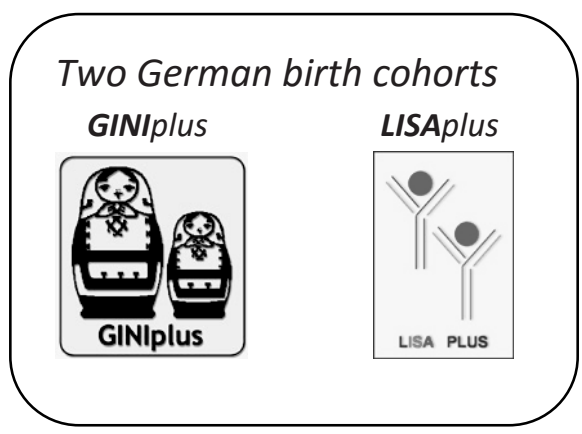

Results from the 10-year follow-up of the GINIplus and LISAplus studies $(n=3,642)$

2 were included in the systematic review on paediatric use of complementary and alternative medicine (CAM) in European and non-European countries.

Utilization of complementary and alternative medicine (CAM) was analysed among

3 chronically ill adolescents from the GINIplus $(n=3,013)$ and LISAplus $(n=1,664)$ studies; total sample size at the 15 -year follow-up: $n=4,677$.

Complementary and alternative medicine use among adolescents living in Germany

4 was analysed based on data from the 15-year follow-up of the GINIplus study $(n=3,013)$.

The use of self-medication drugs and prescribed drugs among adolescents in Ger-

5 many was analysed based on data from the 15-year follow-up of the GINIplus study $(n=3,013)$.

Drug use was compared longitudinally between 10-year-old children and 15-year-old

6 adolescents from the GINIplus/LISAplus studies ( $n=3,642$ participants in the 10-year follow-up; $n=4,677$ participants in the 15-year follow-up; $n=3,194$ in both samples).

The association of prices for over-the-counter drugs with socioeconomic factors was

7 investigated for a cohort of 4,677 adolescents from the GINIplus and LISAplus studies.

Figure 1. Contribution of the GINIplus and LISAplus birth cohorts to chapters 2-7 
The GINIplus study (German Infant study on the influence of Nutrition Intervention plus environmental and genetic influences on allergy development) and LISAplus study (Influence of lifestyle factors on the immune system and allergies in East and West Germany plus the influence of traffic emissions and genetics) are two ongoing German birth cohorts [25-27]. At baseline, exactly 5,991 healthy full-term newborns were recruited for the GINIplus study between September 1995 and June 1998 from obstetric clinics in Munich and Wesel. The LISAplus study started with 3,097 healthy full-term newborns who were enrolled between November 1997 and January 1999 from obstetric clinics in Munich, Leipzig, Bad Honnef, and Wesel (Figure 2). For three children, the consent to participate already given was withdrawn by their parents or legal guardians at a later stage in the study.

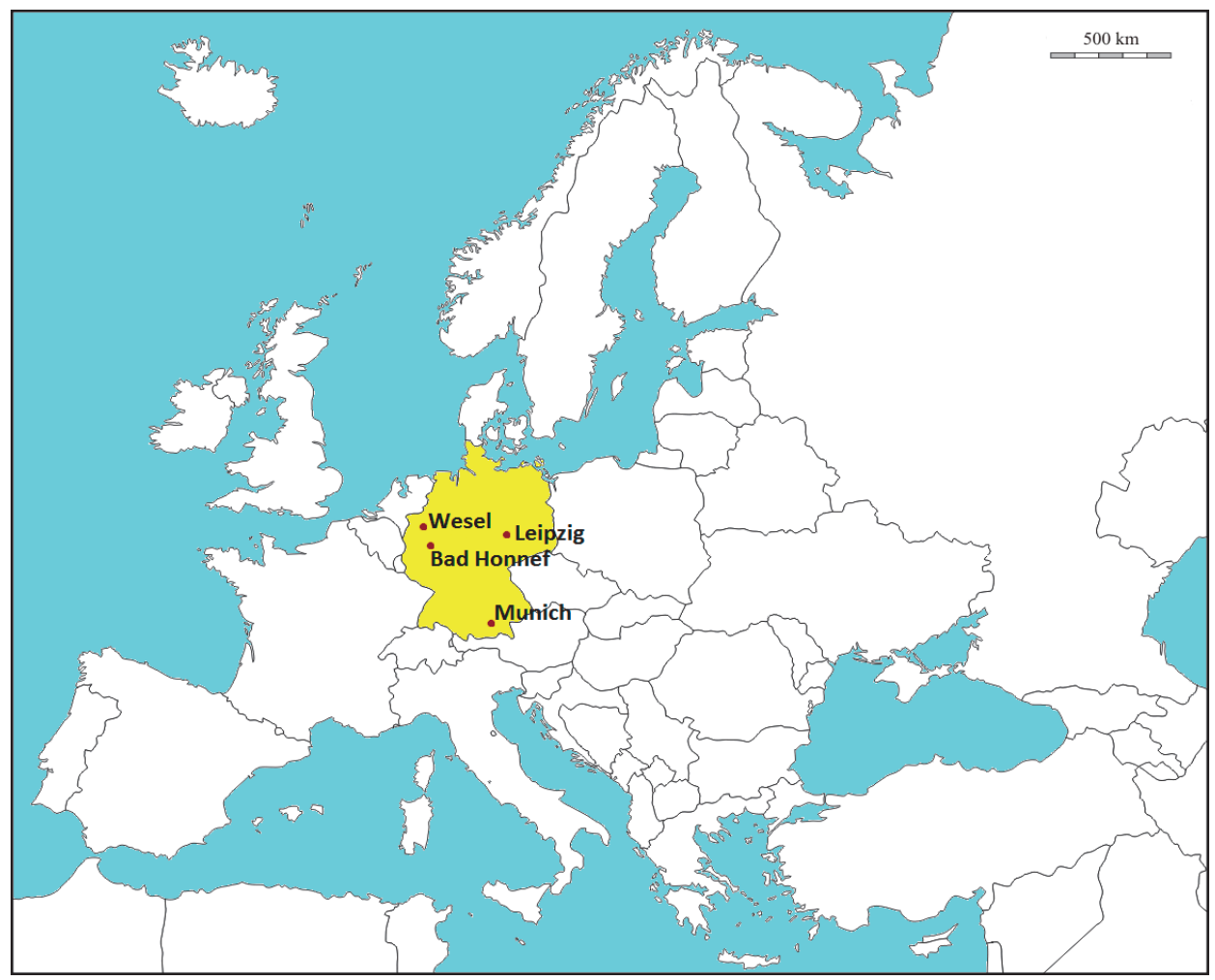

Figure 2. Regional distribution of the four study areas over Germany

Both cohorts participated in the Enrieco project (Environmental Health Risks in European Birth Cohorts), which was conducted within the European Union's $7^{\text {th }}$ Framework Programme $[28,29]$ and includes birth cohorts from 17 European countries. 
Since the start of both cohorts, various research questions have been addressed at several stages of the cohorts. Paediatric drug utilization was assessed at the children's age of 10 years and 15 years. The data collection for the 15 -year follow-up, upon which a substantial part of the present thesis is based, started in January 2011 and was completed in October 2014 (Figure 3). For the assessment of drug utilization at the age of 15 years, an identical questionnaire was used for the GINIplus and LISAplus studies (Appendix Figure S1; original German version used for the 15-year follow-up of the GINIplus study), based on an almost similar questionnaire that had already been used at the 10-year follow-up in both studies. The assessment process over time is displayed for the 15-year follow-up in Figure 3. The amount and type of drugs used may depend, among other things, on the season. Thus, an almost even distribution of the assessment over winter, spring, summer, and autumn would be desirable to get a seasonally independent view of paediatric drug utilization. Figure 4 shows that spring (April-June) and summer (July-September) are slightly overrepresented at the 15-year follow-up in the GINIplus and LISAplus cohorts.

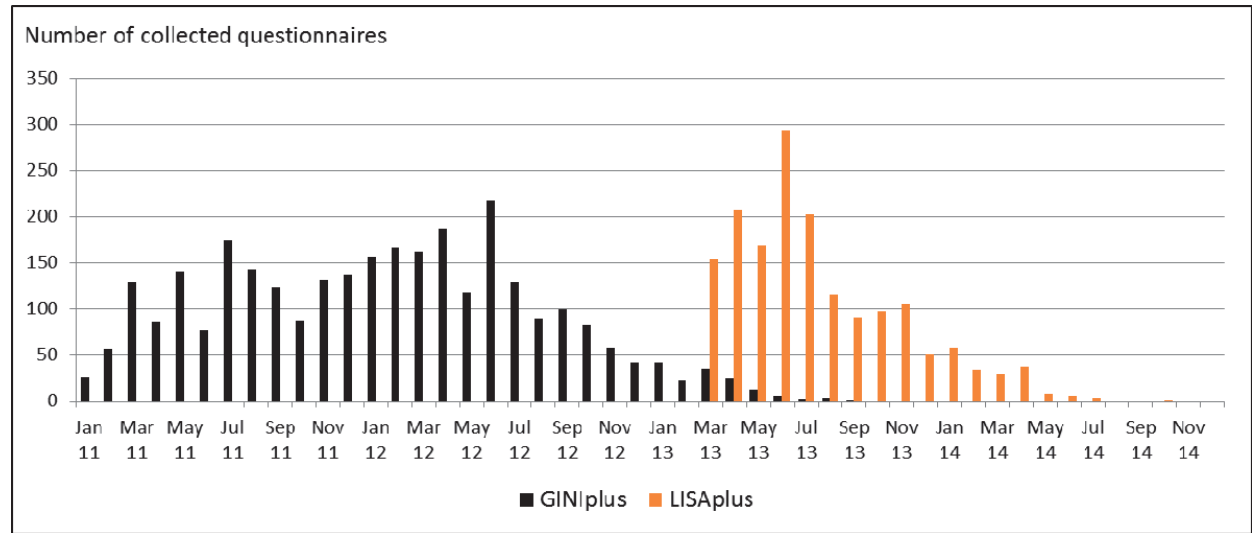

Figure 3. Time schedule of the 15-year follow-up of the GINIplus and LISAplus studies

De facto, the 4-week prevalence of drug use (seasonal mean: 41.1\%) among adolescents from both cohorts together was highest in spring (43.6\%) and lowest in summer (37.6\%). For the 10-year follow-up, most (54\%) of the questionnaires were collected in autumn (October-December), whereas $46 \%$ were collected in almost equal parts during spring, summer, and winter. 


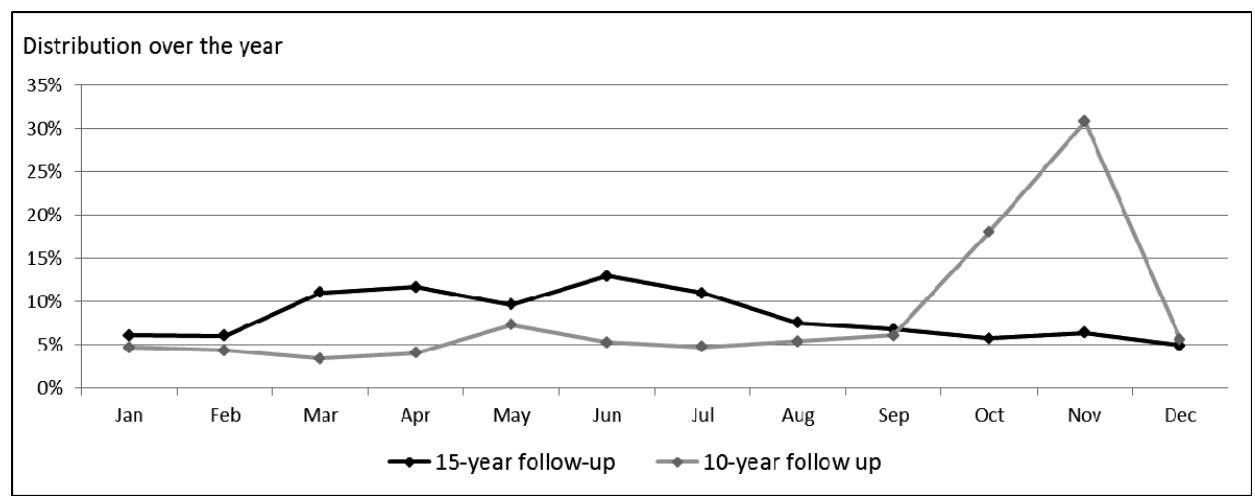

Figure 4. Distribution of data collection over the year (GINIplus and LISAplus together)

The mean age of the participating adolescents was 15.1 years, ranging between 14.2 years and 16.8 years (Figure 5). The distribution of age followed a normal distribution. At the 15-year follow-up, both cohorts were composed of predominantly healthy

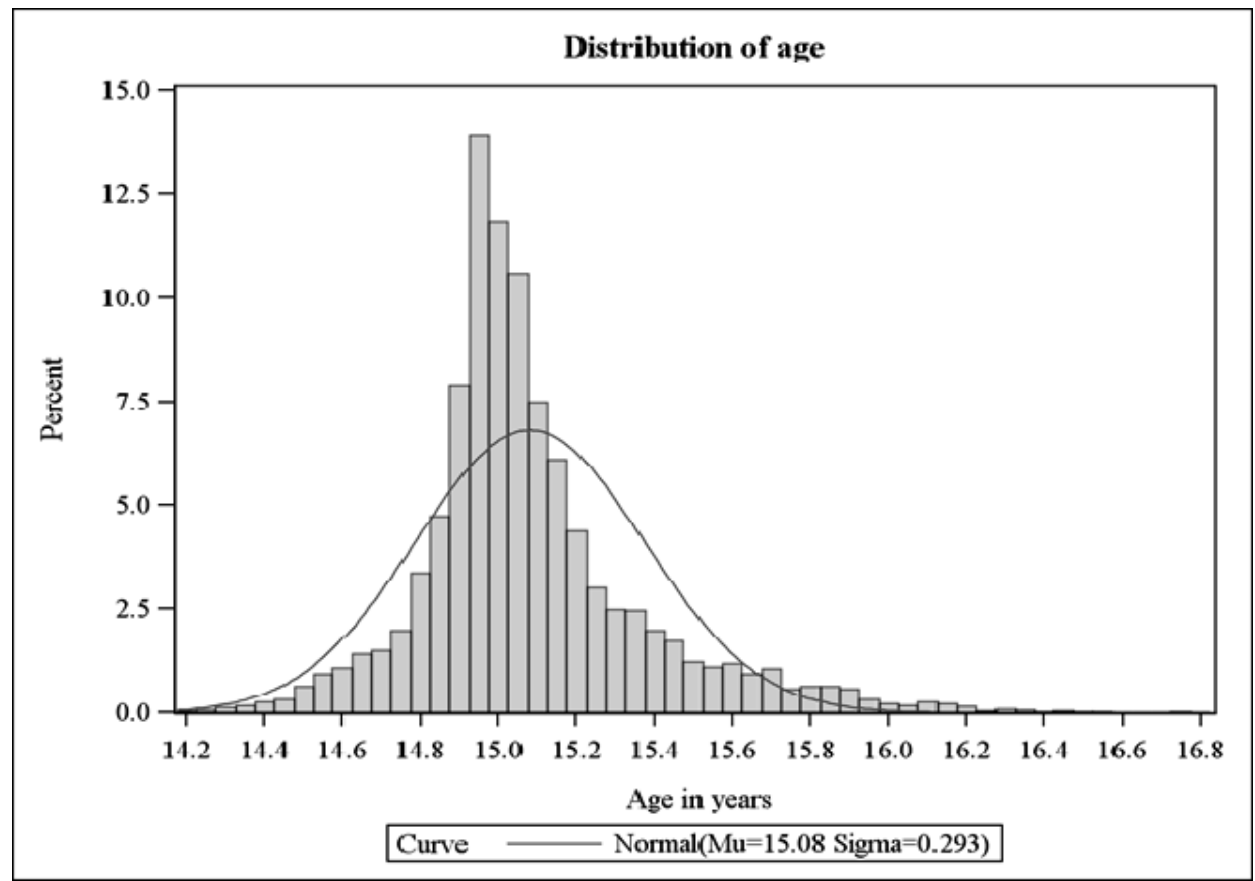

Figure 5. Distribution of adolescents' age, with overlaid normal distribution (15-year follow-up; GINI-plus and LISAplus together) 
adolescents. For instance, the adolescents from the GINIplus and LISAplus cohorts had a mean body mass index (BMI) of $20.8 \mathrm{~kg} / \mathrm{m}^{2}$ (Figure 6), which was lower compared with the findings for 15 -year-old boys $\left(21.7 \mathrm{~kg} / \mathrm{m}^{2}\right)$ and girls $\left(22.0 \mathrm{~kg} / \mathrm{m}^{2}\right)$ from a representative German study [30].

The proportion of adolescents that reported a physician-diagnosed chronic condition during the preceding 12 months was $13.7 \%$. Within the preceding 12 months, asthma, atopic dermatitis, and allergies (hay fever, perennial allergic rhinitis, or food allergy) were diagnosed in $2.5 \%, 2.7 \%$, and $9.9 \%$ of the adolescents respectively. Another German study including 17,641 children aged 0-17 years found higher prevalence rates (diagnosed in the past 12 months) for asthma (4.5\%), atopic dermatitis (6\%), and hay fever (15\%) [31].

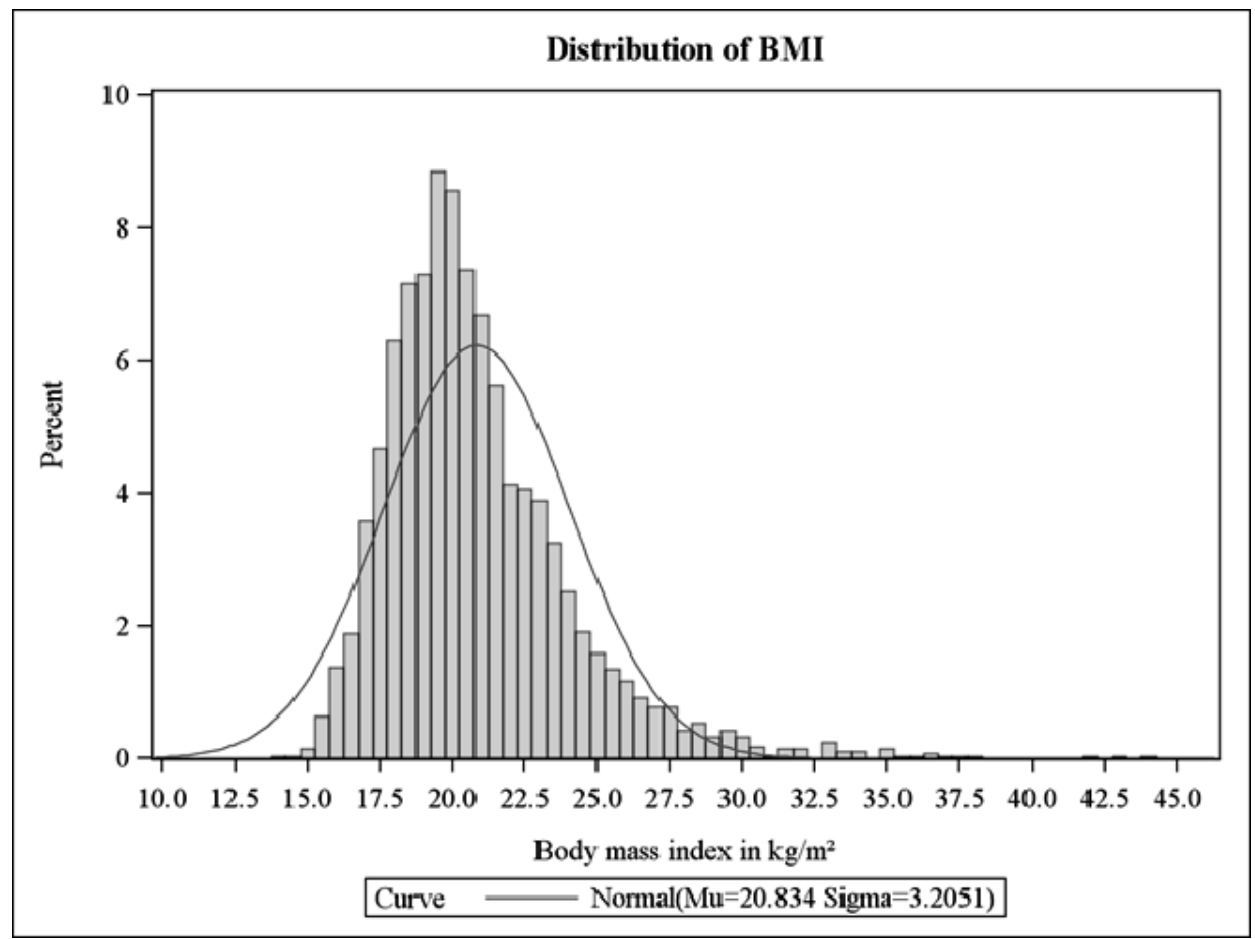

Figure 6. Distribution of adolescents' body mass index (BMI) with overlaid normal distribution (15-year follow-up; GINIplus and LISAplus together)

\section{Comparability of the cohort structure with the mean German population}

Compared with baseline, about $48.5 \%$ of the participants did not complete the questionnaire in the 15-year follow-up. Participants from the higher educational and income 
levels were more likely to remain in the cohorts. The variation in cohort composition over time is displayed in Table 1 . However, there was no significant difference $(p=0.5628)$ with regard to the proportion of male and female participants at baseline and at the 15-year follow-up.

Table 1. Characteristics of the GINIplus and LISAplus cohorts over time

\begin{tabular}{|c|c|c|c|}
\hline & \multicolumn{3}{|c|}{ Distribution of the strata in $\%$} \\
\hline & Baseline & 10-year follow-up & 15-year follow-up \\
\hline Total number of participants & 9,088 & 3,642 & 4,677 \\
\hline \multicolumn{4}{|l|}{ Gender } \\
\hline Male & 51.3 & 51.3 & 50.6 \\
\hline Female & 48.7 & 48.7 & 49.4 \\
\hline \multicolumn{4}{|l|}{ Study area } \\
\hline Munich & 48.6 & 50.8 & 50.1 \\
\hline Leipzig & 10.7 & 10.5 & 8.9 \\
\hline Bad Honnef & 3.4 & 5.4 & 4.0 \\
\hline Wesel & 37.3 & 33.3 & 37.0 \\
\hline \multicolumn{4}{|l|}{ Maternal education } \\
\hline Low & 13.1 & 12.2 & 10.7 \\
\hline Medium & 38.5 & 40.8 & 38.6 \\
\hline High & 48.3 & 47.0 & 50.7 \\
\hline \multicolumn{4}{|l|}{ Paternal education } \\
\hline Low & 23.5 & 23.7 & 21.2 \\
\hline Medium & 22.7 & 21.4 & 22.6 \\
\hline High & 53.7 & 55.0 & 56.2 \\
\hline \multicolumn{4}{|l|}{ Household income $^{a}$} \\
\hline$\leq 60 \%$ of $\mathrm{MEI}$ & & 16.8 & 17.0 \\
\hline $60-100 \%$ of MEI & not available & 44.2 & 37.9 \\
\hline$>100 \%$ of $\mathrm{MEI}$ & & 39.0 & 45.1 \\
\hline
\end{tabular}

Owing to rounding errors, the percentages may not exactly add up to 100

$M E I$, median equivalent income (MEI not available for the baseline survey)

${ }^{a}$ Based on the MEI of 2008 (€1,549; 10-year follow-up) and on the MEI of 2012 (€1,633; 15-year follow-up)

\section{Gender}

With regard to the distribution of gender, the GINIplus and LISAplus cohorts reflect the German mean very well, as $49.4 \%$ of the participating 15 -year-old adolescents were girls, which is quite close to the corresponding German mean (48.7\%) for adolescents [32]. 
Regional distribution

At the 15-year-follow-up, the GINIplus/LISAplus study sample was composed of $50.1 \%$ participants living in Bavaria (Munich), 8.9\% residing in Saxony (Leipzig), and a further $41 \%$ coming from North-Rhine Westphalia (Bad Honnef and Wesel). As about 29\% of the German population lives in the southern federal states Bavaria and BadenWürttemberg, $16 \%$ in the new federal states in eastern Germany, and $55 \%$ in the northern or western regions, the south of Germany was overrepresented, whereas east Germany was underrepresented in the study.

Some $41 \%$ of the participants resided in comparatively rural areas (Bad Honnef and Wesel), whereas 59\% lived in an urban environment (Leipzig and Munich). In comparison with the study sample, only about $22 \%$ of the German population [33] lives in an urban environment (cities $>100,000$ inhabitants).

\section{Maternal and paternal educational background}

On average in Germany, 24.8\% (30.7\%) of women (men) aged 35-45 years, an age group comparable to the participating mothers in the GINIplus/LISAplus cohorts at the 15 -year follow-up time point, had a low educational background ( $<10$ school years). Exactly $40.5 \%$ (33.2\%) had a middle educational level, whereas 34.5\% (36.2\%) belonged to the highest educational level [33]. In comparison with the German mean, the parents of the participating adolescents from the GINIplus and LISAplus studies achieved a higher educational status.

\section{Household income status}

On average, the households of the participants had an equivalent income of $€ 1,763$ at their disposal (median: €1,563). The median equivalent income (MEI) in Germany for 2012 was reported to be $€ 1,643$. This figure is not directly comparable with the figure for the households in the GINIplus/LISAplus cohorts, as it includes both households with children and also single households. However, the share of the population affected by poverty as reported by the German federal statistical office, amounted to $20.3 \%$ in 2013 [34], in comparison with $17 \%$ of the participating families from the GINIplus and LISAplus studies that were poor (60\% or less of the MEI) following the definition of poverty [35] from the Organisation for Economic Co-operation and Development (OECD). Therefore, the higher income classes may be slightly overrepresented in the GINIplus/LISAplus cohorts. 


\section{Migration background}

The impact of migration background, another important socioeconomic variable, on drug use among adolescents from the GINIplus/LISAplus birth cohorts was not analysed for several reasons. In the LISAplus study, children of non-German parents or with parents born outside Germany were excluded. In the GINIplus study, only participants with sufficient German language skills were recruited. Migration background was not directly available for the 15-year follow-up of the GINIplus cohort. Instead, nationality of mothers and fathers was assessed for the baseline survey only. Since then, 15 years have passed, and parental nationality may have changed for some participants. Moreover, the proportion of parents with German nationality is very high (for the 3,013 children from the 15-year follow-up cohort, about $95 \%$ of mothers and $93 \%$ of fathers reported German nationality at baseline), and some of the participants who reported German nationality may nevertheless have a migration background, but this information is not available. Overall, only about $5.6 \%$ of the recruited newborns at baseline had a non-German mother (6.8\% had a non-German father), and this share fell further at the 15-year follow-up of the GINIplus/LISAplus studies, e.g. only 3.1\% of the adolescents had a non-German mother (4.1\% had a non-German father). Compared with Germany, where about $9.5 \%$ of the population [33] has non-German nationality, foreign children are underrepresented in the GINIplus/LISAplus cohorts.

In sum, the GINIplus and LISAplus cohorts are population-based cohorts that, however, do not exactly reflect the mean adolescent population in Germany e.g. with regard to parental educational level or migration background. Thus, the results can be projected to the general German paediatric population to a limited extent only. 


\section{References}

1. Centers for Disease Control and Prevention. Ten great public Health Achievements in the 20th Century. www.cdc.gov/about/history/tengpha.htm (accessed 1 September 2015)

2. World Health Organization. Fact sheet Poliomyelitis. www.who.int/mediacentre/factsheets/fs114/en (accessed 1 September 2015)

3. European Centre for Disease Prevention and Control. Poliomyelitis. Factsheet for general public. http://ecdc.europa.eu/en/healthtopics/polio/pages/index.aspx (accessed 1 September 2015)

4. World Health Organization. The WHO Model Lists of Essential Medicines. www.who.int/medicines/publications/essentialmedicines/en/ (accessed 5 August 2015)

5. European Federation of Pharmaceutical Industries and Associations (EFPIA). The Pharmaceutical Industry in Figures - Key Data 2014. www.efpia.eu/uploads/Modules/Mediaroom/figures-2014-final.pdf (accessed 1 September 2015)

6. German pharmaceutical industry association. Pharmadaten 2014. http://www.bpi.de/daten-undfakten/pharmadaten/ (accessed 1 September 2015)

7. Forbes. The world's biggest public companies. www.forbes.com/global2000/list/\#industry:Pharmaceuticals (accessed 29 August 2015)

8. Statista. The Statistics Portal. http://de.statista.com/statistik/daten/studie/246872/umfrage/umsatzstaerkste-pharmaunternehmen-weltweit/ (accessed 29 August 2015)

9. The SyncForce Ranking the Brands. www.rankingthebrands.com/The-Brand-Rankings.aspx? rankingID=370 (accessed 29 August 2015)

10. OECD. Health at a Glance: Europe 2014. www.oecd.org/health/health-at-a-glance-europe23056088.htm (accessed 1 September 2015)

11. Vogler S, Zimmermann N, Leopold C, Joncheere KD. Pharmaceutical policies in European countries in response to the global financial crisis. South Med Rev 2011;4:22-32. doi:10.5655/smr.v4i2.1004

12. The 2004 German Health Act. GKV-Modernisierungsgesetz. http:///buzer.de/s1.htm?g=GMG\&f=1 (accessed 1 September 2015)

13. Federal Ministry of Health. Das Gesetz zur Neuordnung des Arzneimittelmarktes (AMNOG). www.bmg.bund.de/glossarbegriffe/a/das-gesetz-zur-neuordnung-des-arzneimittelmarktes-amnog.html (accessed 1 September 2015)

14. Baker \& McKenzie Pricing and Reimbursement Handbook. www.bakermckenzie.com/files/Uploads/Documents/Germany/LifeSciences/EuropeanPricingReimburse ment.pdf (accessed 1 September 2015)

15. Vogler S, Arts D, Sandberger K. Impact of pharmacy deregulation and regulation in European countries. (Summary report Vienna, 2012). whocc.goeg.at/Literaturliste/Dokumente/BooksReports/GOeg_FP_PharmacyRegulationDeregulation_ FullReport_March2012.pdf (accessed 31 July 2015)

16. Deloitte. Impact of austerity on European pharmaceutical policy and pricing - Staying competitive in a challenging environment. www2.deloitte.com/content/dam/Deloitte/ch/Documents/life-scienceshealth-care/CH-uk-research-austerity-Ishc-05052014.pdf (accessed 1 September 2015)

17. Creativ-Ceutical. Executive Agency for Health and Consumers-EAHC-European Commission. EU Pharmaceutical expenditure forecast. Final report 26 November 2012.

http://ec.europa.eu/health/healthcare/docs/creativ_ceutical_eu_pharmaceutical_expenditure_ forecast.pdf (accessed 2 September 2015)

18. Du Y, Knopf H. Self-medication among children and adolescents in Germany: results of the National Health Survey for Children and Adolescents (KiGGS). Br J Clin Pharmacol 2009;68:599-608. doi:10.1111/j.1365-2125.2009.03477.x

19. Sozialgesetzbuch (SGB V). § 34 SGB V Ausgeschlossene Arznei-, Heil- und Hilfsmittel. http://www.sozialgesetzbuch-sgb.de/sgbv/34.html (accessed 1 September 2015) 
20. Martikainen J, Rajaniemi S. Drug reimbursement systems in EU Member States, Iceland and Norway. Helsinki: The Social Insurance Institution, Finland, Social security and health reports 54, 2002

21. Report of the working group on promoting good governance of non-prescription drugs in Europe. http://ec.europa.eu/enterprise/sectors/healthcare/files/docs/otc_report_en.pdf (accessed 8 December 2014)

22. European Union. Legal framework governing medicinal products for human use in the EU. ec.europa.eu/health/human-use/legal-framework/index_en.htm (accessed 31 August 2015)

23. European Union. Directive 2001/83/EC of the European Parliament and of the Council of 6 November 2001 on the Community code relating to medicinal products for human use. ec.europa.eu/health/files/eudralex/vol-1/dir_2001_83_consol_2012/dir_2001_83_consol_2012_en.pdf (accessed 1 September 2015)

24. Daniels K, Jones J, Abma J. Use of emergency contraception among women aged 15-44: United States, 2006-2010. NCHS Data brief 2013;112:1-8

25. Heinrich J, Brüske I, Schnappinger M, Standl M, Flexeder C, Thiering E, Tischer C, Tiesler CM, Kohlböck G, Wenig CM, Bauer CP, Schaaf B, von Berg A, Berdel D, Krämer U, Cramer C, Lehmann I, Herbarth O, Behrendt H, Ring J, Kühnisch J, Koletzko S. Die zwei deutschen Geburtskohorten GINIplus und LISAplus [Two German Birth Cohorts: GINIplus and LISAplus] Bundesgesundheitsblatt Gesundheitsforschung Gesundheitsschutz 2012;55:864-874. doi:10.1007/s00103-012-1485-4

26. GINIplus study. https://www.helmholtz-muenchen.de/en/epi1/research/research-units/research-unit-1environmental-epidemiology/projects/giniplus/index.html (accessed 1 September 2015)

27. Die LISA-plus-Studie. www.lisastudie.de/ (accessed 1 September 2015)

28. Enrieco Project. www.enrieco.org (accessed 1 September 2015)

29. Gehring U, Casas M, Brunekreef B, Bergström A, Bonde JP, Botton J, Chévrier C, Cordier S, Heinrich J, Hohmann C, Keil T, Sunyer J, Tischer CG, Toft, G, Wickmann, M, Vrijheid M, Nieuwenhuijsen M. Environmental exposure assessment in European birth cohorts: results from the ENRIECO project. Environ Health 2013;12:8. doi:10.1186/1476-069X-12-8

30. Stolzenberg H, Kahl H, Bergmann KE. Körpermaße bei Kindern und Jugendlichen in Deutschland. Ergebnisse des Kinder-und Jugendgesundheitssurveys (KiGGS) [Body measurements of children and adolescents in Germany. Results of the German Health Interview and Examination Survey for Children and Adolescents (KiGGS)] Bundesgesundheitsblatt Gesundheitsforschung Gesundheitsschutz 2007;50:659669. doi:10.1007/s00103-007-0227-5

31. Robert Koch Institut (Ed). Bundeszentrale für gesundheitliche Aufklärung (Ed) (2008) ErkennenBewerten-Handeln: Zur Gesundheit von Kindern und Jugendlichen in Deutschland. RKI, Berlin (Allergische Erkrankungen Seite 15-20)

32. Federal Agency for Civic Education. Composition of the Population by age groups and gender. www.bpb.de/nachschlagen/zahlen-und-fakten/soziale-situation-in-deutschland/61538/altersgruppen (accessed 2 September 2015)

33. Federal Statistical Office (Destatis). Statistical Yearbook 2014. https://www.destatis.de/DE/Publikationen/StatistischesJahrbuch/StatistischesJahrbuch2014.pdf?_blo b=publicationFile (accessed 2 September 2015)

34. Federal Statistical Office (Destatis). Press release Nr 454 on the share of the population affected by poverty. https://www.destatis.de/DE/PresseService/Presse/Pressemitteilungen/2014/12/PD14_454_634.html (accessed 2 September 2015)

35. European Centre for Social Welfare Policy and Research. Income Poverty in the EU. http://www.euro.centre.org/data/1295444473_73292.pdf (accessed 1 September 2015) 


\section{Appendix}

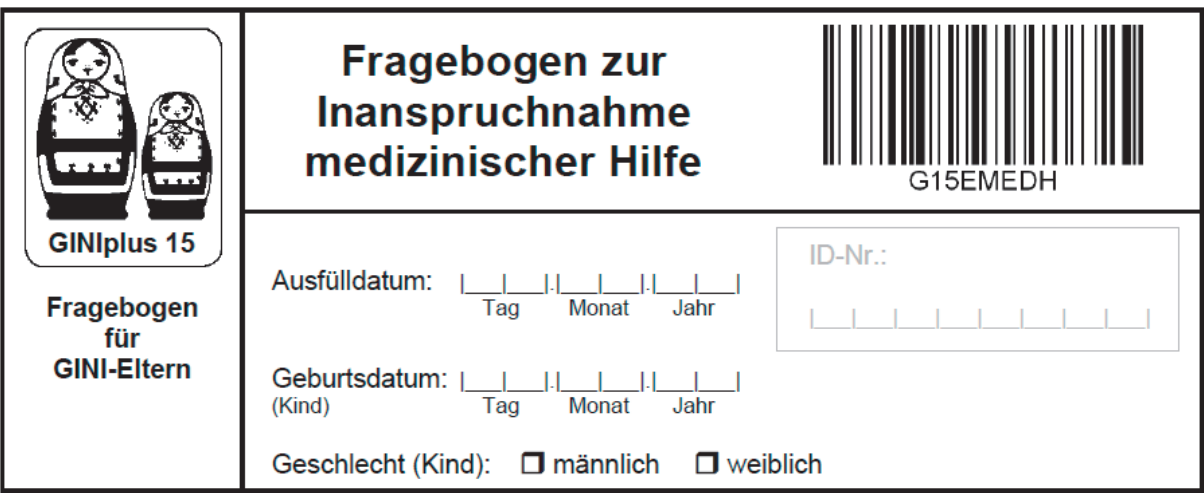

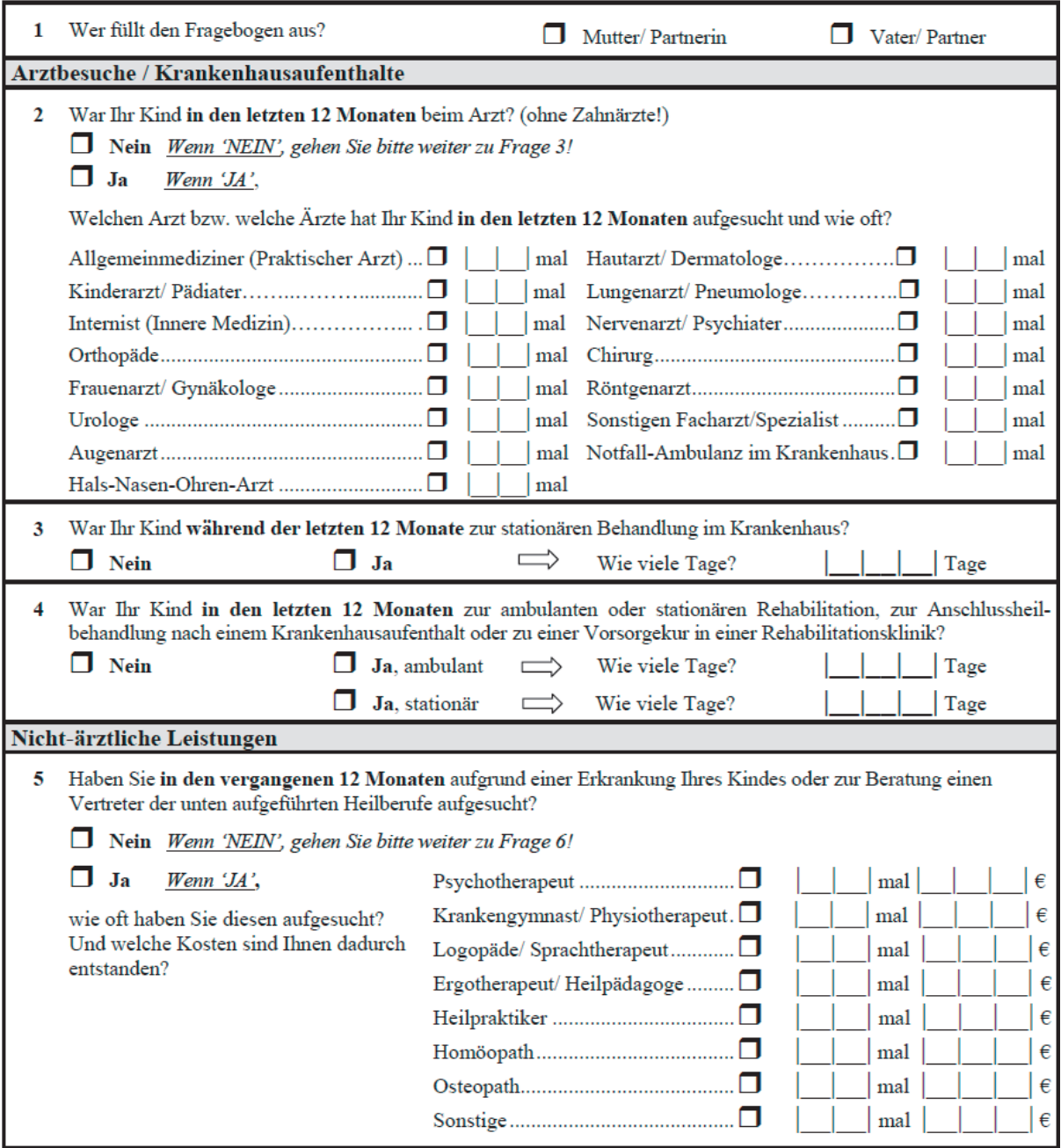




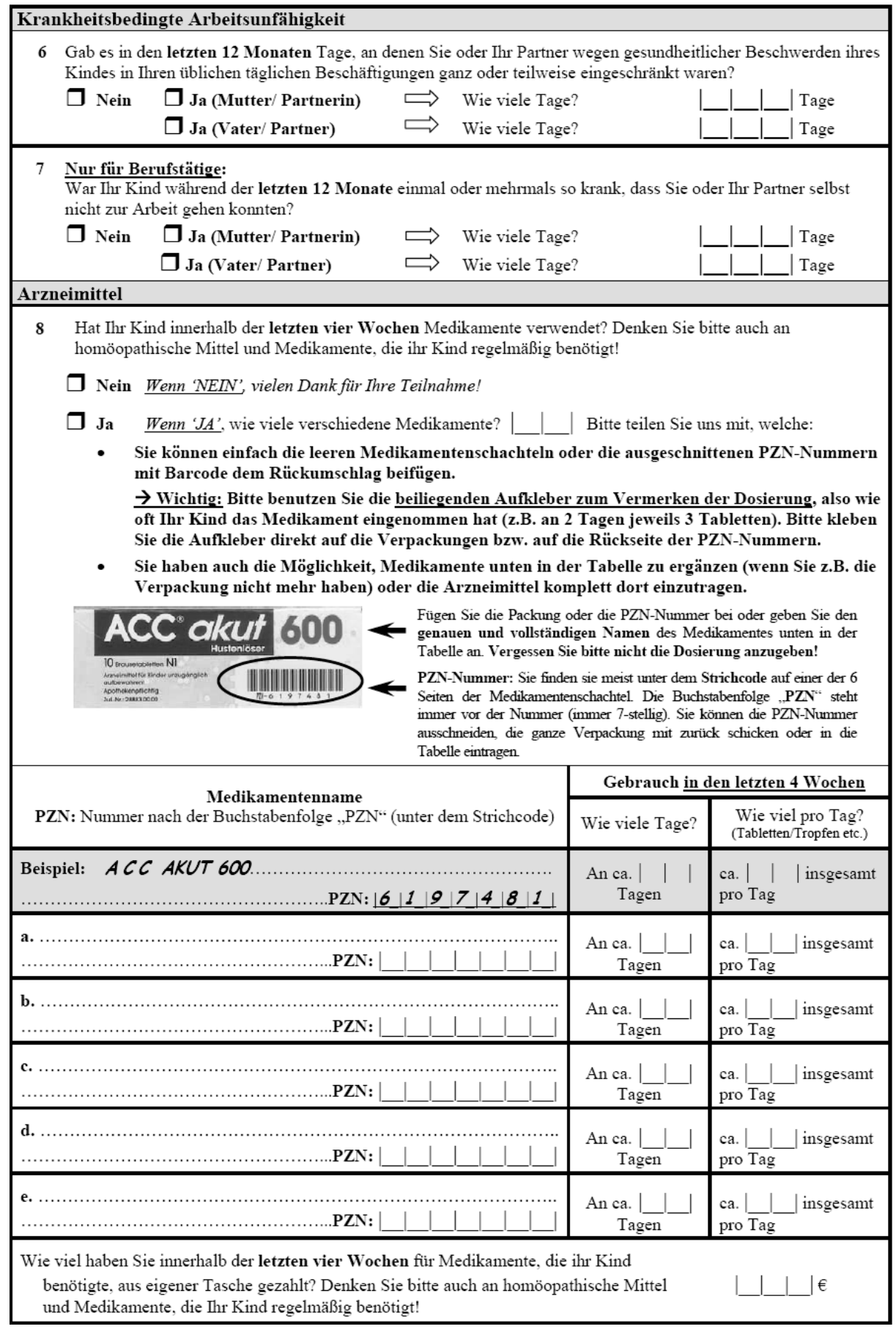

Appendix Figure S1: Original questionnaire on drug use (GINIplus, 15-year follow-up) 
The art of healing comes from nature, not from the physician.

Therefore the physician must start from nature, with an open mind.

\section{Paracelsus}

Swiss-German physician and alchemist 


\section{CHAPTER 2}

\section{Patterns of Complementary and Alternative Medicine (CAM)}

use in children: a systematic review

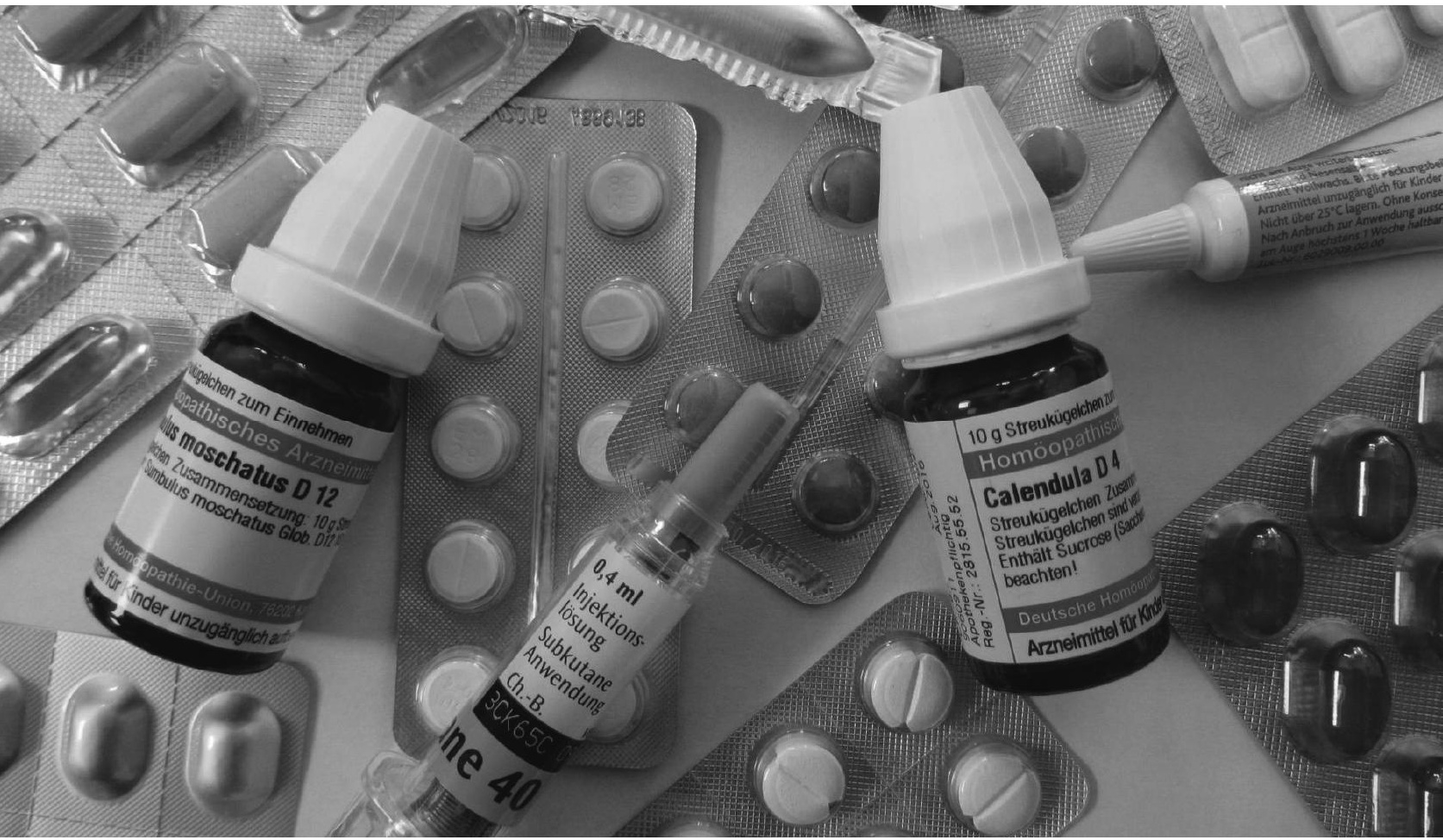

Salvatore Italia, Silke B. Wolfenstetter, Christina M. Teuner.

Patterns of complementary and alternative medicine (CAM) use in children: a systematic review.

Eur J Pediatr 2014;173:1413-1428. doi:10.1007/s00431-014-2300-z

The final publication is available at link.springer.com 


\begin{abstract}
Utilization of Complementary and Alternative Medicine (CAM) among children/adolescents is popular. This review summarizes the international findings for prevalence and predictors of CAM use among children/adolescents. We therefore systematically searched four electronic databases (PubMed, Embase, PsycINFO, AMED; last update in 07/2013) and reference lists of existing reviews and all included studies. Publications without language restriction reporting patterns of CAM utilization among children/adolescents without chronic conditions were selected for inclusion. The prevalence rates for overall CAM use, homeopathy, and herbal drug use were extracted with a focus on country and recall period (lifetime, 1 year, current use). As predictors, we extracted socioeconomic factors, child's age, and gender.

The database search and citation tracking yielded 58 eligible studies from 19 countries. There was strong variation regarding study quality. Prevalence rates for overall CAM use ranged from $10.9-87.6 \%$ for lifetime use and from $8-48.5 \%$ for current use. The respective percentages for homeopathy (highest in Germany, United Kingdom, and Canada) ranged from $0.8-39 \%$ (lifetime) and from 1-14.3\% (current). Herbal drug use (highest in Germany, Turkey, and Brazil) was reported for $0.8-85.5 \%$ (lifetime) and 2.2-8.9\% (current) of the children/adolescents. Studies provided a relatively uniform picture of the predictors of overall CAM use (higher parental income and education, older children), but only a few studies analyzed predictors for single CAM modalities.

Conclusion: CAM use is widespread among children/adolescents. Prevalence rates vary widely regarding CAM modality, country, and reported recall period.
\end{abstract}

\title{
Key words
}

Complementary therapies · Homeopathy · Phytotherapy · Child · Drug utilization . Socioeconomic factors 


\section{Introduction}

Complementary and Alternative Medicine (CAM) covers a broad variety of therapy approaches that are usually not part of conventional medicine.

According to the PubMed hits (searching with "Complementary Therapies"[Mesh]), research activities regarding CAM have grown markedly in the past decades and within only about 20 years increased from 2,260 publications in 1991 to 9,441 articles in 2011. This may reflect an increased scientific interest in this field, but also a growing popularity of CAM among the general population making CAM use an important public health topic.

Due to the considerable number of publications, there is now a substantial knowledge of CAM utilization patterns in adults. Two recently published reviews summarize the results of the respective studies $[15,23]$. Data on the CAM utilization of children are still limited, even though the knowledge gap has been reduced in recent years. A review published in 1999 [16] could only include 10 studies (7 were conducted in children with chronic conditions), because no other data were available at that time. Another review [7] assessed CAM use exclusively in pediatric cancer patients. A recently published narrative review summarized survey data and experts' extrapolations on pediatric CAM use in 20 European countries [71], while a scoping review from 2013 investigated the depth and breadth of pediatric CAM use and identified knowledge gaps regarding the epidemiology of CAM use in children [59].

There is, however, a sizeable difference in the findings for the patterns of CAM use, which in part may result from the different methodology used, but makes comparison of the figures quite difficult. In view of a responsible use of CAM, it is of particular interest to get a clearer picture of CAM utilization in children as they usually do not choose a medical therapy on their own. This systematic review has three main aims:

Firstly, to present an updated overview of the reported prevalence of CAM utilization in children and adolescents, with a focus on homeopathic and herbal remedies (for practical reasons we use the term "prevalence" as a synonym for "rate").

Secondly, to summarize the findings with respect to the predicting factors for CAM utilization, with a focus on child's gender, child's age, and socioeconomic indicators such as parental (or caregivers') education and income.

Thirdly, to compare the utilization patterns across both European and nonEuropean countries. 


\section{Methods}

\section{Database search}

The screening for relevant literature was performed using four databases. A combination of Mesh-terms (exploded) and free text terms were used to search PubMed (Table 1). Three further databases (Embase, AMED, PsycINFO) were searched with an almost identical set of free text terms (Table 1), using the search interface of the German Institute of Medical Documentation and Information (DIMDI). Initially, no limit was set regarding the language of publication. The last search update was performed on 1 July 2013.

Table 1. Free text search terms and Mesh-terms (exploded) for database search (last update 1 July 2013)

\section{PubMed (1945-2013)}

(child* OR kid* OR adolescent* OR teenager* OR youngster* OR juvenile* OR toddler* OR infan* OR pediatr* OR preschool* OR paediatr* OR neonate* OR newborn*)

AND (homeop* OR anthroposoph* OR herbs OR herbal* OR phyto* OR naturopath* OR "Complementary Therapies"[Mesh])

AND (determinant* OR factor* OR predict* OR prevalence* OR utilization OR utilisation OR use OR "Epidemiologic Factors"[Mesh])

AND (gender OR sex OR age OR education OR literacy OR income OR salary OR remuneration OR wealth OR earning* OR deprivation OR occupation* OR employ* OR ethnic* OR "Socioeconomic Factors"[Mesh])

\section{Embase (1947-2013) AMED (1985-2013) PsycINFO (1966-2013)}

(child? OR kid? OR adolescent? OR teenager? OR youngster? OR juvenile? OR toddler? OR infan? OR pediatr? OR preschool? OR paediatr? OR neonate? OR newborn?)

AND (homeop? OR anthroposoph? OR herbs OR herbal? OR phyto? OR naturopath? OR CAM OR complementary OR unconventional)

AND (determinant? OR factor? OR predict? OR prevalence? OR utilization OR utilisation OR use)

AND (gender OR sex OR age OR education OR literacy OR income OR salary OR remuneration OR wealth OR earning? OR deprivation OR occupation? OR employ? OR ethnic? OR socioeconomic?)

Mesh, medical subject heading $\quad *$ and ? standing for truncated terms

In addition, all reference lists of relevant articles and existing reviews were checked for further relevant literature. Full-text copies of all the identified publications were obtained. Data extraction from one Argentinian publication was supported by a native Spanish speaker.

Studies for this review were eligible if they reported figures for children's/adolescents' CAM use in the general population (prevalence of use and preferably at least one 
of the predicting variables under research). Studies including adults were only eligible if stratified figures for children/adolescents were available. Studies on children with chronic diseases or disorders such as cancer, asthma, etc. were excluded because of possible bias towards higher prevalence rates. Studies comparing chronically ill children with healthy children were excluded as well, whereas surveys assessing general drug utilization in children/adolescents were included, if figures for CAM utilization were extractable. Studies focusing on single CAM modalities other than homeopathy or herbal drugs were also excluded.

\section{Data extraction and reporting of findings}

The result lists from the database searches were screened by one reviewer for publications to be excluded by title, abstract, or language. The remaining publications were fully screened to evaluate possible eligibility.

Prevalence rates (calculated always as a percentage of the whole study cohort) and response rates were extracted directly from the text and, if possible, recalculated using given values for approached persons, participants, and CAM users. For consistency, all prevalence and response rate values were rounded to one decimal place; it should be emphasized that the prevalence figures are estimates and that a respective precision is not given for all studies (e.g., small-scaled ones).

In some cases, the prevalence figures had to be extracted from histograms because no percentages or numbers of CAM users were available in the text. Publications with unclear data were read by all authors and finally discussed to eliminate ambiguity of interpretation.

Where information was missing, we tried to contact the corresponding authors. If clarification was not possible for the recall period, prevalence was interpreted as lifetime use to present rather conservative estimates for utilization. Unclear information regarding prevalence for single CAM modalities was not considered if clarification was not possible.

In a few cases, only CAM provider consultation (homeopath, herbalist) was reported or it was unclear whether "pharmacological" treatment with homeopathic and herbal remedies was included. In these cases, we interpreted positive reporting as homeopathic or herbal drug use, respectively. We hypothesized that most consultations with a homeopath will result in homeopathic drug use and that most of the persons visiting a herbalist will subsequently use herbal drugs. 
Findings for predictors of CAM use were excluded if associations were only reported in a descriptive manner without testing statistical significance, e.g., by bivariate Chi $^{2}$-test or multivariate logistic regression. Finally, the publications were sorted by country and publication date to take into account country- and time-specific differences in CAM use.

To estimate overall prevalence rates for different recall periods (up to 1 month, 1 year, lifetime) grouped by continent (i.e., Europe versus North America), meta-analysis was performed for homeopathy and herbal drugs using the package 'meta' in the statistical software ' $R$ '. Reported probabilities were combined via the random effects inverse variance method, where the logit of probabilities was assumed to follow a normal distribution.

\section{Quality assessment}

For assessing the quality of the included studies, we used an existing qualityassessment tool [7] and modified it for our purpose. We checked whether the following quality criteria had been fulfilled by the studies:

1. Attempts to achieve a representative sample for the population of focus, e.g., by population-based surveys or involving more than one setting

2. Setting, as an indicator for potentially higher proportions of chronically ill participants (e.g., emergency departments or hospitalized patients)

3. Validation of the selected assessment tool (e.g., piloted questionnaire, structured interview, or previous use of study materials)

4. Analysis of non-responders and/or inter-rater reliability

5. CAM defined to participants (e.g., by presenting a list of specific CAM modalities) or an expert investigator identified the responses as CAM if all administered drugs/therapies were assessed by the study

6. CAM defined in the article (e.g., by presenting a list of the assessed CAM modalities or reporting figures for specific CAM modalities)

7. Prevalence and/or predictors of specific CAM modalities reported

The quality assessment is available as an appendix to this review (see appendix Table S1). Further relevant quality aspects such as sample size or child's age are integrated into Table 2. 


\section{Results}

\section{Selected studies}

The search of the four databases yielded a total of 8,540 results. A total of 8,301 publications could be excluded by title or abstract as they evidently did not supply information about the prevalence or predictors of CAM use in children/adolescents. After removing duplicates and adding 85 articles from citation tracking, 227 articles were obtained which at first view reported patterns of CAM use in children/adolescents or needed further screening for possible eligibility.

Of these, 12 studies were excluded because the samples consisted of adults and no stratified data for children/adolescents were available. A further 118 studies were removed because they had been conducted with mainly small samples ( 46 studies with $\leq 100$ participants) of chronically ill children, e.g., cancer (38 studies), asthma (12 studies) or diabetes (7 studies). Eighteen studies assessed only non-focused CAM modalities (14 only vitamins/minerals, 3 only traditional Chinese medicine, 1 only nutritional supplements). In three studies, the authors investigated CAM use for one specific indication or purpose only. The complete flow diagram of the selection process is shown in Figure 1.

Finally, 58 studies were considered eligible for this review (Table 2). This included six studies $[1,20,43,52,63,66]$ which were available only as abstracts or short reports, but supplied information on utilization patterns for countries where no or only few other studies had been conducted so far.

Studies of the following countries are included in this review: Denmark (DEN), Finland (FIN), Germany (GER), Ireland (IRE), Israel (ISR), Italy (ITA), Netherlands (NL), Norway (NOR), Switzerland (SWI), Turkey (TUR), United Kingdom (UK), Canada (CAN), United States (USA), Australia (AUS), New Zealand (NZ), Argentina (ARG), Brazil (BRA), South Korea (SKO), and Taiwan (TAI).

The size of the included studies varied from 92 [9] to 20,219 [43] participants. Twenty-one of the studies had been conducted with more than 1,000 participants $[4,6,13,14,27,28,31,34,37,43,50,55,57,58,60,65,67-70,72]$. Most of the studies investigated CAM use in children, six assessed CAM use in samples composed only of adolescents (12-19 years) $[8,21,58,64,65,69]$. Exactly $43 \%$ of the studies had been conducted in 11 European States, including Turkey and Israel, 41\% in North America, and 7\% in Australia/New Zealand. Only five studies reported CAM use in South America or Asia. We found no eligible studies from Eastern Europe (except Turkey) or some of the bigger Western European countries such as France or Spain. 


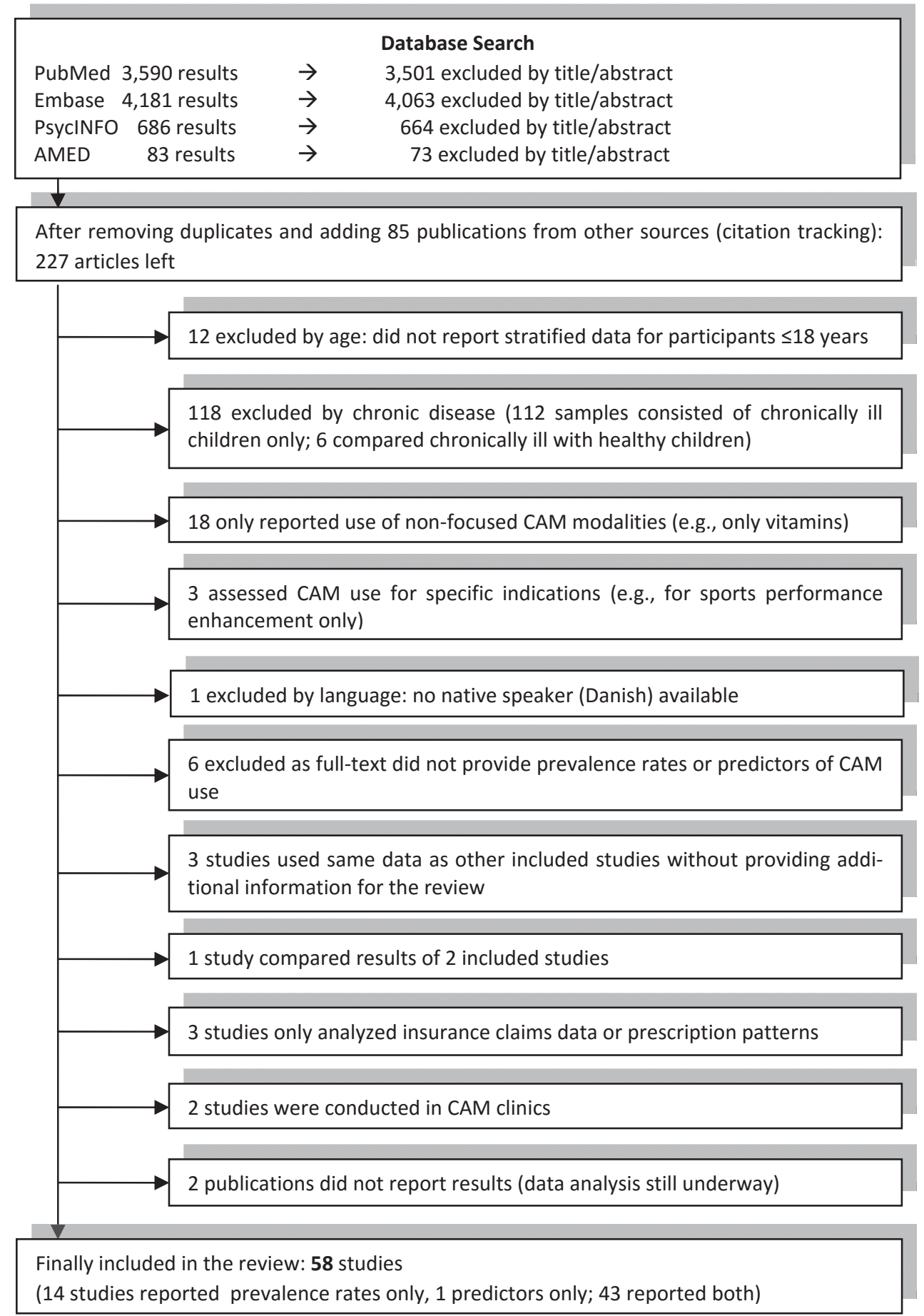

Figure 1. Flow diagram of selected studies 


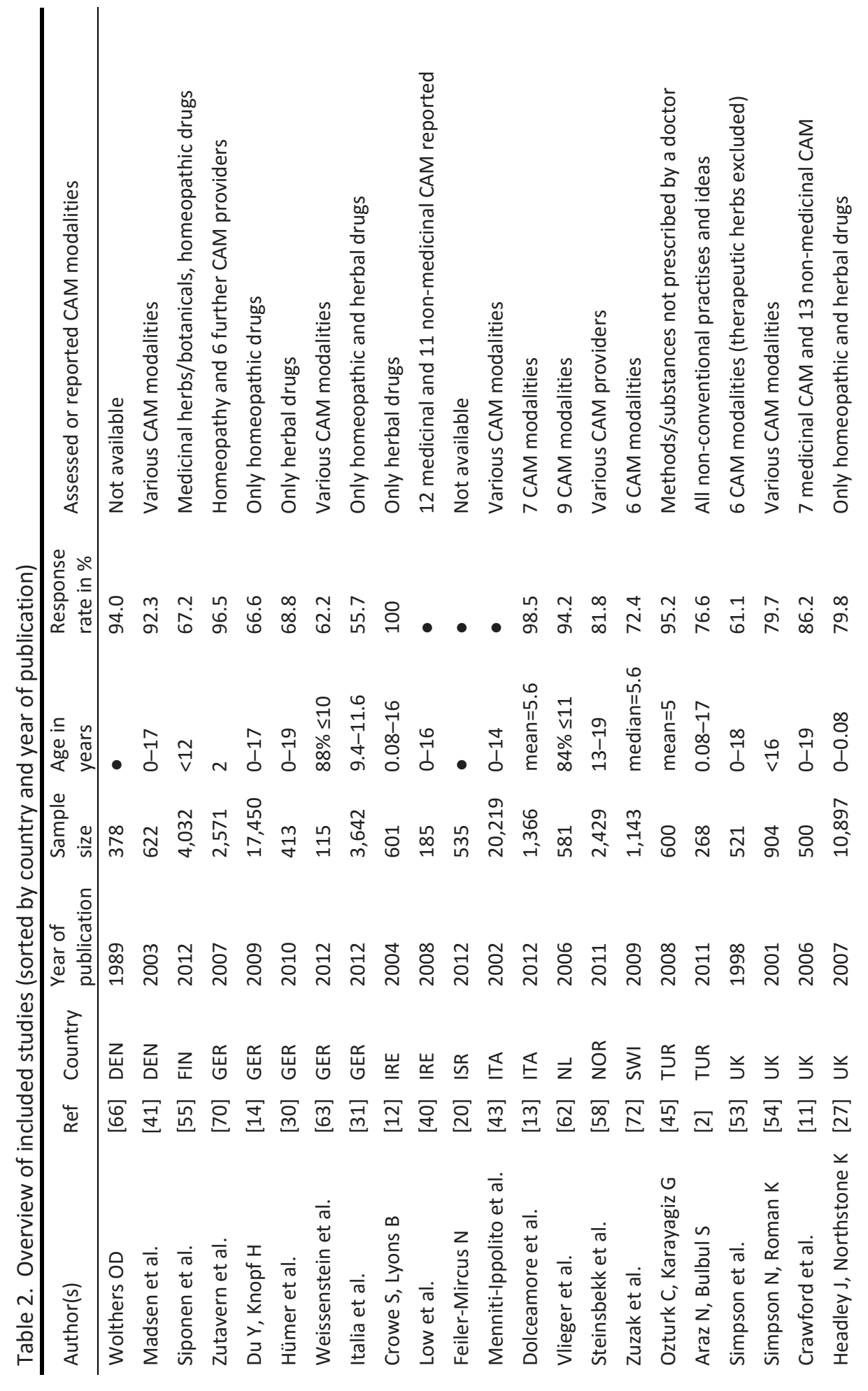




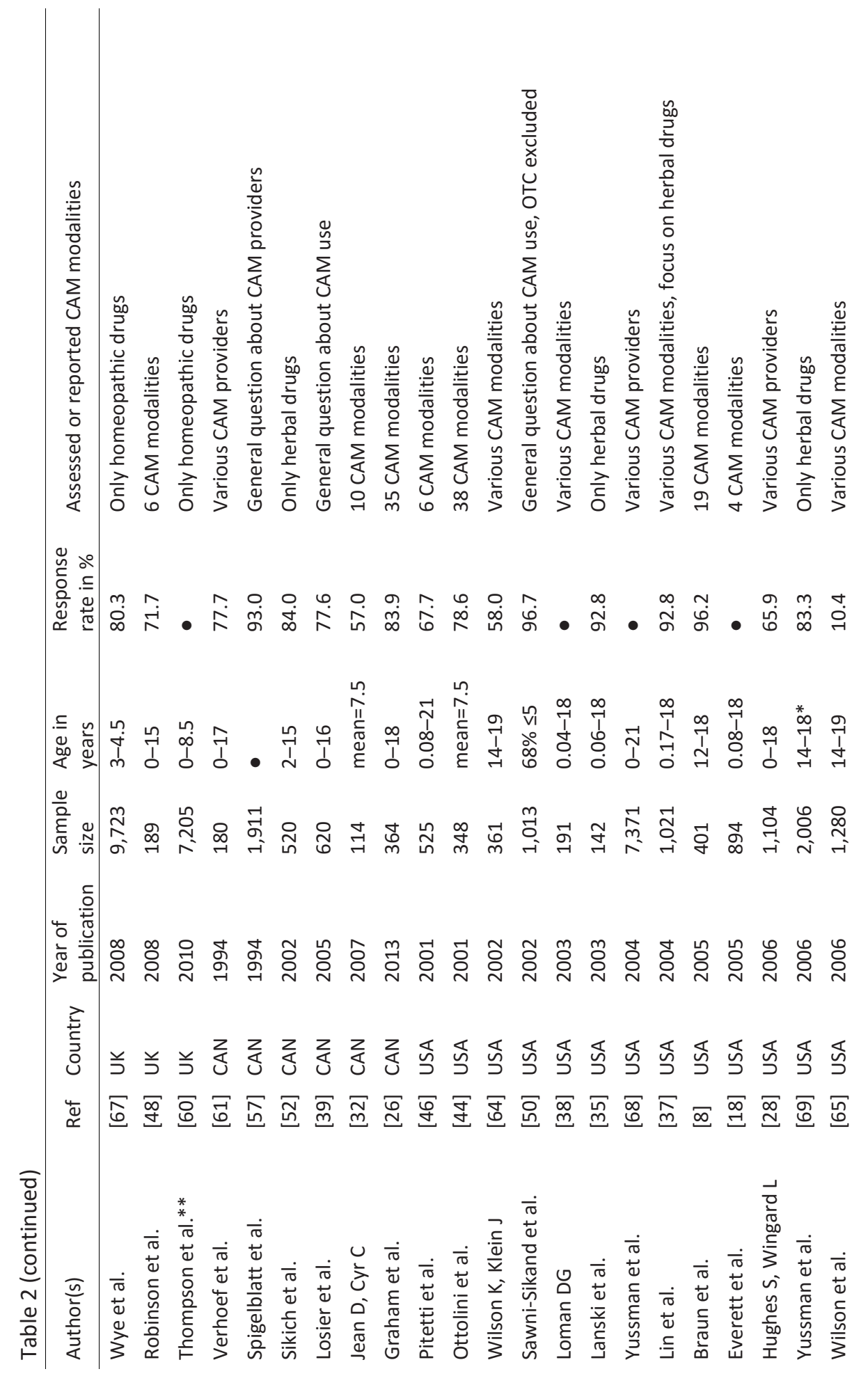




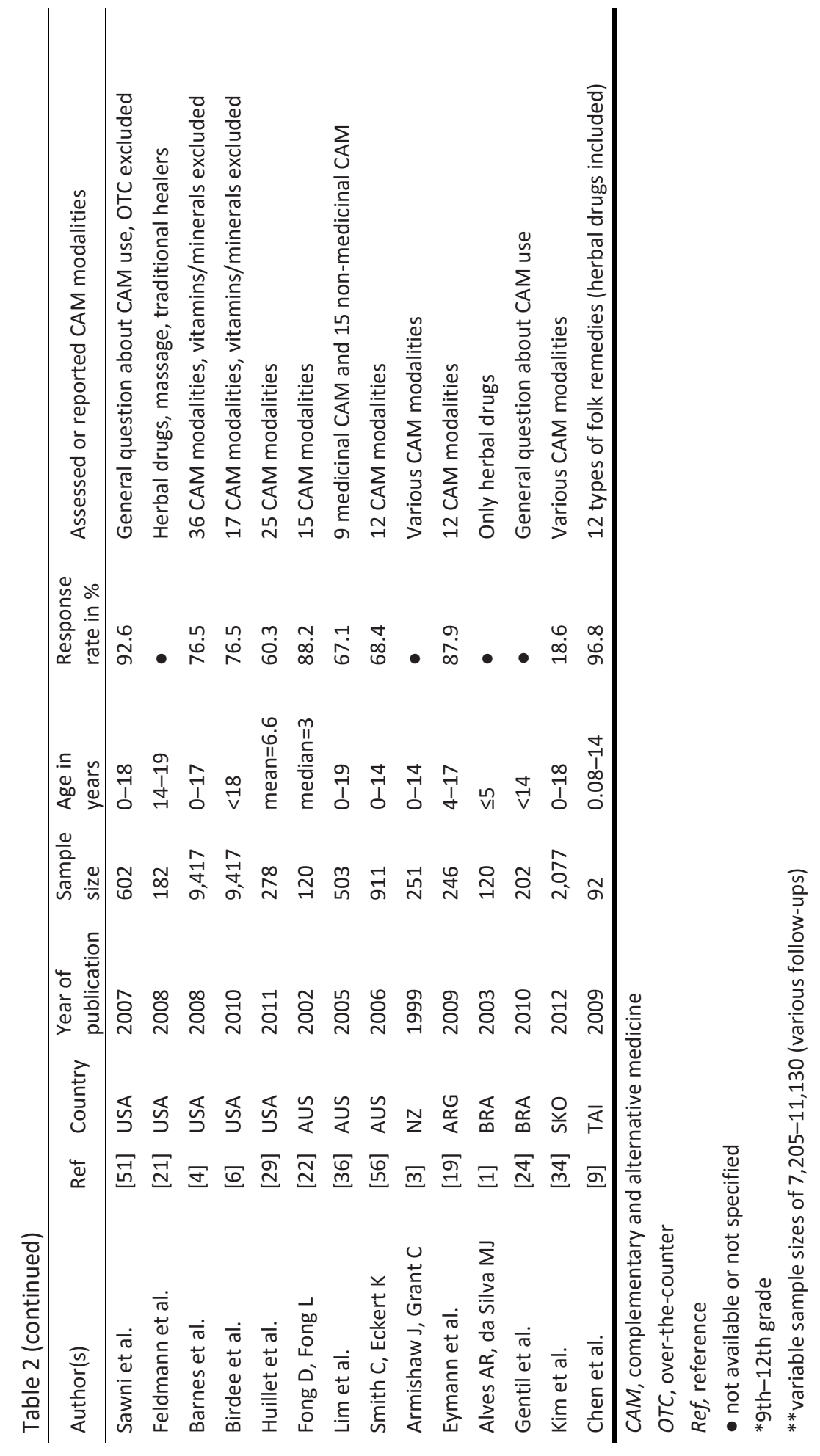


Of the included studies, the first on this topic was published in 1989 [66], whereas about half of the studies had been published only in the past 7 years (2007-2013).

\section{Quality assessment}

The quality of methodology and reporting varies widely, from very small-scaled and simple surveys to large and well performed studies. The results of the quality assessment are displayed in the appendix Table S1.

Eleven studies were read and analyzed by at least two reviewers independently as interpretation of data was ambiguous. The accordance between the reviewers' interpretations was $86 \%$. Inconsistencies were resolved by discussion. Additionally, we tried to contact 18 authors for clarification. Eight responded and supplied clarifying information $[13,22,24,26,41,50,51,63]$.

\section{Prevalence}

Table 3 shows the reported prevalence rates for all CAM, homeopathy, and herbal drugs, sorted by country, publication date, and recall periods (only studies with more than 100 participants considered). Most studies reported lifetime or 1-year prevalence, and six $[9,14,18,27,31,55]$ chose only shorter recall periods. For practical reasons, studies with a recall period of 0.5 years, 1.5 years, and 3 years were allocated to the columns for the 1-year prevalence. We defined current use (=point prevalence) as use within the last month.

One study [10] compared the results of two included studies [11,36] and therefore used the same sets of data. In this comparison article, some prevalence rates for homeopathy and herbal drug use were reported that were missing in the original publications. This additional information was considered in the respective lines of Table 3.

Overall, CAM use differs enormously across the included studies (e.g., lifetime use was reported between 10.9 and $87.6 \%$ ). For homeopathy, the prevalence rates (recall period) range between $0.8-39 \%$ (lifetime), 1.2-30\% (1 year), and 1-14.3\% (current use) across all studies. The respective ranges for herbal drugs are $0.8-85.5 \%$ (lifetime), 2.4-58.6\% (1 year), and 2.2-8.9\% (current use). As expected, longer recall periods yielded (in part noticeably) higher prevalence rates.

Within Europe, the highest prevalence rates for homeopathy and herbal drug use reported were $27.7 \%$ (1 year) and $85.5 \%$ (lifetime), respectively from two German studies $[30,70]$. Herbal drug use among children was also very popular in Turkey $(58.6 \%$ for 1-year prevalence) [2]. 
Table 3. Prevalence of CAM use in children/adolescents in \% (sorted by country and year of publication)

\begin{tabular}{|c|c|c|c|c|c|c|c|c|c|c|c|}
\hline \multirow[t]{2}{*}{ Author(s) } & \multirow[b]{2}{*}{ 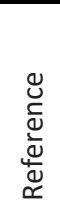 } & \multirow[b]{2}{*}{ 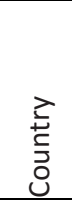 } & \multicolumn{3}{|c|}{ All reported CAM } & \multicolumn{3}{|c|}{ Homeopathy } & \multicolumn{3}{|c|}{ Herbal drugs } \\
\hline & & & 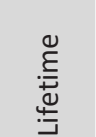 & 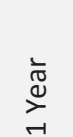 & 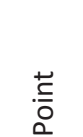 & 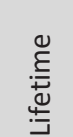 & $\begin{array}{l}\frac{1}{\pi} \\
\stackrel{0}{\beth}\end{array}$ & $\stackrel{+}{\stackrel{ \pm}{0}}$ & & 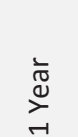 & $\stackrel{\stackrel{H}{\circ}}{\circ}$ \\
\hline Wolthers OD & [66] & DEN & $31.0 *$ & & 8.0 & & & & & & \\
\hline Madsen et al. & [41] & DEN & 52.6 & & $19.5^{4}$ & & & & & & $2.9^{4}$ \\
\hline Siponen et al. ${ }^{7}$ & [55] & FIN & & & 11.0 & & & 1.0 & & & \\
\hline Zutavern et al. & [70] & GER & & & & & 27.7 & & & & \\
\hline Du Y, Knopf $H^{6}$ & [14] & GER & & & & & & 4.6 & & & \\
\hline Hümer et al. & [30] & GER & & & & & & & 85.5 & & \\
\hline Weissenstein et al. & [63] & GER & 75.7 & & & & & & & & \\
\hline Italia et al. & [31] & GER & & & & & & $14.3^{4}$ & & & $8.9^{4}$ \\
\hline Crowe S, Lyons B & [12] & IRE & & & & & & & 16.6 & & 6.4 \\
\hline Low et al. & {$[40]$} & IRE & $56.8^{*}$ & & & $9.2^{*}$ & & & $8.7^{*}$ & & \\
\hline Feiler-Mircus N & [20] & ISR & $27.0 *$ & & & & & & & & \\
\hline Menniti-Ippolito et al. ${ }^{1}$ & [43] & ITA & & 9.1 & & & 7.6 & & & 2.4 & \\
\hline Dolceamore et al. & [13] & ITA & 29.0 & & & & & & & & \\
\hline Vlieger et al. & [62] & NL & & 30.5 & & & 14.6 & & & 13.8 & \\
\hline Steinsbekk et al. & [58] & NOR & & 8.7 & & & & & & & \\
\hline Zuzak et al. & [72] & SWI & $58.2^{*}$ & & 25.5 & & & & & & \\
\hline Ozturk C, Karayagiz G & [45] & TUR & 56.5 & & & & & & 43.3 & & \\
\hline Araz N, Bulbul S & [2] & TUR & & 58.6 & & & & & & 58.6 & \\
\hline Simpson et al. & [53] & UK & 20.7 & & & 14.0 & & & 0.8 & & \\
\hline Simpson N, Roman K & {$[54]$} & UK & 17.9 & & & 10.4 & & & 4.1 & & \\
\hline Crawford et al. & {$[11]$} & UK & & 41.2 & $26.6^{4}$ & & 3.6 & & & 9.8 & $5.0^{4}$ \\
\hline Headley J, Northstone K & [27] & UK & & & & & & $1.2^{4}$ & & & $2.2^{4}$ \\
\hline Wye et al. ${ }^{2}$ & [67] & UK & & & & & 6.0 & & & & \\
\hline Robinson et al. & [48] & UK & 36.5 & & & 16.9 & & & 15.9 & & \\
\hline Thompson et al.** & [60] & UK & & & & & $5.4-8.0$ & & & & \\
\hline Verhoef et al. & [61] & CAN & & 15.6 & & & & & & & \\
\hline Spigelblatt et al. & [57] & CAN & 10.9 & & & 3.8 & & & & & \\
\hline Sikich et al. & [52] & CAN & & & & & & & 22.0 & & \\
\hline Losier et al. & [39] & CAN & $12.8^{*}$ & & & $2.6^{*}$ & & & $1.3^{*}$ & & \\
\hline Jean D, Cyr C & [32] & CAN & & 53.5 & & 39.0 & 30.0 & & & & \\
\hline Graham et al. & [26] & CAN & 69.2 & & 39.6 & 2.2 & & & & & \\
\hline Pitetti et al. & [46] & USA & $12.0^{*}$ & & & & & & & & \\
\hline Ottolini et al. & [44] & USA & & 20.7 & & & 1.2 & & & 8.9 & \\
\hline Wilson K, Klein $\mathrm{J}^{3}$ & [64] & USA & & 54.0 & & & 1.2 & & & 11.5 & \\
\hline Sawni-Sikand et al. & [50] & USA & 12.0 & & & 1.2 & & & 4.9 & & \\
\hline Loman DG & [38] & USA & 49.0 & 33.0 & & 3.7 & 3.1 & & 10.0 & 6.8 & \\
\hline Lanski et al. & [35] & USA & & & & & & & & 45.1 & \\
\hline Yussman et al. & [68] & USA & & 1.8 & & & & & & & \\
\hline
\end{tabular}


Table 3 (continued)

\begin{tabular}{|c|c|c|c|c|c|c|c|c|c|c|c|}
\hline \multirow[t]{2}{*}{ Author(s) } & \multirow[b]{2}{*}{ 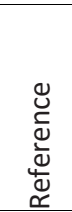 } & \multirow[b]{2}{*}{ 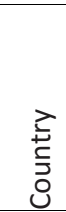 } & \multicolumn{3}{|c|}{ All reported CAM } & \multicolumn{3}{|c|}{ Homeopathy } & \multicolumn{3}{|c|}{ Herbal drugs } \\
\hline & & & 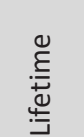 & 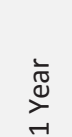 & $\stackrel{+}{\stackrel{ \pm}{0}}$ & 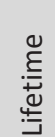 & 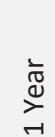 & $\stackrel{+}{\frac{\pi}{0}}$ & 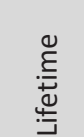 & 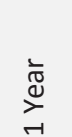 & $\stackrel{+}{\frac{1}{0}}$ \\
\hline Lin et al. & [37] & USA & & 29.5 & & & 3.6 & & & 12.8 & \\
\hline Braun et al. & {$[8]$} & USA & 68.1 & & & 4.0 & & & 27.2 & & \\
\hline Everett et al. ${ }^{5}$ & [18] & USA & & & 41.5 & & & 1.0 & & & 2.9 \\
\hline Hughes S, Wingard L & [28] & USA & & 22.6 & & & & & & & \\
\hline Yussman et al. & [69] & USA & & & & & & & 28.6 & & \\
\hline Wilson et al. & [65] & USA & 79.0 & & $48.5^{4}$ & 4.1 & & $1.2^{4}$ & 22.9 & & $7.0^{4}$ \\
\hline Sawni et al. & [51] & USA & 15.0 & & & & & & 6.2 & & \\
\hline Feldmann et al. & [21] & USA & & 26.9 & & & & & & 23.6 & \\
\hline Barnes et al. & {$[4]$} & USA & & 11.8 & & & 1.3 & & & $3.9^{\mathrm{a}}$ & \\
\hline Huillet et al. & [29] & USA & & 23.0 & & & & & & 7.8 & \\
\hline Fong $\mathrm{D}$, Fong $\mathrm{L}$ & [22] & AUS & 33.0 & & & 0.8 & & & 8.0 & & \\
\hline Lim et al. & [36] & AUS & & 51.3 & $29.4^{4}$ & & 5.4 & & & 18.1 & \\
\hline Smith C, Eckert K & [56] & AUS & & 18.4 & & & 2.0 & & & 6.2 & \\
\hline Armishaw J, Grant C & [3] & $\mathrm{NZ}$ & 28.7 & & 17.5 & & & 4.0 & & & \\
\hline Eymann et al. & [19] & ARG & 13.0 & & & 8.8 & & & & & \\
\hline Alves AR, da Silva MJ & [1] & BRA & & & & & & & $66.0^{*}$ & & \\
\hline Gentil et al. & [24] & BRA & 87.6 & & & 3.5 & & & 63.8 & & \\
\hline Kim et al. & [34] & SKO & & 65.3 & & & & & & & \\
\hline
\end{tabular}

CAM, complementary and alternative medicine

point $=$ use within the last month

recall period: ${ }^{1} 3$ years ${ }^{2} 1.5$ years ${ }^{3} 0.5$ years ${ }^{4} 1$ month ${ }^{5} 2$ weeks ${ }^{6} 1$ week ${ }^{7} 2$ days

*recall period not defined, therefore assumed as lifetime use

**variable recall periods ( 1.5 years or 1 year), due to several follow-ups

anonvitamin, nonmineral, natural products (mainly herbal products)

Compared to Europe, the utilization of homeopathy and herbal drugs in children or adolescents seems to be less common in the United States and Australia.

In South America, homeopathy was given to $8.8 \%$ of the children in Argentina (lifetime use) [19] and 3.5\% of the pediatric population in Brazil (lifetime use) [24]. No use of homeopathy was reported in the studies from Turkey and South Korea [2,34,45].

Meta-analysis (studies grouped by continent; values for prevalence rates given with two decimal places as estimated by the software 'R') yielded an overall 1-year prevalence for homeopathy of $8.98 \%$ (Europe) and 3.08\% (North America). The respective figures for herbal drug use are 13.53\% (Europe) and 12.05\% (North America). Figures 2 and 3 show the forest plots for the calculated 1-year prevalence rates $(P)$ with their $95 \%$ confidence intervals. One study reported different prevalence rates due to several follow-ups [60]. In this case, we used the value in the middle of the reported range of 
prevalence rates for meta-analysis (6.25\%) based on the smallest sample size $(N=7,205)$. Further forest plots of the respective prevalence rates for lifetime and current use are available as an appendix to this review.

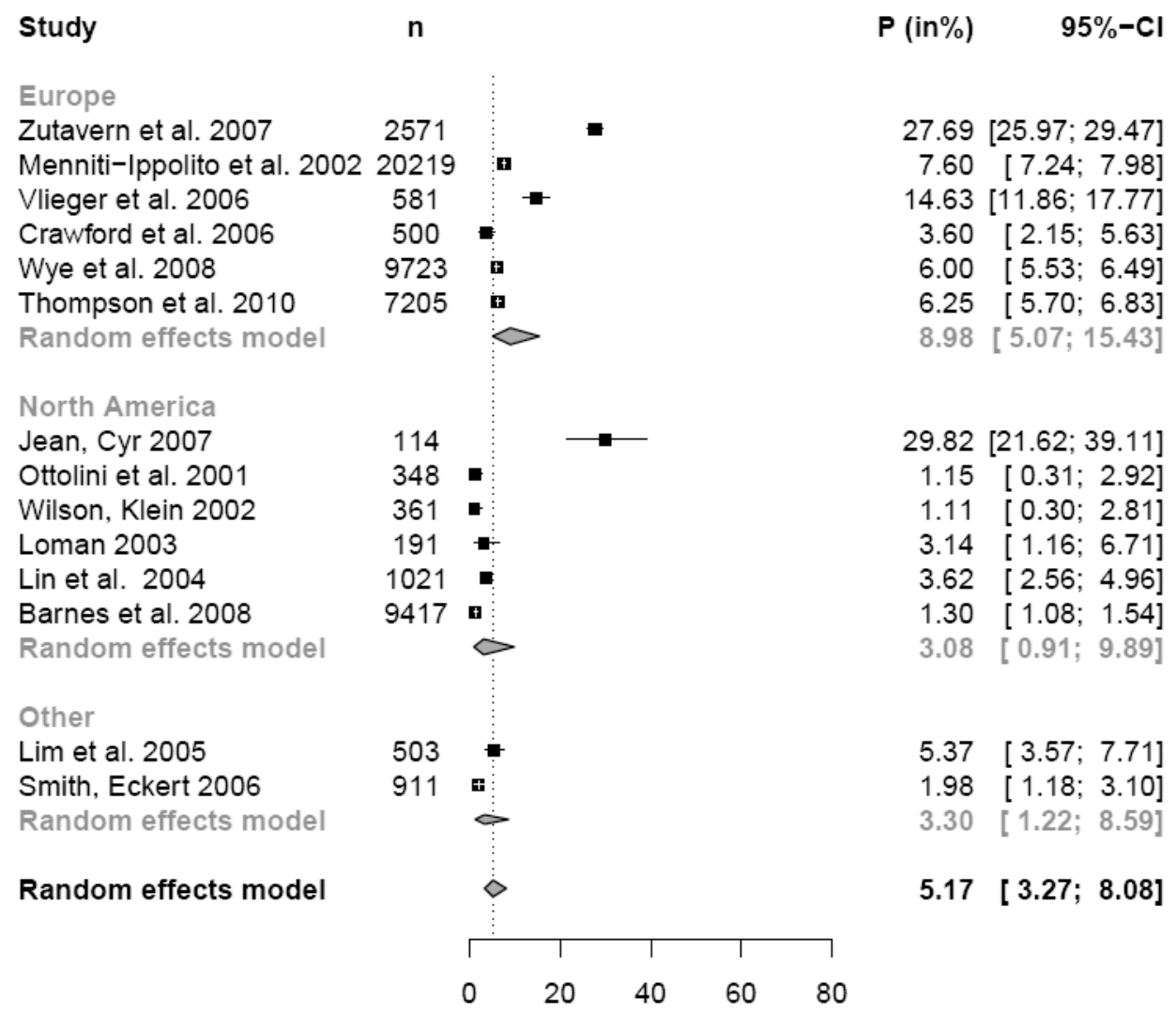

Figure 2. 1-year prevalence rates for use of homeopathic drugs*

* The random effects model estimates the mean prevalence rates $(P)$ and $95 \%$ confidence intervals $(\mathrm{Cl})$ for each group as well as the mean overall prevalence. Small discrepancies in prevalence rates are due to rounding errors. 


\begin{tabular}{|c|c|c|c|c|c|}
\hline Study & $\mathbf{n}$ & & & $P($ in $\%)$ & $95 \%-\mathrm{Cl}$ \\
\hline \multicolumn{6}{|l|}{ Europe } \\
\hline Menniti-Ippolito et al. 2002 & 20219 & t & & 2.40 & {$[2.19 ; 2.62]$} \\
\hline Vlieger et al. 2006 & 581 & - & & 13.77 & {$[11.07 ; 16.84]$} \\
\hline Araz, Bulbul 2011 & 268 & & $\rightarrow-$ & 58.58 & {$[52.43 ; 64.54]$} \\
\hline Crawford et al. 2006 & 500 & 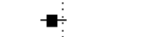 & & 9.80 & {$[7.34 ; 12.75]$} \\
\hline Random effects model & & & & 13.53 & $3[2.30 ; 50.96]$ \\
\hline \multicolumn{6}{|l|}{ North America } \\
\hline Ottolini et al. 2001 & 348 & $\neq$ & & 8.91 & $16.13 ; 12.41]$ \\
\hline Wilson, Klein 2002 & 361 & $\stackrel{-}{-}$ & & 11.63 & $3[8.51 ; 15.40]$ \\
\hline Loman 2003 & 191 & 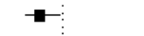 & & 6.81 & 1 [ $3.67 ; 11.36]$ \\
\hline Lanski et al. 2003 & 142 & & $\longrightarrow$ & 45.07 & {$[36.72 ; 53.64]$} \\
\hline Lin et al. 2004 & 1021 & * & & 12.83 & {$[10.84 ; 15.04]$} \\
\hline Feldmann et al. 2008 & 182 & $\rightarrow$ & & 23.63 & $3[17.66 ; 30.48]$ \\
\hline Barnes et al. 2008 & 9417 & ت & & 3.90 & {$[3.52 ; 4.31]$} \\
\hline Huillet et al. 2011 & 278 & - & & 7.91 & $1[5.03 ; 11.74]$ \\
\hline Random effects model & & 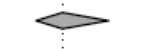 & & 12.05 & $5[6.10 ; 22.41]$ \\
\hline \multicolumn{6}{|l|}{ Other } \\
\hline Lim et al. 2005 & 503 & 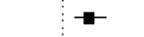 & & 18.09 & {$[14.82 ; 21.74]$} \\
\hline Smith, Eckert 2006 & 911 & . & & 6.15 & {$[4.68 ; 7.91]$} \\
\hline \multicolumn{2}{|l|}{ Random effects model } & & & 10.76 & 6 [ $3.53 ; 28.41]$ \\
\hline \multirow[t]{3}{*}{ Random effects model } & & $\infty$ & & 12.25 & $5[6.80 ; 21.07]$ \\
\hline & & 1 & 1 & $\neg$ & \\
\hline & & 20 & 60 & 80 & \\
\hline
\end{tabular}

Figure 3. 1-year prevalence rates for use of herbal drugs*

* The random effects model estimates the mean prevalence rates $(P)$ and $95 \%$ confidence intervals $(\mathrm{Cl})$ for each group as well as the mean overall prevalence. Small discrepancies in prevalence rates are due to rounding errors.

\section{Predictors}

Regarding predictors of CAM use, we limited this review to the following variables: parental education, parental income, parental or child's ethnicity/country of birth, geographic region inside the country, parental CAM use, child's age, and gender.

Among the 58 included studies, 43 tested the association of CAM use with at least one of the aforementioned variables. The majority reported the predictors for overall CAM use. Only four studies, of those assessing various CAM modalities, analyzed predictors for homeopathy or herbal drug use as well $[6,31,38,65]$, although most studies did also report prevalence rates for those CAM modalities. The predictors are shown in Table 4 (we were unable to summarize the magnitude of the predicting effects because 
of variable methodologies such as different coding of categorical variables, different statistical tests, etc.). In all listed studies, the level for significance was at least $\mathrm{P}<0.05$.

Predictors for overall CAM use

Thirty-six studies analyzed predictors for overall CAM use (see Table 4, category "all CAM"). Education of either parent was tested in 18 studies (10 significant [2,4,6, $28,34,39,40,45,48,55]$ ), maternal in 6 studies (4 significant $[11,57,62,72]$ ), and paternal in 3 (3 significant $[11,62,72]$ ). All significant results showed that higher parental education is associated with higher CAM use in children.

Parental/maternal income was tested in 20 studies. Only seven studies [4,11,26,28, $34,41,48$ indicated that higher income was associated with higher CAM use, while one study found higher CAM use in the financially weakest group [65] (the results of all other studies were not significant). Parental CAM use was the strongest predictor for CAM use in children (22 tests, 21 of them significant $[2,4,6,9,22,29,34,38,44-46,48,50$, $51,54,55,57,62,64,65,68])$. Out of 27 studies analyzing gender, only 3 showed a significant result, all 3 suggesting, that female children/adolescents use more CAM $[58,65,68]$.

The classification of the age groups was inhomogeneous across the included studies. However, with regard to age, 12 studies found the older age groups of the respective sample to use more CAM $[4,6,8,36,38,39,44,50,51,57,68,72]$. Only in one study was younger age [40] a positive predicting factor.

With respect to ethnicity, five out of six significant results from the North American studies $[4,8,28,38,68]$ suggested that overall CAM use was highest in white children/adolescents (only in one study [65] was the highest overall CAM use reported for black adolescents). In the European and Australian studies, which mainly assessed parental/child's country of birth instead of ethnicity (one study assessed ethnicity [48], one parental nationality [30]), all significant results [36,72] showed that those children without migrant background use more CAM. Two American studies analyzed both ethnicity and country of birth $[35,50]$, and one found higher CAM use in children with migrant background [50].

The association of CAM use with the geographic region was only tested in German and American studies.

\section{Homeopathic drug use}

Predictors for homeopathic drug use were analyzed in four studies $[14,31,67,70]$. Higher parental education and income, younger age, and female gender were positive predictors for homeopathic drug use (age was tested only in one study [14], and gender 
was tested in two studies [14,31] with one showing no significant results [14]). The association with parental own use of homeopathy was not tested in any of the studies.

\section{Herbal drug use}

Eight studies which reported predicting factors for herbal drug use were included in the review $[6,21,30,31,35,38,65,69]$. Parental education was positively associated with herbal drug use in children. One out of three tests for income was not significant [31], while two showed a positive association $[30,38]$. The results for age indicate that older children take more herbal drugs. All but one tests for gender-specific differences were not significant.

\section{Additional results}

Eighteen studies provide information on the gender of respondents $[1,2,9,11,26,29-$ $32,34,36-38,44,45,60,63,72]$, and all stated that predominantly mothers had been interviewed or had completed the questionnaires. Reasons for CAM use such as worrying about side effects of conventional medicine were reported by 21 studies [2,8,9,19$22,24,29,30,35,39,46,51,52,54,57,62,63,66,72]$ and costs were assessed by only 10 studies $[8,11,30,31,40,41,54,57,66,68]$. In 25 publications, the authors provided some information on the intensity of CAM use and whether CAM was used complementarily to conventional therapies or used as a substitute for it $[8,9,11,14,21,22,26,28,30$, $31,35,36,41,46,48,50,53,55,60-64,66,69]$. Twenty-seven studies assessed the medical disorders CAM was administered for $[1,2,6,8,13,24,30-32,34-36,41,43-46,48,52,53,56$, $57,60,63,66,70,72]$.

\section{Discussion}

Our findings imply that in those countries where CAM use in children has been investigated by epidemiological studies, utilization of some form of CAM is widespread among children and adolescents. Previous reviews on patterns of pediatric CAM utilization included in part or exclusively studies with samples of chronically ill children [7,16,71], but compared to healthy children, CAM use may be higher in children with chronic conditions. A study analyzing American insurance claims data of 187,323 children showed significantly higher prevalence rates for (provider-based) CAM use in children with chronic disorders such as cancer or low back pain [5]. 


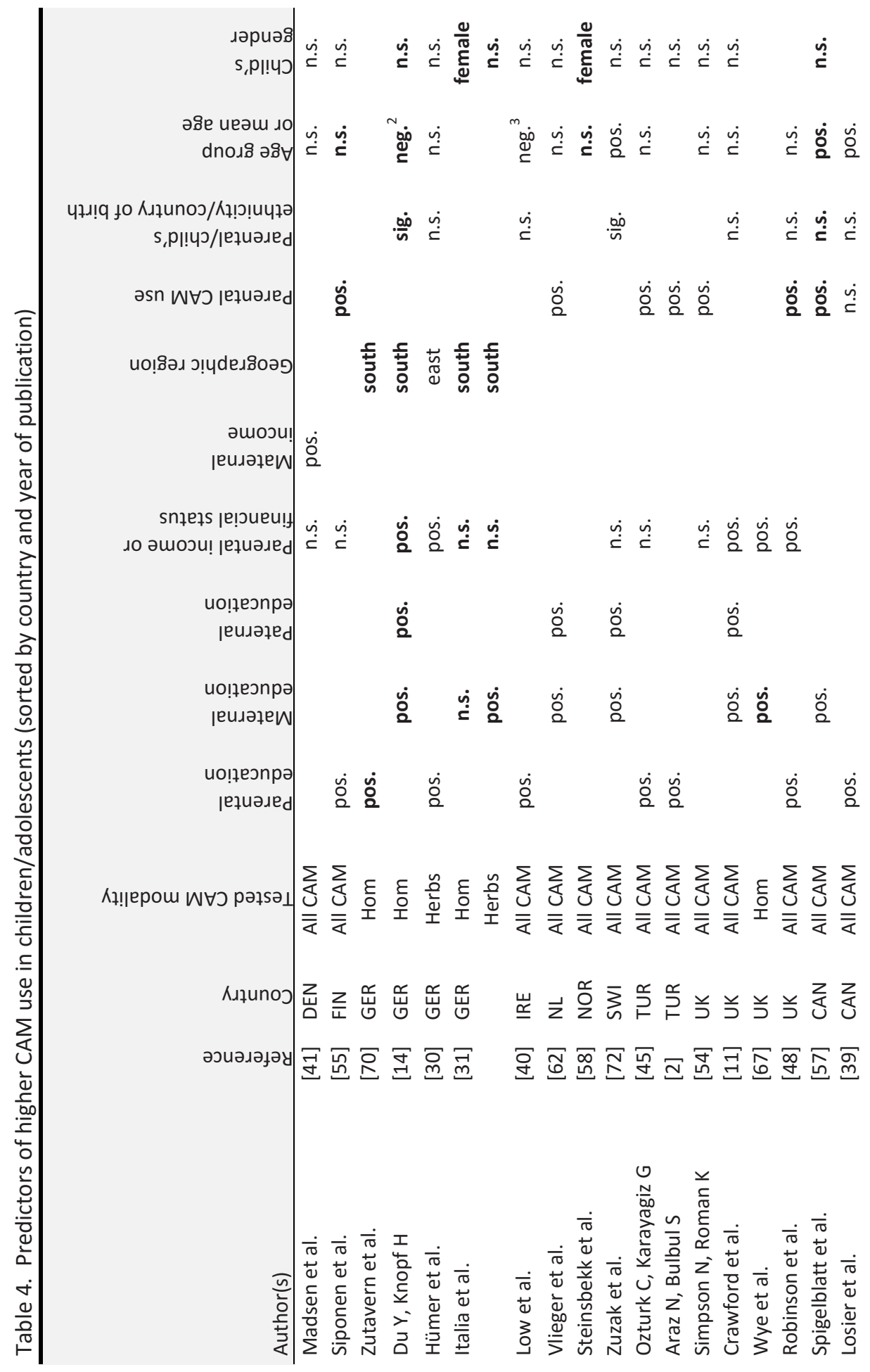




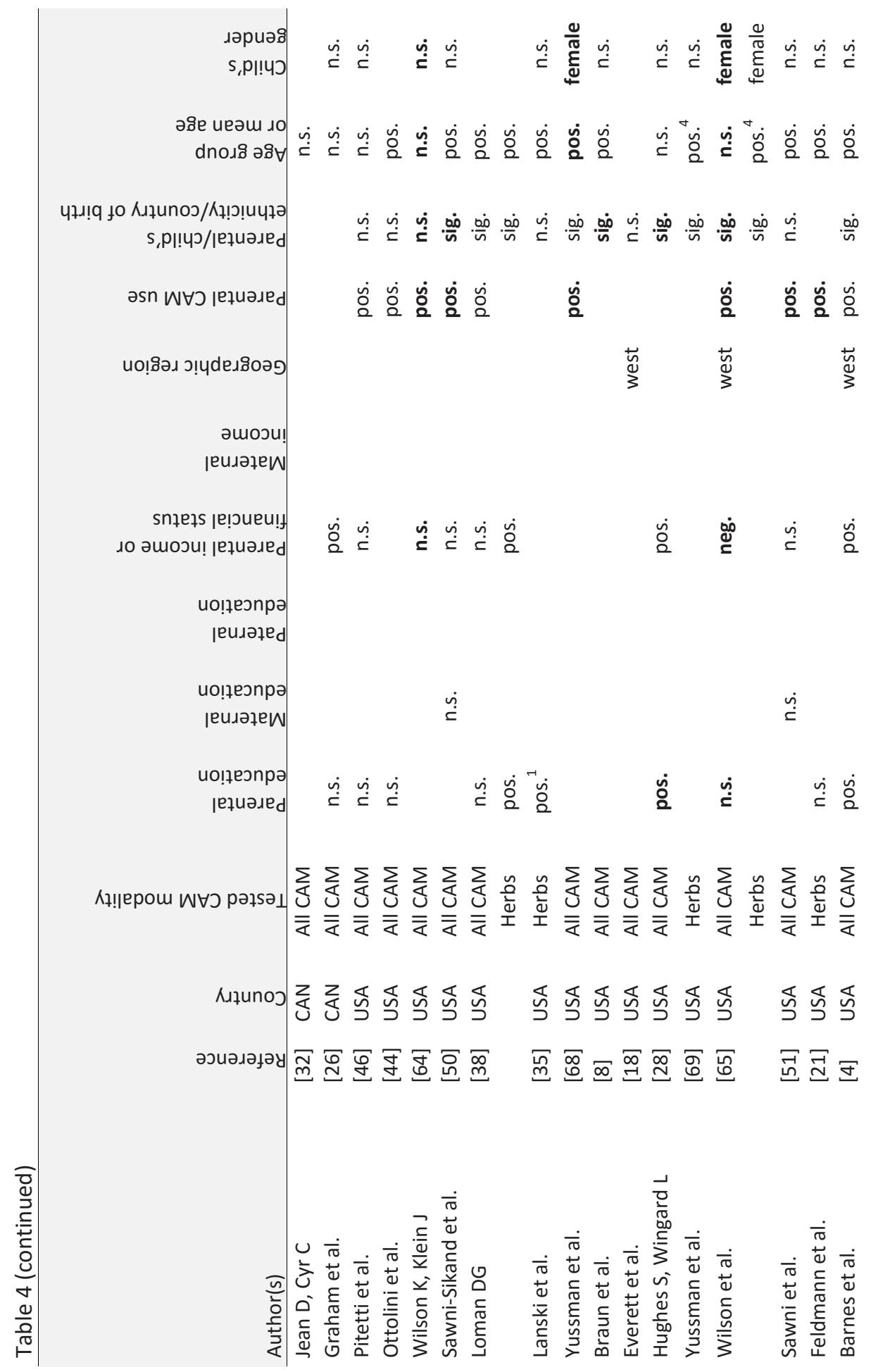




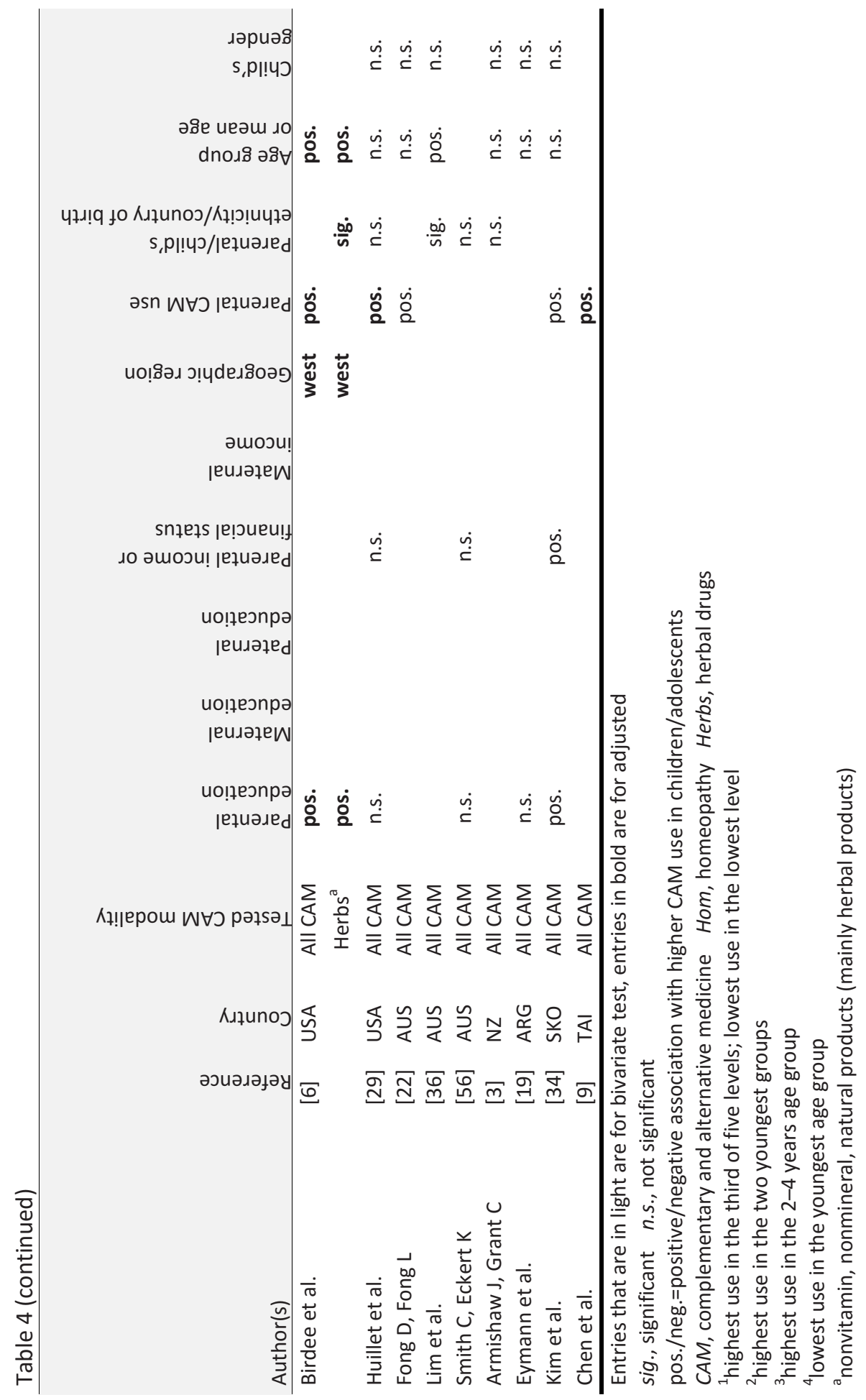


This review presents an overview of findings from study-samples of children without chronic disorders and thus the reported prevalence rates may be more representative for the pediatric population of the respective countries (however, several of the included studies also contained substantial proportions of chronically ill children). In accordance with our results, a recently published review confirmed the lack of published data from Eastern Europe [71].

Utilization of specific CAM modalities seems to be very varied across different countries. Homeopathy use in children is very common in Germany, UK, or the Netherlands, but was not reported from e.g., Turkey or South Korea [2,34,45]. According to a comparative study [49], there is an indication that the use of homeopathy in children may also be unpopular in Bulgaria, Slovakia, Russia, and Spain, as no homeopathics were found among the drugs/remedies prescribed by pediatricians or physicians (no data was supplied for self-medication or other CAM modalities; for France, the proportion of homeopathics in all administered drugs was reported to be $1.7 \%$ ). Possible reasons for this variability may be differences in acceptance, limited availability of homeopathic remedies, or legal aspects [34,71].

In countries such as Brazil or Turkey, herbal remedies like teas evidently play an important role in the treatment of ill children. It may be hypothesized that good access to herbal remedies (and probably poor access to conventional treatments for a part of the population) and lower or no costs for this kind of treatment (e.g., when picked in the own garden or in nature) could be one reason for the high popularity especially in these countries.

The socioeconomic predictors for CAM use seem to be uniform across the included studies, but only very few studies differentiated between single CAM modalities. The impact of parental income, education, and parents' own CAM use appears to be significant, but factors that are not influenced by parental background such as child's gender and age may also have an impact. In all instances of significant results for gender, female children used more CAM than male children. Two further large studies analyzing insurance claims data (for CAM provider visits) [5] and physicians' prescribing patterns (for anthroposophic remedies), respectively [33] also found female children to use significantly more CAM.

As it is unlikely that the high CAM popularity is only a passing phenomenon, the results of this review may have implications for decision makers. Seemingly, there is a demand for (supposedly) gentle and holistic therapy approaches (if in some countries or regions limited access to conventional medicine or limited financial resources are one reason for CAM use, respective measures for improvement by authorities are indispensable). Meanwhile, CAM has also become an economic factor. In 2011, the sales of herbal, homeopathic, and anthroposophic drugs together amounted to one billion euros in German pharmacies [25]. Homeopathy and herbal drugs, listed in many studies 
among the most popular CAM modalities, exhibit two problems often mentioned in the context of CAM use: it is not superior to a placebo ("homeopathy") [17] or it has problematic side effects/interactions ("herbals") $[18,35,52,68,69]$. It is essential that CAM with poor evidence of efficacy are not used as a substitute for conventional medicine in patients with severe conditions. Physicians should be aware of possible CAM use especially in their pediatric patients. Nevertheless, harmless CAM may have a benefit, even if it is only due to placebo effect. It should also be noted that there are approved conventional drugs which lack clear evidence of efficacy (e.g., Acetylcysteine, a mucolytic drug widely used for children [42]). With respect to the high prevalence rates in Europe, costs and benefits of the single CAM modalities have to be investigated more intensely. Health care managers should then take position if and which CAM should be covered by health insurances. Also, with respect to the new European patient mobility, it would be desirable that the regulations for covering CAM would increasingly converge across the European Union.

To evaluate the extent of CAM use in children, reliable and informative data are needed. Many of the included studies are not comparable with respect to the range of assessed CAM modalities. In this context, the analysis of clearly defined individual CAM modalities and the reporting of the underlying recall period are two important aspects to obtain comparable figures.

For future publications (especially data from Eastern Europe, Asia, South America, and Africa are currently lacking), it would be desirable that researchers increasingly analyze the single CAM modalities as prevalence rates and predictors for overall CAM use have only limited informational content. A respective suggestion for a tool towards a more detailed and standardized assessment of CAM use has been developed [47]. To reduce the risk of bias, the data of only one child per surveyed family should be analyzed and seasonal factors should also be considered. When analyzing the impact of the family's financial situation on CAM use, equivalent income might be more appropriate than parental income.

With regard to "alternative" drugs such as homeopathic or herbal remedies, it is important to know both the prevalence of use and the quantities of the remedies actually consumed, as well as the duration of CAM use.

For decision makers, precise figures on expenditures for CAM use (both covered by insurance companies and paid out-of-pocket) would be helpful. Information on how many conventional prescription drugs are ultimately not used by patients because of poor tolerance (eventually induced by nocebo effect) or missing acceptance (after reading the patient information leaflet) would also be valuable. In this context, future studies could compare expenditures for conventional treatment with CAM therapies and how CAM use affects the financial situation of health care systems. 
This review has several strenghts and limitations. The database search strategy yielded a high number of results to be screened, increasing the probability of including most of the relevant literature. Data for prevalence rates and predictors were carefully extracted for the single CAM modalities (homeopathy, herbal remedies). To our knowledge, this is the first comprehensive international review displaying the figures for CAM use sorted by recall period, facilitating comparison of the various findings. For the first time, the findings for some of the main socioeconomic predictors of CAM utilization in children/adolescents were compared.

Despite the extensive literature search, we cannot exclude the possibility that some potentially important publications were missed, as we did not search in non-English databases or gray literature.

Due to the heterogeneity of the included studies, a pooling of the findings for predictors was not feasible. Furthermore, it is not ensured that allocation criteria for homeopathic remedies and herbal drugs, respectively were uniform across all included studies. Differences in the definition of CAM may be the reason for some remarkably high or low prevalence rates for herbal or homeopathic drug use reported by a few studies. To our knowledge, there is no universally valid definition of CAM. This might have an impact on the prevalence rates of overall CAM use summarized in this review especially when looking at different countries. To account for the huge variety of CAM definitions in the reviewed studies, meta-analysis was not performed for overall CAM use but restricted to homeopathic and herbal remedies.

We anticipated that use of homeopathy and herbal remedies would differ noticeably across countries and thus to obtain data for as many countries as possible, we also considered studies with lower quality and possibly limited representativeness.

Due to different settings, some studies contained substantial percentages (up to $37 \%$ ) of children with chronic diseases presumably overestimating CAM use [e.g., $3,9,32,39,40,45]$.

\section{Conclusions}

This review presents prevalence rates (sorted by recall period) and predictors for overall CAM use in children/adolescents and, if available, detailed information on homeopathy and herbal drug use is given. Prevalence rates vary noticeably across the compared countries but are generally on a high level, depending among others on the viewed CAM modality. Information on predictors for single CAM modalities is rare, and for many European and non-European countries no published studies are available. 


\section{Acknowledgments}

This work was supported by the Munich Center of Health Sciences (MC-Health) at Ludwig-Maximilians-Universität (LMU) München. The authors want to thank Prof. Helmut Brand, Professor of European Public Health at Maastricht University, for his contribution and support. In addition, we would like to thank PD Dr. Björn Stollenwerk and Dr. Matthias Hunger for their statistical advice and support.

\section{Conflict of interest}

The authors declare that they have no conflict of interest. 


\section{References}

1. Alves AR, da Silva MJ (2003) Use of phytotherapy in children up to 5 years of age in a central and peripheral area of the city of Sao Paulo. Rev Esc Enferm USP 37:85-91, Portuguese

2. Araz N, Bulbul S (2011) Use of complementary and alternative medicine in a pediatric population in southern Turkey. Clin Invest Med 34:21-29

3. Armishaw J, Grant CC (1999) Use of complementary treatment by those hospitalised with acute illness. Arch Dis Child 81:133-137

4. Barnes PM, Bloom B, Nahin RL (2008) Complementary and alternative medicine use among adults and children: United States, 2007. Natl Health Stat Report 12:1-23

5. Bellas A, Lafferty WE, Lind B, Tyree PT (2005) Frequency, predictors, and expenditures for pediatric insurance claims for complementary and alternative medical professionals in Washington State. Arch Pediatr Adolesc Med 159:367-372. doi:10.1001/archpedi.159.4.367

6. Birdee GS, Phillips RS, Davis RB, Gardiner P (2010) Factors associated with pediatric use of complementary and alternative medicine. Pediatrics 125:249-256. doi:10.1542/peds.2009-1406

7. Bishop FL, Prescott P, Chan YK, Saville J, von Elm E, Lewith GT (2010) Prevalence of complementary medicine use in pediatric cancer: a systematic review. Pediatrics 125:768-776. doi:10.1542/peds.20091775

8. Braun CA, Bearinger LH, Halcón LL, Pettingell SL (2005) Adolescent use of complementary therapies. J Adolesc Health 37:76. doi:10.1016/j.jadohealth.2004.07.010

9. Chen LL, Huang LC, Lin SC, Smith M, Liu SJ (2009) Use of folk remedies among families of children hospitalised in Taiwan. J Clin Nurs 18:2162-2170. doi:10.1111/j.1365-2702.2008.02539.x

10. Cincotta DR, Crawford NW, Lim A, Cranswick NE, Skull S, South M, Powell CV (2006) Comparison of complementary and alternative medicine use: reasons and motivations between two tertiary children's hospitals. Arch Dis Child 91:153-158. doi:10.1136/adc.2005.074872

11. Crawford NW, Cincotta DR, Lim A, Powell CV (2006) A cross-sectional survey of complementary and alternative medicine use by children and adolescents attending the University Hospital of Wales. BMC Complement Altern Med 6:16. doi:10.1186/1472-6882-6-16

12. Crowe S, Lyons B (2004) Herbal medicine use by children presenting for ambulatory anesthesia and surgery. Paediatr Anaesth 14:916-919. doi:10.1111/j.1460-9592. 2004.01353.x

13. Dolceamore TR, Altomare F, Zurlo F, Miniero R (2012) Use of alternative-complementary-medicine (CAM) in Calabrian children. Ital J Pediatr 38:70. doi:10.1186/1824-7288-38-70

14. Du Y, Knopf H (2009) Paediatric homoeopathy in Germany: results of the German Health Interview and Examination Survey for Children and Adolescents (KiGGS). Pharmacoepidemiol Drug Saf 18:370-379. doi:10.1002/pds.1720

15. Eardley S, Bishop FL, Prescott P, Cardini F, Brinkhaus B, Santos-Rey K, Vas J, von Ammon K, Hegyi G, Dragan S, Uehleke B, Fønneb $\varnothing$ V, Lewith G (2012) A systematic literature review of complementary and alternative medicine prevalence in EU. Forsch Komplementmed 19 (Suppl 2):18-28. doi:10.1159/000342708

16. Ernst E (1999) Prevalence of complementary/alternative medicine for children: a systematic review. Eur J Pediatr 158:7-11

17. Ernst E (2008) The truth about homeopathy. Br J Clin Pharmacol 65:163-164. doi:10.1111/j.13652125.2007.03007.x

18. Everett LL, Birmingham PK, Williams GD, Brenn BR, Shapiro JH (2005) Herbal and homeopathic medication use in pediatric surgical patients. Paediatr Anaesth 15:455-460. doi:10.1111/j.14609592.2005.01487.x

19. Eymann A, Bellomo MM, Catsicaris C, Wahren C (2009) Utilización de medicina alternativa o complementaria en una población pediátrica de un hospital de comunidad [Use of alternative or complemen- 
tary medicine by the pediatric population of a community hospital]. Arch Argent Pediatr 107:321-328. doi:10.1590/s0325-00752009000400009, Spanish

20. Feiler-Mircus N (2012) P04.44. The association between the use of complementary and alternative medicine in children with demographic indicators and vaccinations. BMC Complement Altern Med 12 (Suppl 1):314. doi:10.1186/1472-6882-12-S1-P314

21. Feldmann JM, Wiemann CM, Sever L, Hergenroeder AC (2008) Folk and traditional medicine use by a subset of Hispanic adolescents. Int J Adolesc Med Health 20:41-51

22. Fong DP, Fong LK (2002) Usage of complementary medicine among children. Aust Fam Physician 31:388-391

23. Frass M, Strassl RP, Friehs H, Müllner M, Kundi M, Kaye AD (2012) Use and acceptance of complementary and alternative medicine among the general population and medical personnel: a systematic review. Ochsner J 12:45-56

24. Gentil LB, Robles AC, Grosseman S (2010) Uso de terapias complementares por mães em seus filhos: estudo em um hospital universitário [Use of complementary therapies by mothers in their children: study at an university hospital]. Cien Saude Colet 15 (Suppl 1):1293-1299, Portuguese

25. German Pharmaceutical Industry Association (2012) Pharmadaten 2012: data on the German pharmaceutical market 2012. Available at: www.bpi.de/daten-und-fakten/pharmadaten/. Accessed 1 Aug 2013

26. Graham ME, Brake MK, Taylor SM, Flowerdew G, Hong P (2013) Complementary and alternative medicine use among patients presenting to a pediatric otolaryngology clinic. Int J Pediatr Otorhinolaryngol 77:721-725. doi:10.1016/j.ijporl.2013.01.026

27. Headley J, Northstone K (2007) Medication administered to children from 0 to 7.5 years in the Avon Longitudinal Study of Parents and Children (ALSPAC). Eur J Clin Pharmacol 63:189-195. doi:10.1007/s00228-006-0231-y

28. Hughes SC, Wingard DL (2006) Children's visits to providers of complementary and alternative medicine in San Diego. Ambul Pediatr 6:293-296. doi:10.1016/j.ambp.2005.11.007

29. Huillet A, Erdie-Lalena C, Norvell D, Davis BE (2011) Complementary and alternative medicine used by children in military pediatric clinics. J Altern Complement Med 17:531-537. doi:10.1089/acm.2010.0339

30. Hümer M, Scheller G, Kapellen T, Gebauer C, Schmidt H, Kiess W (2010) Phytotherapie in der Kinderheilkunde: Prävalenz, Indikationen und Motivation [Use of herbal medicine in German children — prevalence, indications and motivation]. Dtsch Med Wochenschr 135:959-964. doi:10.1055/s-0030-1253683, German

31. Italia S, Batscheider A, Heinrich J, Wenig C, Bauer CP, Koletzko S, Lehmann I, Herbarth O, von Berg A, Berdel D, Hoffmann B, Schaaf B, Wolfenstetter SB (2012) Utilization and costs of conventional and alternative pharmaceuticals in children: results from the German GINIplus and LISAplus birth cohort studies. Pharmacoepidemiol Drug Saf 21:1102-1111. doi:10.1002/pds.3323

32. Jean D, Cyr C (2007) Use of complementary and alternative medicine in a general pediatric clinic. Pediatrics 120:e138-e141. doi:10.1542/peds.2006-3105

33. Jeschke E, Ostermann T, Tabali M, Kröz M, Bockelbrink A, Witt CM, Willich SN, Matthes H (2011) Anthroposophic medicine in pediatric primary care: a prospective, multicenter observational study on prescribing patterns. Altern Ther Health Med 17:18-28

34. Kim JH, Nam CM, Kim MY, Lee DC (2012) The use of complementary and alternative medicine (CAM) in children: a telephone-based survey in Korea. BMC Complement Altern Med 12:46. doi:10.1186/14726882-12-46

35. Lanski SL, Greenwald M, Perkins A, Simon HK (2003) Herbal therapy use in a pediatric emergency department population: expect the unexpected. Pediatrics 111(5 Pt 1):981-985

36. Lim A, Cranswick N, Skull S, South M (2005) Survey of complementary and alternative medicine use at a tertiary children's hospital. J Paediatr Child Health 41:424-427. doi:10.1111/j.1440-1754.2005.00659.x

37. Lin YC, Bioteau AB, Ferrari LR, Berde CB (2004) The use of herbs and complementary and alternative medicine in pediatric preoperative patients. J Clin Anesth 16:4-6. doi:10.1016/j.jclinane.2003.03.005 
38. Loman DG (2003) The use of complementary and alternative health care practices among children. J Pediatr Health Care 17:58-63. doi:10.1067/mph.2003.29

39. Losier A, Taylor B, Fernandez CV (2005) Use of alternative therapies by patients presenting to a pediatric emergency department. J Emerg Med 28:267-271. doi:10.1016/j.jemermed.2004.11.019

40. Low E, Murray DM, O'Mahony O, O’B Hourihane J (2008) Complementary and alternative medicine use in Irish paediatric patients. Ir J Med Sci 177:147-150. doi:10.1007/s11845-008-0152-0

41. Madsen H, Andersen S, Nielsen RG, Dolmer BS, Høst A, Damkier A (2003) Use of complementary/alternative medicine among paediatric patients. Eur J Pediatr 162:334-341. doi:10.1007/s00431003-1180-4

42. Mallet P, Mourdi N, Dubus JC, Bavoux F, Boyer-Gervoise MJ, Jean-Pastor MJ, Chalumeau M (2011) Respiratory paradoxical adverse drug reactions associated with acetylcysteine and carbocysteine systemic use in paediatric patients: a national survey. PLoS One 6(7):e22792. doi:10.1371/journal.pone.0022792

43. Menniti-Ippolito F, Forcella E, Bologna E, Gargiulo L, Traversa G, Raschetti R (2002) Use of unconventional medicine in children in Italy. Eur J Pediatr 161:690. doi:10.1007/s00431-002-1085-7

44. Ottolini MC, Hamburger EK, Loprieato JO, Coleman RH, Sachs HC, Madden R, Brasseux C (2001) Complementary and alternative medicine use among children in the Washington, DC area. Ambul Pediatr $1: 122-125$

45. Ozturk C, Karayagiz G (2008) Exploration of the use of complementary and alternative medicine among Turkish children. J Clin Nurs 17:2558-2564. doi:10.1111/j.1365-2702.2008.02329.x

46. Pitetti R, Singh S, Hornyak D, Garcia SE, Herr S (2001) Complementary and alternative medicine use in children. Pediatr Emerg Care 17:165-169

47. Quandt SA, Verhoef MJ, Arcury TA, Lewith GT, Steinsbekk A, Kristoffersen AE, Wahner-Roedler DL, Fønneb $\varnothing$ V (2009) Development of an international questionnaire to measure use of complementary and alternative medicine (I-CAM-Q). J Altern Complement Med 15:331-339. doi:10.1089/acm.2008.0521

48. Robinson N, Blair M, Lorenc A, Gully N, Fox P, Mitchell K (2008) Complementary medicine use in multiethnic paediatric outpatients. Complement Ther Clin Pract 14:17-24. doi:10.1016/j.ctcp.2007.07.003

49. Sanz E, Hernández MA, Ratchina S, Stratchounsky L, Peiré MA, Lapeyre-Mestre M, Horen B, Kriska M, Krajnakova H, Momcheva H, Encheva D, Martínez-Mir I, Palop V (2004) Drug utilisation in outpatient children. A comparison among Tenerife, Valencia, and Barcelona (Spain), Toulouse (France), Sofia (Bulgaria), Bratislava (Slovakia) and Smolensk (Russia). Eur J Clin Pharmacol 60:127-134. doi:10.1007/s00228-004-0739-y

50. Sawni-Sikand A, Schubiner H, Thomas RL (2002) Use of complementary/alternative therapies among children in primary care pediatrics. Ambul Pediatr 2:99-103

51. Sawni A, Ragothaman R, Thomas RL, Mahajan P (2007) The use of complementary/alternative therapies among children attending an urban pediatric emergency department. Clin Pediatr (Phila) 46(1):36-41

52. Sikich N, Petroz G, Lerman J (2002) Herbal medicine use in children scheduled for anaesthesia. Can J Anaesth 49:35

53. Simpson N, Pearce A, Finlay F, Lenton S (1998) The use of complementary medicine in paediatric outpatient clinics. Ambul Child Health 3:351-356

54. Simpson N, Roman K (2001) Complementary medicine use in children: extent and reasons. A population-based study. Br J Gen Pract 51:914-916

55. Siponen SM, Ahonen RS, Kettis A, Hämeen-Anttila KP (2012) Complementary or alternative? Patterns of complementary and alternative medicine (CAM) use among Finnish children. Eur J Clin Pharmacol 68:1639-1645. doi:10.1007/s00228-012-1294-6

56. Smith C, Eckert K (2006) Prevalence of complementary and alternative medicine and use among children in South Australia. J Paediatr Child Health 42:538-543. doi:10.1111/j.1440-1754.2006.00918.x 
57. Spigelblatt L, Lâiné-Ammara G, Pless IB, Guyver A (1994) The use of alternative medicine by children. Pediatrics 94(6 Pt 1):811-814

58. Steinsbekk A, Rise MB, Bishop F, Lewith G (2011) Predictors for adolescent visits to practitioners of complementary and alternative medicine in a total population (the Young-HUNT Studies). PLoS One 6(10):e25719. doi:10.1371/journal.pone.0025719

59. Surette S, Vanderjagt L, Vohra S (2013) Surveys of complementary and alternative medicine usage: a scoping study of the paediatric literature. Complement Ther Med 21 (Suppl 1):48-53. doi:10.1016/j.ctim.2011.08.006

60. Thompson EA, Bishop JL, Northstone K (2010) The use of homeopathic products in childhood: data generated over 8.5 years from the Avon Longitudinal Study of Parents and Children (ALSPAC). J Altern Complement Med 16:69-79. doi:10.1089/acm.2009.0007

61. Verhoef MJ, Russell ML, Love EJ (1994) Alternative medicine use in rural alberta. Can J Public Health 85:308-309

62. Vlieger AM, van de Putte EM, Hoeksma $\mathrm{H}$ (2006) The use of complementary and alternative medicine in children at a general paediatric clinic and parental reasons for use. Ned Tijdschr Geneeskd 150:625-630 Dutch

63. Weissenstein A, Straeter A, Villalon G, Luchter E, Bittmann S (2012) High frequency of CAM use among children in Germany. J Altern Complement Med 18:729-730. doi:10.1089/acm.2012.0398

64. Wilson KM, Klein JD (2002) Adolescents' use of complementary and alternative medicine. Ambul Pediatr 2:104-110

65. Wilson KM, Klein JD, Sesselberg TS, Yussman SM, Markow DB, Green AE, West JC, Gray NJ (2006) Use of complementary medicine and dietary supplements among U.S. adolescents. J Adolesc Health 38:385394. doi:10.1016/j.jadohealth.2005.01.010

66. Wolthers OD (1989) Use of alternative forms of treatment by patients attending a pediatric outpatient clinic. A questionnaire study. Ugeskr Laeger 151:87-90, Danish

67. Wye L, Hay AD, Northstone K, Bishop J, Headley J, Thompson E (2008) Complementary or alternative? The use of homeopathic products and antibiotics amongst pre-school children. BMC Fam Pract 9:8. doi:10.1186/1471-2296-9-8

68. Yussman SM, Ryan SA, Auinger P, Weitzman M (2004) Visits to complementary and alternative medicine providers by children and adolescents in the United States. Ambul Pediatr 4:429-435. doi:10.1367/a03$091 \mathrm{r} 1.1$

69. Yussman SM, Wilson KM , Klein JD (2006) Herbal products and their association with substance use in adolescents. J Adolesc Health 38:395-400. doi:10.1016/j.jadohealth.2004.10.015

70. Zutavern A, Schaaf B, von Berg A, Borte M, Herbarth O, Wichmann H, Heinrich J (2007) Inanspruchnahme von Homöopathie und Konsultation von Heilpraktikern - Ergebnisse einer deutschen Geburtskohortenstudie (LISA) im Alter von 2 Jahren [Use of homeopathy and consultation with alternative medicine practitioners: Results of a German birth cohort study (LISA) at the age of 2 years]. Monatsschrift Kinderheilkunde 155:439-445. doi:10.1007/s00112-007-1497-6, German

71. Zuzak TJ, Boňková J, Careddu D, Garami M, Hadjipanayis A, Jazbec J, Merrick J, Miller J, Ozturk C, Persson IA, Petrova G, Saz Peiró P, Schraub S, Simões-Wüst AP, Steinsbekk A, Stockert K, Stoimenova A, Styczynski J, Tzenova-Savova A, Ventegodt S, Vlieger AM, Längler A (2013) Use of complementary and alternative medicine by children in Europe: published data and expert perspectives. Complement Ther Med 21 (Suppl 1):34-47. doi:10.1016/j.ctim.2012.01.001

72. Zuzak TJ, Zuzak-Siegrist I, Simões-Wüst AP, Rist L, Staubli G (2009) Use of complementary and alternative medicine by patients presenting to a paediatric emergency department. Eur J Pediatr 168:431-437. doi:10.1007/s00431-008-0765-3 


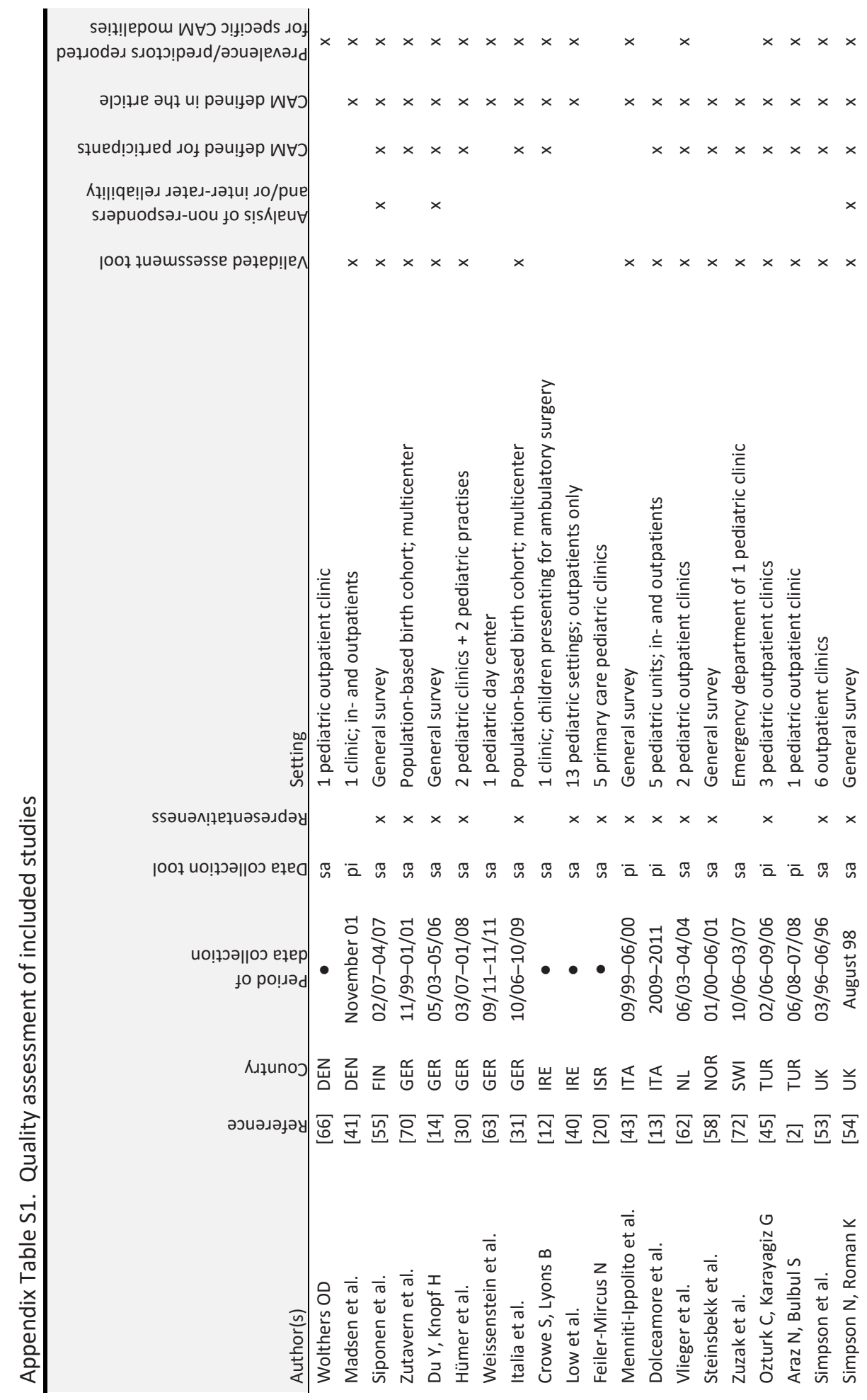




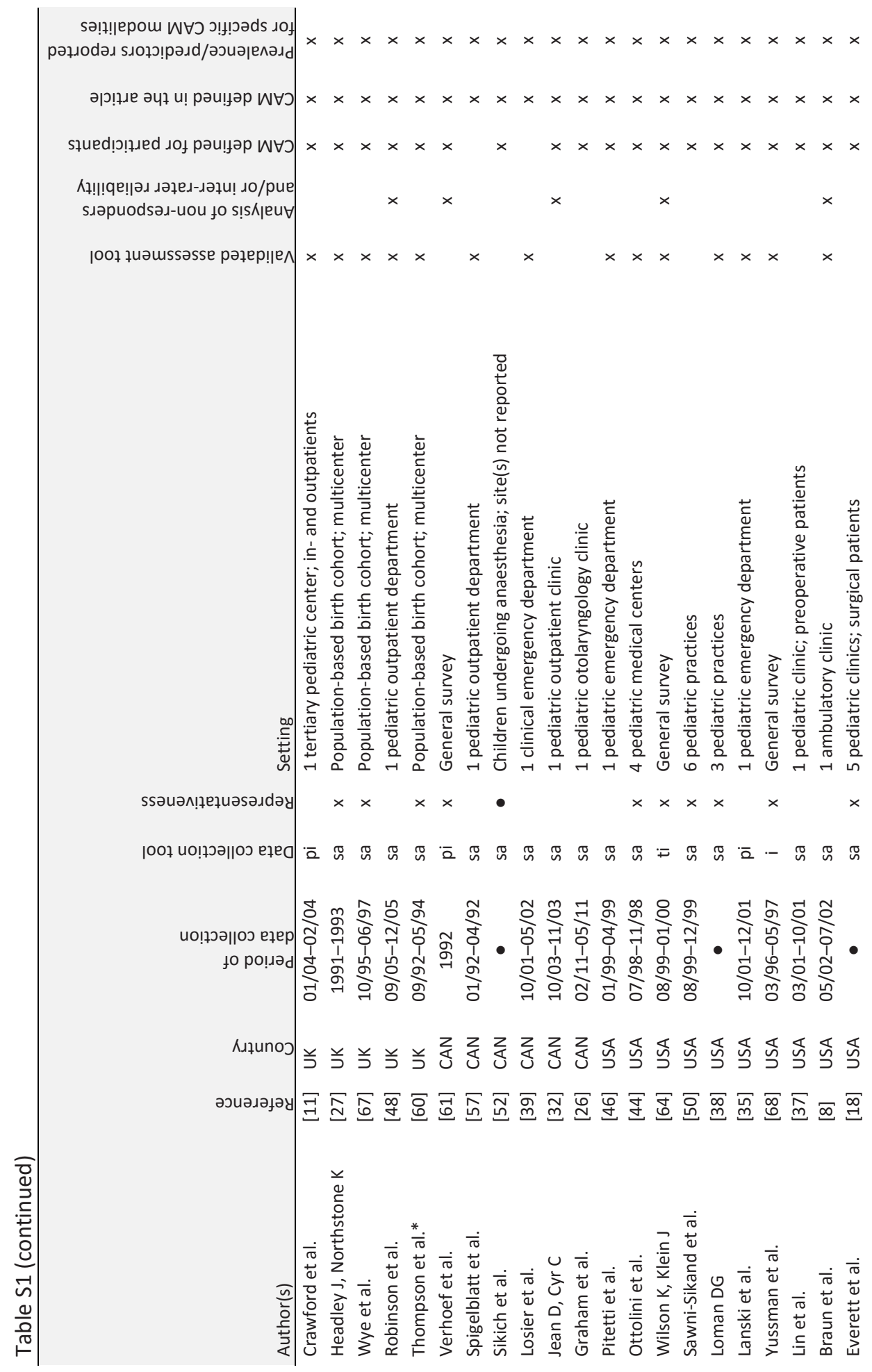




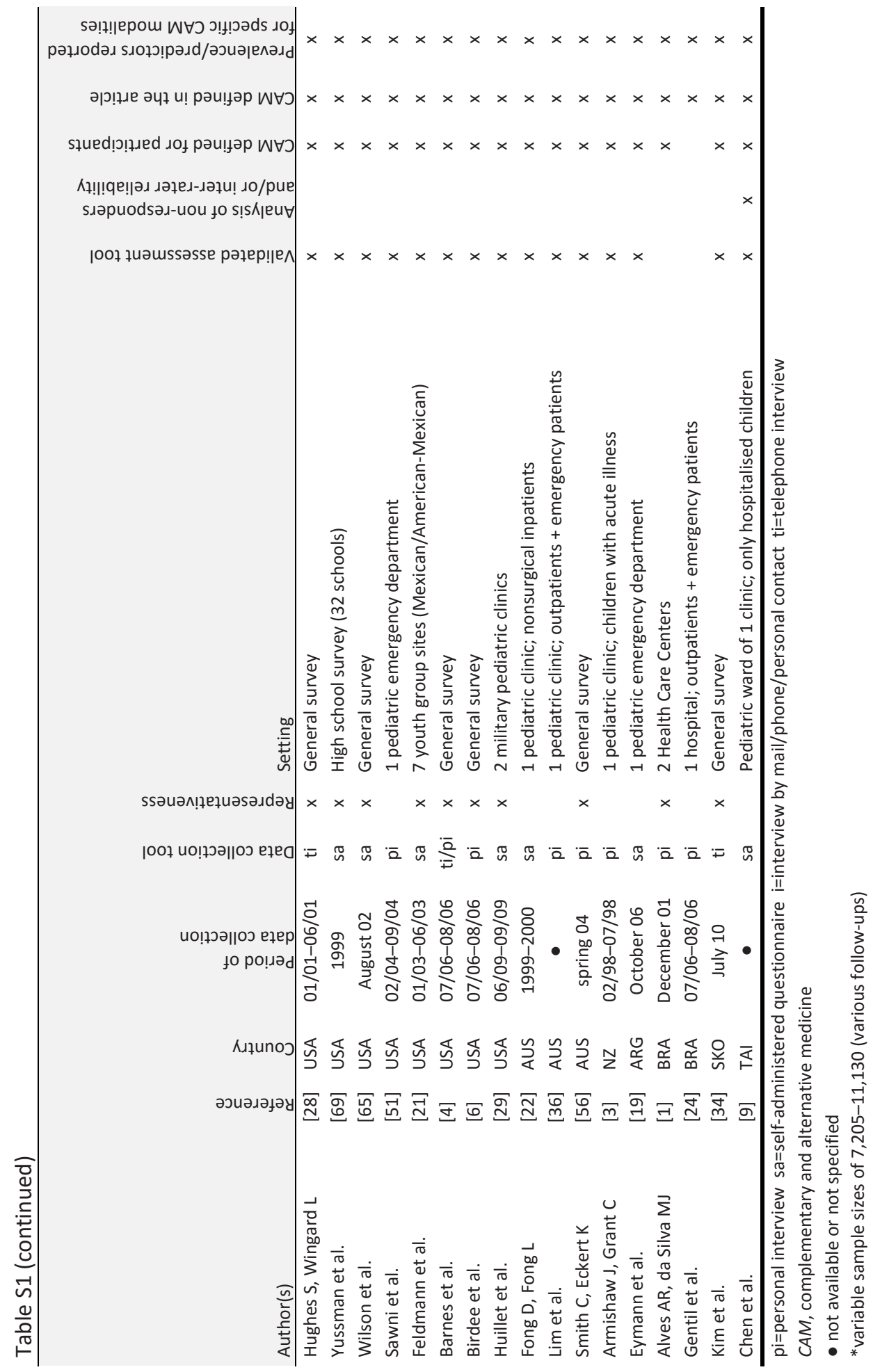




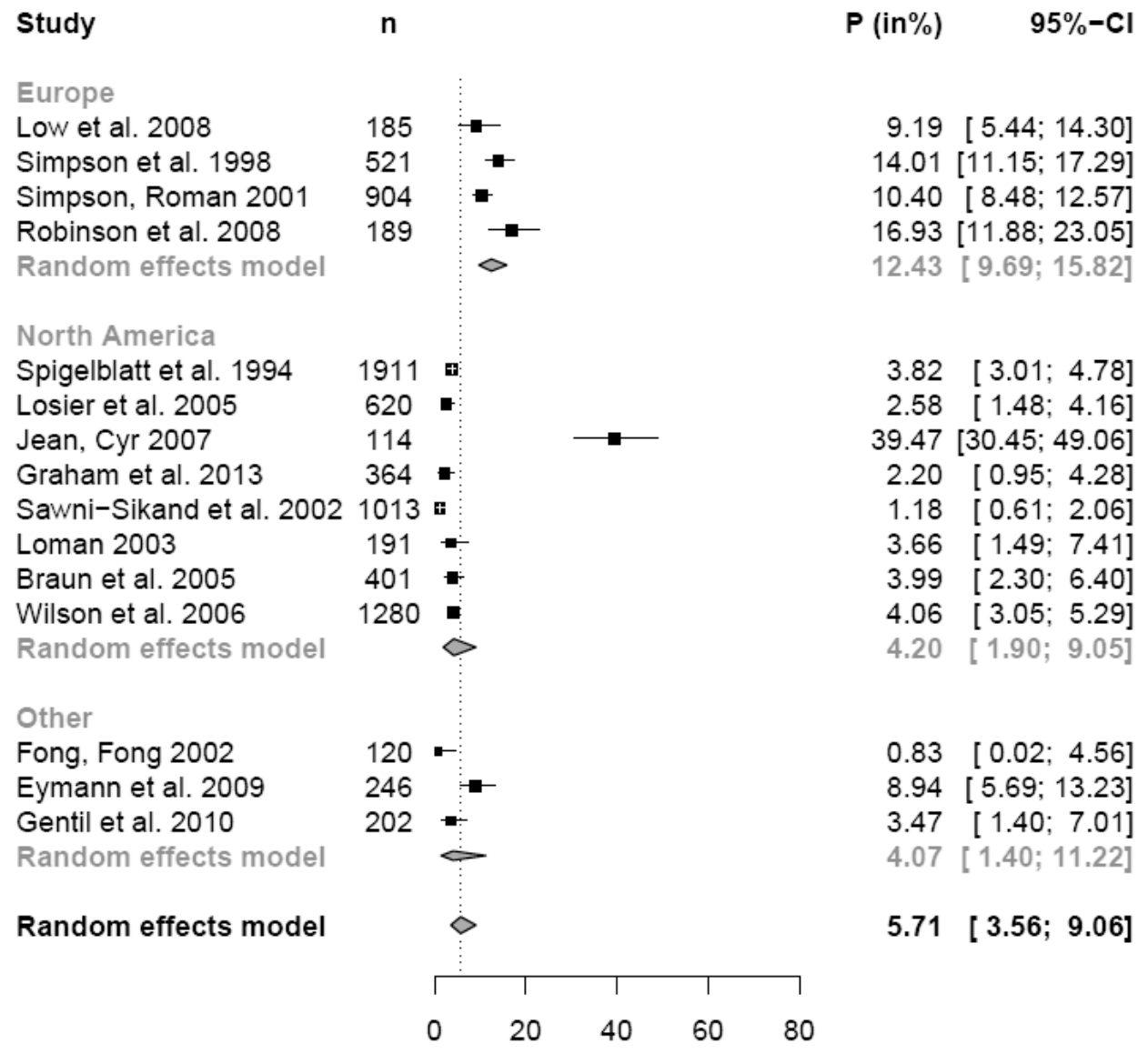

Appendix Figure S1. Lifetime prevalence rates for use of homeopathic drugs*

* The random effects model estimates the mean prevalence rates $(P)$ and $95 \%$ confidence intervals $(\mathrm{Cl})$ for each group as well as the mean overall prevalence. Small discrepancies in prevalence rates are due to rounding errors. 




Appendix Figure S2. Lifetime prevalence rates for use of herbal drugs*

* The random effects model estimates the mean prevalence rates $(P)$ and $95 \%$ confidence intervals $(\mathrm{Cl})$ for each group as well as the mean overall prevalence. Small discrepancies in prevalence rates are due to rounding errors. 


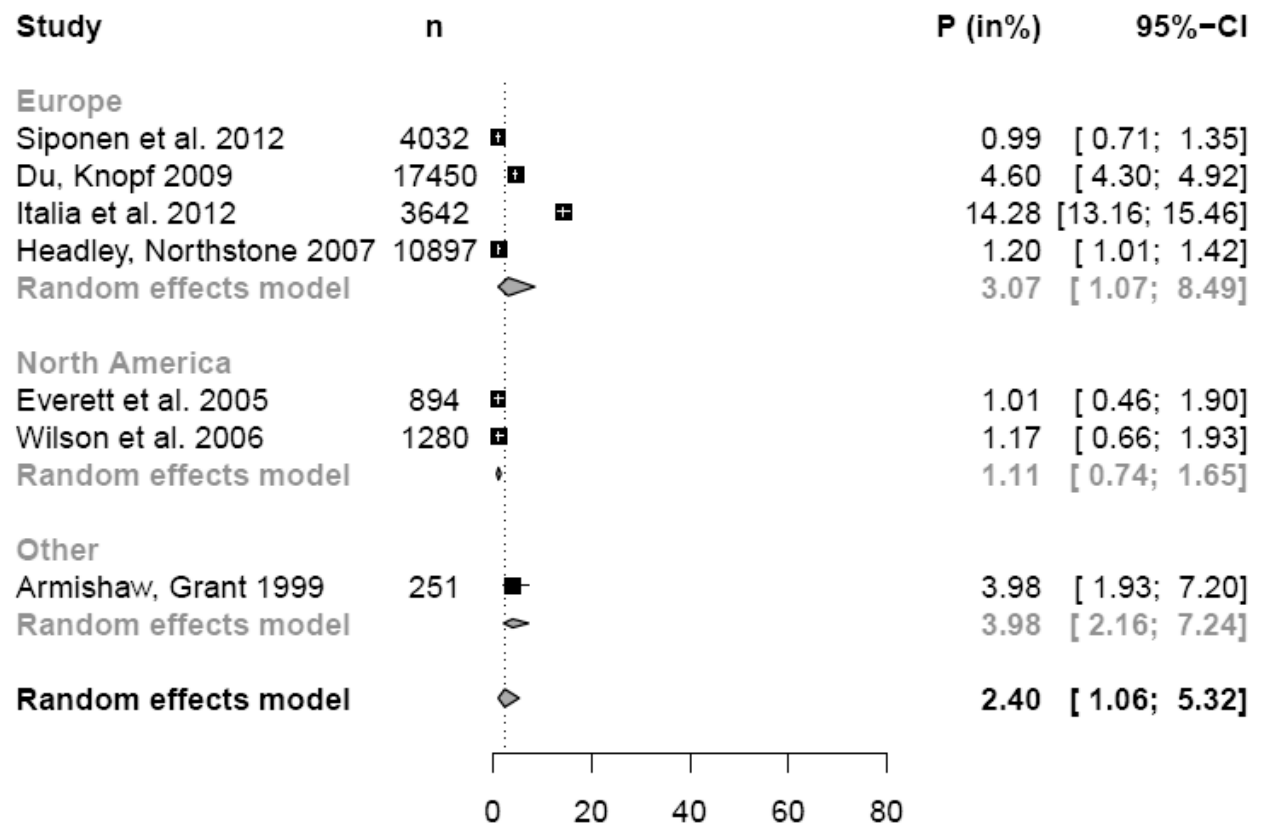

Appendix Figure S3. Short-term prevalence rates for use of homeopathic drugs*

* The random effects model estimates the mean prevalence rates $(\mathrm{P})$ and $95 \%$ confidence intervals $(\mathrm{Cl})$ for each group as well as the mean overall prevalence. Small discrepancies in prevalence rates are due to rounding errors. 
Study

Europe

Madsen et al. 2003

Italia et al. 2012

Crowe, Lyons 2004

Crawford et al. 2006

Headley, Northstone 2007

Random effects model

\section{North America}

Everett et al. 2005

Wilson et al. 2006

Random effects model

Random effects model n

$\mathrm{P}$ (in $\%) \quad 95 \%-\mathrm{Cl}$

$2.89 \quad[1.72 ; 4.54]$

$8.87 \quad[7.97 ; 9.84]$

$6.49 \quad[4.65 ; 8.76]$

$5.00 \quad[3.26 ; 7.29]$

$2.20 \quad[1.94 ; 2.50]$

$4.54[2.13 ; 9.41]$

$2.91 \quad[1.91 ; 4.23]$

$7.03 \quad[5.69 ; 8.57]$

4.61 [1.91; 10.69]

$4.55[2.59 ; 7.89]$

Appendix Figure S4. Short-term prevalence rates for use of herbal drugs*

* The random effects model estimates the mean prevalence rates $(P)$ and $95 \%$ confidence intervals $(\mathrm{Cl})$ for each group as well as the mean overall prevalence. Small discrepancies in prevalence rates are due to rounding errors. 
It does not matter how slowly you go as long as you do not stop.

\section{Confucius}

Chinese teacher and philosopher 


\section{CHAPTER 3}

Complementary and alternative medicine (CAM) use among chronically ill adolescents from two German birth cohorts

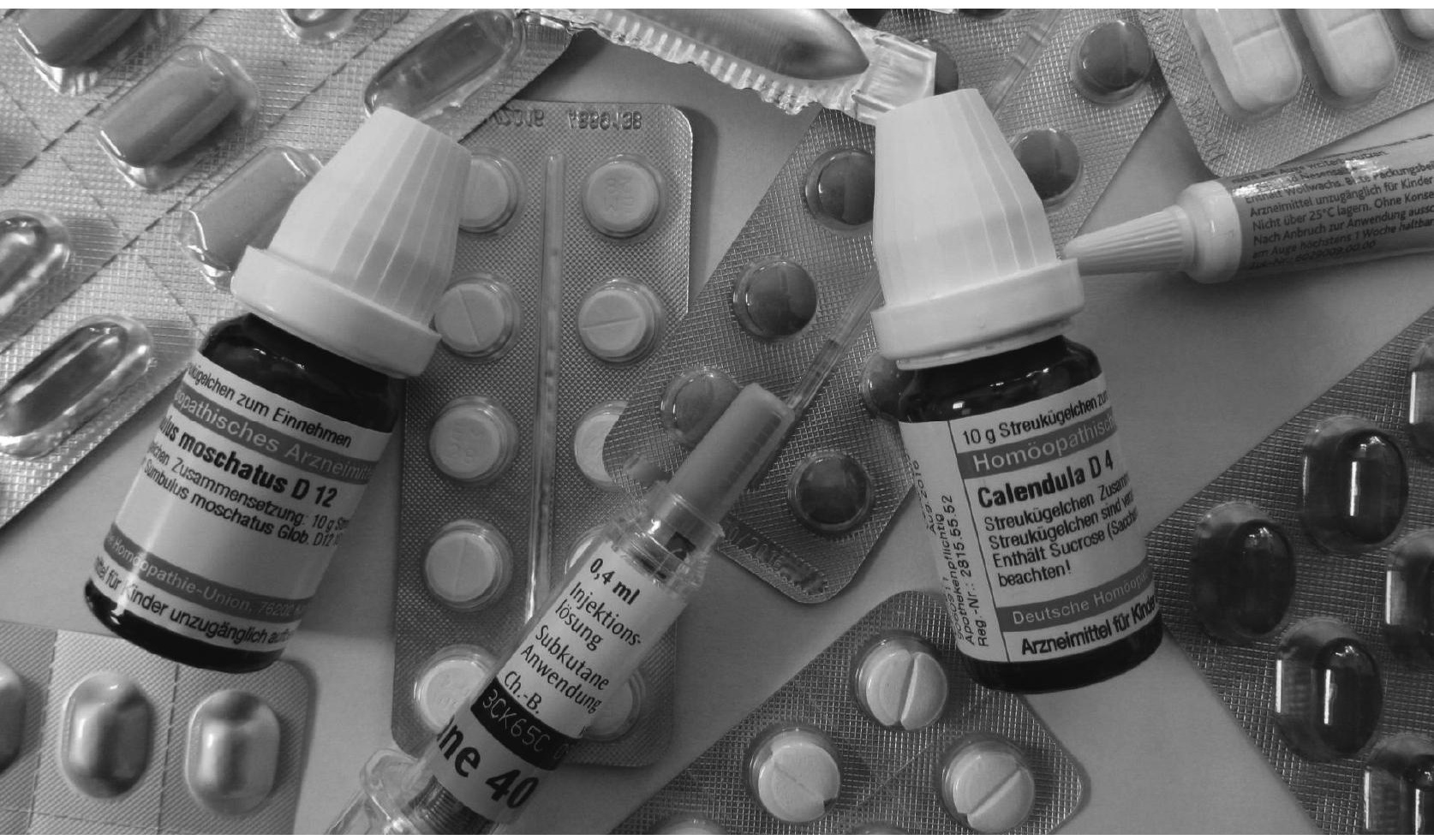

Salvatore Italia, Irene Brüske, Joachim Heinrich, Dietrich Berdel, Andrea von Berg, Irina Lehmann, Marie Standl, Silke B. Wolfenstetter.

Complementary and alternative medicine (CAM) use among chronically ill adolescents from two German birth cohorts.

Forsch Komplementmed [accepted 18 May 2016] 


\section{Zusammenfassung:}

Hintergrund: Der Gebrauch komplementärer und alternativer Medizin (CAM) ist unter Kindern in Europa sehr verbreitet, möglicherweise besonders stark unter chronisch kranken Kindern. Ziel dieser Untersuchung ist die Erfassung des CAM-Gebrauchs unter chronisch kranken Jugendlichen.

Methoden: Daten zur Arzneimittelinanspruchnahme (letzte 4 Wochen) und zur Konsultation nichtärztlicher alternativer Gesundheitsdienstleister (letztes Jahr) wurden mit einem selbst auszufüllenden Fragebogen für 4677 Jugendliche der deutschen GINIplus/LISAplus-Geburtskohorten erhoben. Alle berichteten Arzneimittel wurden in therapeutische Gruppen eingeteilt (herkömmliche Arzneimittel, Homöopathie, Phytotherapie, etc.). Die Teilnehmer wurden außerdem gebeten, ärztlich innerhalb der letzten 5 Jahre diagnostizierte chronische Erkrankungen zu berichten (Allergien, Neurodermitis, Asthma, weitere).

Ergebnisse: Im Vergleich zur Gesamtkohorte war die Prävalenz des Gebrauchs aller Arzneimittel zusammengenommen (60.1\% vs. $41.1 \%)$, der Homöopathie $(11.1 \%$ vs. 8.1\%) und der Konsultation nichtärztlicher alternativer Gesundheitsdienstleister (16.9\% vs. $10.9 \%$ ) unter chronisch kranken Jugendlichen signifikant erhöht. Allerdings nutzten chronisch kranke Jugendliche relativ gesehen (Anteil der definierten therapeutischen Gruppen an allen genommenen Arzneimitteln) mehr herkömmliche Arzneimittel als gesunde Jugendliche.

Schlussfolgerung: Die Prävalenz des CAM-Gebrauchs ist, im Vergleich zu gesunden Jugendlichen, bei chronisch kranken Jugendlichen erhöht. Wegen des generell stärkeren Arzneimittelgebrauchs durch chronisch kranke Jugendliche kann das Risiko von Arzneimittelinteraktionen erhöht sein.

\section{Schlüsselwörter}

Jugendliche Kinder - Alternativmedizin · Homöopathie · Phytotherapie ·

Arzneimittelgebrauch · Chronische Erkrankungen 


\begin{abstract}
Background: Pediatric use of complementary and alternative medicine (CAM) is popular in Europe, and utilization may be even more prevalent in chronically ill children/adolescents. This study's aim is to assess CAM use among adolescents with chronic conditions.
\end{abstract}

Methods: Data on drug utilization (past 4 weeks) and consultation with CAM providers (past year) were collected using a self-administered questionnaire from 4,677 adolescents from the German GINIplus/LISAplus birth cohorts. All reported drugs were classified into therapeutic categories (conventional drugs, homeopathy, herbal drugs, etc.). Additionally, participants were asked to report chronic diseases (allergies, atopic dermatitis, asthma, or other chronic diseases) that were parent-reported diagnoses by a physician during the past 5 years.

Results: Compared with the total sample, drug utilization in general (60.1\% vs. $41.1 \%)$, homeopathy use $(11.1 \%$ vs. $8.1 \%)$, and consultation with CAM providers $(16.9 \%$ vs. $10.9 \%)$ was significantly more prevalent among chronically ill adolescents. However, chronically ill adolescents used relatively (proportion of the defined therapeutic category among all drugs used) more conventional drugs than healthy adolescents.

Conclusion: Compared with healthy adolescents, CAM use is more prevalent among adolescents with chronic conditions. Owing to the higher drug use in general, the risk of pharmacological interactions may be elevated in chronically ill adolescents.

\title{
Key words
}

Adolescent · Complementary therapies · Homeopathy · Phytotherapy · Drug utilization · Chronic disease 


\section{Introduction}

Non-conventional therapy approaches that are not part of mainstream medicine are often referred to as complementary and alternative medicine (CAM). For analysis of utilization patterns, a universally valid definition for CAM would be desirable but may be very difficult.

However, according to available studies and literature reviews, utilization of CAM products such as homeopathy or herbal drugs is widespread among children and adolescents in Europe and worldwide as well [1,2]. The prevalence of pediatric CAM use may be even higher among children/adolescents suffering from chronic conditions [3]. The number of studies that investigated CAM use in this pediatric subgroup by directly comparing healthy and chronically ill children from the same sample is limited [4-8], especially with regard to the use of non-conventional medicinal products such as homeopathic remedies, herbal drugs, or nutritional supplements, some of the most commonly used medicinal CAM [9]. A 2013 study conducted in Germany with 163 healthy children and 242 chronically ill children found higher prevalence rates of CAM use in children with chronic conditions [5]. Some further studies yielded similar significant result for the pediatric or general population [6,10-13] or listed the presence of chronic conditions among the commonest motivating factors for CAM use [14-17], whereas other authors found no higher prevalence rates for CAM use in children with (specific) chronic conditions $[4,7,8,18]$.

As children/adolescents with chronic conditions may belong to a particularly vulnerable patient group, a thorough view on their (self-)medication with CAM is important with respect to possible side-effects, interactions, or the substitution of conventional drugs by non-conventional drugs without the physician's knowledge.

This study aims at a comparison of CAM use among chronically ill adolescents from two large German birth cohorts with the utilization of CAM among adolescents without chronic conditions from the same sample. In addition to the analysis of prevalence rates, the amount of medicinal products (with a focus on homeopathic and herbal drugs) actually used within a defined observation period has also been addressed.

\section{Material and Methods}

\section{Study population}

The GINIplus (German Infant study on the Influence of Nutrition Intervention plus environmental and genetic influences on allergy development) and LISAplus (Influence of lifestyle factors on the immune system and allergies in East and West Germany plus the influence of traffic emissions and genetics) studies are based on two German birth 
cohorts that started with 5,991 (GINIplus) and 3,097 (LISAplus) healthy full-term newborns. The children were recruited between September 1995 and January 1999 from obstetric clinics in Munich, Leipzig, Wesel, and Bad Honnef. The recruitment sites were chosen to achieve a heterogeneous sample with regard to geographic region (South Germany = Munich; East Germany = Leipzig; West Germany = Wesel and Bad Honnef) and degree of urbanization (urban areas = Munich and Leipzig; more rural areas = Wesel and Bad Honnef). From both studies, non-term children and children of less than 2,500 g birth weight were excluded.

\section{Data collection}

For the 15-year follow-up, 6,094 participants' parents or legal guardians were contacted between January 2011 and October 2014. With the main questionnaire, the parents/legal guardians were asked whether they had consulted physicians from various medical specialties and alternative health care providers (non-medical health provider ("Heilpraktiker"), homeopath, osteopath, and "others") during the past 12 months for their children's illness or disorder. The questionnaire also assessed further variables such as children's gender, parental education, and household income. One question addressed the diagnosis of several diseases by a physician. The parents/legal guardians were asked to report which disease out of a presented list of 10 diseases had been diagnosed in their child within the 5 past years. Additionally, the exact year of diagnosis was assessed. Furthermore, the participants were given the possibility to enter other chronic diseases or disorders suffered by their child (and the year of diagnosis) that were not part of the presented list of chronic diseases.

The data on pediatric drug utilization (use within the past 4 weeks) were collected using a separate self-administered questionnaire, where the participants could enter the drug names and the pharmaceutical identification numbers (PZN) into 5 designated spaces. The PZN exactly identifies the drugs with respect to package size, dosage, manufacturer, etc. In case the limited designated spaces were not sufficient to enter all drugs, the participants were invited to note separately the precise number of drugs used. The data collection was performed almost evenly over the four seasons, with slight peaks in April and June.

\section{Drug classification}

All reported drugs were classified into several therapeutic modalities. The classification and the exact definition of the various modalities have been described in detail in a previously published study [19]. For the present study, the following medicinal CAM modalities were considered: 
(1) Homeopathic remedies (medicinal products prepared according to the production specification of the Homeopathic Pharmacopeia HAB [20], also including anthroposophic drugs)

(2) Herbal drugs

(3) Other non-conventional medicinal products (nutritionals such as vitamins and combined food supplements, minerals and trace elements, non-pathogenic microorganisms, further medicinal CAM such as Bach flower remedies or traditional Chinese medicine).

\section{Outcome definition and statistical analysis}

Participants who reported the use of at least one homeopathic remedy during the past 4 weeks were classified as "homeopathy users". Those taking one or more herbal drugs were classified as "herbal drug users", respectively. "Overall medicinal CAM users" took at least one drug from the defined medicinal CAM modalities 1-3. A "CAM provider user" had consulted a non-medical health provider ("Heilpraktiker"), a homeopath, an osteopath, or another type of CAM provider at least once during the past year. Finally, "overall drug users" took one or more drugs from any therapeutic category (conventional or non-conventional) within the past 4 weeks.

For analysis, the statistical software package SAS was used (SAS Institute Inc., Cary, NC, USA, version 9.3). The difference in CAM use between adolescents with chronic conditions and adolescents without the defined chronic diseases was tested using the Pearson $\mathrm{Chi}^{2}$ test $(\mathrm{p}<0.05)$. The following categories of chronic conditions (diagnosed in the last year; diagnosed in the preceding 5 years) were defined:

(1) Allergies (hay fever, perennial allergic rhinitis, food allergy)

(2) Atopic dermatitis (neurodermatitis, allergic or atopic eczema)

(3) Asthma

(4) Any kind of chronic condition: Adolescents who suffered from allergies (1), atopic dermatitis (2), asthma (3), or from other self-reported chronic conditions that were not part of the presented list of diagnosed diseases (e.g., diabetes, celiac disease, etc.)

The GINIplus and LISAplus cohorts obtained approval from the ethics committees of the Bavarian Medical Council, the University of Leipzig, and the Medical Council of North Rhine-Westphalia. Furthermore, written informed consent was given by the participants' parents or legal guardians and by participants. 


\section{Results}

From the 6,094 contacted parents/legal guardians, 4,677 returned the completed questionnaire on drug usage (response rate $=76.8 \%$ ). The mean age of the adolescents was 15.1 years, with a range from 14.2 years to 16.8 years (standard deviation \pm 0.29 years). The sample was evenly composed of boys (50.6\%) and girls (49.4\%). With regard to the participants' place of residence, $50.1 \%$ resided in Munich, $8.9 \%$ in Leipzig, $4.0 \%$ in Bad Honnef, and $37.0 \%$ were from Wesel. Most of the children's mothers $(50.7 \%)$ had a higher educational level that qualified them to study at a university, whereas $10.7 \%$ of the mothers had only a secondary school degree or no school degree at all, and $38.6 \%$ had a medium educational level. The participants' mean equivalent income was $€ 1,738$ (median: €1,563).

The majority (68.0\%) of the reported 3,873 drugs were "conventional drugs" containing chemically defined active pharmaceutical ingredients such as ibuprofen or paracetamol. Some $15.1 \%$ were homeopathic drugs, $8.4 \%$ were herbal drugs, and $3.8 \%$ belonged to the category of "other non-conventional medicinal products". Owing to the possibility of ambiguous interpretation, $2.7 \%$ of the reported drugs (e.g., medicinal products containing iodide normally used for prophylaxis according to medical guidelines) were allocated to neither the category "conventional drugs" nor the category "medicinal CAM drugs". For $2.0 \%$ of the reported drugs, an allocation to a specific therapeutic category was not possible and the information was interpreted as "overall drug use" only.

In sum, $41.1 \%$ of the total sample of 4,677 adolescents had used at least one type of drug during the past 4 weeks. The 4 -week prevalence for homeopathy use was $8.1 \%$, and $5.9 \%$ of the adolescents had used herbal drugs (fig. 1). The 1-year prevalence of consultation with any type of CAM provider was $10.9 \%$. Herbal drug use and consultation with CAM providers were positively associated with higher maternal education, whereas homeopathy was used most by girls and by participants residing in Munich, confirming the results from a previously published study analyzing the GINIplus cohort only [19].

From the total sample, $13.7 \%$ reported the diagnosis of a chronic disease in the past year. The corresponding figure for the past 5 years was $26.5 \%$. The corresponding percentages for adolescents suffering from allergies, atopic dermatitis, or asthma are displayed in table 1, together with the stratified prevalence rates of drug use and consultation with CAM providers. As shown in figure 1, drug utilization in general $(60.1 \%)$, homeopathy $(11.1 \%)$ and consultation with CAM providers (16.9\%) were significantly more prevalent among adolescents who reported any type of chronic condition (diagnosed in the past year) compared with adolescents without chronic conditions (afterwards also referred to as "total sample"). Nevertheless, the picture was not homoge- 
neous across the various types of chronic conditions. While homeopathy use, utilization of any type of medicinal CAM, and consultation with CAM providers were more prevalent among adolescents with allergies, adolescents with atopic dermatitis or asthma did not use significantly more CAM. Only consultation with CAM providers was more prevalent among those participants with an asthma diagnosis in any of the preceding 5 years. In none of the analyzed chronic conditions was the prevalence of herbal drug use significantly higher compared with its use among apparently healthy adolescents. The respective prevalence rates for herbal drug use were only slightly higher among chronically ill adolescents compared with use among the total sample (table 1).

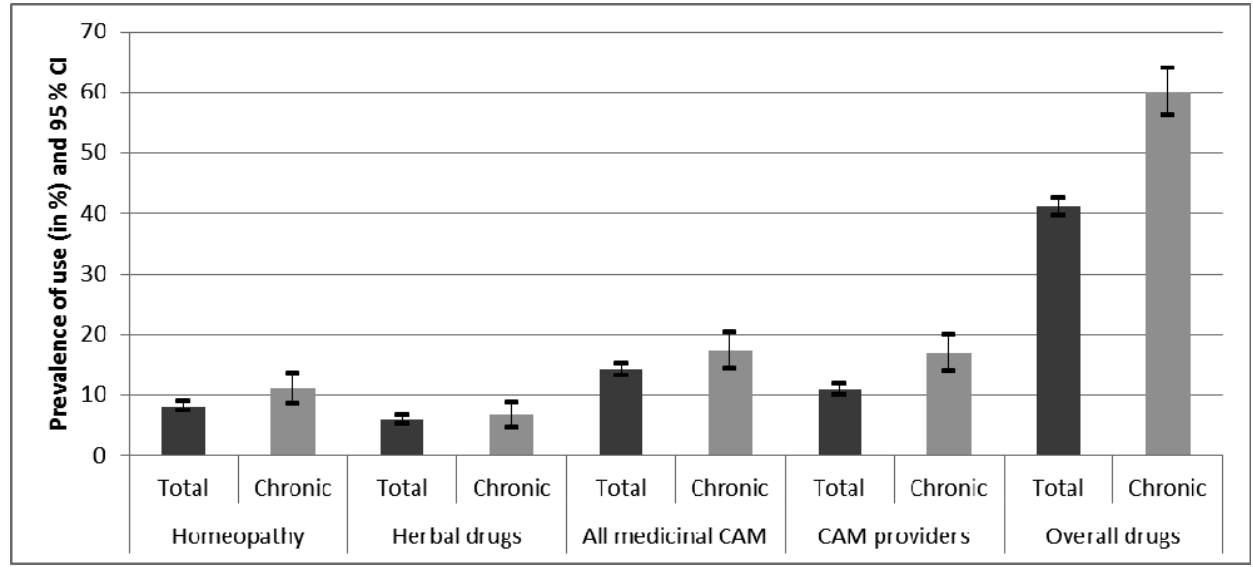

Figure 1. Prevalence (with 95\% confidence intervals) of medicinal product use (within the last 4 weeks) and consultation with CAM providers (within the last year) among the total sample ("total") and among adolescents with any kind of chronic disease diagnosed in the last year

In most instances, the prevalence rates of CAM use and overall drug use were higher, if the chronic conditions were diagnosed in the past year compared with those diagnosed in any of the preceding 5 years (table 1 ).

The average number of used packages from the category "homeopathic drugs" was slightly higher in the strata of chronically ill adolescents (not in those with asthma or atopic dermatitis), whereas adolescents with any type of chronic conditions took substantially more conventional drugs on average. For herbals drugs, there was hardly any difference between chronically ill and healthy adolescents (table 2). If only those adolescents were considered who took at least one drug from any therapeutic category, then the average numbers of used drug packages show that chronically ill adolescents take even fewer medicinal CAM on average compared with drug users from the total sample (table 2). 


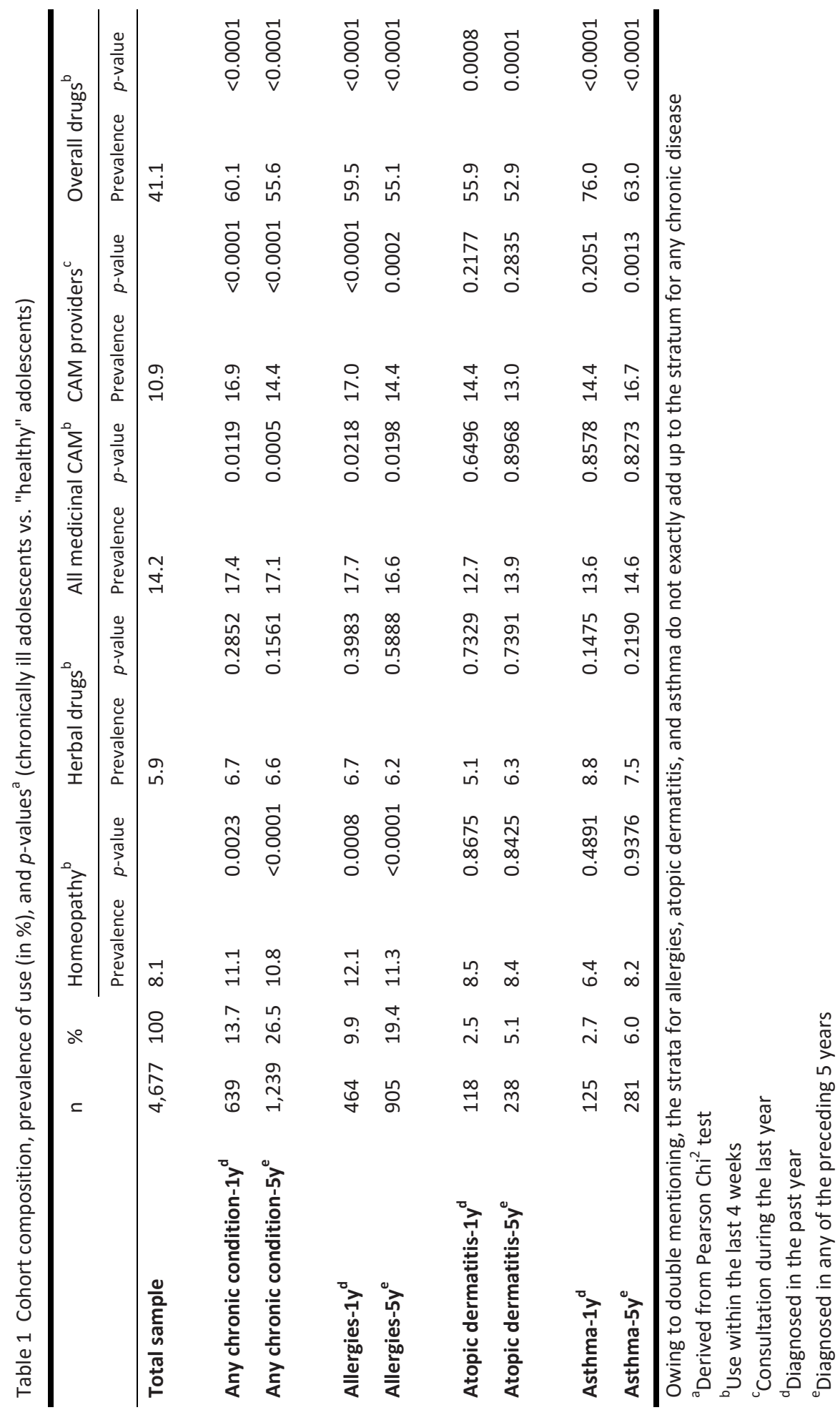


In relation to the proportion of the various medicinal CAM categories among all drugs utilized, the percentages of homeopathic products, herbal drugs, or other types of medicinal CAM were lower in any of the defined chronic conditions compared with the total sample. Hence, all adolescents with a diagnosed chronic condition used relatively more conventional drugs than their healthy counterparts (fig. 2). Also, the proportion of adolescent drug users who took no conventional drugs but medicinal CAM products only was lower in chronically ill children than in apparently healthy adolescents (fig. 3).

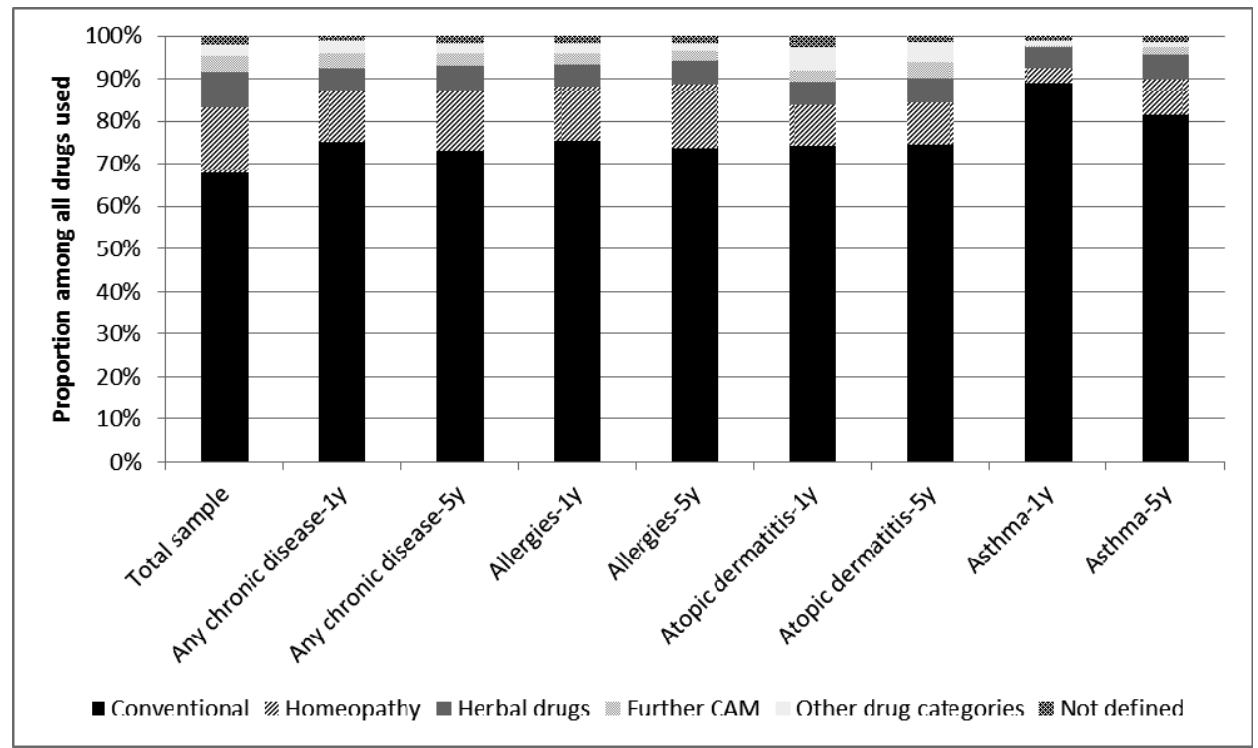

Figure 2. Proportions of the various categories of medicinal products among all drugs used for the total sample and for chronic diseases diagnosed in the last year (-1y) and in any of the preceding five years $(-5 y)$

\section{Discussion}

The findings of this study demonstrate that adolescents from the GINIplus and LISAplus cohorts who suffer from any kind of chronic conditions have significantly higher prevalence rates for medicinal CAM use and consultation with CAM providers. This is in line with the results from other studies conducted in children or adults [3,5,21]. A much smaller German study assessing lifetime prevalence of CAM use [5] also found higher prevalence rates for CAM use among children with chronic medical conditions compared with healthy children. No prevalence rates were assessed for the single CAM modalities. Therefore, a direct comparison with our results is difficult. However, in contrast to our results, the prevalence of CAM use was highest among children with a 


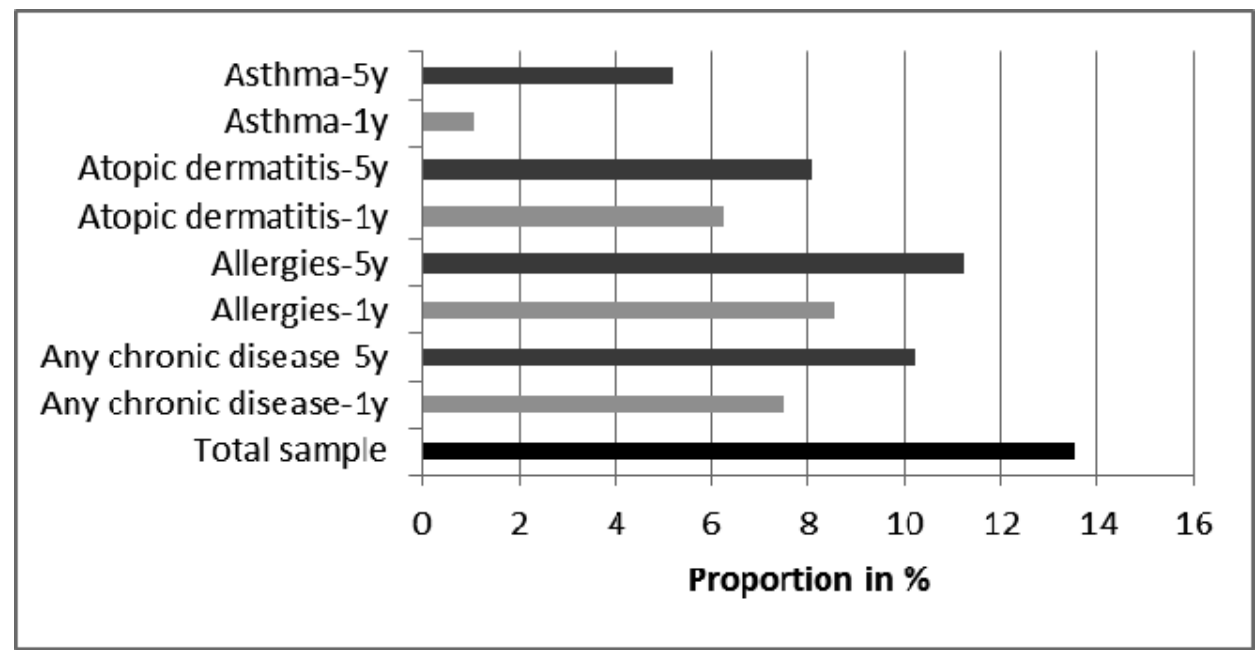

Figure 3. Proportion (among all drug users from the corresponding stratum) of adolescents who used medicinal CAM only (total sample versus chronic diseases diagnosed in the past year (-1y) or in any of the 5 preceding years $(-5 y)$ )

respiratory or skin disease, a subgroup that showed no significantly higher prevalence rates for medicinal CAM use.

In accordance with our results, another German publication on pediatric use of herbal drugs found no significant difference between chronically ill children and healthy ones [22], whereas a Swedish study found that a chronic disease significantly predicted higher use of herbal products among a population aged 16 years and above [23]. In our study, the prevalence rates of CAM use were usually higher if the chronic disease was diagnosed in the last year, instead of in any of the past 5 years. This might result in part from the fact that most patients may cope better with some chronic conditions with time.

Studies assessing CAM use in children with allergies or atopic dermatitis are rare. One Japanese study stated that CAM use among children with food allergies is very high, but comparability with European studies is limited [24]. Another study conducted in an Israeli CAM clinic found that allergy problems were the most mentioned reason for using CAM [25], and Canadian children reported allergies among the most reported reasons for visiting a naturopathic college clinic [26]. Interestingly, an English study [27] reported that traditional Chinese medicine was the most commonly used CAM modality for the treatment of children suffering from atopic dermatitis. In our study, traditional Chinese Medicine was reported by none of the participating 4,677 adolescents. As in our study, two larger studies investigating CAM use among children with asthma $[28,29]$ found a modest use of herbal and homeopathic drugs among children with 


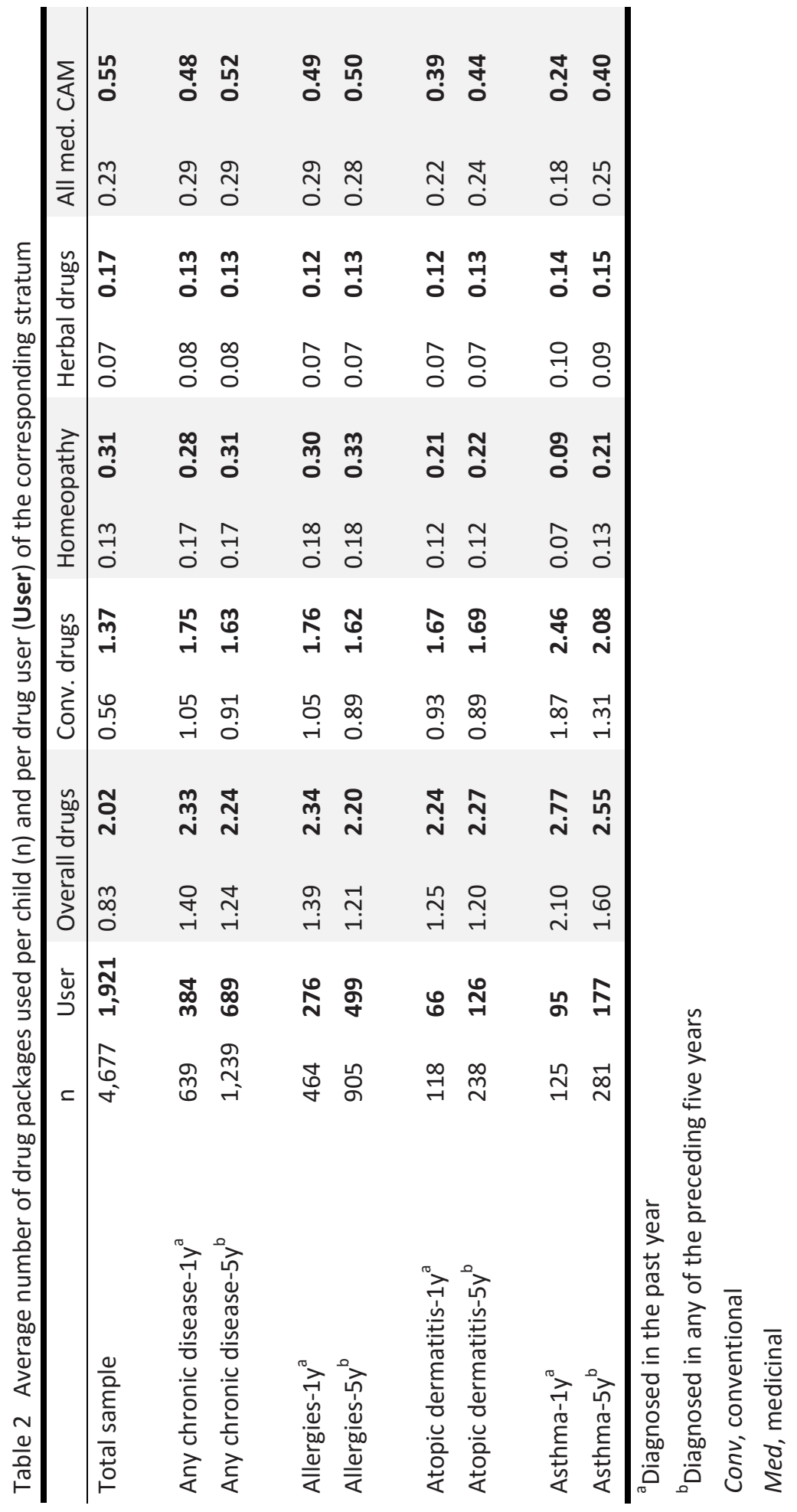


asthma, and another study confirmed our results that asthmatic adolescents consult CAM practitioners more [30] than healthy adolescents.

Despite the fact that chronically ill adolescents show higher prevalence rates of CAM use, this does not mean that they unreasonably substitute treatment with conventional drugs for a non-conventional medicinal therapy approach with CAM. The higher prevalence rates for medicinal CAM use among chronically ill adolescents (compared with healthy adolescents) found in this cohort may result mainly from the generally higher drug use (from any therapeutic category) among adolescents with chronic conditions. Nevertheless, with regard to the average number of drug packages used, chronically ill adolescents used substantially more conventional drugs (e.g., any chronic condition diagnosed in the last year $=1.05$ drug packages vs. total sample $=0.56$ drug packages), but only slightly more homeopathic remedies (0.17 vs. 0.13 ) or herbal drugs (0.08 vs. 0.07). A more detailed view on the drugs utilized reveals that, compared with the total sample, chronically ill adolescents actually use relatively more conventional drugs, as the proportion of conventional drugs among all drugs used was higher for any of the defined chronic categories compared with the proportion of conventional drugs among all drugs used for the total sample. Additionally, higher CAM use seems to depend on both the type of chronic condition and the underlying CAM category, as e.g., adolescents with atopic dermatitis did not show significantly higher prevalence rates for any CAM category, whereas adolescents with allergies used significantly more homeopathic remedies but not more herbal drugs. In spite of the higher prevalence rates for medicinal CAM found among adolescents with chronic conditions, it seems that medicinal CAM products do not play a bigger role in the treatment of chronically ill adolescents, when comparing the findings with the drug consumption among the total sample.

This study has several strengths and limitations. The results are based on recently assessed data from two large German birth cohorts. Several categories of chronic conditions (with the year of diagnosis) were assessed, and the predicting effect of the chronic condition was analyzed for various specific (medicinal) CAM categories. On the other hand, some of the self-reported chronic conditions (other than the 10 diseases in the presented list of diseases) may not be interpreted as chronic diseases or conditions in the strict sense (e.g., iron deficiency, allergy to erythromycin). However, the number of these "ambiguous cases" is very limited. Additionally, the number of used packages is only a rough estimation of the actually consumed amount of medicinal products, as the size or the defined daily doses are not considered. CAM use is known to be very high among children suffering from severe diseases with poor prognosis such as cancer [31]. Data for such diseases were not available in this study. With regard to adolescents who consulted a CAM provider, it must be considered that a homeopath may also be a conventional physician who uses the term "homeopath" as an additional title. Never- 
theless, the results were very similar if only non-medical health providers ("Heilpraktiker"), the most mentioned type of "CAM provider" were considered for analysis. Finally, owing to the higher educational and income levels compared with the German mean, the findings for the total cohort and the subgroups with chronic conditions as well do not exactly reflect CAM use among the German adolescent population.

\section{Conclusions}

Depending on the underlying chronic disease, adolescents with chronic conditions showed significantly higher prevalence rates of homeopathy use, utilization on any medicinal CAM category, and consultation with CAM providers. Nevertheless, the proportion of medicinal CAM among all drugs utilized was lower among adolescents who suffered from a chronic disease. This indicates that chronically ill adolescents do not substitute conventional medicinal products with medicinal CAM because of their chronic disease, but may use non-conventional therapy approaches as an additional treatment option. Owing to the fact that chronically ill adolescents evidently use more medicinal products in general, the risk of pharmacological interactions (e.g., between conventional drugs, but between conventional drugs and non-conventional drugs as well) may be higher among adolescents with chronic conditions compared with healthy adolescents.

\section{Authors' contribution}

SI prepared the data with regard to the classification of the reported drugs. Furthermore, he performed the statistical analysis, interpreted the results, conceptualized the initial manuscript, and approved the final manuscript as submitted. SW contributed to the data analysis and interpretation of the results. She critically revised the initial manuscript, and approved the final manuscript as submitted. IB, JH, DB, AB, IL, and MS were involved in data collection. They critically revised the initial manuscript, and approved the final manuscript as submitted.

\section{Compliance with Ethical Standards}

The 15-year follow-up examination of the GINIplus study was partially supported by the Commission of the European Communities, the $7^{\text {th }}$ Framework Programme, MeDALL project as well as by the companies Mead Johnson and Nestlé. This work was also supported by the German Competence Network Obesity ('Kompetenznetz Adipositas') funded by the German Federal Ministry of Education and Research (BMBF) as part of the 'Core Domain Health Economics' (Grant No. 01GI1127). This specific analysis on 
'Complementary and alternative medicine (CAM) use among adolescents with chronic conditions from the German GINIplus and LISAplus birth cohorts' was exclusively funded by the Helmholtz Zentrum Munich.

\section{Conflict of interest}

The authors declare that they have no conflict of interest.

\section{Acknowledgments}

We thank the families for participation in the study, the obstetric units for allowing recruitment and the GINIplus and LISAplus study teams for excellent work.

The GINIplus study group at 15 years consisted of: Helmholtz Zentrum München, Institute of Epidemiology I, München (J Heinrich, M Schnappinger, I Brüske, H Schulz, M Standl, M Sußmann, E Thiering); Research Institute, Department of Pediatrics, MarienHospital, Wesel (D Berdel, A von Berg); Department of Pediatrics, Ludwig Maximilians University, Munich (S Koletzko); Department of Pediatrics, Technical University, Munich (CP Bauer, U Hoffmann, M Paschke); IUF - Leibniz Research Institute for Environmental Medicine, Düsseldorf (U Krämer, E Link, C Klümper, B Hoffmann);

The LISAplus study group at 15 years consisted of: Helmholtz Zentrum München, German Research Center for Environmental Health, Institute of Epidemiology I, Munich (J Heinrich, I Brüske, H Schulz, M Standl, M Schnappinger, M Sußmann, E Thiering, C Flexeder, C Zeller); Department of Pediatrics, Marien Hospital Wesel, Wesel (A von Berg); Pediatric Practice, Bad Honnef (B Schaaf); Technical University, Munich (CP Bauer, U Hoffmann); Helmholtz Centre for Environmental Research - UFZ, Department of Environmental Immunology/Core Facility Studies, Leipzig (I Lehmann, M Bauer, G Herberth, J Müller, S Röder, M Schilde); Department of Pediatrics, Municipal Hospital "St. Georg", Leipzig (M Borte, U Diez, C Dorn, E Braun); ZAUM - Center for Allergy and Environment, Technical University Munich (M Ollert, J Grosch). 


\section{References}

1. Italia S, Wolfenstetter SB, Teuner CM: Patterns of complementary and alternative medicine (CAM) use in children: a systematic review. Eur J Pediatr 2014;173:1413-1428.

2. Zuzak TJ, Boňková J, Careddu D, Garami M, Hadjipanayis A, Jazbec J, Merrick J, Miller J, Ozturk C, Persson IA, Petrova G, Saz Peiró P, Schraub S, Simões-Wüst AP, Steinsbekk A, Stockert K, Stoimenova A, Styczynski J, Tzenova-Savova A, Ventegodt S, Vlieger AM, Längler A: Use of complementary and alternative medicine by children in Europe: published data and expert perspectives. Complement Ther Med 2013;21(Suppl 1):34-47.

3. Bellas A, Lafferty WE, Lind B, Tyree PT: Frequency, predictors, and expenditures for pediatric insurance claims for complementary and alternative medical professionals in Washington State. Arch Pediatr Adolesc Med 2005;159:367-372.

4. Ang JY, Ray-Mazumder S, Nachman SA, Rongkavilit C, Asmar BI, Ren CL: Use of complementary and alternative medicine by parents of children with HIV infection and asthma and well children. South Med J 2005;98:869-875.

5. Gottschling S, Gronwald B, Schmitt S, Schmitt C, Längler A, Leidig E, Meyer S, Baan A, Shamdeen MG, Berrang J, Graf N: Use of complementary and alternative medicine in healthy children and children with chronic medical conditions in Germany. Complement Ther Med 2013;21(Suppl 1):61-69.

6. McCann LJ, Newell SJ: Survey of paediatric complementary and alternative medicine use in health and chronic illness. Arch Dis Child 2006;91:173-174.

7. Ozturk C, Karayagiz G: Exploration of the use of complementary and alternative medicine among Turkish children. J Clin Nurs 2008;17:2558-2564.

8. Wilson K, Dowson C, Mangin D: Prevalence of complementary and alternative medicine use in Christchurch, New Zealand: children attending general practice versus paediatric outpatients. N Z Med J 2007;120:U2464.

9. Surette S, Vanderjagt L, Vohra S: Surveys of complementary and alternative medicine usage: a scoping study of the paediatric literature. Complement Ther Med 2013;21(Suppl 1):48-53.

10. Birdee GS, Phillips RS, Davis RB, Gardiner P: Factors associated with pediatric use of complementary and alternative medicine. Pediatrics 2010;125:249-256.

11. Huillet A, Erdie-Lalena C, Norvell D, Davis BE: Complementary and alternative medicine used by children in military pediatric clinics. J Altern Complement Med 2011;17:531-537.

12. Menniti-Ippolito F, Bologna E, Gargiulo L, Forcella E, Sabbadini LL, Raschetti R: [Characteristics of unconventional medicine users and their households in Italy]. Caratteristiche individuali e familiari degli utilizzatori di terapie non convenzionali in Italia. Ann Ist Super Sanita 2004;40:455-461, Italian.

13. Zutavern A, Schaaf B, von Berg A, Borte M, Herbarth O, Wichmann H, Heinrich J: Inanspruchnahme von Homöopathie und Konsultation von Heilpraktikern - Ergebnisse einer deutschen Geburtskohortenstudie (LISA) im Alter von 2 Jahren [Use of homeopathy and consultation with alternative medicine practitioners: Results of a German birth cohort study (LISA) at the age of 2 years]. Monatsschrift Kinderheilkunde 2007;155:439-445, German.

14. Low E, Murray DM, O'Mahony O, O'B Hourihane J: Complementary and alternative medicine use in Irish paediatric patients. Ir J Med Sci 2008;177:147-150.

15. Pitetti R, Singh S, Hornyak D, Garcia SE, Herr S: Complementary and alternative medicine use in children. Pediatr Emerg Care 2001;17:165-169.

16. Sawni-Sikand A, Schubiner $H$, Thomas RL: Use of complementary/alternative therapies among children in primary care pediatrics. Ambul Pediatr 2002;2:99-103.

17. Simpson N, Roman K: Complementary medicine use in children: extent and reasons. A population-based study. Br J Gen Pract 2001;51:914-916.

18. Losier A, Taylor B, Fernandez CV: Use of alternative therapies by patients presenting to a pediatric emergency department. J Emerg Med 2005;28:267-271. 
19. Italia S, Brand H, Heinrich J, Berdel D, von Berg A, Wolfenstetter SB: Utilization of complementary and alternative medicine (CAM) among children from a German birth cohort (GINIplus): patterns, costs, and trends of use. BMC Complement Altern Med 2015;15:49 DOI:10.1186/s12906-015-0569-8.

20. Bundesministerium für Gesundheit (ed): Homöopathisches Arzneibuch 2010 (HAB) Amtliche Ausgabe. Stuttgart, Deutscher Apotheker Verlag, 2010.

21. Metcalfe A, Williams J, McChesney J, Patten SB, Jetté N: Use of complementary and alternative medicine by those with a chronic disease and the general population - results of a national population based survey. BMC Complement Altern Med 2010;10:58 DOI:10.1186/1472-6882-10-58.

22. Hümer M, Scheller G, Kapellen T, Gebauer C, Schmidt H, Kiess W: Phytotherapie in der Kinderheilkunde: Prävalenz, Indikationen und Motivation [Use of herbal medicine in German children - prevalence, indications and motivation]. Dtsch Med Wochenschr 2010;135:959-964, German.

23. Al-Windi A: Predictors of herbal medicine use in a Swedish health practice. Pharmacoepidemiol Drug Saf 2004;13:489-496.

24. Nakano T, Shimojo N, Okamoto Y, Ebisawa M, Kurihara K, Hoshioka A, Yamaguchi K, Ito K, Fujisawa T, Kameda M, Suehiro Y, Ogura H, Shibata R, Suzuki S, Takahashi Y, Ikeda M, Kohno Y: The use of complementary and alternative medicine by pediatric food-allergic patients in Japan. Int Arch Allergy Immunol 2012;159:410-415.

25. Erez C, Reuveni H, Freud T, Peleg R: Reasons for referrals of children and adolescents to alternative medicine in Southern Israel. J Altern Complement Med 2009;15:681-684.

26. Wilson K, Busse JW, Gilchrist A, Vohra S, Boon H, Mills E: Characteristics of pediatric and adolescent patients attending a naturopathic college clinic in Canada. Pediatrics 2012;115:e338-343 DOI:10.1542/peds.2004-1901.

27. Johnston GA, Bilbao RM, Graham-Brown RAC: The use of complementary medicine in children with atopic dermatitis in secondary care in Leicester. Br J Dermatol 2003;149:566-571.

28. Shen J, Oraka E: Complementary and alternative medicine (CAM) use among children with current asthma. Prev Med 2012;54:27-31.

29. Torres-Llenza V, Bhogal S, Davis M, Ducharme FM: Use of complementary and alternative medicine in children with asthma. Can Respir J 2010;17:183-187.

30. Steinsbekk A, Rise MB, Bishop F, Lewith G: Predictors for adolescent visits to practitioners of complementary and alternative medicine in a total population (the Young-HUNT Studies). PLoS One 2011;6(10):e25719 DOI:10.1371/journal.pone.0025719.

31. Bishop FL, Prescott P, Chan YK, Saville J, von Elm E, Lewith GT: Prevalence of complementary medicine use in pediatric cancer: a systematic review. Pediatrics 2010;125:768-776. 
We especially need imagination in science. It is not all mathematics, nor all logic, but it is somewhat beauty and poetry.

Maria Montessori

Italian physician and educator 


\section{CHAPTER 4}

\section{Utilization of complementary and alternative medicine (CAM)}

among children from a German birth cohort (GINIplus): patterns, costs, and trends of use

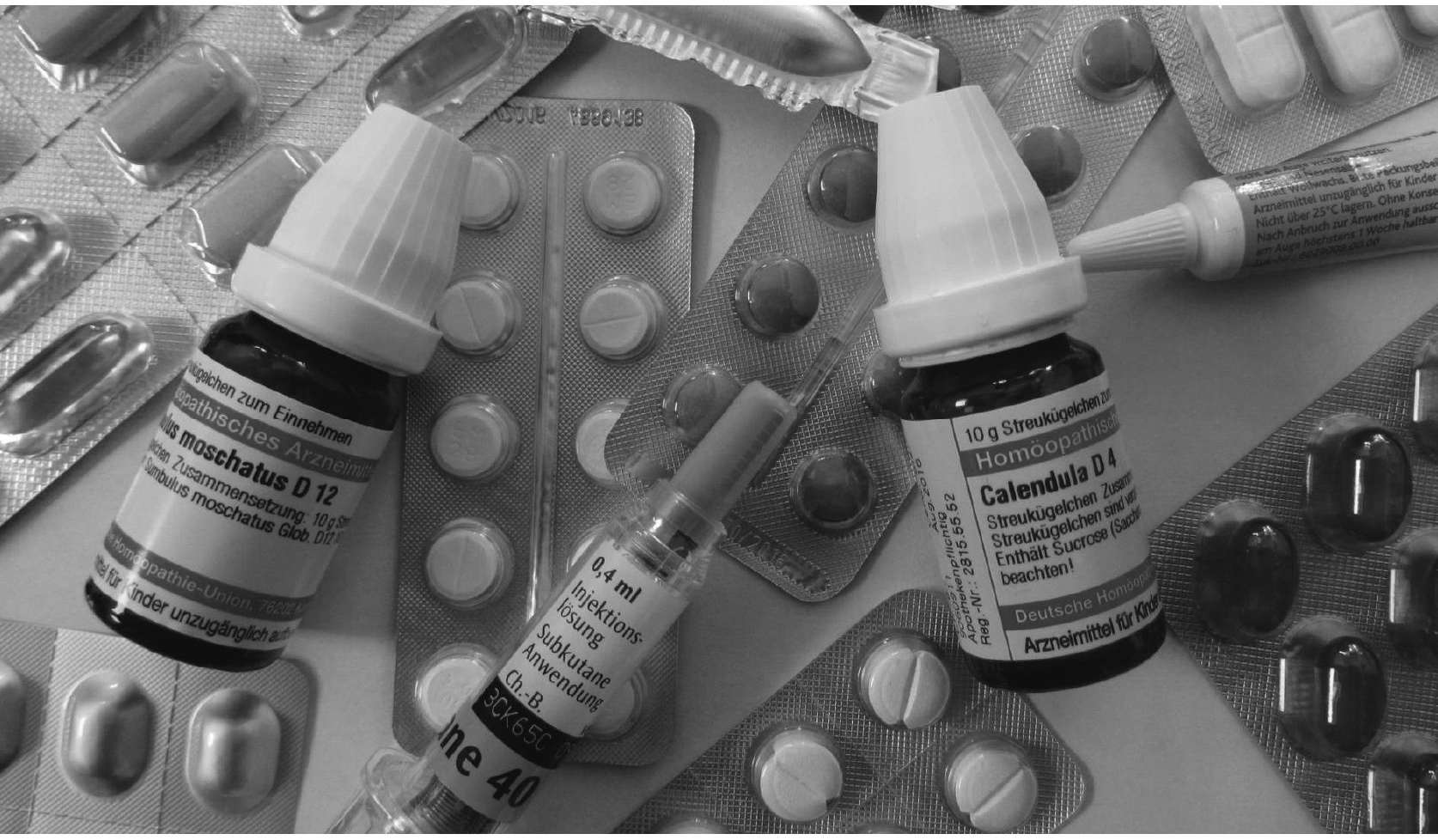

Salvatore Italia, Helmut Brand, Joachim Heinrich, Dietrich Berdel, Andrea von Berg, Silke B. Wolfenstetter.

Utilization of complementary and alternative medicine (CAM) among children from a German birth cohort (GINIplus): patterns, costs, and trends of use.

BMC Complement Altern Med 2015;15:49. doi:10.1186/s12906-015-0569-8 


\begin{abstract}
Background: The use of complementary and alternative medicine (CAM) is widespread among children in Germany and other European countries. Only a few studies are available on trends in pediatric CAM use over time. The study's objective was to present updated results for prevalence, predictors, and costs of CAM use among German children and a comparison with findings from a previous follow-up of the same birth cohort.
\end{abstract}

Methods: Data were collected for 3013 children on their utilization of medicinal products (during the last 4 weeks) and consultation with CAM providers (in the preceding year) from a German birth cohort study (GINIplus, 15-year follow-up) using a selfadministered questionnaire. The reported medicinal CAMs were classified into six categories (homeopathy, herbal drugs, nutritionals, minerals and trace elements, microorganisms, further CAM). Drug prices were traced using pharmaceutical identification numbers (PZNs), or otherwise conservatively estimated. Finally, the results were compared with data obtained from the 10-year follow-up of the same birth cohort study by adopting the identical methodology.

Results: In all, $26 \%$ of the reported 2489 drugs were medicinal CAM. The 4-week prevalence for homeopathy and herbal drug use was $7.5 \%$ and $5.6 \%$, respectively. Some $13.9 \%$ of the children used at least one type of medicinal CAM in the preceding 4 weeks. The 1 -year prevalence for consultation with CAM providers was $10.8 \%$. From the drugs identified as CAM, 53.7\% were homeopathic remedies, and $30.8 \%$ were herbal drugs.

Factors associated with higher medicinal CAM use were female gender, residing in Munich, and higher maternal education.

A homeopathy user utilized on average homeopathic remedies worth EUR 15.28. The corresponding figure for herbal drug users was EUR 16.02, and EUR 18.72 for overall medicinal CAM users.

Compared with the 10-year follow-up, the prevalence of homeopathy use was more than halved (-52\%) and dropped substantially for herbal drug use (-36\%) and overall CAM use $(-38 \%)$ as well.

Conclusion: CAM use among 15-year-old children in the GINIplus cohort is popular, but decreased noticeably compared with children from the same cohort at the age of 10 years. This is possibly mainly because German health legislation normally covers CAM for children younger than 12 years only.

\title{
Key words
}

Complementary therapies · CAM · Homeopathy · Phytotherapy · Child · Germany ·

Drug utilization $\cdot$ Socioeconomic factors $\cdot$ Trends 


\section{Background}

Therapy approaches that are not part of conventional medicine are often referred to as complementary and alternative medicine (CAM), although there is no universally valid definition of CAM. However, there seems to be an unbroken high demand for such kinds of therapy approaches in the European population and outside Europe as well. Some recently published reviews give updated overviews on the prevalence of CAM use in adults $[1,2]$ and children $[3,4]$. Owing to different methodology and CAM definition, the findings of the included studies on CAM use vary widely with respect to the prevalence and predictors of use. For instance, overall CAM use in children without chronic conditions was reported to be between $1.8 \%$ and $87.6 \%$, depending on included CAM modalities, country, and underlying recall period [3].

When looking at specific CAM categories, many of the reviewed studies listed homeopathy and herbal drugs among the most popular types of CAM. Within Europe, Germany ranks between the countries with the highest prevalence rates for homeopathy and herbal drug use in children. For homeopathy, prevalence rates of $27.7 \%$ (1-year prevalence) [5] and 14.3\% (4-week prevalence) [6] were reported in German children. Other European countries with high prevalence rates for homeopathy use are The Netherlands with 14.6\% (1-year prevalence) [7] and the UK with 16.9\% (lifetime use) [8]. With concern to herbal drugs, a 2010 publication found $85.5 \%$ of German children [9] using herbal drugs (lifetime use). In Turkey, the prevalence of pediatric use of herbal drugs was $58.6 \%$ (1-year prevalence) [10]. The evidently high popularity of nonconventional medicine in Germany and other countries makes CAM use a relevant public health topic.

This article presents data from the recently completed 15-year follow-up of a German birth cohort study. The aim was to extract prevalence rates and predictors for the utilization of various CAM modalities (homeopathy use, herbal drug use, medicinal CAM utilization in general, and consultation with CAM providers). Furthermore, expenditures on pediatric CAM use were analyzed. Finally, in order to detect possible time trends and differences in CAM use, the results were compared with the findings from the 10-year follow-up of a smaller but similarly composed sample from the same birth cohort.

\section{Methods}

\section{Study population}

GINIplus (German Infant study on the Influence of Nutrition Intervention plus environmental and genetic influences on allergy development) is a German birth cohort study 
[11]. It started with 5991 healthy full-term newborns (children with a birth weight $<2500$ g were not eligible for inclusion), who were recruited between September 1995 and June 1998 from obstetric clinics in an urban region of southern Germany (Munich) and a more rural region in the western part of Germany (Wesel).

For the 15-year follow-up, 3895 participants were contacted between January 2011 and September 2013. With regard to the season, $27 \%$ of the questionnaires were collected in winter (January-March), 29\% in spring (April-June), 26\% in summer (JulySeptember), and the remaining $18 \%$ in autumn (October-December). Among other things, the main questionnaire assessed the children's gender, parental income and education, and consultation with various alternative health care providers during the previous 12 months.

In addition to the main questionnaire, a self-administered questionnaire on the consumption of drugs and medicinal products was included based on an almost identical questionnaire that had already been adopted for the 10-year follow-up. The design of the questionnaire on drug utilization corresponds to the validated questionnaire from the German KiGGS-Study that was conducted with 17641 children [12]. Parents/legal guardians were invited to report the drugs their child used during the last 4 weeks by entering the drugs' names into designated spaces or attaching the empty drug packages to the questionnaire. The exact number of drugs used was assessed by an additional question in case the limited number (five) of designated spaces would not suffice to report all drugs utilized.

Moreover, the participants were also asked to enter the pharmaceutical identification number (PZN) of the reported drugs. The PZN, which is printed on the drug package, precisely identifies the drug utilized and provides further information such as the size of the package, the dosage, the pharmaceutical manufacturer, the listed price, etc.

To avoid ambiguity of interpretation, the authors would like to note that we also considered preparations that are no medicinal products in the strict sense (e.g., nutritional supplements), but were reported as drugs utilized by the participating children.

\section{Drug classification}

All reported drugs were classified into several therapeutic categories. The following medicinal CAM modalities were defined and extracted from the entity of reported drugs:

(1) Homeopathic/anthroposophic drugs (afterwards referred to as 'Homeopathy'): Drugs that have been prepared according to the production specification of the Homeopathic Pharmacopoeia HAB [13], including anthroposophic remedies and biochemic remedies (Schuessler salts). 
(2) Herbal drugs: Herbal extracts and their preparations, teas. Preparations containing active pharmaceutical ingredients of herbal origin (e.g., codeine) that are available by prescription only were excluded.

(3) Nutritionals: Vitamins and combined food supplements. Preparations containing vitamin $D$ for prophylaxis according to medical guidelines were excluded.

(4) Minerals and trace elements: Mono-preparations of minerals or trace elements such as calcium, magnesium, selenium, etc. Preparations containing iodide and/or fluoride for prophylaxis according to medical guidelines were excluded.

(5) Microorganisms: Non-pathogenic microorganisms or their metabolites used to regulate the intestinal flora or stimulate the immune system.

(6) Further medicinal CAM: Bach flower, traditional Chinese medicine, etc.

As well as medicinal CAM use, consultation with CAM providers was assessed during the previous 12 months (non-medical health provider ('Heilpraktiker'), homeopath, osteopath, and 'others') for the child's disease or disorder.

\section{Cost accounting}

Parents were asked to report expenditures for consultations with CAM providers. Prices for medicinal CAM were traced via PZNs (official pharmacy prices from the 'Lauer' price list as of August 2012). For drug entries without PZNs, conservative assumptions were made (e.g., smallest package size, most favorable price).

\section{Comparison of the results}

The results were compared with data based on the 10-year follow-up of the combined GINIplus and LISAplus birth cohort studies ( $n=3642$ ) [6]. For comparison, only data from the GINIplus subset were used, which included 2065 children from Munich and Wesel. The distribution of the participants with regard to gender, study area, maternal educational background, and parental income background was very similar to the composition of the GINIplus cohort of the 15-year follow-up ( $n=3013)$. Furthermore, the same methodology (drug classification, logistic regression model, etc.) was adopted for the analysis of both follow-ups.

\section{Outcome definition and statistical analysis}

Several outcomes were defined for the statistical analysis. Those participants who reported utilization of at least one homeopathic drug during the past 4 weeks were defined as 'homeopathy users' and those taking at least one herbal drug as 'herbal drug 
users', respectively. 'Overall CAM users' took at least one drug from the therapeutic categories 1-6. Finally, a 'CAM provider user' consulted at least once during the past year with a non-medical health provider ('Heilpraktiker'), a homeopath, an osteopath, or another type of CAM provider.

The statistical analysis was performed with the SAS software package (SAS Institute Inc., Cary, NC, USA, version 9.3). Odds ratios (ORs) and their 95\% confidence intervals (CI) were obtained using a multivariate logistic regression model. The significance level for the estimates was set at $p<0.05$. All independent variables included in the model were checked using the F-test for significance. Bivariate associations between the independent variables and users' prevalence rates were analyzed by $\mathrm{Chi}^{2}$ test $(p<0.05)$.

To define educational status, the mothers' educational background was classified into four levels based on their highest school degree:

Level 1: secondary school

Level 2: junior high school

Level 3: baccalaureate (= qualification for university entrance)

Level 4: university degree

Mothers who reported no school degree at all $(n=5)$ were allocated to education level 1. Entries for mothers $(n=4)$ reporting another (not further specified) kind of school degree than those listed above, were treated as missing values for educational background.

The income status was defined using the median equivalent income (MEI) for 2012 (€1633 net/month) [14] where the household members were weighted according to the new scale of the Organisation for Economic Co-operation and Development (OECD) [15]. The income cut-offs were chosen according to the definition of poverty $(60 \%$ of $\mathrm{MEI})[16]$.

The GINIplus cohort obtained approval from the ethics committee of the Bavarian Medical Council and the Medical Council of North Rhine-Westphalia. Furthermore, written informed consent was given by the participants' parents or legal guardians and by participants.

\section{Results}

Cohort structure and prevalence of CAM use

Out of 3895 distributed questionnaires assessing drug utilization, 3013 were completed and returned, yielding a response rate of $77.4 \%$. The children's average age was 15.1 years, ranging between 14.5 years and 16.8 years. Mothers completed $85.5 \%$ of the 
questionnaires, fathers $5.1 \%$, and questionnaires completed by both parents accounted for $2.7 \%$ (missing values $=6.7 \%$ ). Compared with the baseline survey, the parents of those children who participated in the 15-year follow-up have higher levels of school education and income. Table 1 shows the cohort structure and the stratified prevalence rates of CAM use. The 4-week prevalence $(95 \% \mathrm{Cl})$ of homeopathy use was $7.5 \%$ $[(6.5 ; 8.5) n=226]$, whereas 170 children [5.6\% (4.8;6.5)] used herbal drugs. As defined in the methods section, 10 prescription drugs containing opium alkaloids (noscapine, morphine) or allergens extracted from pollen were excluded from the CAM modality 'herbal drugs'. Looking at all CAM categories, 418 children [13.9\% $(12.6 ; 15.1)]$ used at least one drug from the CAM categories 1-6.

Table 1. Characteristics of the GINIplus cohort and prevalence of use

\begin{tabular}{|c|c|c|c|c|c|}
\hline & \multirow[b]{2}{*}{$\mathrm{n}$} & \multicolumn{4}{|c|}{ Prevalence of use in \% } \\
\hline & & Homeopathy $^{1}$ & Herbal drugs $^{1}$ & All medicinal CAM ${ }^{1}$ & CAM providers $^{2}$ \\
\hline \multicolumn{6}{|l|}{ Gender } \\
\hline Male & 1500 & 6.1 & 4.8 & 11.5 & 9.9 \\
\hline Female & 1513 & 8.9 & 6.5 & 16.3 & 11.6 \\
\hline \multicolumn{6}{|l|}{ Study area } \\
\hline Munich & 1457 & 9.0 & 5.8 & 15.7 & 14.0 \\
\hline Wesel & 1556 & 6.1 & 5.5 & 12.2 & 7.7 \\
\hline \multicolumn{6}{|l|}{ Maternal education } \\
\hline Secondary school & 380 & 5.0 & 3.2 & 9.0 & 4.2 \\
\hline Junior high school & 1251 & 7.7 & 5.6 & 14.2 & 10.4 \\
\hline Baccalaureate & 580 & 8.6 & 6.7 & 15.3 & 12.4 \\
\hline University degree & 795 & 7.7 & 6.2 & 14.6 & 13.2 \\
\hline \multicolumn{6}{|l|}{ Household income } \\
\hline$\leq 60 \%$ of $\mathrm{MEI}$ & 529 & 6.8 & 4.7 & 11.2 & 6.6 \\
\hline $60-100 \%$ of $\mathrm{MEI}$ & 985 & 7.7 & 6.3 & 15.2 & 10.5 \\
\hline$>100 \%$ of $\mathrm{MEI}$ & 1071 & 7.8 & 5.6 & 14.4 & 13.4 \\
\hline Total & 3013 & 7.5 & 5.6 & 13.9 & 10.8 \\
\hline
\end{tabular}

Owing to missing values, the strata may not add up to the total number of participants $M E I$, median equivalent income

${ }^{1}$ Use within the last 4 weeks

${ }^{2}$ Consultation with any type of CAM provider in the previous 12 months

CAM provider = non-medical health practitioner, homeopath, osteopath, and 'others'

In sum, 1234 of the 3013 participating children reported having used at least one drug during the 4 weeks prior to the assessment date. The total number of drugs utilized was 
2489, of which 2444 could be allocated to a therapeutic category. The remaining 45 drug entries did not provide enough information to identify the therapeutic category and were therefore interpreted as drug use only. The majority of utilized drugs were conventional drugs with chemically active pharmaceutical ingredients such as ibuprofen or paracetamol. Nevertheless, about $26 \%(n=643)$ belonged to the non-conventional drug categories, as defined above in the section 'drug classification'. Of the 643 identified CAM, 642 were available without medical prescription. The detailed distribution of non-conventional drugs over the various CAM modalities is shown in Figure 1. Homeopathic remedies were the most commonly used CAM modality $(14.1 \%$ of all identified drugs), followed by herbal drugs (8.1\%), minerals and trace elements (1.9\%), and nutritionals (1.1\%). Other medicinal CAM modalities such as Bach flower remedies or traditional Chinese medicine played only a marginal role.

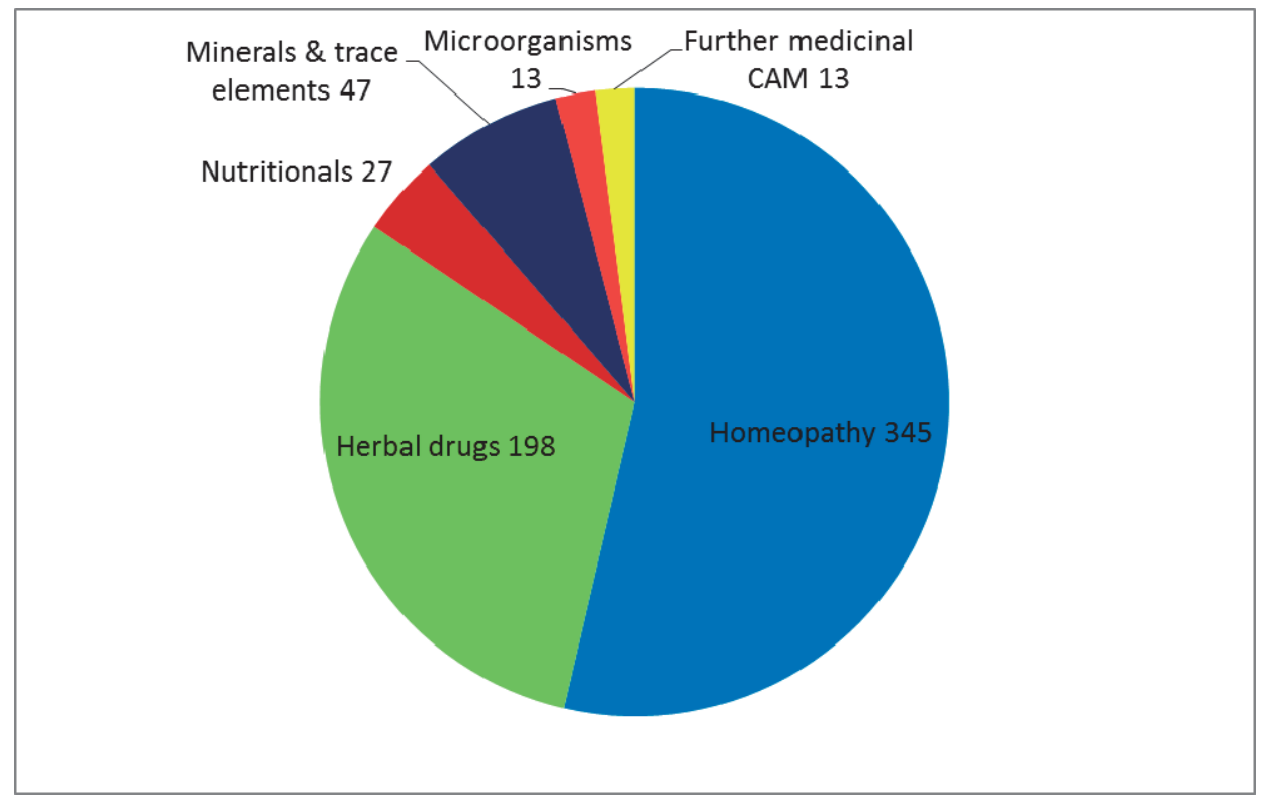

Figure 1. Proportion of the single medicinal CAM modalities in all reported medicinal CAM $(n=643)$

The most mentioned homeopathic and herbal drugs are displayed with their ATC codes in Table 2. Concerning homeopathy, 141 of the 345 reported homeopathic remedies were combined preparations. A further 146 were single homeopathic drugs such as Arnica ( $n=26)$, Belladonna $(n=9)$, and Gelsemium $(n=9)$, which were the most frequent single homeopathic remedies. Twelve drugs were clearly identified as anthroposophic remedies. Single remedies as well as biochemic remedies according to Dr. Schuessler 
are partly used for several disease patterns. An allocation to ATC categories is therefore not possible.

With respect to herbal drugs, more than $70 \%$ of the 198 drugs from this category were used for the treatment of coughs and colds. The mean duration of overall CAM use was 11.1 days (median=6). The corresponding figures for homeopathy and herbal drugs were 9.7 days (median=5) and 8.6 days (median=5). In comparison with CAM, the mean duration of conventional drug use was 11.4 days (median=5).

Table 2. Most frequent homeopathic and herbal drugs

\begin{tabular}{|c|c|c|c|c|c|c|c|}
\hline \multicolumn{4}{|c|}{ Homeopathic drugs $(n=345)$} & \multicolumn{4}{|c|}{ Herbal drugs $(n=198)$} \\
\hline ATC code & Remedy & $\mathrm{n}$ & (in \%) & ATC code & Remedy & $\mathrm{n}$ & (in \%) \\
\hline $\mathrm{R} 05 \mathrm{XH} 20$ & Flu remedies* & 31 & (9.1) & R01BP30 & Systemic rhinologicals* & 50 & $(25.3)$ \\
\hline $\mathrm{R} 02 \mathrm{AH} 20$ & $\begin{array}{l}\text { Therapeutics for throat } \\
\text { and pharynx* }\end{array}$ & 14 & (4.1) & R05CA19 & $\begin{array}{l}\text { Expectorants } \\
\text { (Myrtol standardized) }\end{array}$ & 23 & $(11.6)$ \\
\hline $\mathrm{R} 01 \mathrm{BH} 20$ & Rhinologicals* & 9 & (2.6) & R05CP02 & Ivy leaves & 22 & (11.1) \\
\hline $\mathrm{SO} 2 \mathrm{DH} 20$ & Otologicals* & 8 & (2.3) & A03FP30 & Prokinetics* & 18 & $(9.1)$ \\
\hline $\mathrm{M02AH} 20$ & $\begin{array}{l}\text { Remedies for muscle } \\
\text { and joint pains* }\end{array}$ & 7 & $(2.0)$ & R05CP05 & Pelargonium root & 18 & (9.1) \\
\hline / & Single preparations & 146 & $(42.3)$ & G02CP01 & Vitex agnus-castus & 10 & (5.1) \\
\hline / & $\begin{array}{l}\text { Biochemic remedies } \\
\text { (= Schuessler salts) }\end{array}$ & 58 & $(16.8)$ & R05CA25 & $\begin{array}{l}\text { Expectorants } \\
(1,8-\text {-Cineol) }\end{array}$ & 6 & (3.0) \\
\hline
\end{tabular}

ATC, anatomical therapeutical classification

*Combined preparations

About $47 \%$ of the minerals and trace elements $(n=47)$ were preparations containing iron ( $n=22)$. Medicinal mono-preparations with iodide $(n=43)$, fluoride $(n=1)$, and vitamin $D(n=6)$ were not defined as CAM, as they are normally used for prophylaxis according to medical guidelines.

The prevalence for consultation with CAM providers (within the previous 12 months) was lower than for medicinal CAM use. Some 144 children (4.8\%) visited a non-medical health provider ('Heilpraktiker'). Consultation with a homeopath was reported for 98 children (3.3\%), with an osteopath for 102 children (3.4\%), and 38 participants $(1.3 \%)$ consulted with other CAM providers. Overall, 324 children [10.8\% $(9.6 ; 11.9)]$ visited at least one type of CAM provider during the 12 months prior to the assessment date. 
Table 3 summarizes the ORs for predicting factors for CAM use.

Female gender significantly predicted homeopathy use $(O R=1.48)$ and overall CAM use (OR=1.49). Girls were more likely to be 'herbal drug users' as well, but the ORs were not significant for this CAM modality.

Compared with Munich (urban area), the participants from Wesel (rural area) used fewer homeopathic drugs $(\mathrm{OR}=0.62)$ and were less likely to be 'overall CAM users' $(\mathrm{OR}=0.75)$. Children from Wesel also consulted CAM providers less (OR=0.57).

Higher education has a positive effect on CAM use. With the lowest maternal education level as a reference, children whose mother had a university degree showed significantly higher ORs for herbal drug use $(O R=2.03)$, and consultation with CAM providers (OR=2.49), but no significant association with educational status was found for homeopathy use.

Table 3. Predictors of complementary and alternative medicine use

\begin{tabular}{|c|c|c|c|c|c|c|c|c|}
\hline & \multicolumn{8}{|c|}{ Adjusted odds ratio of utilization (and 95\% confidence interval) } \\
\hline & \multicolumn{2}{|c|}{ Homeopathy } & \multicolumn{2}{|c|}{ Herbal drugs } & \multicolumn{2}{|c|}{ All medicinal CAM } & \multicolumn{2}{|c|}{ CAM providers } \\
\hline \multicolumn{9}{|l|}{ Gender } \\
\hline Male & \multicolumn{2}{|c|}{ Reference } & \multicolumn{2}{|c|}{ Reference } & \multicolumn{2}{|c|}{ Reference } & \multicolumn{2}{|c|}{ Reference } \\
\hline Female & $1.48^{*}$ & $(1.12-1.95)$ & 1.36 & $(0.99-1.86)$ & $1.49 *$ & $(1.21-1.84)$ & 1.19 & $(0.94-1.50)$ \\
\hline \multicolumn{9}{|l|}{ Study area } \\
\hline Munich & \multicolumn{2}{|c|}{ Reference } & \multicolumn{2}{|c|}{ Reference } & \multicolumn{2}{|c|}{ Reference } & \multicolumn{2}{|c|}{ Reference } \\
\hline Wesel & $0.62 *$ & $(0.46-0.84)$ & 0.97 & $(0.69-1.36)$ & 0.75 & $(0.59-0.94)$ & $0.57 * *$ & $(0.44-0.74)$ \\
\hline \multicolumn{9}{|l|}{ Maternal education } \\
\hline Secondary school & \multicolumn{2}{|c|}{ Reference } & \multicolumn{2}{|c|}{ Reference } & \multicolumn{2}{|c|}{ Reference } & \multicolumn{2}{|c|}{ Reference } \\
\hline Junior high school & 1.61 & $(0.96-2.68)$ & 1.79 & $(0.96-3.36)$ & 1.66 & $(1.12-2.45)$ & $2.57^{*}$ & $(1.50-4.39)$ \\
\hline Baccalaureate & 1.72 & $(0.99-3.01)$ & 2.15 & $(1.10-4.21)$ & 1.71 & $(1.12-2.62)$ & $2.80 *$ & $(1.59-4.92)$ \\
\hline University degree & 1.38 & $(0.79-2.41)$ & 2.03 & $(1.03-3.98)$ & 1.54 & $(1.00-2.35)$ & $2.49 *$ & $(1.42-4.36)$ \\
\hline \multicolumn{9}{|l|}{ Household income } \\
\hline$\leq 60 \%$ of $\mathrm{MEI}$ & \multicolumn{2}{|c|}{ Reference } & \multicolumn{2}{|c|}{ Reference } & \multicolumn{2}{|c|}{ Reference } & \multicolumn{2}{|c|}{ Reference } \\
\hline $60-100 \%$ of $\mathrm{MEI}$ & 0.99 & $(0.65-1.51)$ & 1.20 & $(0.74-1.96)$ & 1.27 & $(0.92-1.77)$ & 1.35 & $(0.90-2.03)$ \\
\hline$>100 \%$ of $\mathrm{MEI}$ & 0.87 & $(0.56-1.37)$ & 0.99 & $(0.59-1.67)$ & 1.08 & $(0.76-1.53)$ & 1.45 & $(0.96-2.20)$ \\
\hline
\end{tabular}

Bold numbers = significant at $\mathrm{p}<0.05 * \mathrm{p}<0.01 * * \mathrm{p}<0.0001$

$\mathrm{MEI}$, median equivalent income

The equivalent income had no significant impact on any category of medicinal CAM use. However, children from poor households tend to consult CAM providers less. Compared with the lowest income class (up to $60 \%$ of $\mathrm{MEI}$ ), children of parents with 60$100 \%$ of $\mathrm{MEI}$ visited more CAM providers (OR=1.35; $\mathrm{p}=0.15)$, and children of parents 
from the highest income class (more than 100\% of MEI) had the highest ORs for consultation with a CAM provider (OR=1.45; $\mathrm{p}=0.08)$.

\section{Expenditures on medicinal CAM and CAM providers}

Prices were traceable via PZNs for 300 (46.7\%) of the 643 reported CAM. The prices of a further 324 CAM were conservatively estimated. The remaining 19 drug entries were not considered for cost analysis as information content was too poor to estimate a price. The mean price of a homeopathic drug was $€ 10.14$ (range: $€ 3.70-€ 116.69$ ), and the average price for herbal drugs amounted to €13.72 (range: €1.99-€94.45). Looking at all medicinal CAM, the mean cost of one drug was $€ 12.56$, ranging between $€ 1.02$ and $€ 116.69$. Within a period of 4 weeks, a 'homeopathy user' utilized on average homeopathic drugs worth $€ 15.28$ (range: $€ 3.70-€ 124.54)$. The respective figures for 'herbal drug users' were $€ 16.02$ (range: €1.99-€94.45) and €18.72 (range: €1.02$€ 181.22$ ) for 'overall CAM users'. A total of 215 'CAM provider users' reported expenditures for consultation with a CAM provider during the previous 12 months. The mean expenditure was $€ 214$ (range: $€ 5-€ 1600$ ).

Comparison of the results with the results from the 10-year follow-up

Children from the 15-year follow-up (= GINI-15) of the GINIplus birth cohort used significantly less medicinal CAM than those from the 10 -year follow-up (= GINI-10). The 4-week prevalence for homeopathy use was more than halved, and herbal drug use dropped by more than a third. In sum, the prevalence of overall medicinal CAM use decreased from $22.3 \%$ (GINI-10) to $13.9 \%$ (GINI-15), whereas the prevalence of conventional drug use increased from $30.6 \%$ to $34.1 \%$.

The decline in consultations with CAM providers was lower compared with medicinal CAM use. However, the 1-year prevalence fell from $12.6 \%$ (GINI-10) to $10.8 \%$ (GINI15). Altogether, the prevalence of overall drug use (conventional + non-conventional drugs put together) did not change significantly. The prevalence rates from both followups and the mean package consumption per child with respect to the various CAM modalities are shown in Figures 2 and 3. Figure 4 visualizes the relative change in CAM utilized, comparing GINI-10 with GINI-15. The findings for predicting factors were in line with the results from the 10 -year follow-up. 


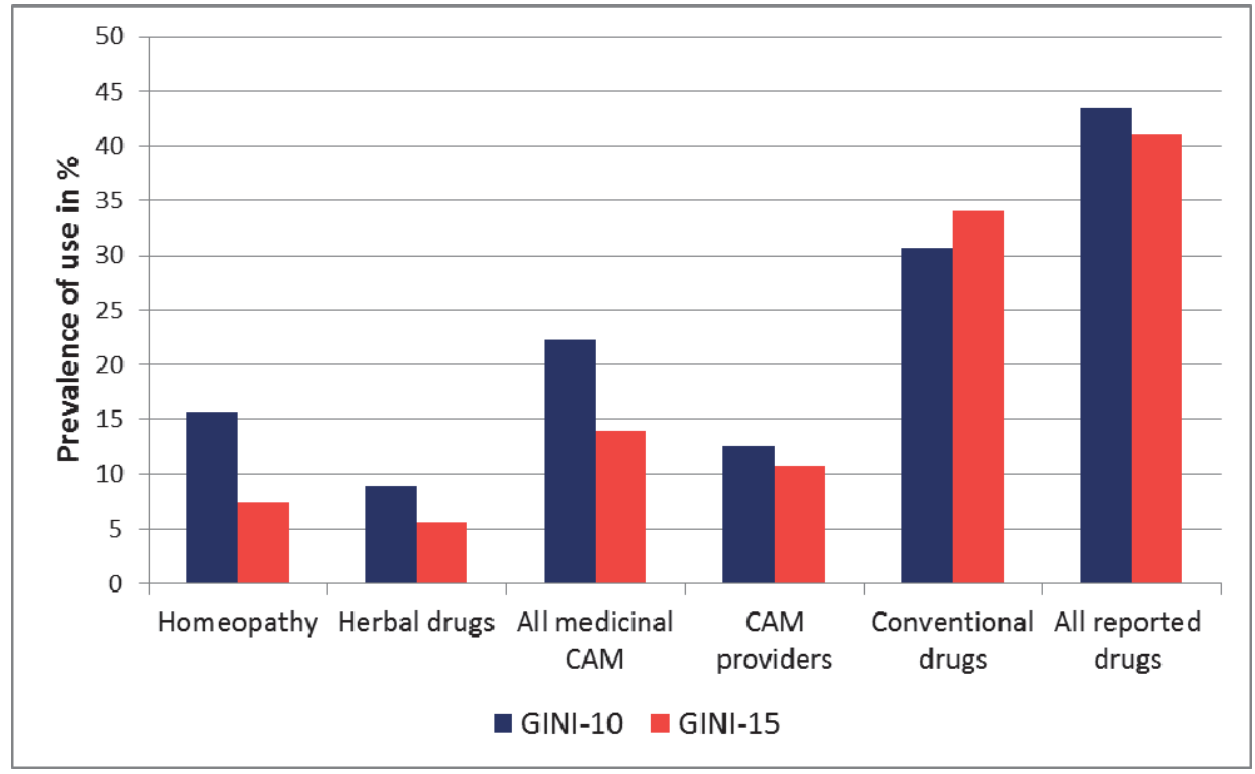

Figure 2. Comparison of prevalence rates (10-year follow-up (GINI-10) vs. 15-year follow-up (GINI-15))

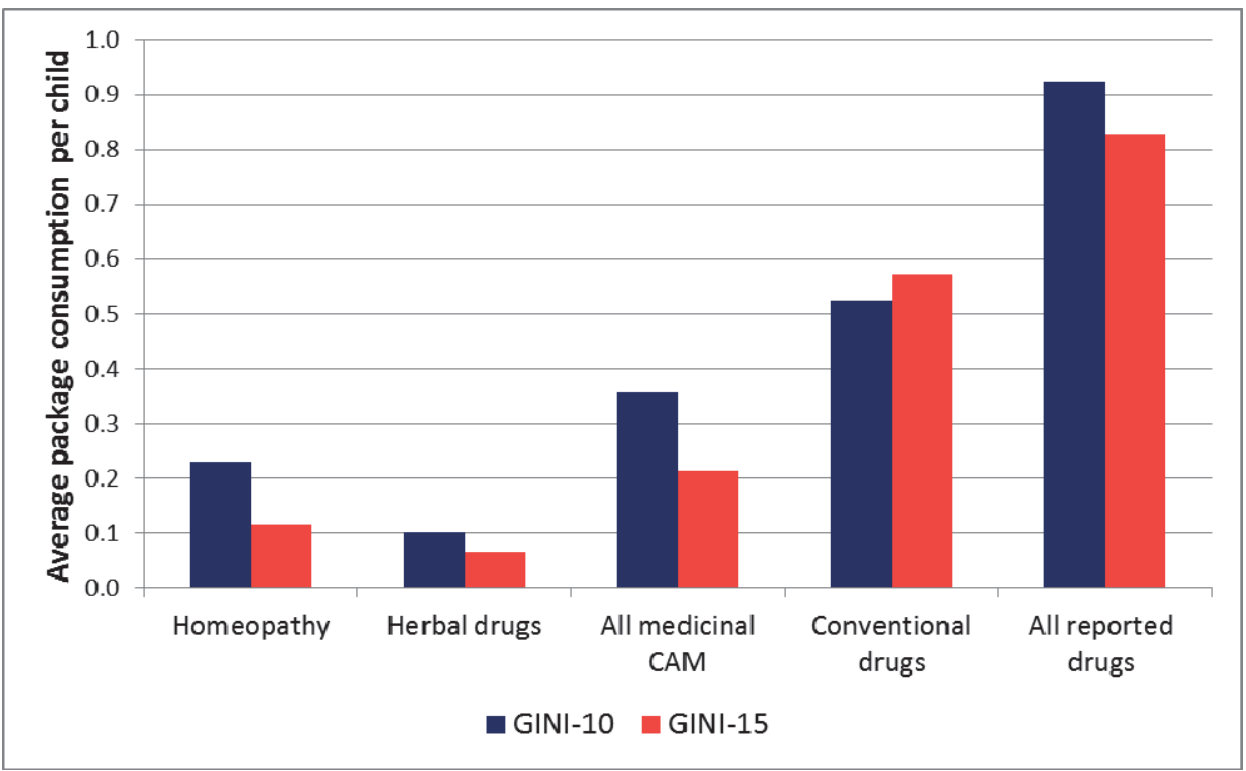

Figure 3. Average consumption of drug packages (per child in each cohort) in GINI-10 $(n=2065)$ and GINI-15 (n=3013) 


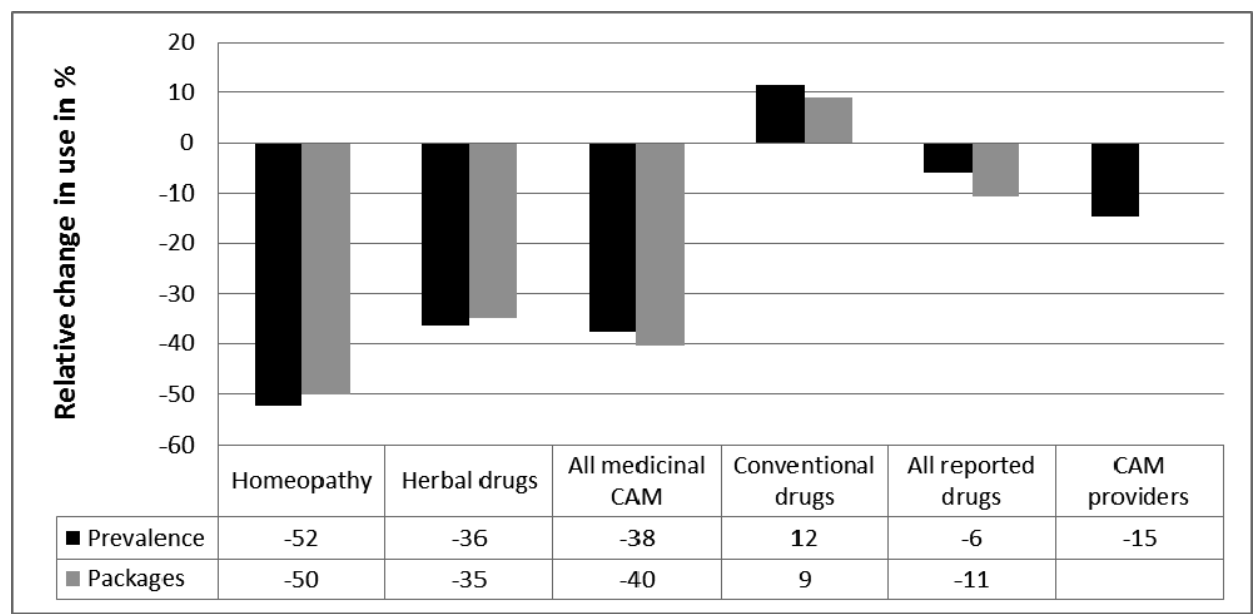

Figure 4. Relative change in pediatric CAM use (prevalence of use and average consumption of drug packages) in GINI-15 compared with GINI-10

\section{Discussion}

The present results imply that CAM use in Germany is considerable among 15-year-old children and confirm the popularity of CAM among German children found by other studies. [5,6,9,17-19]. A birth cohort study from 2007 [5] analyzing homeopathy use and consultation with a non-medical health practitioner ('Heilpraktiker') in 2-year-old children found a 1-year prevalence for homeopathy use of $27.7 \%$. Furthermore, $4.5 \%$ of the parents had consulted a 'Heilpraktiker' within the last 6 months for their child's disorder, which is well in line with our findings for GINI-15 (4.8\%, 1-year prevalence) and GINI-10 (6.2\%, 1-year prevalence). Another study reporting a lifetime prevalence of $85.5 \%$ for herbal drug use [9] also included lifetime use of herbal teas such as chamomile or fennel, presumably explaining the very high utilization compared with our findings.

A recent publication on herbal drug use (based on data collected between 2003 and 2006) in a sample of German children aged between 0 and 17 years [18] found a 7-day prevalence of 5.8\%. The same data source yielded a 7-day prevalence for homeopathy use of $4.6 \%$ [17]. Both results were close to the findings of the present study for homeopathy and herbal drug use, considering the shorter recall period ( 7 days vs. 4 weeks) which may explain the slightly lower prevalence rates compared with ours. Further results from studies conducted in children with chronic conditions may have yielded higher prevalence rates than in the respective general population and were therefore not considered for comparison with our results. 
The children's financial background seems to have only a weak impact on CAM use in Germany, but education significantly predicted the use of several CAM modalities. Children from the level with the lowest maternal education showed the lowest prevalence of herbal drug use, overall CAM use, and consultation with CAM providers, whereas there was hardly any difference between the three higher education levels. It may be assumed that CAM use is also a matter of health literacy, and children or their mothers from the lowest education stratum are less able or less motivated to inform themselves about health issues such as alternative therapy approaches. Nevertheless, this positive association of drug use with a higher maternal education level was also true for 'conventional drugs'.

Interestingly, the prevalence rates for medicinal CAM use were substantially lower than the respective figures from the 10-year follow-up in a similar German birth cohort. In contrast to our results, most of the studies reporting a significant association of CAM use with the children's age found higher prevalence rates in older children [3]. Only three studies (two were German studies) found decreasing prevalence rates with older age $[17,18,20]$. The fall in CAM use among 15-year-old children (compared with the children from GINI-10) cannot be explained by lower drug utilization in general, as the consumption of 'conventional drugs' in GINI-15 did not decrease at the same time. Another German study [21] (using data collected between 2003 and 2006) showed that the prevalence rate for drug utilization in general is not lower in 15-year-old children than in 10-year-old children (children aged between 14 and 17 years were compared with children aged between 7 and 10 years).

Owing to German health legislation from 2004, statutory health insurance covers costs for CAM only in exceptional cases for patients older than 12 years. Therefore, it can reasonably be assumed that most of the medicinal CAM utilized by the children in the present cohort was bought over the counter without medical prescription or a physician's knowledge.

In contrast to the 15-year follow-up, statutory health insurance would normally cover most of the medicinal CAM prescribed by a physician for the 10 -year-old children. De facto, $29.3 \%$ of homeopathy, $35.6 \%$ of herbal drugs, and $31.3 \%$ of overall CAM were prescribed by physicians for the 10-year-old children in GINI-10 (prescription status was assessed in GINI-10 only). A German population-based study also found a reverse association of herbal drug use with children's age [18]. The authors' hypothesis is in line with our supposition that this correlation may be due to the possibility of getting expenditure on CAM reimbursed from statutory health insurance. Children may use less CAM if it has to be paid for out of pocket, regardless of their financial background. Consultations with CAM providers were not affected by the reimbursement cuts in the 2004 health act. This may explain the moderate decline in CAM provider visits compared with the substantial fall in medicinal CAM use. 
Two longitudinal studies analyzing pediatric CAM use [22,23] found increasing or almost stable prevalence rates over time. A Norwegian publication presented a 1-year prevalence of $8.7 \%$ for visits to CAM practitioners among adolescents (17-19 years), an increase of $26 \%$ compared with the same group surveyed 4 years before. Another longitudinal study conducted in the UK found only a small variation in homeopathy use, with the same prevalence of $8.0 \%$ at the first and last follow-up (at the age of 18 months and 103 months respectively; variable underlying recall periods between 1 and 1.5 years), while the results from the other follow-ups ranged between $5.4 \%$ and $6.6 \%$. These results obtained from studies with a longitudinal design further support our hypothesis that the decrease in CAM use in GINI-15 compared with GINI-10 may result from German restrictions (for children older than 12 years) concerning reimbursement for CAM.

This study has strengths and limitations as well. The various CAM modalities were strictly classified and carefully extracted by a pharmacist. Owing to the almost even distribution of data collection over winter, spring, summer, and autumn, the seasonal impact on drug utilization was minimized. The comparably short recall period of 4 weeks presumably reduced recall bias. To our knowledge, only a very few other studies have performed a longitudinal comparison of CAM use over time for cohorts comparable in size and socioeconomic variables [22,23].

Compared with the German mean, the higher education and income levels were overrepresented in the present cohort, because of the disproportionate number of dropouts from the lower socioeconomic levels since the start of the study. Additionally, it must be considered that 15-year-old children may begin to make their own decisions concerning their (self-) medication, and CAM use may also have been influenced by the children's educational level, which was not assessed in this study. Furthermore, we were unable to rule out non-response bias, as $49.7 \%$ of the children recruited at the beginning of the study did not participate in the 15-year follow-up.

With regard to children who consulted a CAM provider, it must be considered that a homeopath may be a conventional physician who uses the term 'homeopath' as an additional title. However, a sensitivity analysis that excluded a 'homeopath' from the definition as a 'CAM provider' yielded no substantial differences with regard to the predictors of consultation with 'non-conventional' health providers. The questionnaire for the 15-year follow-up did not explicitly assess whether the reported drugs were prescribed/recommended by a physician or bought on the children's/parents' own initiative. Moreover, no information was available on the proportion of privately insured participants among all participating children (with regard to reimbursement for CAM, private health insurance companies may have fewer restrictions than statutory health insurance companies). Therefore, we cannot determine exactly how much of the decrease in CAM use (GINI-15 vs. GINI-10) can be attributed to fewer CAM prescriptions from physicians. Nevertheless, the proportion of over-the-counter drugs (such as me- 
dicinal CAM) among all prescribed drugs is estimated to be $17 \%$ [24]. The aforementioned figure may be somewhat lower in the present cohort, since the figure refers to the whole German population including children younger than 12 years. Due to potentially different definitions of CAM, the comparability of our results with other international findings may be limited with regard to the predictors and the prevalence of overall CAM use.

Prices for over-the-counter drugs are freely calculable in Germany. The present analysis of expenditures on CAM is based on rough price estimations. Owing to competition, pharmacies may offer CAM at prices lower than those listed in the official price list 'Lauer'. On the other hand, prices for drugs without available PZNs may have been underestimated by conservative assumptions. Nevertheless, we found no other German studies on pediatric CAM use tracking or estimating prices for the reported remedies utilized.

\section{Conclusions}

Health insurance contributions are mainly generated by the insured persons. Therefore, it may be appropriate that the use of these financial resources should also adequately reflect the obviously existing wish of a noticeable percentage of the German population to integrate CAM into the treatment of their disorders. People with minor ailments may (subjectively) experience a benefit from the use of harmless CAM. At the same time, patients with severe conditions should be aware that CAM is not a suitable substitute for conventional medicine.

The 2004 German health act removed nearly all over-the-counter drugs from the list of reimbursable drugs for children older than 12 years. This may have contributed to the decrease in medicinal CAM use in children from the GINI-15 cohort compared with those from GINI-10, but other reasons such as a possibly lower acceptance of CAM among adolescents (compared with younger children) may have contributed to the drop in CAM use as well. Since 2012 [25], German statutory health insurance companies have again had the possibility to reimburse the costs of over-the-counter drugs (including medicinal CAM such as homeopathy, herbal drugs, etc.). Nevertheless, still many health insurance companies do not cover expenditures on CAM or limit the coverage to a fixed yearly amount [26]. For health insurers, it might be valuable information if reimbursement of CAM influences the decision of insured persons to choose a specific health insurance company.

Future studies assessing exactly how many medicinal CAM are prescribed by physicians may support policy makers and health care managers in their further decisionmaking process concerning the inclusion of CAM in the list of reimbursable therapy approaches. 


\section{Competing interests}

The authors declare that they have no competing interests.

\section{Authors' contributions}

SI prepared the data with regard to categorization of the reported drugs and tracked or conservatively estimated the drugs' prices based on the official 'Lauer' price list. Furthermore, he performed the statistical analysis and interpreted the results. He conceptualized the initial manuscript, and approved the final manuscript as submitted.

SW and HB contributed to the data analysis and interpretation of the results. They critically revised the initial manuscript, and approved the final manuscript as submitted. $\mathrm{JH}, \mathrm{DB}$, and $\mathrm{AB}$ were involved in data collection. They critically revised the initial manuscript, and approved the final manuscript as submitted.

\section{Acknowledgments}

We thank the families for participation in the study, the obstetric units for allowing recruitment, the GINIplus study team for excellent work, and several funding agencies listed herein.

The 15-year follow-up examination of the GINIplus study was partially supported by the Commission of the European Communities, the $7^{\text {th }}$ Framework Programme, MeDALL project as well as by the companies Mead Johnson and Nestlé. This work was also supported by the German Competence Network Obesity ('Kompetenznetz Adipositas') funded by the German Federal Ministry of Education and Research (BMBF) as part of the 'Core Domain Health Economics' (Grant No. 01GI1127). This specific analysis on 'Utilization of Complementary and Alternative Medicine' was exclusively funded by the Helmholtz Zentrum Munich.

GINIplus study group

The GINIplus Study Team: Institute of Epidemiology I, Helmholtz Zentrum München, German Research Center for Environmental Health, Neuherberg (J. Heinrich, I. Brüske, H. Schulz, C. Flexeder, C. Zeller, M. Standl, M. Schnappinger, M. Sußmann, E. Thiering, C. Tiesler); Department of Pediatrics, Marien-Hospital, Wesel (D. Berdel, A. von Berg); Ludwig-Maximilians-University of Munich, $\mathrm{Dr}$ von Hauner Children's Hospital (S. Koletzko); Child and Adolescent Medicine, University Hospital rechts der Isar of the Technical University Munich (C.P. Bauer, U. Hoffmann); IUF - Environmental Health Research Institute, Düsseldorf (B. Hoffmann, E. Link, C. Klümper). 


\section{References}

1. Eardley S, Bishop FL, Prescott P, Cardini F, Brinkhaus B, Santos-Rey K, Vas J, von Ammon K, Hegyi G, Dragan S, Uehleke B, Fønnebø V, Lewith $\mathrm{G}$. A systematic literature review of complementary and alternative medicine prevalence in EU. Forsch Komplementmed. 2012;19 Suppl 2:18-28.

2. Frass M, Strassl RP, Friehs H, Müllner M, Kundi M, Kaye AD. Use and acceptance of complementary and alternative medicine among the general population and medical personnel: a systematic review. Ochsner J. 2012;12:45-56.

3. Italia S, Wolfenstetter SB, Teuner CM. Patterns of complementary and alternative medicine (CAM) use in children: a systematic review. Eur J Pediatr. 2014;173:1413-1428.

4. Zuzak TJ, Boňková J, Careddu D, Garami M, Hadjipanayis A, Jazbec J, Merrick J, Miller J, Ozturk C, Persson IA, Petrova G, Saz Peiró P, Schraub S, Simões-Wüst AP, Steinsbekk A, Stockert K, Stoimenova A, Styczynski J, Tzenova-Savova A, Ventegodt S, Vlieger AM, Längler A. Use of complementary and alternative medicine by children in Europe: published data and expert perspectives. Complement Ther Med. 2013;21 Suppl 1:34-47.

5. Zutavern A, Schaaf B, von Berg A, Borte M, Herbarth O, Wichmann H, Heinrich J. Use of homeopathy and consultation with alternative medicine practitioners: Results of a German birth cohort study (LISA) at the age of 2 years. Monatsschrift Kinderheilkunde. 2007;155:439-445.

6. Italia S, Batscheider A, Heinrich J, Wenig C, Bauer CP, Koletzko S, Lehmann I, Herbarth O, von Berg A, Berdel D, Hoffmann B, Schaaf B, Wolfenstetter SB. Utilization and costs of conventional and alternative pharmaceuticals in children: results from the German GINIplus and LISAplus birth cohort studies. Pharmacoepidemiol Drug Saf. 2012;21:1102-1111.

7. Vlieger AM, van de Putte EM, Hoeksma $\mathrm{H}$. The use of complementary and alternative medicine in children at a general paediatric clinic and parental reasons for use. Ned Tijdschr Geneeskd. 2006;150:625630.

8. Robinson N, Blair M, Lorenc A, Gully N, Fox P, Mitchell K. Complementary medicine use in multi-ethnic paediatric outpatients. Complement Ther Clin Pract. 2008;14:17-24.

9. Hümer M, Scheller G, Kapellen T, Gebauer C, Schmidt H, Kiess W. Use of herbal medicine in German children - prevalence, indications and motivation. Dtsch Med Wochenschr. 2010;135:959-964.

10. Araz N, Bulbul S. Use of complementary and alternative medicine in a pediatric population in southern Turkey. Clin Invest Med. 2011;34:21-29.

11. Helmholtz Zentrum München [www.helmholtz-muenchen.de/en/epi1/research/research-units /research-unit-1-environmental-epidemiology/projects/giniplus/index.html]

12. Kurth BM, Kamtsiuris $P$, Hölling $H$, Schlaud $M$, Dölle R, Ellert $U$, Kahl H, Knopf H, Lange M, Mensink GBM, Neuhauser H, Schaffrath Rosario A, Scheidt-Nave C, Schenk L, Schlack R, Stolzenberg H, Thamm M, Thierfelder $\mathrm{W}$, Wolf $\mathrm{U}$. The challenge of comprehensively mapping children's health in a nation-wide health survey: Design of the German KiGGS-Study. BMC Public Health. 2008;8:196.

13. Bundesministerium für Gesundheit, editor. Homöopathisches Arzneibuch 2010 (HAB) Amtliche Ausgabe. Stuttgart: Deutscher Apotheker Verlag; 2010.

14. Statistisches Landesamt Baden-Württemberg [www.statistik.baden-wuerttemberg.de/VolkswPreise/ Haushalte/EU-SILC/MedAequivalenzEU.asp]

15. OECD Equivalence Scales [www.oecd.org/eco/growth/OECD-Note-EquivalenceScales.pdf]

16. European Centre for Social Welfare Policy and Research [www.euro.centre.org/data/ 1295444473_73292.pdf]

17. Du Y, Knopf H. Paediatric homeopathy in Germany: results of the German Health Interview and Examination Survey for Children and Adolescents (KiGGS). Pharmacoepidemiol Drug Saf. 2009;18:370-379.

18. Du Y, Wolf IK, Zhuang W, Bodemann S, Knöss W, Knopf H. Use of herbal medicinal products among children and adolescents in Germany. BMC Complement Altern Med. 2014;14:218. 
19. Weissenstein A, Straeter A, Villalon G, Luchter E, Bittmann S. High frequency of CAM use among children in Germany. J Altern Complement Med. 2012;18:729-730.

20. Low E, Murray DM, O'Mahony O, O'B Hourihane J. Complementary and alternative medicine use in Irish paediatric patients. Ir J Med Sci. 2008;177:147-150.

21. Knopf H. Medicine use in children and adolescents. Data collection and first results of the German Health Interview and Examination Survey for Children and Adolescents (KIGGS). Bundesgesundheitsblatt Gesundheitsforschung Gesundheitsschutz. 2007;50(5-6):863-870.

22. Steinsbekk A, Rise MB, Bishop F Lewith G. Predictors for adolescent visits to practitioners of complementary and alternative medicine in a total population (the Young-HUNT Studies). PLoS One. 2011;6(10):e25719.

23. Thompson EA, Bishop JL, Northstone K. The use of homeopathic products in childhood: data generated over 8.5 years from the Avon Longitudinal Study of Parents and Children (ALSPAC). J Altern Complement Med. 2010;16:69-79.

24. Bundesverband der Arzneimittel-Hersteller e.V. Der Arzneimittelmarkt in Deutschland in Zahlen (2013) [https://www.bah-bonn.de/index.php?elD=dumpFile\& $t=f \& f=4089 \&$ token $=$ 3ec3eb2533e1c4c5ab6a42e783f0651d200c7e08]

25. Bundesministerium für Gesundheit [www.bmg.bund.de/glossarbegriffe/v-y/gkvversorgungsstrukturgesetz.html]

26. Bundesverband der pharmazeutischen Industrie [www.bpi.de/home/nachrichten/bpi-ratgeber/ansicht/ zahlen-sie-noch-selbst-immer-mehr-krankenkassen-erstatten-otc-arzneimittel] 
Education is the most powerful weapon which you can use to change the world.

Nelson Mandela

South African anti-apartheid revolutionary and politician 


\section{CHAPTER 5}

Utilization of self-medication and prescription drugs among 15-year-old children from the German GINIplus birth cohort

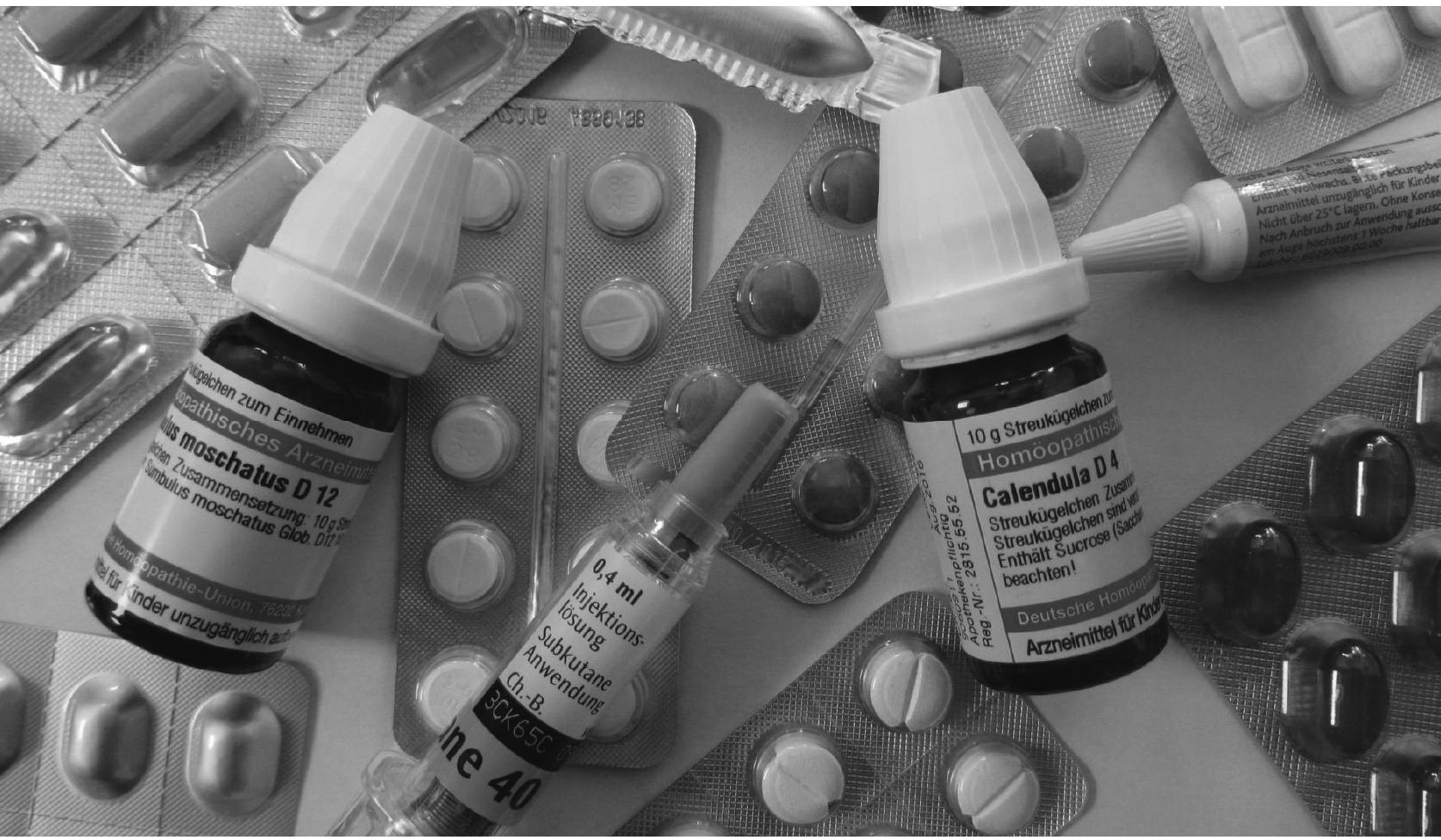

Salvatore Italia, Helmut Brand, Joachim Heinrich, Dietrich Berdel, Andrea von Berg, Silke B. Wolfenstetter.

Utilization of self-medication and prescription drugs among 15-year-old children from the German GINIplus birth cohort.

Pharmacoepidemiol Drug Saf 2015;24:1133-1143. doi:10.1002/pds.3829

The final publication is available at wileyonlinelibrary (Copyright (C) 2015 John Wiley \& Sons, Ltd) 


\begin{abstract}
Purpose: The objective was to analyse paediatric drug utilization in relation to selfmedication, prescription drugs, and the most reported therapeutic drug categories.

Methods: Data were collected for 3,013 children on their utilization of drugs (4-week prevalence) from a German birth cohort study (GINIplus, 15-year follow-up) using a self-administered questionnaire. The drugs were grouped into over-the-counter drugs and prescription drugs, and were classified according to the anatomical therapeutic chemical classification system. Predictors were analysed using a logistic regression model with four independent variables (gender, study area, maternal education, and parental income).
\end{abstract}

Results: Some $69 \%$ of the reported 2,489 drugs were over-the-counter drugs, and $31 \%$ were prescription drugs. The 4-week prevalence for using any type of drug was $41.0 \%$. Drug categories with high prevalence rates of use were antiinflammatory drugs $(10.3 \%)$, analgesics (7.1\%), and antiallergics (5.0\%).

Factors associated with higher use of over-the-counter drugs were female gender $(O R=1.56, p<0.0001)$ and higher maternal education $(O R=1.60, p=0.0021$; university degree vs. secondary high school). Maternal education was correlated with the use of prescribed or self-medicated antiallergics (positive association) and contraceptives (negative association). The use of antibiotics, methylphenidate, and drugs for thyroid therapy was associated with lower parental income.

Conclusion: The use of over-the-counter drugs in 15-year-old children from the GINIplus birth cohort is very common and is predicted by socioeconomic factors such as maternal education. This has to be considered by health care managers when deciding about the exclusion of over-the-counter drugs (normally used for self-medication) from reimbursement or the deregulation of drug sales.

\title{
Key words
}

Germany · Adolescent · Drug utilization - Self-medication · Prescription drugs ·

Socioeconomic factors · Pharmacoepidemiology 


\section{Introduction}

Drug use among adolescent children may be influenced by various factors. Normally, their physicians decide on those drugs available on prescription only, whereas selfmedication may depend not just on parental decisions but also on the children's own attitude as, e.g. 15-year-old children may begin to purchase drugs on their own initiative. By law, 15-year-old adolescents are still underage children, but with respect to the reimbursement of over-the-counter drugs (OTC), German Health Legislation practically treats them as adults, as OTC drugs are usually reimbursed for children up to the age of 12 years only [1]. With regard to the safe use of drugs, many aspects have to be considered, such as side-effects, pharmacological interactions, but also undersupply or oversupply of drugs in different population strata. To our knowledge, the data on the prevalence and socioeconomic predictors of paediatric drug utilization in Germany are comparatively rare, especially with regard to self-medication. A study that investigated drug utilization among German children aged 14-17 years [2] reported a 1-week prevalence of $50.7 \%$ (prescription drugs and self-medication drugs together). Another publication based on the same data source found that $25.2 \%$ of children aged $\leq 17$ years had used self-medication drugs during the past 7 days, and self-medication accounted for $38.5 \%$ of the total medicine use [3]. Two further studies looking at both prescription drugs and self-medication reported a 4-month prevalence of 70\% among children aged 5-7 years [4] and a 4-week prevalence of $42.3 \%$ among 10-year-old children [5]. Age-stratified data on prescription drug use is also provided by health insurance companies $[6,7]$. According to the available studies, the paediatric use of drugs may be very common in Germany. Surveillance of the prevalence of drug utilization among adolescent children and the determinants of use are relevant Public Health issues, particularly in relation to those drugs taken by children without their physicians' knowledge.

The aim of this paper is to analyse drug utilization among adolescents from the German Infant study on the Influence of Nutrition Intervention plus environmental and genetic influences on allergy development (GINIplus), based on data from the recently completed 15-year follow-up. A further objective of this study is the comparison of prescription drugs with OTC drugs, predominantly used for self-medication, and analysis of the utilization patterns of the most mentioned drug categories addressing both prescription and self-medication drugs. 


\section{Methods}

\section{Study population and data collection}

The GINIplus study is based on a German birth cohort $[5,8,9]$ that started with 5,991 healthy full-term newborns. The children were recruited between September 1995 and June 1998 from obstetric clinics in an urban region of Southern Germany (Munich) and a comparatively rural region in Western Germany (Wesel).

For the 15-year follow-up, exactly 3,895 participants were contacted between January 2011 and September 2013. The assessment was distributed almost evenly over the seasons. Among other things, the main questionnaire assessed the children's gender, parental income and education, and consultation with physicians from various medical specialities during the last year.

In addition to the main questionnaire, a self-administered questionnaire on consumption of drugs and medicinal products was included based on a slightly modified questionnaire that had already been used for the 10-year follow-up [5]. The children's parents/legal guardians were asked to report all drugs' names their child used in the previous 4 weeks or to enclose the empty drug packages with a self-addressed envelope. The precise number of drugs used was assessed with an additional question in case the limited number (five) of designated spaces would not suffice to enter all drug names. In addition, the participants were also invited to report the pharmaceutical identification number (PZN) of the drugs used. The PZN is printed on the drug package and precisely identifies the drug utilized with regard to the size of the package, the dosage, etc.

Those drugs available on prescription only were defined as prescription drugs ( $R x)$. All medicinal products available without medical prescription (which may be sold by a pharmacist and also those that may be sold in any shop) were defined as OTC drugs. Allocation of the drugs subdivided into prescription drugs and OTC drugs was performed according to the German Ordinance on Prescription-Only Medicinal Products [10]. If available, the respective codes from the anatomical therapeutic chemical classification (ATC) were assigned to the drugs [11,12].

\section{Outcome definition and statistical analysis}

The participants who reported utilization of at least one prescription drug during the past 4 weeks were defined as 'Rx users' and those taking at least one OTC drug as 'OTC users', respectively. 'Overall users' took at least one drug of any type. Based on the ATC classification, the most mentioned drugs were grouped, and the following therapeutic 
categories were defined for the analysis of those children using at least one drug from the defined categories:

Antiinflammatory drugs:

Analgesics:

Contraceptives:

Drugs for obstructive airway diseases

('antiasthmatics'):

Antiallergics

(systemic, nasal, or ophthalmic use):

Methylphenidate:

Antibiotics:

Thyroid therapy:
ATC M01

ATC NO2

ATC G03A, G03HB01, G02BBO1

ATC RO3

ATC R06, R01AC, R01AD, S01GX

ATC N06BA04

ATC J01

ATC HO3

The statistical analysis was performed using the SAS software package (SAS Institute Inc., Cary, NC, USA, version 9.3). Interaction between the independent variables (gender, study area, maternal education, and parental income) was checked using Pearson correlation coefficients. Bivariate associations were tested with Pearson $\mathrm{Chi}^{2}$ test. Odds ratios (ORs) and their $95 \%$ confidence intervals $(\mathrm{Cl})$ were obtained from a multivariate logistic regression model (significance level: $p<0.05$ ). Mothers rather than fathers may decide on the (self-) medication of their children. Hence, for the definition of educational status, the mothers' educational background was classified into four levels based on their highest school degree:

Level 1: secondary school

Level 2: junior high school

Level 3: baccalaureate (= qualification for university entrance)

Level 4: university degree

Mothers who did not report any school degree at all $(n=5)$ were allocated to education level 1. Entries for mothers $(n=4)$ reporting another (but not further specified) kind of school degree than those listed above were treated as missing values for educational status. Income status was classified following the median equivalent income (MEI) for 2012 ( $€ 1,633$ net/month) [13] where the household members were weighted according to the new scale of the Organisation for Economic Co-operation and Development (OECD) [14]. The income cut-offs were chosen in accordance with the definition of poverty (60\% of MEI) [15].

The GINIplus cohort received approval from the ethics committee of the Bavarian Medical Council and the Medical Council of North Rhine-Westphalia. Additionally, writ- 
ten informed consent was provided by the participants' parents or legal guardians and by participants.

\section{Results}

Study population and prevalence of drug use

From the 3,895 distributed questionnaires, precisely 3,013 were completed and returned (response rate: $77.4 \%$ ). The children's average age was 15.1 years (range: $14.5-$ 16.8 years). The questionnaires were completed mainly by the mothers (85.5\%). In all, $41.0 \%(n=1,234)$ of the children used at least one drug within the defined recall period of 4 weeks. The number of reported drugs amounted to 2,489 . The majority $(44.3 \%)$ of the 1,234 drug users took one medicinal product only. Nevertheless, $29.7 \%$ used two drugs, $13.5 \%$ took three drugs, and $12.5 \%$ took four or more drugs (up to nine drugs in one case) within a period of 4 weeks. About $28 \%$ of the reported drugs were available on prescription only, whereas $69 \%$ of the drugs utilized were OTC drugs (Figure 1 ). Exactly 74 drugs (3\%) were narcotics available by specific narcotic prescription forms only (one with ATC N02AA01 containing morphine, and 73 with ATC N06BA04 containing methylphenidate for the treatment of attention deficit (and hyperactivity) disorder).

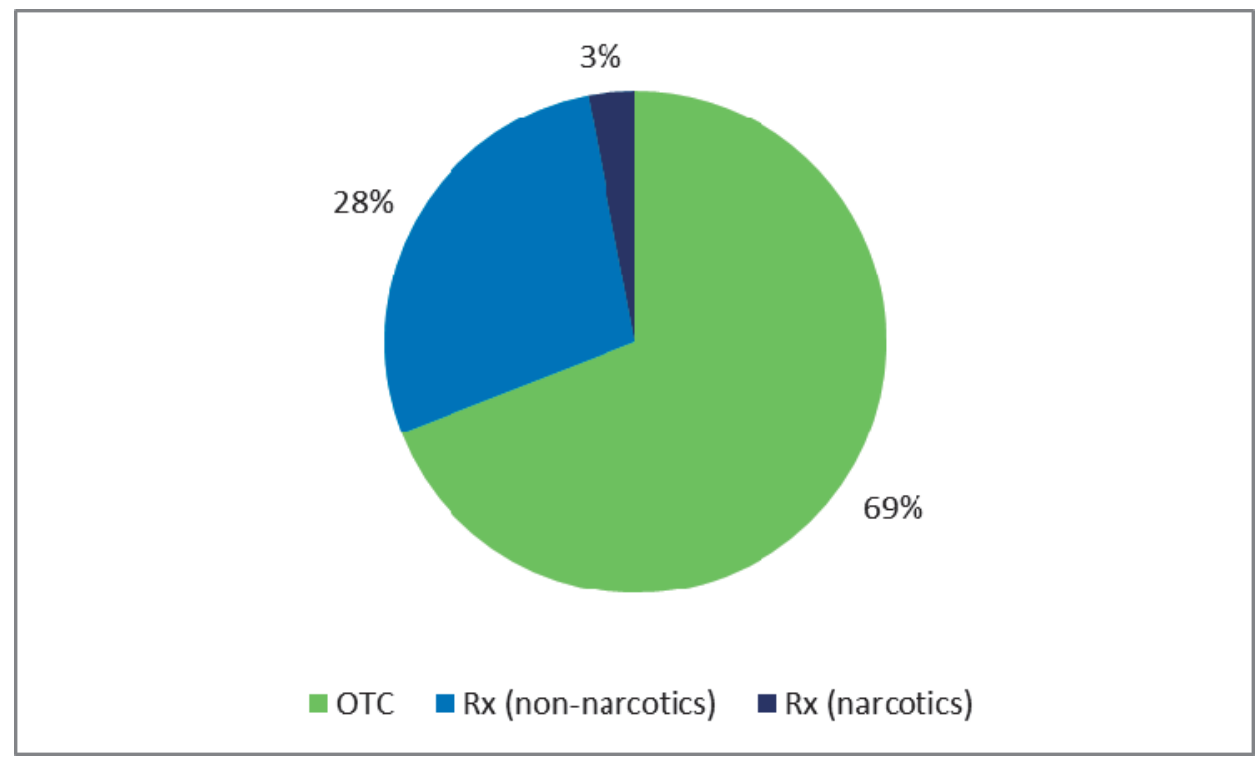

Figure 1. Proportion of over-the-counter drugs (OTC) and prescription drugs (Rx) in all drugs utilized (data available for $n=2,446$ drugs) 
The 4-week prevalence $(95 \% \mathrm{Cl})$ of prescription drug use ( $\mathrm{n}=514 \mathrm{Rx}$ users) was $17.1 \%$ (15.7-18.4), and $31.6 \%(30.0-33.3)$ of the children ( $n=952)$ used OTC drugs. The detailed composition of the cohort and the stratified prevalence rates of drug utilization are displayed in Table 1, which also includes the children's consultation with a physician of any medical speciality within the last year.

Table 1. Characteristics of the GINIplus cohort and prevalence of use

\begin{tabular}{|c|c|c|c|c|c|c|c|c|c|}
\hline & \multicolumn{9}{|c|}{ Prevalence of use in $\%$ and $p$-values* } \\
\hline & $\mathrm{n}$ & \multicolumn{2}{|c|}{ Overall drug use $\mathrm{e}^{1}$} & \multicolumn{2}{|c|}{ Rx drugs $^{1}$} & \multicolumn{2}{|c|}{ OTC drugs ${ }^{1}$} & \multicolumn{2}{|c|}{ Physician $^{2}$} \\
\hline \multicolumn{2}{|l|}{ Gender } & & & & & & & & \\
\hline Male & 1,500 & 36.3 & \multirow{2}{*}{$<0.0001$} & 14.7 & \multirow{2}{*}{0.0005} & 26.8 & \multirow{2}{*}{$<0.0001$} & 79.3 & \multirow{2}{*}{0.0038} \\
\hline Female & 1,513 & 45.6 & & 19.4 & & 36.4 & & 83.4 & \\
\hline \multicolumn{10}{|l|}{ Study area } \\
\hline Munich & 1,457 & 43.0 & \multirow{2}{*}{0.0248} & 17.4 & \multirow{2}{*}{0.6667} & 34.4 & \multirow{2}{*}{0.0014} & 85.1 & \multirow{2}{*}{$<0.0001$} \\
\hline Wesel & 1,556 & 39.0 & & 16.8 & & 29.0 & & 77.9 & \\
\hline \multicolumn{10}{|l|}{ Maternal education } \\
\hline Secondary school & 380 & 31.1 & \multirow{4}{*}{0.0005} & 15.0 & & 22.4 & & 77.5 & \\
\hline Junior high school & 1,251 & 42.0 & & 18.6 & \multirow{3}{*}{0.1180} & 31.7 & \multirow{3}{*}{0.0003} & 81.0 & \multirow{3}{*}{0.1279} \\
\hline Baccalaureate & 580 & 42.2 & & 14.5 & & 33.8 & & 82.0 & \\
\hline University degree & 795 & 43.0 & & 17.4 & & 34.2 & & 83.1 & \\
\hline \multicolumn{10}{|l|}{ Household income } \\
\hline$\leq 60 \%$ of $\mathrm{MEI}$ & 529 & 39.3 & \multirow{3}{*}{0.4132} & 18.9 & \multirow{3}{*}{0.5593} & 27.8 & \multirow{3}{*}{0.0390} & 81.4 & \multirow{3}{*}{0.7385} \\
\hline $60-100 \%$ of $\mathrm{MEI}$ & 985 & 42.7 & & 18.0 & & 32.5 & & 81.3 & \\
\hline$>100 \%$ of $\mathrm{MEI}$ & 1,071 & 42.2 & & 16.8 & & 34.1 & & 82.5 & \\
\hline Total & 3,013 & 41.0 & & 17.1 & & 31.6 & & 81.3 & \\
\hline
\end{tabular}

Owing to missing values, the strata may not add up to the total number of participants

MEI, median equivalent income

OTC, over-the-counter drugs

$R x$, prescription drugs

*Derived from Pearson $\mathrm{Chi}^{2}$ test

${ }^{1}$ Use within the last 4 weeks

${ }^{2}$ Consultation with a physician of any medical speciality in the last 12 months (data available for 3,005 children only)

The most mentioned drug categories belonged to the ATC groups named M01 (antiinflammatory drugs), R05 (cough and cold preparations), N02 (analgesics), and R01 (nasal preparations). All four aforementioned ATC groups were dominated by OTC drugs (Figure 2). 


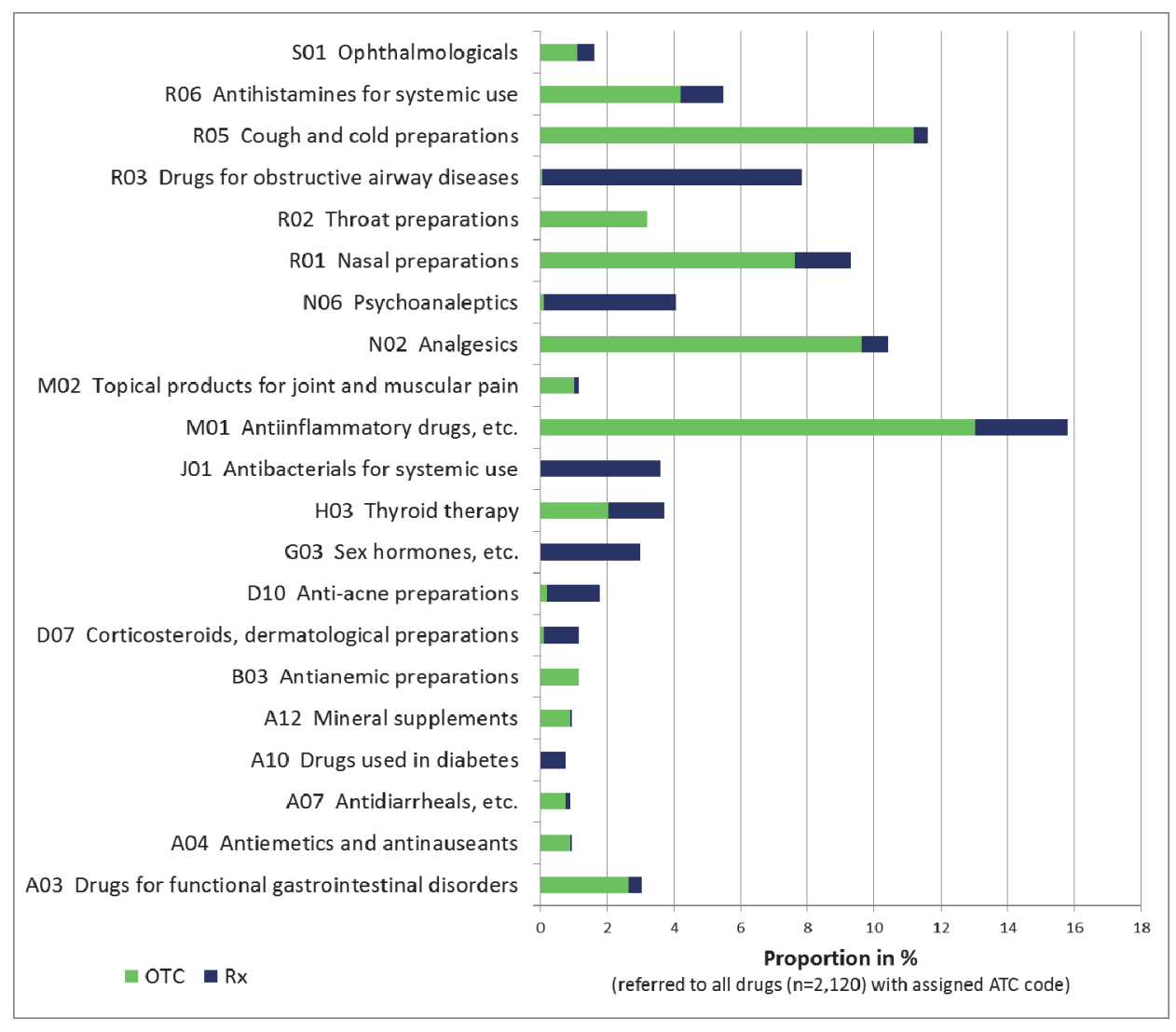

Figure 2. Distribution by ATC group (allocation to ATC groups for $n=2,120$ possible; only ATC groups with $n \geq 15$ drugs considered, reflecting $78 \%$ of all reported drugs)

The most used active pharmaceutical ingredients were ibuprofen $(n=284)$, paracetamol $(n=142)$, methylphenidate $(n=73)$, cetirizine $(n=66)$, and acetylcysteine $(n=64)$. The 25 most frequent ATC codes accounted for about $50 \%$ of all drugs utilized. Within an observation period of 4 weeks, $10.3 \%$ of the children used an antiinflammatory drug, $7.1 \%$ an analgesic, 5.0\% an antiallergic (systemic, nasal, or ophthalmic use), and $3.7 \%$ an antiasthmatic drug (Table 2). Remedies for cough and cold (ATC R05), another widely used drug category, were taken by $6.4 \%$ of the children. 


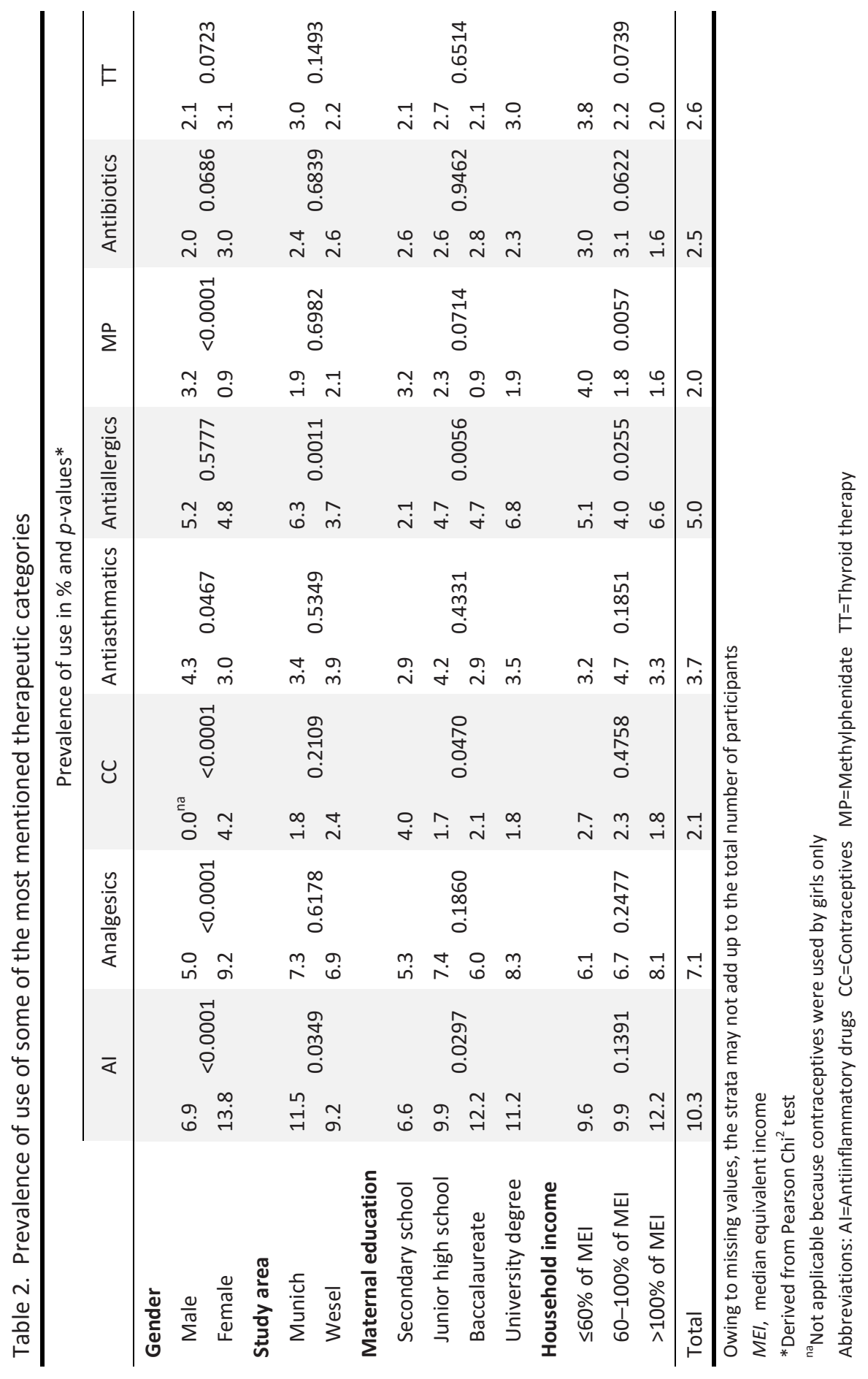




\section{Predictors of drug use}

The results show a clear association of female gender with higher use of OTC drugs $(O R=1.56)$ and prescription drugs $(O R=1.42)$ as well. If contraceptives were excluded from the analysis, female gender no longer predicted the use of prescription drugs $(\mathrm{OR}=1.12 ; \mathrm{p}=0.2565)$. Maternal education level had a significant impact on OTC drug use only. Children with mothers from the lowest education level used fewer OTC drugs than those whose mothers had a university degree $(O R=1.60)$ or a baccalaureate $(O R=1.66)$. According to the logistic regression model, there is no significant difference between OTC users and Rx users with regard to income status (Table 3 ).

Table 3. Predictors of drug use and consultation with a physician

\begin{tabular}{|c|c|c|c|c|c|c|c|c|}
\hline & \multicolumn{8}{|c|}{ Adjusted odds ratio of utilization (and $95 \%$ confidence interval) } \\
\hline & \multicolumn{2}{|c|}{ Overall drug use ${ }^{1}$} & \multicolumn{2}{|c|}{ Rx drugs $^{1}$} & \multicolumn{2}{|c|}{ OTC drugs ${ }^{1}$} & \multicolumn{2}{|c|}{ Physician $^{2}$} \\
\hline \multicolumn{9}{|l|}{ Gender } \\
\hline Male & \multicolumn{2}{|c|}{ Reference } & \multicolumn{2}{|c|}{ Reference } & \multicolumn{2}{|c|}{ Reference } & \multicolumn{2}{|c|}{ Reference } \\
\hline Female & $1.47^{* *}$ & $(1.27-1.71)$ & $1.42 *$ & $(1.17-1.72)$ & $1.56 * *$ & $(1.33-1.82)$ & $1.31 *$ & $(1.09-1.58)$ \\
\hline \multicolumn{9}{|l|}{ Study area } \\
\hline Munich & \multicolumn{2}{|c|}{ Reference } & \multicolumn{2}{|c|}{ Reference } & \multicolumn{2}{|c|}{ Reference } & \multicolumn{2}{|c|}{ Reference } \\
\hline Wesel & 0.86 & $(0.73-1.01)$ & 0.93 & $(0.75-1.15)$ & 0.82 & $(0.69-0.97)$ & $0.59 * *$ & $(0.48-0.73)$ \\
\hline \multicolumn{9}{|l|}{ Maternal education } \\
\hline Secondary school & \multicolumn{2}{|c|}{ Reference } & \multicolumn{2}{|c|}{ Reference } & \multicolumn{2}{|c|}{ Reference } & \multicolumn{2}{|c|}{ Reference } \\
\hline Junior high school & $1.61 *$ & $(1.26-2.06)$ & 1.31 & $(0.95-1.81)$ & $1.59 *$ & (1.21-2.09) & 1.29 & $(0.97-1.71)$ \\
\hline Baccalaureate & $1.58^{*}$ & (1.19-2.09) & 0.97 & $(0.67-1.41)$ & $1.66^{*}$ & $(1.22-2.25)$ & 1.31 & $(0.94-1.82)$ \\
\hline University degree & $1.60 *$ & $(1.21-2.12)$ & 1.22 & $(0.85-1.75)$ & $1.60 *$ & (1.19-2.17) & 1.25 & $(0.89-1.74)$ \\
\hline \multicolumn{9}{|l|}{ Household income } \\
\hline$\leq 60 \%$ of $\mathrm{MEI}$ & \multicolumn{2}{|c|}{ Reference } & \multicolumn{2}{|c|}{ Reference } & \multicolumn{2}{|c|}{ Reference } & \multicolumn{2}{|c|}{ Reference } \\
\hline $60-100 \%$ of $\mathrm{MEI}$ & 1.05 & $(0.84-1.31)$ & 0.92 & $(0.70-1.22)$ & 1.12 & $(0.88-1.43)$ & 0.88 & $(0.67-1.16)$ \\
\hline$>100 \%$ of $\mathrm{MEI}$ & 0.95 & $(0.75-1.20)$ & 0.83 & $(0.61-1.12)$ & 1.10 & $(0.85-1.42)$ & 0.80 & $(0.59-1.08)$ \\
\hline \multicolumn{9}{|c|}{ Bold numbers $=$ significant at $p<0.05 * p<0.01 \quad * * p<0.0001$} \\
\hline \multicolumn{9}{|c|}{ MEI, median equivalent income } \\
\hline \multicolumn{9}{|c|}{ OTC, over-the-counter drugs } \\
\hline \multicolumn{9}{|c|}{$R x$, prescription drugs } \\
\hline \multicolumn{9}{|c|}{${ }^{1}$ Use within the last 4 weeks } \\
\hline $\begin{array}{l}{ }^{2} \text { Consultation with a } \\
\text { children only) }\end{array}$ & hysician & of any medica & I speci & ty in the last & 12 mont & s (data avai & & 005 \\
\hline
\end{tabular}


When looking at the various defined therapeutic categories (Table 4), girls used significantly more antiinflammatory drugs $(O R=2.16)$ and analgesics $(1.93)$, whereas they took far fewer preparations containing methylphenidate ( $O R=0.27)$.

Maternal education background had a strong positive influence on the use of antiallergics (e.g. university degree vs. secondary school: $\mathrm{OR}=2.81$ ) and a clearly negative impact on the use of contraceptives (e.g. junior high school vs. secondary school: $\mathrm{OR}=0.40$ ).

A higher parental income ( $>100 \%$ of $\mathrm{MEI}$ vs. $\leq 60 \%$ of $\mathrm{MEI}$ ) was inversely associated with the use of methylphenidate $(O R=0.41)$, antibiotics $(O R=0.46)$, and drugs for thyroid therapy $(\mathrm{OR}=0.34)$. The four variables included in the logistic regression model did not predict the use of antiasthmatics (ATC R03), cough and cold preparations (ATC RO5), mucolytics (ATC R05CB01 and R05CBO6), and nasal preparations containing sympathomimetics only (ATC R01AA), four further therapeutic (sub)groups that were among the most mentioned therapeutic groups.

\section{Discussion}

The findings of this study indicate that the 4-week prevalence of drug use, both $\mathrm{Rx}$ (17.1\%) and OTC drug use (31.6\%), among 15-year-old children from the present cohort is quite high. The majority (69\%) of the drugs utilized were OTC drugs, many of them presumably bought out-of-pocket without medical prescription. Moreover, the results imply that gender, study area, and socioeconomic variables such as maternal education and parental income significantly predict the use of OTC drugs or the utilization of specific therapeutic categories. Compared with the prevalence rates of the 10-year followup, 10-year-old children used more OTC (35.6\%) and fewer Rx (15.3\%) drugs [5], which may be explained by the fact that, owing to the 2004 German health act OTC drugs are not normally reimbursed by statutory health insurance for children older than 12 years.

Another German study [2] reported a 7-day prevalence for overall drug use (Rx and OTC drugs together, age stratum 14-17 years) of 50.7\%, which was even higher than in our study $(41.0 \%)$, and $58 \%$ of the drugs utilized were prescribed by a physician. The same data source yielded a 1-week prevalence of OTC drug use of $25.2 \%$ for all children aged $\leq 17$ years (and slightly higher for children between 14-17 years), which is roughly in line with our results considering the shorter recall period [3]. A smaller study with German adolescents (15-17 years) found a 2-week prevalence of 57\% for drug use [16]. The regional differences in consultation with physicians may partly be explained by the higher physician density in Munich because an increased supply with services/products may generally result in an increased demand [17]. 


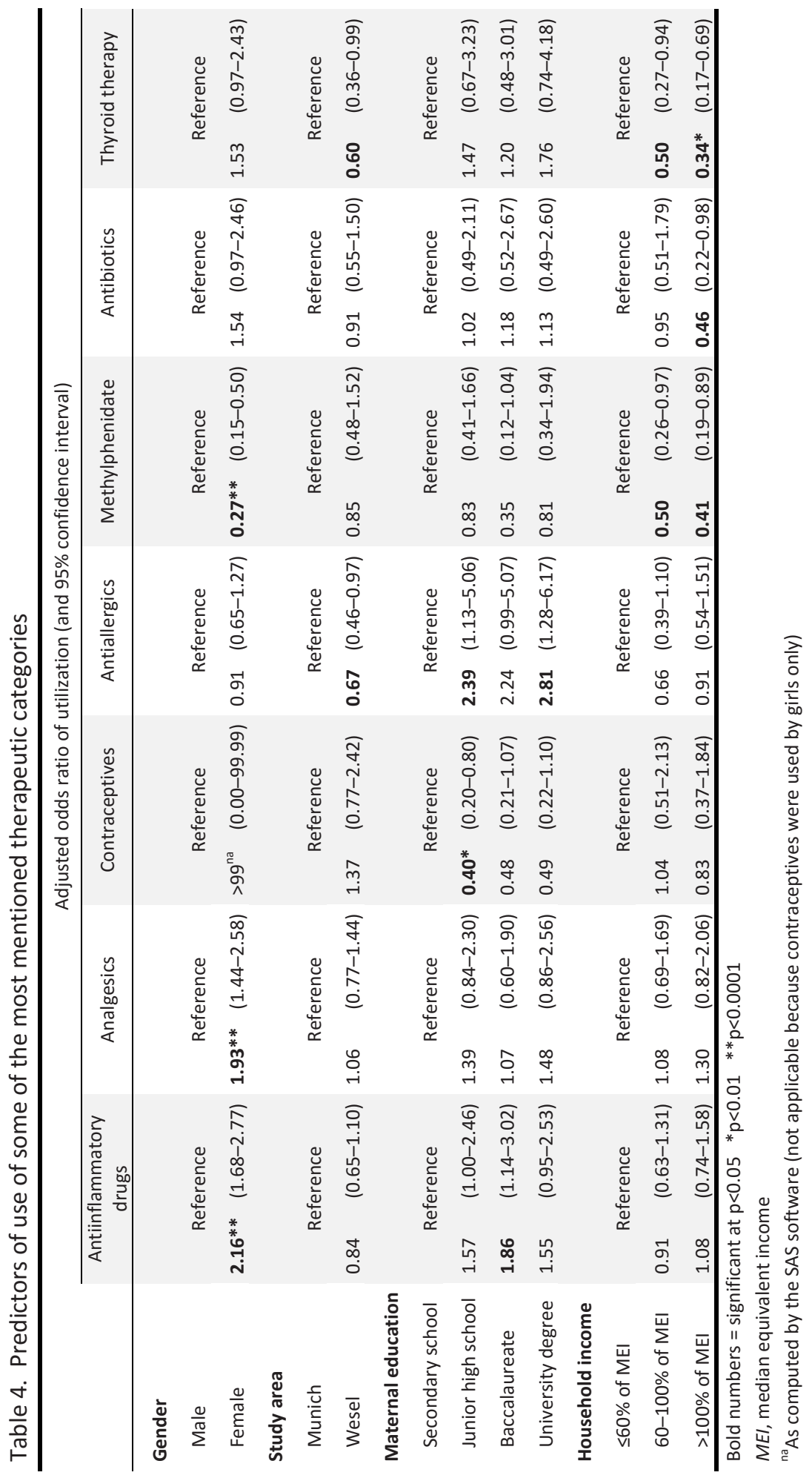


The high prevalence of drug use among adolescents is not a specifically German phenomenon. On the European scale, prevalence rates for OTC drug use during childhood or adolescence were reported with 17-39\% (use within the last 2 days) for Finland $[18,19]$, with 35\% (2-week prevalence) for the Netherlands [20], and 67\% (1-year prevalence) for Sweden [21]. Prescription drugs were found to be utilized by $15 \%$ of the Finnish children within an observation period of 2 days [18]. In Denmark, Italy, and the Netherlands, $38-57 \%$ of the adolescents used at least one prescription drug during the last year [22-26]. In Spain [27], 31.6\% of the children older than 10 years took a medicinal product (Rx and OTC drugs together) within a period of 2 weeks, which is quite similar to the corresponding prevalence in our study (41\%) considering use within the last 4 weeks.

Overall, the data on the socioeconomic predictors of paediatric drug use are limited. Du and Knopf [3] found a positive association of self-medication with maternal education (in accordance with our findings) and parental income (in contrast to our results). In a study that analysed the use of specific drug categories among Danish adolescents, higher socioeconomic status predicted higher use of e.g. drugs for treating headache or nervousness [28]. As in our study, a Dutch study found a positive association of socioeconomic status with adolescents' use of OTC drugs only and no association with prescription drugs [20], whereas in a Finnish study (children $<12$ years), OTC drug use or Rx use was not associated with parental education or income [19].

Efficient drugs with a benefit for the patients, regardless of whether they are Rx or OTC drugs, are valuable products, and their affordability/accessibility or proper use should not depend on the patients' socioeconomic status. Just recently, the European Commission has confirmed the particular status of medicinal products by leaving the responsibility for medicines in the hands of the Health Commissioner rather than moving it to the Directorate-General for Industry and Entrepreneurship [29,30].

However, as soon as drugs are switched to non-prescription status, they are subject to free pricing and advertising. Moreover, to a large extent, the patients' health literacy influences the appropriate use of drugs, emphasizing the role of pharmacists and the importance of pharmaceutical advice when dispensing OTC drugs. In Germany, competition has meant that OTC drugs such as analgesics are partly available at prices lower than one euro. Low prices may to some extent explain the high prevalence of, e.g. analgesic drug use among adolescents found in Germany [2,3] and other European countries [21,31-33]. In Norway (and elsewhere in Europe, but not in Germany), OTC drugs such as analgesics are partly sold outside pharmacies [34]. Interestingly, a Norwegian study [33] conducted in 2007 (in Norway, since 2003, analgesics have been freely available outside pharmacies) found a much higher 4-week prevalence of OTC analgesics use $(61 \%$ vs. $39 \%)$ among 15 - to 16 -year-old teenagers than a Norwegian study [32] conducted just 5 years before. Presumably, the facilitated access may have contributed 
to the increase in analgesic use among teenagers and may also lead to higher consumption of analgesics in adulthood [35].

Apparently, socioeconomic factors predict the use of OTC drugs among adolescents stronger than utilization of prescription drugs, and OTC drugs account for the majority of drugs utilized. With the 2004 German Health act, the reimbursement of OTC drugs was restricted substantially for patients older than 12 years. Since 2012 [36], OTC drugs sold by pharmacies may again be covered (with restrictions) by a limited number of German statutory health insurance companies [37]. The OTC market is a relevant economic market (for 2011, estimated to be worth 3 billion euros [38] in Germany and 27 billion euros in the European Union [39]) and accounts for roughly $50 \%$ of all drugs utilized in Europe [38,39]. Currently, a discussion is going on as to whether OTC drugs should generally be reimbursed by statutory health insurance companies, at least for children (up to 18 years) and for those older than 65 years $[40,41]$.

In the context of reimbursement of OTC drugs or the deregulation of OTC sales making them available outside pharmacies, decision makers from the various stakeholder groups should consider not only the economic aspects (e.g. the potential for savings of financial resources, the acquisition of new health insurance members, the increase in OTC sales in the stagnating OTC market $[38,41,42]$, etc.), but also the impact of socioeconomic variables on drug use and the subsequent undersupply or oversupply of medicinal products in specific population strata.

This study shows strengths and limitations as well. The drug classification was carefully performed by a health professional. With regard to minimization of the seasonal impact, the data collection was distributed almost evenly over the year. Moreover, the relatively short observation period of 4 weeks may have minimized recall bias. On the other hand, underreporting may be possible for some specific drug categories (e.g. contraceptives). Owing to the disproportionate number of dropouts from the lower socioeconomic levels since the beginning of the study, this cohort does not exactly reflect the mean socioeconomic status of the German population. The distribution of the education and income levels differed between Munich and Wesel, and the magnitude of the variables' predicting effect may vary between the two included study areas. Furthermore, we were not able to rule out non-response bias, as only $50.3 \%$ of the children recruited at the start of the GINIplus study responded to the questionnaire at the 15-year follow-up.

The questionnaire did not explicitly assess whether the reported drugs were prescribed or recommended by a physician or bought over the counter without medical prescription. Despite the fact that OTC drugs are usually not reimbursed by the statutory health insurance agencies, some OTC drugs that were not reimbursed may nevertheless have been prescribed by the children's physician as a medical recommendation only (the proportion of prescribed OTC drugs in all OTC drugs sold may be estimated at 
$17 \%$ for Germany [42]). No information was available on the proportion of privately insured children among all participants (with regard to reimbursement for OTC drugs, private health insurance companies may have fewer restrictions than statutory health insurance companies). However, privately insured individuals in Germany only account for about $13 \%$ of all insured people, but this proportion may be slightly higher in the present sample [43].

Owing to the specific regulations for prescription-only medicines, the prescription status is not only defined by the active ingredient and its dose, but may also depend on the specified indication (e.g. ibuprofen $\geq 400 \mathrm{mg}$, acetylcysteine). Hence, for 76 drug entries with ambiguous information the prescription status was conservatively assumed, and the respective drugs were allocated to OTC drugs. However, a sensitivity analysis yielded no substantial differences relating to the predictors of use for either OTC or Rx drugs. Finally, other socioeconomic variables that were not analysed in this study may also predict drug use (e.g. migration background).

\section{Conflict of interest}

The authors declare no conflict of interest.

KEY POINTS

- Overall, the 4-week prevalence of drug use among 15-year-old children from the GINIplus birth cohort was high (41\%), and more than two thirds of the drugs utilized were over-the-counter drugs.

- Parental income did not predict the use of over-the-counter drugs or prescription drugs among adolescent children, whereas a higher maternal education level was positively associated with the utilization of over-the-counter drugs.

- Socioeconomic factors such as maternal education or parental income have an impact on the use of various specific drug categories, e.g. analgesics, antiallergics, contraceptives, methylphenidate.

- Health care managers should also consider the impact of socioeconomic variables on drug utilization when deciding on the exclusion of (over-the-counter) drugs from reimbursement by statutory health insurance companies or the liberalization of drug sales. 


\section{Acknowledgements}

We thank the families for participation in the study, the obstetric units for allowing recruitment, the GINIplus study team for excellent work, and several funding agencies listed herein.

The 15-year follow-up examination of the GINIplus study was partially supported by the Commission of the European Communities, the $7^{\text {th }}$ Framework Programme, MeDALL project as well as by the companies Mead Johnson and Nestlé. This work was also supported by the German Competence Network Obesity ('Kompetenznetz Adipositas') funded by the German Federal Ministry of Education and Research (BMBF) as part of the 'Core Domain Health Economics' (Grant No. 01GI1127). This specific analysis on 'Utilization of self-medication and prescription drugs' was exclusively funded by the Helmholtz Zentrum Munich.

\section{GINIplus study group}

The GINIplus Study Team: Institute of Epidemiology I, Helmholtz Zentrum München, German Research Center for Environmental Health, Neuherberg (J. Heinrich, I. Brüske, H. Schulz, C. Flexeder, C. Zeller, M. Standl, M. Schnappinger, M. Sußmann, E. Thiering, C. Tiesler); Research Institute, Department of Pediatrics, Marien-Hospital, Wesel (D. Berdel, A. von Berg); Ludwig-Maximilians-University of Munich, Dr von Hauner Children's Hospital (S. Koletzko); Child and Adolescent Medicine, University Hospital rechts der Isar of the Technical University Munich (C.P. Bauer, U. Hoffmann); IUF - Environmental Health Research Institute, Düsseldorf (B. Hoffmann, E. Link, C. Klümper).

\section{Author contributions}

SI prepared the data with regard to the classification of the reported drugs and tracked or conservatively estimated the drug prices based on the official 'Lauer' price list. Moreover, he performed the statistical analysis and the interpretation of the results. $\mathrm{He}$ conceptualized the initial manuscript, and approved the final manuscript as submitted. SBW and HB contributed to the data analysis and interpretation of the results. They critically revised the initial manuscript, and approved the final manuscript as submitted. $\mathrm{JH}, \mathrm{DB}$, and $\mathrm{AB}$ were involved in data collection. They critically revised the initial manuscript, and approved the final manuscript as submitted. 


\section{References}

1. Sozialgesetzbuch (SGB V). § 34 SGB V Ausgeschlossene Arznei-, Heil- und Hilfsmittel. http://www.sozialgesetzbuch-sgb.de/sgbv/34.html [4 January 2015]

2. Knopf H. Medicine use in children and adolescents. Data collection and first results of the German Health Interview and Examination Survey for Children and Adolescents (KiGGS). Bundesgesundheitsblatt Gesundheitsforschung Gesundheitsschutz 2007; 50(5-6): 863-870. doi:10.1007/s00103-007-0249-z.

3. Du Y, Knopf H. Self-medication among children and adolescents in Germany: results of the National Health Survey for Children and Adolescents (KiGGS). Br J Clin Pharmacol 2009; 68: 599-608. doi:10.1111/j.1365-2125.2009.03477.x.

4. Dunkelberg S, Brand H, Brand A. Elternbefragung zum Arzneimittelgebrauch bei 5- bis 7jährigen Kindern. Kinderarztl Prax 1998; 5: 244-251.

5. Italia S, Batscheider A, Heinrich J, Wenig C, Bauer CP, Koletzko S, Lehmann I, Herbarth O, von Berg A, Berdel D, Hoffmann B, Schaaf B, Wolfenstetter SB. Utilization and costs of conventional and alternative pharmaceuticals in children: results from the German GINIplus and LISAplus birth cohort studies. Pharmacoepidemiol Drug Saf 2012; 21: 1102-1111. doi:10.1002/pds.3323.

6. Scientific research institute of AOK (WIdO). Arzneiverordnungsreport. www.wido.de/arzneiverordnungs-rep.html [24 March 2015]

7. Barmer GEK. Arzneimittelreport 2014. https://presse.barmer-gek.de/barmer/web/Portale/ Presseportal/Subportal/Infothek/Studien-und-Reports/Arzneimittelreport/EinstiegArzneimittelreport.html [24 March 2015]

8. Helmholtz Zentrum München. GINIplus birth cohort. http://www.helmholtz-muenchen.de/en/epi1/ research/research-units/research-unit-1-environmental-epidemiology/projects/giniplus/index.html [21 November 2014]

9. von Berg A, Krämer U, Link E, Bollrath C, Heinrich J, Brockow I, Koletzko S, Grübl A, Filipiak-Pittroff B, Wichmann HE, Bauer CP, Reinhardt D, Berdel D; GINIplus study group. Impact of early feeding on childhood eczema: development after nutritional intervention compared with the natural course-the GINIplus study up to the age of 6 years. Clin Exp Allergy 2010; 40: 627-636. doi:10.1111/j.13652222.2009.03444.x.

10. Federal Ministry of Justice and Consumer Protection. Ordinance on prescription-only medicinal products. http://www.gesetze-im-internet.de/amvv/BJNR363210005.html [1 December 2014]

11. WIdO. Scientific research institute of the AOK. Anatomical therapeutic chemical classification with defined daily doses for Germany 2010. http://wido.de/amtl_atc-code.html [1 December 2014]

12. WHO Collaborating Centre for Drug Statistics Methodology. http://whocc.no/atc_ddd_index/ [12 December 2014]

13. Statistical Office of the Federal State of Baden-Württemberg. http://www.statistik.badenwuerttemberg.de/VolkswPreise/Haushalte/EU-SILC/MedAequivalenzEU.asp [27 November 2014]

14. OECD Equivalence Scales. http://www.oecd.org/eco/growth/OECD-Note-EquivalenceScales.pdf [27 November 2014]

15. European Centre for Social Welfare Policy and Research. Income Poverty in the EU. http://www.euro.centre.org/data/1295444473_73292.pdf [27 November 2014]

16. Stoelben S, Krappweis J, Rössler G, Kirch W. Adolescents' drug use and drug knowledge. Eur J Pediatr 2000; 159: 608-614.

17. Faktencheck Gesundheit. Ärztedichte. https://aerztedichte.faktencheck-gesundheit.de/interaktivekarten/kinderaerzte/ [24 March 2015]

18. Ylinen S, Hämeen-Anttila K, Sepponen K, Lindblad AK, Ahonen R. The use of prescription medicines and self-medication among children-a population-based study in Finland. Pharmacoepidemiol Drug Saf 2010; 19: 1000-1008. doi:10.1002/pds.1963. 
19. Hämeen-Anttila K, Lindell-Osuagwu L, Sepponen K, Vainio K, Halonen P, Ahonen R. Factors associated with medicine use among children aged under 12 years - a population survey in Finland.

Pharmacoepidemiol Drug Saf 2010; 19: 400-407: doi:10.1002/pds.1887.

20. Tobi H, Meijer WM, Tuinstra J, de Jong-van den Berg LT. Socio-economic differences in prescription and OTC drug use in Dutch adolescents. Pharm World Sci 2003; 25: 203-206.

21. Nydert P, Kimland E, Kull I, Lindemalm S. Over-the-counter drug use-estimations within the Swedish paediatric population. Eur J Pediatr 2011; 170: 583-588. doi:10.1007/s00431-010-1321-5.

22. Madsen $\mathrm{H}$, Andersen $\mathrm{M}$, Hallas J. Drug prescribing among Danish children: a population-based study. Eur J Clin Pharmacol 2001; 57: 159-165. doi:10.1007/s002280100279.

23. Thrane N, Sørensen HT. A one-year population-based study of drug prescriptions for Danish children. Acta Paediatr 1999; 88: 1131-1136.

24. Clavenna A, Sequi M, Bortolotti A, Merlino L, Fortino I, Bonati M. Determinants of the drug utilization profile in the paediatric population in Italy's Lombardy Region. Br J Clin Pharmacol 2009; 67: 565-571. doi:10.1111/j.1365-2125.2009.03380.x.

25. Piovani D, Clavenna A, Bonati M. Drug use profile in outpatient children and adolescents in different Italian regions. BMC Pediatr 2013; 13:46. doi:10.1186/1471-2431-13-46

26. Schirm E, van den Berg P, Gebben H, Sauer P, de-Jong-van den Berg L. Drug use of children in the community assessed through pharmacy dispensing data. Br J Clin Pharmacol 2000; 50: 473-478.

27. Carrasco-Garrido $P$, Jiménez-García R, Barrera VH, de Andrés AL, de Miguel AG. Medication consumption in the Spanish paediatric population: related factors and time trend, 1993-2003.

Br J Clin Pharmacol 2009; 68: 455-461. doi:10.1111/j.1365-2125.2009.03449.x.

28. Holstein $\mathrm{BE}$, Hansen $\mathrm{EH}$, Due P. Social class variation in medicine use among adolescents. Eur J Public Health 2004; 14: 49-52.

29. European Public Health Alliance EPHA. Open Letter to President-elect Jean-Claude Juncker on move of medicinal products and health technologies to the portfolio of the commissioner for internal market and industry. http://epha.org/6157 [8 December 2014]

30. Rücker D. Arzneimittel im Gesundheitsressort. Pharmazeutische Zeitung 2014; 159(43): 8.

31. Piccinini M, Vieno A, Santinello M. Uso di medicinali e stili di vita tra gli adolescenti italiani [Use of medicines and lifestyles among Italian adolescents]. Epidemiol Prev 2011; 35: 222-228.

32. Furu K, Skurtveit S, Rosvold EO. Selvrapportert legemiddelbruk hos 15-16-åringer i Norge [Self-reported medical drug use among 15-16 year-old adolescents in Norway]. Tidsskr Nor Laegeforen 2005; 125 : 2759-2761.

33. Lagerløv $\mathrm{P}$, Holager $\mathrm{T}$, Helseth $\mathrm{S}$, Rosvold EO. Selvmedisinering med reseptfrie smertestillende legemidler hos 15-16-åringer [Self-medication with over-the-counter analgesics among 15-16 year-old teenagers]. Tidsskr Nor Laegeforen 2009; 129: 1447-1450. doi:10.4045/tidsskr.09.32759.

34. Vogler S, Arts D, Sandberger K. GOeG. Impact of pharmacy deregulation and regulation in European Countries. 2012. http://whocc.goeg.at/Publications/BooksReports [14 December 2014]

35. Andersen A, Holstein BE, Due $\mathrm{P}$, Hansen EH. Medicine use for headache in adolescents predicts medicine use for headache in young adulthood. Pharmacoepidemiol Drug Saf 2009; 18: 619-623. doi:10.1002/pds.1748.

36. Federal Ministry of Health. http://www.bmg.bund.de/glossarbegriffe/v-y/gkvversorgungsstrukturgesetz.html [10 December 2014]

37. German Pharmaceutical Industry Association. http://www.bpi.de/home/nachrichten/bpiratgeber/ansicht/zahlen-sie-noch-selbst-immer-mehr-krankenkassen-erstatten-otc-arzneimittel [10 December 2014]

38. German Pharmaceutical Industry Association. Pharmadaten 2014. http://www.bpi.de/daten-undfakten/pharmadaten/ [12 December 2014]

39. Report of the working group on promoting good governance of non-prescription drugs in Europe. http://ec.europa.eu/enterprise/sectors/healthcare/files/docs/otc_report_en.pdf [8 December 2014] 
40. Rücker D. Steffens kritisiert Preiswettbewerb. Pharmazeutische Zeitung 2014; 159(44): 14.

41. Rücker D. Switches sind ein Wachstumsmotor. Pharmazeutische Zeitung 2014; 159(45): 6-8.

42. Federal association of the pharmaceutical industry. Der Arzneimittelmarkt in Deutschland in Zahlen 2013. https://www.bah-bonn.de/index.php?elD=dumpFile\&t=f\&f=4089\&token= 3ec3eb2533e1c4c5ab6a42e783f0651d200c7e08 [12 December 2012]

43. Sundmacher L, Ozegowski S. Ziehen Privatpatienten Ärzte an. Gesundheit und Gesellschaft 2013; 16: 31-35. https://faktencheck-gesundheit.de/fileadmin/daten_fckv/Dokumente/GG_12_13_31-351_Sundmacher_Ozegowski.pdf [1 December 2014] 
When I approach a child, he inspires in me two sentiments; tenderness for what he is, and respect for what he may become.

Louis Pasteur

French chemist and microbiologist 


\section{CHAPTER 6}

A longitudinal comparison of drug use among 10-year-old children and 15-year-old adolescents from the German GINIplus and LISAplus birth cohorts



Salvatore Italia, Irene Brüske, Joachim Heinrich, Dietrich Berdel, Andrea von Berg, Irina Lehmann, Marie Standl, Silke B. Wolfenstetter.

A longitudinal comparison of drug use among 10-year-old children and 15-year-old adolescents from the German GINIplus and LISAplus birth cohorts.

Eur J Clin Pharmacol 2016;72:301-310. doi:10.1007/s00228-015-1977-x 


\begin{abstract}
Purpose: The purpose of this study was to compare longitudinal data on drug utilization between 10-year-old children and 15-year-old adolescents and to analyse the association of drug use at the age of 15 years with drug use at the age of 10 years.

Methods: Based on the German GINIplus (German infant study on the Influence of Nutrition Intervention plus environmental and genetic influences on allergy development) and LISAplus (Influence of lifestyle factors on the immune system and allergies in East and West Germany plus the influence of traffic emissions and genetics) birth cohorts, data on drug utilization (past 4 weeks) were collected using a self-administered questionnaire for 3,642 children (10-year follow-up) and 4,677 adolescents (15-year follow-up). The drugs were classified by therapeutic categories (conventional drugs, homeopathic drugs, etc.) and by codes according to the anatomical therapeutic chemical (ATC) classification system. Associations of adolescents' drug use with gender, study area, maternal education, parental income, presence of chronic conditions, and prior drug use at the age of 10 years were analysed using a logistic regression model.

Results: The 4-week prevalence rates of overall drug use were similar for adolescents (41.1\%) and children (42.3\%). However, adolescents used noticeably more antiinflammatory drugs, analgesics, and systemic antihistamines. Exactly 3,194 children/adolescents participated in both follow-ups. Adolescents' use of antiinflammatory drugs was predicted $(\mathrm{OR}=3.37)$ by use of anti-inflammatory drugs as a child. In summary, the strongest predictor of adolescents' use of specific therapeutic categories or ATC groups was the previous use of the same therapeutic drug category or ATC group as a 10-year-old child.
\end{abstract}

Conclusions: Despite similar prevalence rates of overall drug utilization among both age groups, there is a noticeable difference concerning the use of drugs from specific ATC groups. Drug use as a child may partly determine what they use as an adolescent.

\title{
Key words
}

Adolescent · Child · Drug utilization · Longitudinal study · Anti-inflammatory drugs · Germany 


\section{Introduction}

Pharmaceutical products play an important role in the health system, both from the medical point of view as well as in economic terms. In Germany, the turnover in medicinal products (prescription drugs and self-medicated drugs together) amounted to about 34 billion euros in 2013 [1]. At about 30 billion euros, expenditures on medicinal products accounted for about $16 \%$ of the total expenditures covered by the German statutory health insurance companies. They ranked third among their expenditure items in 2013 [1], only exceeded by costs of hospital treatments (65 billion euros) and medical expenses (32 billion euros). According to available publications, the prevalence of drug use is generally quite high among adolescents in Germany and other European countries as well. In Germany, a 1-week prevalence for overall drug use (prescription drugs and self-medicated drugs together) of $50.7 \%$ was reported for adolescents aged 14-17 years [2]. Another German study that included both prescription drugs and selfmedicated drugs found that $41 \%$ of 15 -year-old adolescents used at least one drug within an observation period of 4 weeks [3]. A Spanish study yielded similar results, with $31.6 \%$ of children older than 10 years using prescription drugs or over-the-counter (OTC) drugs during the last 2 weeks prior to the assessment [4]. In other studies from Denmark, Italy, and the Netherlands that analysed prescription drug use only, the 1-year prevalence ranged between 38 and 57\% [5-9]. Moreover, the share of selfmedicated drugs among all drugs used by adolescents may be considerable (e.g. reported at 69\% among 15-year-old adolescents and 38.5\% among children aged 0-17 years, respectively, from two German studies [2,10]). Further European studies yielded prevalence rates for OTC drug or self-medicated drug use during childhood or adolescence of 17-39\% (use within the last 2 days) in Finland [11,12], about 35\% (2-week prevalence) in the Netherlands [13], and 67\% (1-year prevalence) in Sweden [14].

The evidently high prevalence of (self-medicated) drug use among the general adolescent population raises some public health questions, e.g. whether all of the drugs taken are medically advisable and appropriate, or whether some self-medicated drugs such as analgesics are considered by adolescents to be ordinary commodities that may become part of everyday life over time.

The aim of this study is to analyse drug utilization longitudinally among children from two German birth cohorts by comparing drug use at two defined time points (at the age of 10 years and 15 years, respectively). A further objective of this study was to detect whether there was an association of drug use at the age of 15 years with prior drug use at the age of 10 years. 


\section{Methods}

\section{Study population}

The GINIplus study (German infant study on the Influence of Nutrition Intervention plus environmental and genetic influences on allergy development) and the LISAplus study (Influence of lifestyle factors on the immune system and allergies in East and West Germany plus the influence of traffic emissions and genetics) are based on two German birth cohorts [15,16] that started with 5,991 (GINIplus) and 3,097 (LISAplus) healthy full-term newborns who were recruited between September 1995 and January 1999 from obstetric clinics in four German regions (Munich, Leipzig, Bad Honnef, Wesel). The recruitments sites were chosen to achieve an almost heterogeneous sample with regard to geographic region (South Germany: Munich; East Germany: Leipzig; West Germany: Bad Honnef and Wesel) and degree of urbanization (urban areas: Munich and Leipzig; comparatively rural areas: Bad Honnef and Wesel). From both studies, nonterm children and children of less than 2,500 g birth weight were excluded. Children with non-German parents or parents born outside Germany were not enrolled for the LISAplus study. Additionally, participants with insufficient German language skills were not eligible for both cohorts.

\section{Data collection}

For the 15-year follow-up, exactly 6,094 participants' parents or legal guardians were contacted between January 2011 and October 2014. Socioeconomic variables such as parental education and income were collected with the main questionnaire, which also assessed the participants' gender. Additionally, a separate self-administered questionnaire on drug utilization within the past 4 weeks assessed various details on the drugs that had been used by the adolescents within the past 4 weeks. The participants were asked to enter the drug names and the pharmaceutical identification numbers (PZN) into five designated spaces or to enclose the empty drug packages in a self-addressed envelope. The PZN, which is printed on the drug package, exactly identifies the drugs with respect to package size, dosage, manufacturer, listed price, etc. In case the limited number of designated spaces was not sufficient to enter all drugs, the participants were invited to separately note the precise number of drugs used. An almost similar methodology was adopted for the 10-year follow-up, in which 6,541 parents/legal guardians had been contacted between October 2006 and October 2009. Exactly 3,194 subjects participated in the 10-year follow-up and the 15-year follow-up as well. 


\section{Drug classification}

According to the German Medicines Act, homeopathic, anthroposophic, and herbal products are defined as medicinal products as well. Therefore, all reported drugs were considered for analysis and were classified into several therapeutic modalities such as conventional drugs with chemical active pharmaceutical ingredients, homeopathic drugs, and herbal drugs. The exact definition of the various therapeutic modalities has been described in detail in a previously published study [17]. If available, codes were assigned to the drugs according to the anatomical therapeutic chemical (ATC) classification system $[18,19]$.

\section{Outcome definition and statistical analysis}

Participants who reported use of at least one drug from any therapeutic category within the past 4 weeks were classified as 'overall drug users'. Those participants taking one or more drugs from a specific drug category (e.g. homeopathic drugs) or ATC group (e.g. ATC NO2 for 'analgesics') were classified as users of the respective drug category (e.g. 'homeopathy users') or ATC group (e.g. 'analgesic users').

For analysis, the statistical software package SAS was used (SAS Institute Inc., Cary, NC, USA, version 9.3). Bivariate associations were tested with the Pearson chi ${ }^{2}$ test $(p<0.05)$. Interaction between the independent variables was checked using Pearson's correlation coefficients. Odds ratios (ORs) and their $95 \%$ confidence intervals $(\mathrm{Cl})$ were obtained from a multivariate logistic regression model that included several independent variables (study area, child's gender, maternal education, parental income, presence of a child's chronic disease, previous use of the same defined drug categories or ATC groups at the age of 10 years). In addition, for all models, a stepwise backward elimination procedure was performed at a significance level for removal from the model with $p \geq 0.05$. Associations with $p<0.05$ were considered to be significant. Mothers rather than fathers may decide on the (self-) medication of their children. Thus, for the definition of educational status, the mothers' educational background was used. To account for differences in school systems between West and East Germany before reunification in 1990, maternal education was classified into three levels based on the mothers' maximum completed years of schooling:

Level 1: low education level ( $<10$ years)

Level 2: medium education level (exactly 10 years)

Level 3: high education level (>10 years) 
Mothers who did not report any school degree at all $(n=26)$ were allocated to the low education level. Entries for mothers $(n=14)$ reporting another (but not further specified) kind of school degree than those listed above were treated as missing values for educational status.

Income status was classified following the median equivalent income (MEI) for 2012 (€1,633 net/month for the 15-year follow-up) and 2008 (€1,549 net/month for the 10-year follow-up) $[20,21]$, where the household members were weighted according to the new scale of the Organisation for Economic Co-operation and Development (OECD) [22]. Three income levels were defined: low ( $\leq 60 \%$ of MEI), medium $(60-100 \%$ of $\mathrm{MEI}$ ), and high ( $>100 \%$ of $\mathrm{MEI}$ ). The income cut-offs correspond to the definition of poverty (60\% of MEI) [23].

To take into account also the impact of chronic disorders on drug use, adolescents were defined as chronically ill if the participants reported the diagnosis of a chronic disease by a physician during the preceding 5 years. The following chronic conditions (physician diagnosed) were considered: hay fever, perennial allergic rhinitis, food allergy, atopic dermatitis, and asthma. Additionally, also further self-reported chronic conditions such as diabetes and celiac disease were considered.

The GINIplus and LISAplus cohorts obtained approval from the ethics committees of the Bavarian Medical Council, the University of Leipzig, and the Medical Council of North Rhine-Westphalia. Furthermore, written informed consent was given by the participants' parents or legal guardians and by participants.

\section{Results}

The questionnaires on drug utilization were completed for 3,642 children at the 10-year follow-up (response rate: 55.7\%) and 4,677 adolescents at the 15-year follow-up (response rate: $76.8 \%)$. Compared with baseline, both samples showed no variation with regard to gender ( $p=0.9936$ (10-year follow-up); $p=0.4437$ (15-year follow-up)), while the composition differed significantly with regard to study area $(p<0.0001$ (10-year follow-up); $p=0.0023$ (15-year follow-up)) and maternal education (both samples at $\mathrm{p}<0.0001)$. The differences between the samples in the 10-year follow-up and the 15year follow-up were not significant with regard to gender $(p=0.5375)$ and maternal education ( $p=0.3696)$, whereas both samples varied significantly $(p<0.0001)$ with regard to study area and household income. The detailed composition of the cohorts over time is displayed in Table 1. The total number of reported drugs amounted to 3,215 drugs in the 10-year follow-up and 3,873 drugs in the 15-year follow-up.

In summary, there was no statistically significant difference $(p=0.2555)$ with regard to the prevalence rates of overall drug use between 15-year-old adolescents $(41.1 \%$; 95\% Cl: 39.7-42.5) and 10-year-old children (42.3\%; 95\% Cl: 40.7-43.9). About 71\% of 
the drugs used by adolescents were OTC drugs ( $29 \%$ were prescription drugs). The corresponding figures for 10 -year-old children were $75 \%$ (OTC drugs) and $25 \%$ (prescription drugs). Compared with 10-year-old children, 15-year-old adolescents used fewer homeopathic and herbal drugs, whereas they took more conventional drugs containing chemical active ingredients (Supplementary Figure S1). The respective prevalence rates of use differed significantly between both age groups at $p<0.0001$ (homeopathy use), $p<0.0001$ (use of herbal drugs), and $p=0.0006$ (use of conventional drugs). Overall, adolescents took fewer OTC drugs than children $(p=0.0077)$.

Table 1. Characteristics of the GINIplus and LISAplus cohort over time

\begin{tabular}{|c|c|c|c|c|}
\hline & \multicolumn{3}{|c|}{ Distribution of the strata in \% } & \multirow[b]{2}{*}{$p$-value } \\
\hline & Baseline & $\begin{array}{c}\text { 10-year } \\
\text { follow-up }\end{array}$ & $\begin{array}{l}\text { 15-year } \\
\text { follow-up }\end{array}$ & \\
\hline Total number of participants & 9,088 & 3,642 & 4,677 & \\
\hline \multicolumn{5}{|l|}{ Gender } \\
\hline Male & 51.3 & 51.3 & 50.6 & \multirow{2}{*}{0.5375} \\
\hline Female & 48.7 & 48.7 & 49.4 & \\
\hline \multicolumn{5}{|l|}{ Study area } \\
\hline Munich & 48.6 & 50.8 & 50.1 & \multirow{4}{*}{$<0.0001$} \\
\hline Leipzig & 10.7 & 10.5 & 8.9 & \\
\hline Bad Honnef & 3.4 & 5.4 & 4.0 & \\
\hline Wesel & 37.3 & 33.3 & 37.0 & \\
\hline \multicolumn{5}{|l|}{ Maternal education } \\
\hline Low & 16.0 & 9.8 & 10.7 & \multirow{3}{*}{0.3696} \\
\hline Medium & 39.0 & 39.4 & 38.6 & \\
\hline High & 45.0 & 50.8 & 50.7 & \\
\hline \multicolumn{5}{|l|}{ Household income $^{a}$} \\
\hline$\leq 60 \%$ of $\mathrm{MEI}$ & & 16.8 & 17.0 & \multirow{3}{*}{$<0.0001$} \\
\hline $60-100 \%$ of $\mathrm{MEI}$ & not available & 44.2 & 37.9 & \\
\hline$>100 \%$ of $\mathrm{MEI}$ & & 39.0 & 45.1 & \\
\hline
\end{tabular}

$\mathrm{MEI}$, median equivalent income (MEI not available for the baseline survey)

${ }^{a}$ Based on the MEl of 2008 ( $€ 1,549 ; 10$-year follow-up) and on the MEI of 2012 ( $€ 1,633 ; 15$-year follow-up)

${ }^{b}$ Derived from $\mathrm{chi}^{2}$ test, testing the difference of the sample composition between the 15-year follow-up and the 10-year follow-up

The 12 most frequent ATC codes in each follow-up, which accounted for 36.3\% (10-year follow-up) and $37.6 \%$ (10-year follow-up) of all reported drugs in the corresponding follow-up, are displayed in Table 2. In the 10-year follow-up, one single homeopathic remedy (Arnica globules ( $n=59$ ); not listed in Table 2 as no ATC code available) was also among the most mentioned drugs. Four out of 12 of the most commonly used active 
ingredients that were taken by adolescents were anti-inflammatory agents (ibuprofen, naproxen) or analgesics (paracetamol, acetylsalicylic acid).

Table 2. Most frequent ATC codes (absolute number and percentage of all reported drugs)

\begin{tabular}{|c|c|c|c|c|c|c|c|}
\hline \multicolumn{4}{|c|}{ 10-year follow-up } & \multicolumn{4}{|c|}{ 15-year follow-up } \\
\hline ATC & Active ingredient & $\mathrm{n}$ & $\%$ & ATC & Active ingredient & $\mathrm{n}$ & $\%$ \\
\hline N02BE01 & Paracetamol & 191 & 5.9 & M01AE01 & Ibuprofen & 484 & 12.5 \\
\hline M01AE01 & Ibuprofen & 169 & 5.3 & N02BE01 & Paracetamol & 204 & 5.3 \\
\hline R01AA07 & Xylometazoline & 125 & 3.9 & N06BA04 & Methylphenidate & 108 & 2.8 \\
\hline R03AC02 & Salbutamol & 114 & 3.5 & R06AE07 & Cetirizine & 101 & 2.6 \\
\hline N06BA04 & Methylphenidate & 99 & 3.1 & R01AA07 & Xylometazoline & 101 & 2.6 \\
\hline R05CB01 & Acetylcysteine & 91 & 2.8 & R03AC02 & Salbutamol & 85 & 2.2 \\
\hline R05CB06 & Ambroxol & 76 & 2.4 & R05CB01 & Acetylcysteine & 82 & 2.1 \\
\hline R01BP30 & Systemic rhinologicals ${ }^{a}$ & 68 & 2.1 & R01BP30 & Systemic rhinologicals ${ }^{a}$ & 74 & 1.9 \\
\hline R05CP02 & Ivy leaves & 68 & 2.1 & $\mathrm{R} 05 \mathrm{XH} 20$ & $\begin{array}{l}\text { Homeopathic } \\
\text { flu remedies }\end{array}$ & 59 & 1.5 \\
\hline $\mathrm{R} 05 \mathrm{XH} 20$ & $\begin{array}{l}\text { Homeopathic } \\
\text { flu remedies }{ }^{a}\end{array}$ & 62 & 1.9 & Н03СА01 & lodide & 56 & 1.4 \\
\hline R03BA02 & Budesonide & 54 & 1.7 & N02BA01 & Acetylsalicylic acid & 54 & 1.4 \\
\hline R06AE07 & Cetirizine & 53 & 1.6 & M01AE02 & Naproxen & 50 & 1.3 \\
\hline
\end{tabular}

3,215 drugs used at the 10-year follow-up and 3,873 at the 15-year follow-up

ATC, anatomical therapeutic chemical classification system

${ }^{\mathrm{a}}$ Combined preparations

The comparison by ATC group (Figure 1) revealed that adolescents took fewer drugs from the ATC groups R03 (drugs for obstructive airway diseases; $\mathrm{p}<0.0001$ ), R05 (cough and cold preparations; $\mathrm{p}<0.0001$ ), and $R 01$ (nasal preparations; $\mathrm{p}=0.0076$ ). On the other hand, they used substantially more $(p<0.0001)$ anti-inflammatory drugs (ATC M01) and somewhat more analgesics (ATC N02; $\mathrm{p}=0.0323$ ), antihistamines (ATC R06; $\mathrm{p}<0.0006$ ), and drugs for functional gastrointestinal disorders (ATC A03; $\mathrm{p}<0.0001$ ).

A detailed view of the prevalence rates of anti-inflammatory drug use and analgesic use, which increased from $4.6 \%(95 \% \mathrm{Cl}: 3.9-5.3)$ to $11.2 \%(95 \% \mathrm{Cl}: 10-3-12.1)$ and from $6.0 \%$ (95\% Cl: $5.2-6.7)$ to $6.6 \%$ (95\% Cl: 5.9-7.3), respectively, showed that the higher prevalence rates among adolescents resulted mainly from an increase in the female stratum (Figure 2), where 15-year-old girls used, for example, more than three times the number of anti-inflammatory drugs (4.9\% (95\% Cl: $3.8-5.9)$ vs. $14.8 \%$ (95\% Cl: 13.3-16.2)). Additionally, there was no gender difference with regard to the use of antiinflammatory drugs or analgesics among 10-year-old children, whereas 15-year-old girls used significantly more anti-inflammatory drugs or analgesics than 15 -year-old boys (Figure 2). 


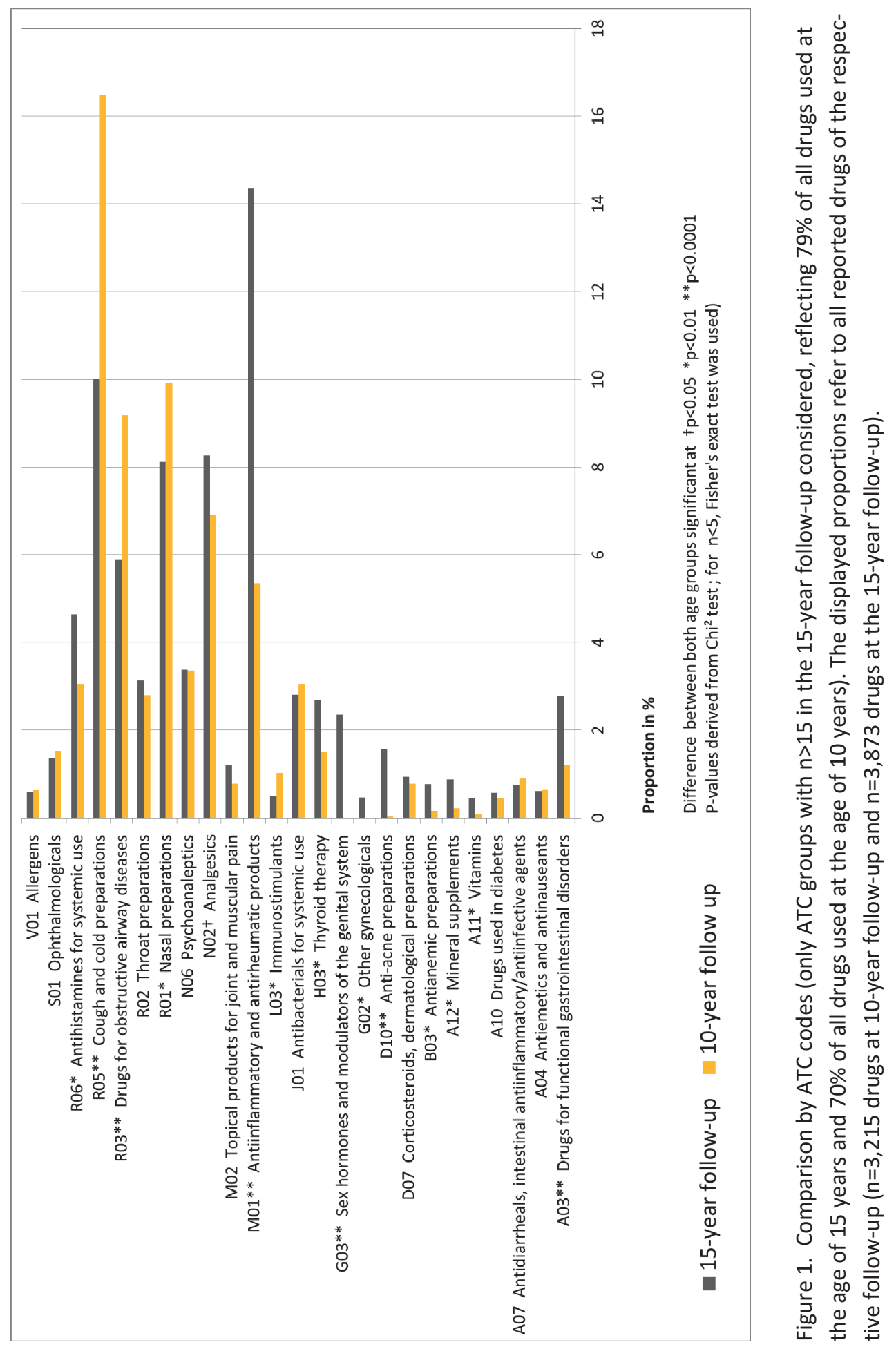




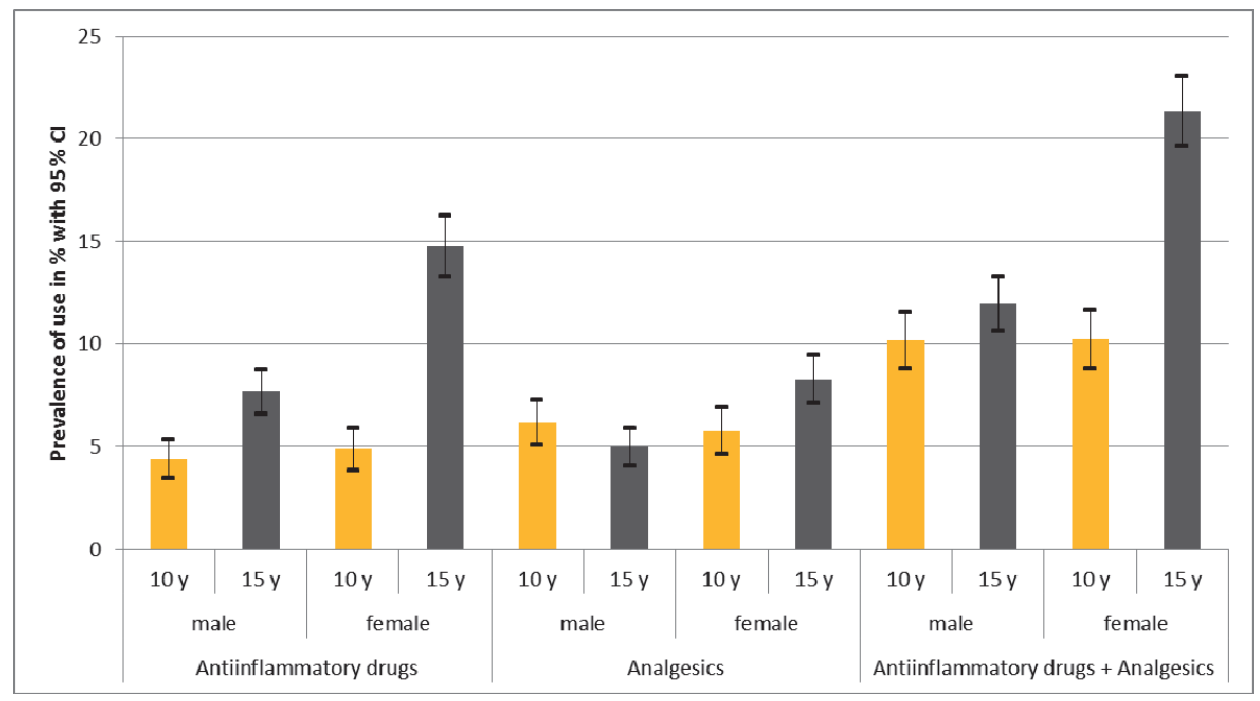

Figure 2. Prevalence of use of anti-inflammatory drugs and analgesics stratified by gender

\section{Medication tracking}

From the 3,642 children who participated in the 10-year follow-up, exactly 3,194 $(87.7 \%)$ were still in the GINIplus/LISAplus cohorts at the 15-year follow-up. Adolescents were more than twice as likely $(\mathrm{OR}=2.25 ; 95 \% \mathrm{Cl}: 1.94-2.61)$ to be an 'overall drug user' if they had already been an 'overall drug user' at the age of 10 years. With regard to the use of the various drug categories (Table 3), the likelihood of being a drug user of the same drug category at the age of 10 years and as an adolescent as well was highest for homeopathic drugs ( $\mathrm{OR}=3.82 ; 95 \% \mathrm{Cl}$ : 2.91-5.00).

The independent variables for previous use of conventional drugs, homeopathy, and herbal drugs, as displayed in Table 3, remained in the models after performing a backward elimination procedure. The longitudinal association of drug use was also given for various ATC groups. Table 4 shows the odds ratios of drug utilization from the most common ATC groups (except ATC group G03, where no use was reported among 10 -year-old children), derived from the final multivariate logistic regression model with backward elimination.

In most instances, the strongest predictor of adolescents' drug use was the previous use of drugs from the same ATC group at the age of 10 years. For example, adolescents used significantly more antibacterials (OR=3.95; 95\% Cl: 1.75-8.91), antiinflammatory drugs (OR=3.37; 95\% Cl: 2.28-4.99), analgesics (OR=3.25; 95\% Cl: $2.13-$ $4.94)$, or throat preparations ( $\mathrm{OR}=3.74 ; 95 \% \mathrm{Cl}: 1.67-8.38)$, if they had used drugs from the same ATC group 5 years before. 
Table 3. Predictors of use of conventional drugs, homeopathic drugs, and herbal drugs (full models without backward elimination)

\begin{tabular}{|c|c|c|c|}
\hline & \multicolumn{3}{|c|}{ Adjusted odds ratio of utilization (and $95 \% \mathrm{Cl}$ ) } \\
\hline & Conventional drugs & Homeopathic drugs & Herbal drugs \\
\hline \multicolumn{4}{|l|}{ Gender } \\
\hline Male & Reference & Reference & Reference \\
\hline Female & $1.54 * * \quad(1.32-1.79)$ & $1.57 * \quad(1.22-2.02)$ & $1.33(1.00-1.78)$ \\
\hline \multicolumn{4}{|l|}{ Study area } \\
\hline Munich & Reference & Reference & Reference \\
\hline Leipzig & $0.91 \quad(0.70-1.19)$ & $1.10 \quad(0.72-1.69)$ & $1.50 \quad(0.94-2.39)$ \\
\hline Bad Honnef & $(0.88-1.78)$ & $(0.62-1.97)$ & $(0.80-2.76)$ \\
\hline Wesel & $(0.89-1.28)$ & $(0.64-1.17)$ & $(0.92-1.83)$ \\
\hline \multicolumn{4}{|c|}{ Maternal education } \\
\hline Low & Reference & Reference & Reference \\
\hline Medium & $1.42 \quad(1.05-1.92)$ & $1.92 \quad(1.05-3.51)$ & $1.77 \quad(0.87-3.60)$ \\
\hline High & (1.05-1.93) & $(1.15-3.83)$ & $(1.15-4.74)$ \\
\hline \multicolumn{4}{|c|}{ Household income } \\
\hline Low & Reference & Reference & Reference \\
\hline Medium & $1.22 \quad(0.95-1.57)$ & $1.09 \quad(0.70-1.69)$ & $1.32 \quad(0.82-2.12)$ \\
\hline High & $(0.83-1.40)$ & $(0.67-1.64)$ & $(0.55-1.49)$ \\
\hline \multicolumn{4}{|c|}{ Chronic disease $^{a}$} \\
\hline No & Reference & Reference & Reference \\
\hline Yes & $1.98 * * \quad(1.68-2.34)$ & $1.53 \quad(1.18-1.99)$ & $1.20 \quad(0.87-1.64)$ \\
\hline \multicolumn{4}{|c|}{$\begin{array}{l}\text { Previous use of } \\
\text { conventional drugs }\end{array}$} \\
\hline No & Reference & & \\
\hline Yes & $2.45 * * \quad(2.08-2.88)$ & & \\
\hline \multicolumn{4}{|c|}{$\begin{array}{l}\text { Previous use of } \\
\text { homeopathic drugs }^{b}\end{array}$} \\
\hline No & & Reference & \\
\hline Yes & & $3.82 * * \quad(2.91-5.00)$ & \\
\hline \multicolumn{4}{|c|}{$\begin{array}{l}\text { Previous use of } \\
\text { herbal drugs }^{b}\end{array}$} \\
\hline No & & & Reference \\
\hline Yes & & & $3.28 * * \quad(2.29-4.71)$ \\
\hline \multicolumn{4}{|c|}{$\mathrm{Cl}$, confidence interval } \\
\hline $\begin{array}{l}\text { Bold numbers } \\
{ }^{\mathrm{a} D i a g n o s e d} \text { by } \\
{ }^{\mathrm{b}} \text { Use at the age }\end{array}$ & $\begin{array}{l}\text { ant at } p<0.05 * p<0.0 \\
\text { an during the precedir } \\
\text { ars }\end{array}$ & $\begin{array}{l}1 * * p<0.0001 \\
\text { ng } 5 \text { years }\end{array}$ & \\
\hline
\end{tabular}


The continuity of using the same type of drugs was visible for some very narrowly defined ATC subgroups as well, e.g. the use of ibuprofen (ATC M01AE01), paracetamol (ATC N02BE01), or mucolytics (RO5CB) as an adolescent was predicted by the prior use of ibuprofen (OR=3.71; 95\% Cl: 2.49-5.53), paracetamol (OR=3.80; 95\% Cl: 2.29-6.30), or mucolytics (OR=3.67; $95 \% \mathrm{Cl}: 1.88-7.16)$, respectively, at the age of 10 years. The model fit statistics for all regression models shown in Table 3 and Table 4 were satisfactory ( $p$ at least $p<0.05$ ). A detailed table that also contains the $95 \% \mathrm{Cl}$ of the ORs shown in Table 4 is available as supplementary material to this article (Supplementary Table S2).

\section{Discussion}

The findings of this study revealed that the prevalence of overall drug use was almost at the same level when comparing 15-year-old adolescents with 10-year-old children. At the same time, there was a noticeable difference in drug utilization with regard to specific ATC groups, e.g. a significantly higher use of anti-inflammatory drugs (ATC MO1) among 15-year-old adolescents. The gender difference among 15-year-old adolescents may presumably in part result from the fact that female adolescents use e.g. ibuprofen for period pains. A high paediatric use of anti-inflammatory drugs or analgesics was also found in other European studies [2,10,14,24-26]. Generally, the high prevalence of drug use raises the question of whether all the drugs used by adolescents were really medically necessary or advisable, not least in view of the fact that medicinal products such as anti-inflammatory drugs, analgesics, or antihistamines can also have severe side-effects [27-29].

Another finding of this study was that adolescents used fewer homeopathic drugs and herbal drugs. Other studies analysing herbal drug use only [30] or various complementary and alternative medicine (CAM) modalities [31] also found lower prevalence rates for herbal drugs or homeopathy. This may be explained in part by the fact that OTC drugs (almost all homeopathic and herbal drugs were OTC drugs) are not normally reimbursed by German statutory insurance companies for children older than 12 years [32], but a lower acceptance of homeopathy or phytotherapy might also be a reason for the lower prevalence rates found for adolescents, as adolescents may begin to take their own decisions on self-medication with drugs. Moreover, the perception that homeopathic or herbal drugs are supposedly gentle remedies (one possible reason for their high use among children) may decrease or may play a less important role during transition to adolescence. A further striking outcome was that adolescents' drug use from a specific ATC group was strongly predicted by the previous use of a drug from the same ATC group. This could have been expected for drugs that are used for the treat- 


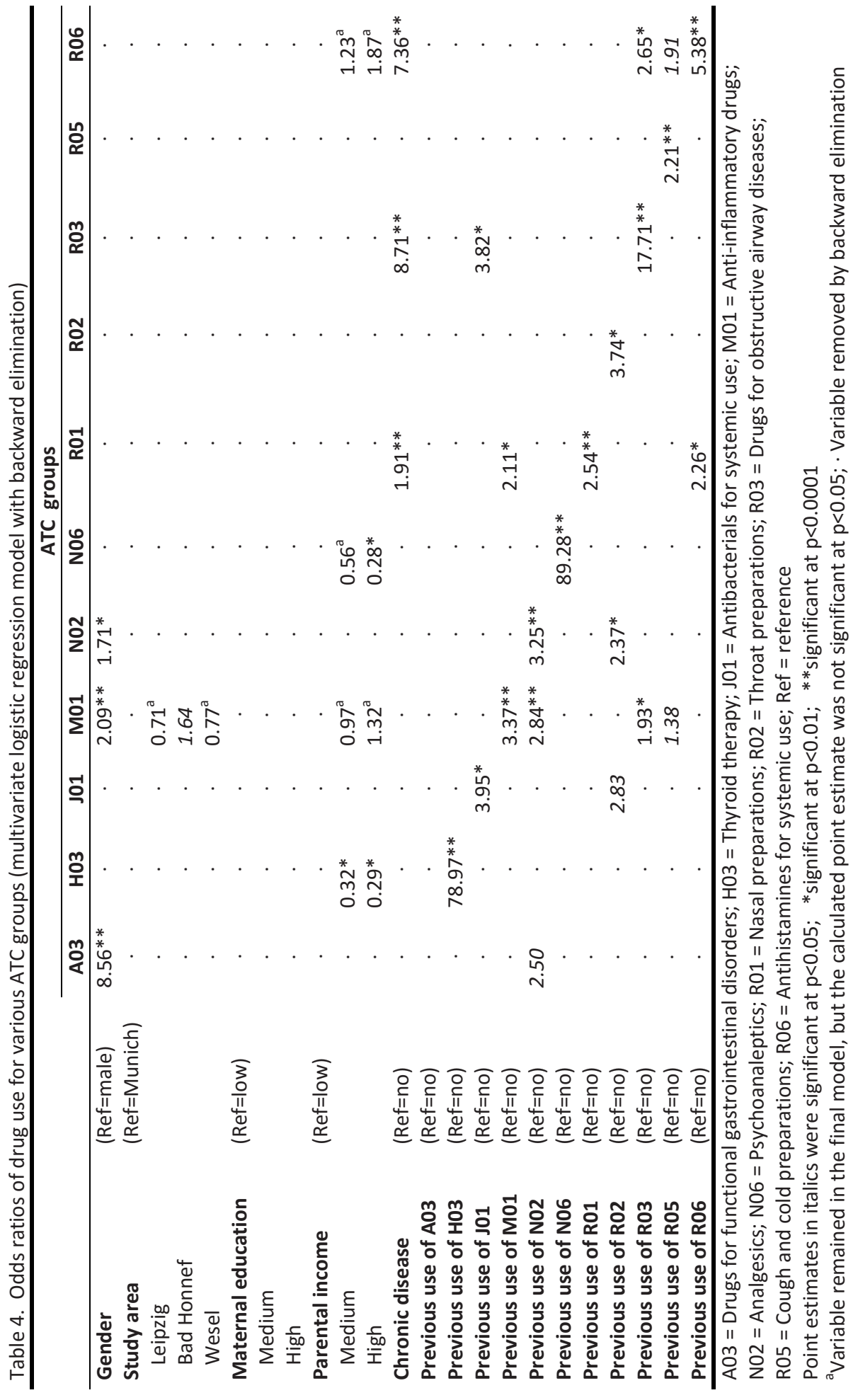


ment of chronic or persistent conditions such as asthma, attention deficit and hyperactivity disorder, or thyroid disorders. On the other hand, this is a remarkable result for medicinal products (prescribed drugs as well as self-medicated drugs) that are supposedly used predominantly to treat an acute condition such as antibiotics, antiinflammatory drugs, or analgesics. With regard to analgesics, another study [33] yielded a similar result, finding a strong association between headache medicine use at the age of 27 years and prior use of headache medicine at the age of 15 years or 19 years.

An additional aspect that has to be considered is the difference between both age groups with regard to the proportion of prescribed drugs. While most (64\%) of the drugs used by 10 -year-old children were prescribed by a physician (only $36 \%$ were purchased on the participants' own initiative), the share of prescribed drugs may be much lower among adolescents (this proportion was not directly assessed in the 15-year follow-up, but may be estimated at somewhat higher than $30 \%$, as exactly $29 \%$ were prescription drugs and presumably only a few of the reported OTC drugs used by adolescents may have been prescribed or recommended by a physician [32]). This high share of OTC drugs emphasizes the importance of personal health literacy and the role of advice from a physician or a pharmacist with regard to adolescents' self-medication with drugs.

This study has strengths and limitations as well. The data are based on the recently completed follow-ups of two large German birth cohorts. The data collection for the 15year follow-up was performed almost evenly over the four seasons, with slight peaks in April and June, whereas data for the 10-year follow-up were collected mainly in the autumn (54\%). Nevertheless, the prevalence rate for overall drug use in the autumn was roughly at the same level as for all four seasons together (it was highest in spring and winter and lowest in summer). The difference between the distributions of data assessment over the year may also partly explain the different prevalence rates of use of seasonally sensitive ATC-groups (e.g. cough and cold remedies, anti-allergy). Additionally, the different composition of both cohorts with regard to study area and household income may also have contributed to the different prevalence rates of drug use between both age groups. Moreover, other socioeconomic variables may also predict paediatric drug use, but could not be analysed in this study because of lacking availability (e.g. migration background). To our knowledge, the number of studies that analysed longitudinal data on paediatric drug use is very limited. Owing to the relatively short observation period of 4 weeks, the recall bias may have been minimized. On the other hand, underreporting may be likely for some types of drugs (e.g. contraceptives). Furthermore, categorization by the main ATC groups is relatively rough, as some ATC groups such as $R 05$ include various types of chemical active ingredients. On the other hand, similar associations with prior drug use were found for very narrowly defined ATC groups as well. Defined daily doses could provide further important data for the com- 
parison of drug use between both age groups, but were not considered in this study because for many of the reported drugs (e.g., homeopathic drugs or drug entries with an unclear package size) no defined daily doses were available.

In sum, both studies cannot be considered as being representative for the total German population due to arbitrarily selection of the four study areas, the exclusion criteria at baseline, and the selective follow-up. Therefore, the results can be projected to the general German adolescent population to a limited extent only, as the present cohort may not exactly reflect the German mean, e.g. with regard to maternal education level, parental income, or the adolescents' general health status.

\section{Conclusions}

Apparently, adolescents' drug utilization depends partly on their drug use as children and may also determine what they will use in adulthood. It should be kept in mind that drugs are special products and not simple commodities. They should be utilized according to need and not following habitual patterns only. In Europe, OTC drugs are also gradually becoming available outside pharmacies [34,35] and are often subject to free advertising. It remains a difficult balancing act between free availability of medicinal products, adequate drug prices, and the appropriate use of self-medicated drugs. Overall, a good advice on the safe use of self-medication drugs might best be ensured by pharmacies $[36,37]$ rather than non-medical sales points such as supermarkets or petrol stations.

\section{Acknowledgements}

We thank the families for participation in the study, the obstetric units for allowing recruitment, the GINIplus and LISAplus study teams for excellent work, and several funding agencies listed herein.

The 15-year follow-up examination of the GINIplus study was partially supported by the Commission of the European Communities, the $7^{\text {th }}$ Framework Programme, MeDALL project as well as by the companies Mead Johnson and Nestlé. This work was also supported by the German Competence Network Obesity ('Kompetenznetz Adipositas') funded by the German Federal Ministry of Education and Research (BMBF) as part of the 'Core Domain Health Economics' (Grant No. 01GI1127). This specific analysis on 'drug use among 10-year-old children and 15-year-old adolescents from the German GINIplus and LISAplus birth cohorts' was exclusively funded by the Helmholtz Zentrum Munich. 


\section{Authors' contribution}

SI classified the reported drugs (therapeutic categories, ATC codes, prescription status, etc.), performed the statistical analysis, and interpreted the results. He conceptualized the initial manuscript, and approved the final manuscript as submitted. SW contributed to the data analysis and interpretation of the results. She critically revised the initial manuscript, and approved the final manuscript as submitted. IB, JH, DB, AB, IL, and MS were involved in data collection. They critically revised the initial manuscript, and approved the final manuscript as submitted.

\section{Compliance with ethical standards}

The GINIplus and LISAplus cohorts obtained approval from the ethics committees of the Bavarian Medical Council, the University of Leipzig, and the Medical Council of North Rhine-Westphalia. Furthermore, written informed consent was given by the participants' parents or legal guardians and by participants.

\section{Conflict of interest}

The authors declare that they have no conflict of interest.

\section{Open Access}

This article is distributed under the terms of the Creative Commons Attribution 4.0 International License (http://creativecommons.org/licenses/by/4.0/), which permits unrestricted use, distribution, and reproduction in any medium, provided you give appropriate credit to the author(s) and the source, provide a link to the Creative Commons license, and indicate if any changes were made. 


\section{References}

1. German pharmaceutical industry association. Pharmadaten 2014. http://www.bpi.de/daten-undfakten/pharmadaten/. Accessed 15 August 2015

2. Knopf H (2007) Medicine use in children and adolescents. Data collection and first results of the German Health Interview and Examination Survey for Children and Adolescents (KiGGS). Bundesgesundheitsblatt Gesundheitsforschung Gesundheitsschutz 50:863-870. doi:10.1007/s00103-007-0249-z

3. Italia S, Brand H, Heinrich J, Berdel D, von Berg A, Wolfenstetter SB (2015) Utilization of self-medication and prescription drugs among 15-year-old children from the German GINIplus birth cohort.

Pharmacoepidemiol Drug Saf 24:1133-1143. doi:10.1002/pds.3829

4. Carrasco-Garrido P, Jiménez-García R, Barrera VH, de Andrés AL, de Miguel AG (2009) Medication consumption in the Spanish paediatric population: related factors and time trend, 1993-2003. Br J Clin Pharmacol 68:455-461. doi:10.1111/j.1365-2125.2009.03449.x

5. Madsen H, Andersen M, Hallas J (2001) Drug prescribing among Danish children: a population-based study. Eur J Clin Pharmacol 57:159-165. doi:10.1007/s002280100279

6. Thrane N, Sørensen HT (1999) A one-year population-based study of drug prescriptions for Danish children. Acta Paediatr 88:1131-1136

7. Clavenna A, Sequi M, Bortolotti A, Merlino L, Fortino I, Bonati M (2009) Determinants of the drug utilization profile in the paediatric population in Italy's Lombardy Region. Br J Clin Pharmacol 67:565-571. doi:10.1111/j.1365-2125.2009.03380.x

8. Piovani D, Clavenna A, Bonati M (2013) Drug use profile in outpatient children and adolescents in different Italian regions. BMC Pediatr 13:46. doi:10.1186/1471-2431-13-46

9. Schirm E, van den Berg P, Gebben H, Sauer P, de-Jong-van den Berg L (2000) Drug use of children in the community assessed through pharmacy dispensing data. Br J Clin Pharmacol 50:473-478

10. Du Y, Knopf H (2009) Self-medication among children and adolescents in Germany: results of the National Health Survey for Children and Adolescents (KiGGS). Br J Clin Pharmacol 68:599-608. doi:10.1111/j.1365-2125.2009.03477.x

11. Hämeen-Anttila K, Lindell-Osuagwu L, Sepponen K, Vainio K, Halonen P, Ahonen R (2010) Factors associated with medicine use among children aged under 12 years - a population survey in Finland.

Pharmacoepidemiol Drug Saf 2010 19:400-407. doi:10.1002/pds.1887

12. Ylinen S, Hämeen-Anttila K, Sepponen K, Lindblad AK, Ahonen R (2010) The use of prescription medicines and self-medication among children - a population-based study in Finland. Pharmacoepidemiol Drug Saf 19:1000-1008. doi:10.1002/pds.1963

13. Tobi H, Meijer WM, Tuinstra J, de Jong-van den Berg LT (2003) Socio-economic differences in prescription and OTC drug use in Dutch adolescents. Pharm World Sci 25:203-206

14. Nydert P, Kimland E, Kull I, Lindemalm S (2011) Over-the-counter drug use - estimations within the Swedish paediatric population. Eur J Pediatr 170:583-588. doi:10.1007/s00431-010-1321-5

15. Heinrich J, Brüske I, Schnappinger M, Standl M, Flexeder C, Thiering E, Tischer C, Tiesler CM, Kohlböck G, Wenig CM, Bauer CP, Schaaf B, von Berg A, Berdel D, Krämer U, Cramer C, Lehmann I, Herbarth O, Behrendt H, Ring J, Kühnisch J, Koletzko S (2012) Die zwei deutschen Geburtskohorten GINIplus und LISAplus [Two German Birth Cohorts: GINIplus and LISAplus]. Bundesgesundheitsblatt Gesundheitsforschung Gesundheitsschutz 55:864-874. doi:10.1007/s00103-012-1485-4

16. von Berg A, Krämer U, Link E, Bollrath C, Heinrich J, Brockow I, Koletzko S, Grübl A, Filipiak-Pittroff B, Wichmann HE, Bauer CP, Reinhardt D, Berdel D; GINIplus study group (2010) Impact of early feeding on childhood eczema: development after nutritional intervention compared with the natural course - the GINIplus study up to the age of 6 years. Clin Exp Allergy 40:627-636. doi:10.1111/j.13652222.2009.03444.x

17. Italia S, Batscheider A, Heinrich J, Wenig C, Bauer CP, Koletzko S, Lehmann I, Herbarth O, von Berg A, Berdel D, Hoffmann B, Schaaf B, Wolfenstetter SB (2012) Utilization and costs of conventional and alter- 
native pharmaceuticals in children: results from the German GINIplus and LISAplus birth cohort studies. Pharmacoepidemiol Drug Saf 21:1102-1111. doi: 10.1002/pds.3323

18. WHO Collaborating Centre for Drug Statistics Methodology. http://whocc.no/atc_ddd_index/. Accessed 15 August 2015

19. WIdO. Scientific research institute of the AOK. Anatomical therapeutic chemical classification with defined daily doses for Germany (2010). http://wido.de/amtl_atc-code.html. Accessed 15 August 2015

20. Statistical Office of the Federal State of Baden-Württemberg. http://www.statistik.badenwuerttemberg.de/VolkswPreise/Haushalte/EU-SILC/MedAequivalenzEU.asp. Accessed 02 June 2014

21. Deckl S. Leben in Europa 2009 Bundesergebnisse für Sozialindikatoren über Einkommen, Armut und Lebensbedingungen. Statistisches Bundesamt.

https://www.destatis.de/DE/Publikationen/WirtschaftStatistik/WirtschaftsrZeitbudget/LEBENEUROPA2 009122010.pdf?_blob=publicationFile. Accessed 02 August 2015

22. OECD Equivalence Scales. http://www.oecd.org/eco/growth/OECD-Note-EquivalenceScales.pdf. Accessed 15 August 2015

23. European Centre for Social Welfare Policy and Research. Income Poverty in the EU. http://www.euro.centre.org/data/1295444473_73292.pdf. Accessed 15 August 2015

24. Piccinini M, Vieno A, Santinello M (2011) Uso di medicinali e stili di vita tra gli adolescenti italiani [Use of medicines and lifestyles among Italian adolescents]. Epidemiol Prev 35:222-228

25. Furu K, Skurtveit S, Rosvold EO (2005) Selvrapportert legemiddelbruk hos 15-16-åringer i Norge [Selfreported medical drug use among 15-16 year-old adolescents in Norway]. Tidsskr Nor Laegeforen 125:2759-2761

26. Lagerl $\varnothing v \mathrm{P}$, Holager T, Helseth S, Rosvold EO (2009) Selvmedisinering med reseptfrie smertestillende legemidler hos 15-16-åringer [Self-medication with over-the-counter analgesics among 15-16 year-old teenagers]. Tidsskr Nor Laegeforen 129:1447-1450. doi:10.4045/tidsskr.09.32759

27. Kim HY, Yang HK, Kim SH, Park JH (2014) Ibuprofen associated acute vanishing bile duct syndrome and toxic epidermal necrolysis in an infant. Yonsei Med J 55:834-837. doi:10.3349/ymi.2014.55.3.834

28. Lee WJ, Lee TA, Pickard AS, Caskey RN, Schumock GT (2014) Drugs associated with adverse events in children and adolescents. Pharmacotherapy 34:918-926. doi:10.1002/phar.1455

29. Badawi AH, Tefft K, Fraga GR, Liu DY (2014) Cetirizine-induced acute generalized exanthematous pustuIosis: a serious reaction to a commonly used drug. Dermatol Online J 20:22613

30. Du Y, Wolf IK, Zhuang W, Bodemann S, Knöss W, Knopf H (2014) Use of herbal medicinal products among children and adolescents in Germany. BMC Complement Altern Med 14:218. doi:10.1186/14726882-14-218

31. Italia S, Brand H, Heinrich J, Berdel D, von Berg A, Wolfenstetter SB (2015) Utilization of complementary and alternative medicine (CAM) among children from a German birth cohort (GINIplus): patterns, costs, and trends of use. BMC Complement Altern Med 15:49. doi:10.1186/s12906-015-0569-8

32. Sozialgesetzbuch (SGB V). § 34 SGB V Ausgeschlossene Arznei-, Heil- und Hilfsmittel. http://www.sozialgesetzbuch-sgb.de/sgbv/34.html. Accessed 15 August 2015

33. Andersen A, Holstein BE, Due P, Hansen EH (2009) Medicine use for headache in adolescents predicts medicine use for headache in young adulthood. Pharmacoepidemiol Drug Saf 18:619-623. doi:10.1002/pds.1748

34. Vogler S, Arts D, Sandberger K. GOeG. Impact of pharmacy deregulation and regulation in European Countries. 2012. http://whocc.goeg.at/Publications/BooksReports. Accessed 15 August 2015

35. Tisman A (IMS Health). The rising tide of OTC in Europe. https://www.imshealth.com/deployedfiles/imshealth/Global/Content/Healthcare/Healthcare Solutions/Consumers/The_Rising_Tide_Of_OTC_Europe.pdf. Accessed 15 August 2015

36. Brabers AEM, van Dijk L, Bouvy ML, de Jong JD (2013) Where to buy OTC medications? A cross-sectional survey investigating consumers' confidence in over-the-counter (OTC) skills and their attitudes towards the availability of ОTC painkillers. BMJ Open 3:e003455. doi:10.1136/bmjopen-2013-003455 
37. Kasperczyk M. According to Poles, pharmacies are the best places to buy OTC drugs and dietary supplements. http://www.research-pmr.com/a19/according-to-poles-pharmacies-are-the-best-place-tobuy-otc-drugs-and.dietary-supplements. Accessed 15 August 2015 


\section{Appendix}
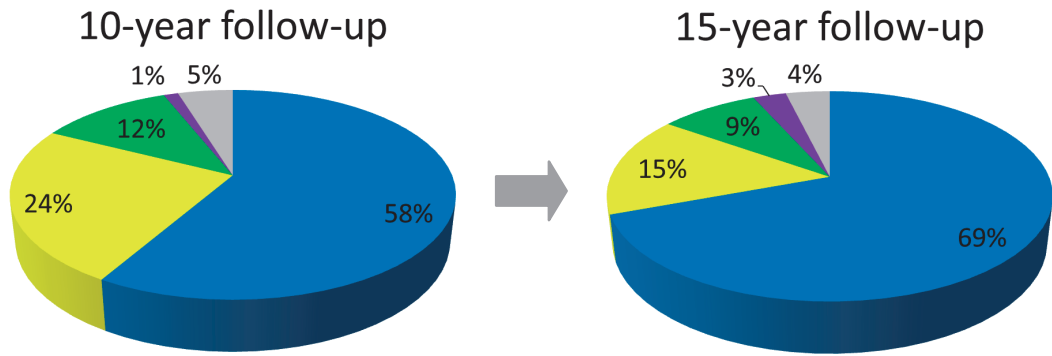

Conventional drugs $\square$ Homeopathy Herbal drugs $\square$ Vitamins/mineral supplements $\square$ Other

Supplementary Figure S1. Comparison of drug utilization by drug category (preparations containing iodide, fluoride, and vitamin D used for prophylaxis according to medical guidelines were excluded from the category 'Vitamins \& mineral supplements') 


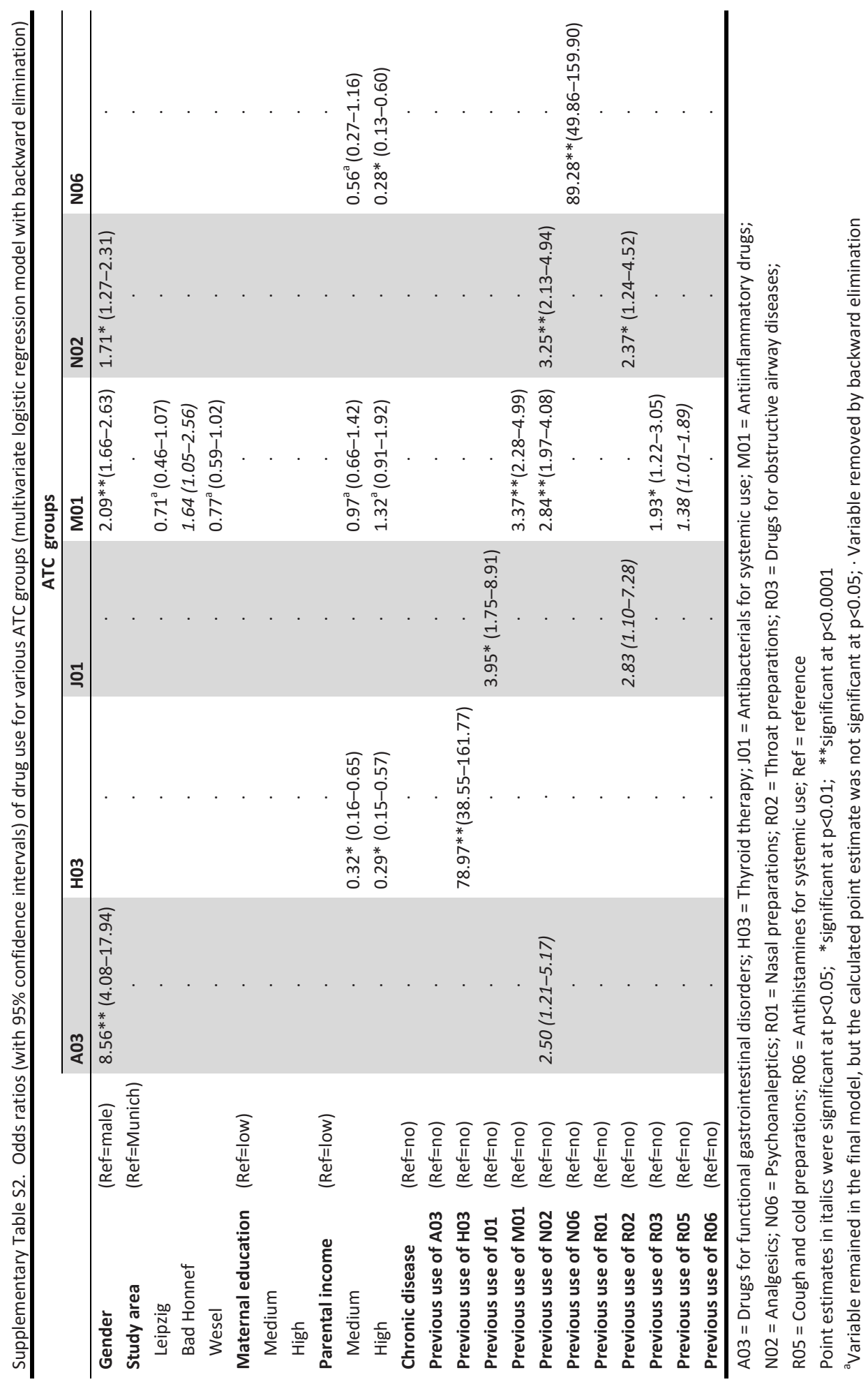




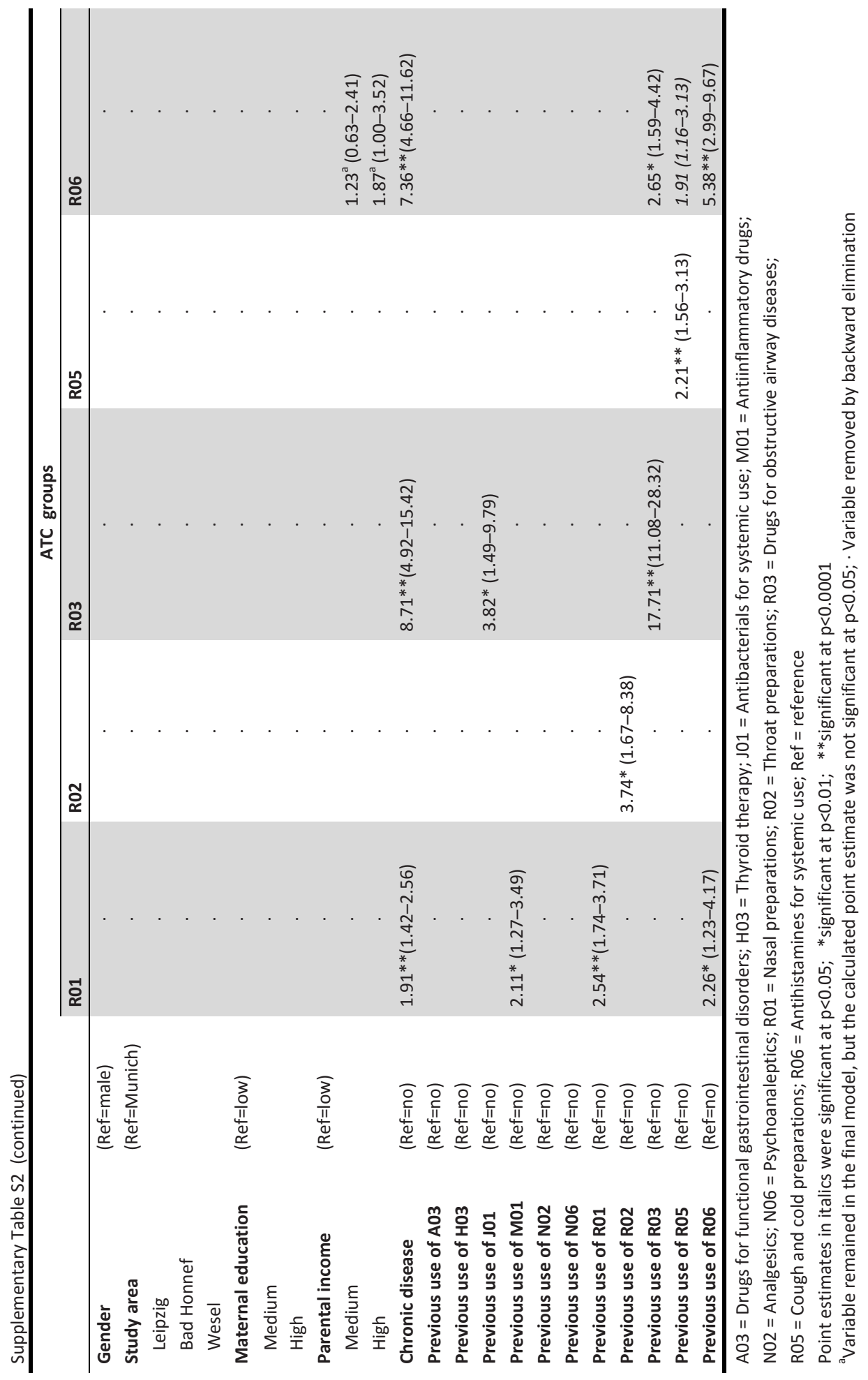



We try never to forget that medicine is for the people. It is not for the profits.

The profits follow, and if we have remembered that, they have never failed to appear.

George W. Merck

American pharmaceutical entrepreneur of German origin and former president of

Merck \& Co., Inc., USA 


\section{CHAPTER 7}

Prices of over-the-counter drugs used by adolescents in Germany and their association with socioeconomic factors

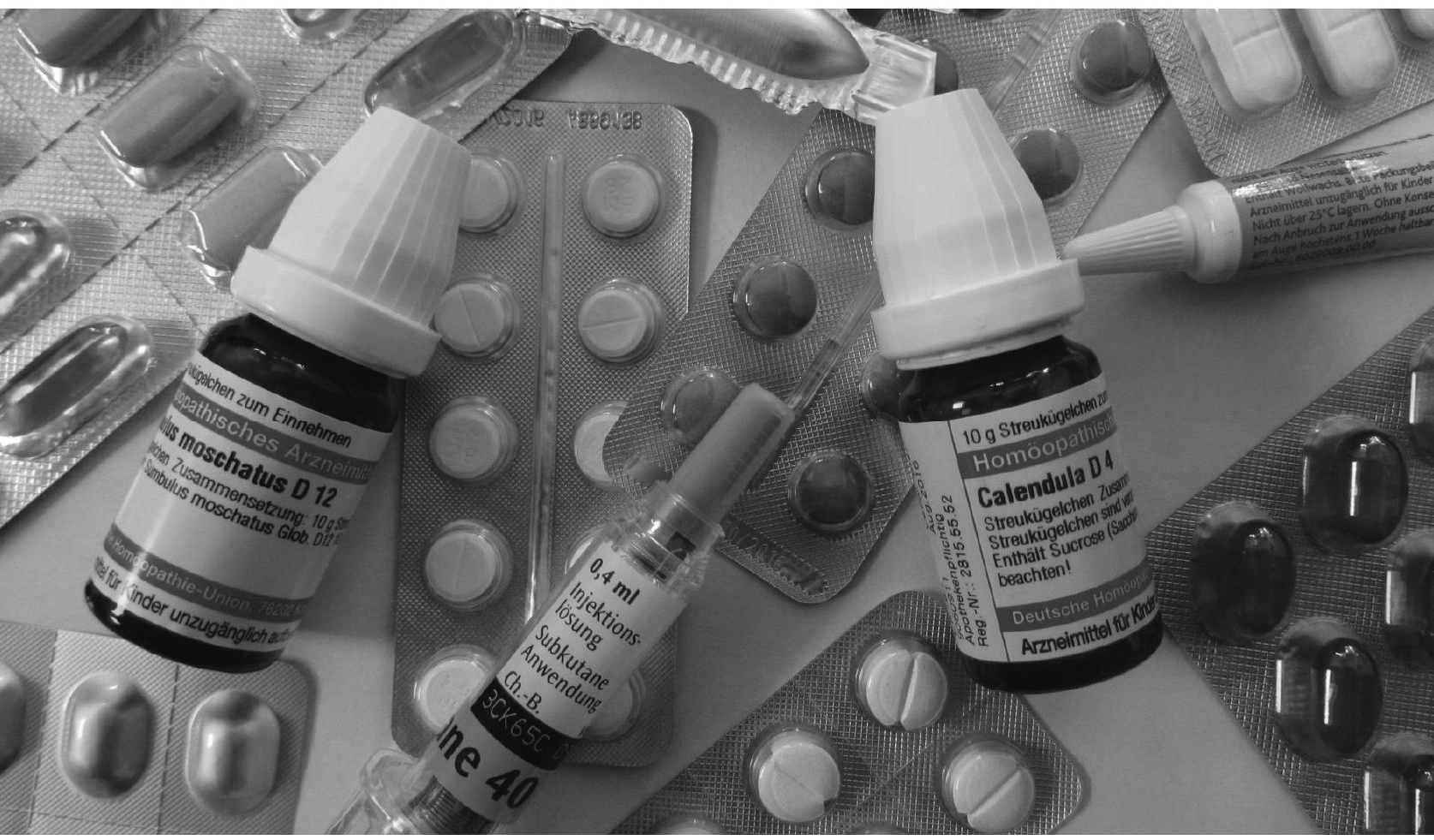

Salvatore Italia, Christina M. Teuner, Irene Brüske, Joachim Heinrich, Dietrich Berdel, Andrea von Berg, Irina Lehmann, Marie Standl, Silke B. Wolfenstetter.

Prices of over-the-counter drugs used by adolescents in Germany and their association with socioeconomic factors.

Das Gesundheitswesen [submitted 15 April 2016] 


\begin{abstract}
Purpose: This study's objective was to analyse the prices of over-the-counter (OTC) drugs used by adolescents in Germany and their association with socioeconomic factors.

Methods: Based on the German GINIplus and LISAplus birth cohorts, data on drug utilization among 15 -year-old adolescents $(n=4,677)$ were collected using a selfadministered questionnaire. The reported drugs were subdivided into prescription drugs and OTC drugs. Prices of OTC drugs were tracked by the pharmaceutical identification numbers.

Results: Overall, 1,499 OTC drugs with clearly identifiable prices were eligible for analysis. Their mean price was $€ 9.75$ [95\% Cl: $€ 9.27-10.22$ ]. About $75 \%$ of the OTC drugs cost less than $€ 10$. Higher mean prices were associated with residing in Munich (€10.74; 95\% Cl: €9.97-11.52), with higher maternal/paternal education (e.g. highest paternal education: €10.17; 95\% Cl: €9.47-10.86), and with higher parental income (e.g. highest income group: €10.24; 95\% Cl: €9.34-11.14).

Conclusions: The price of $€ 10$ for OTC drugs that have to be paid for out of pocket may represent a psychological threshold. Higher prices could discourage especially adolescents from a lower socioeconomic background from taking medically advisable but not reimbursable OTC drugs.
\end{abstract}

\title{
Key words
}

Adolescent · Drug utilization · Drug prices · Socioeconomic factors ·

Over-the-counter drugs 


\section{Introduction}

In Germany, drugs available without a physician's prescription are not normally covered by statutory health insurance for children aged $\geq 12$ years. As in Germany, over-thecounter (OTC) drugs are not reimbursed in many other European countries as well [1]. However, the prevalence of paediatric utilization of OTC drugs has been found to be significantly associated with socioeconomic factors such as maternal education [2,3]. Many OTC drugs are useful, but socioeconomic barriers might result in adolescents not taking medically advisable (especially higher priced) OTC drugs in case of illness if they have to be paid for out of pocket.

To our knowledge, there are no data on how socioeconomic factors are correlated with the prices of OTC drugs used by adolescents in Germany. Therefore, the main objective of this study is to analyse whether there was an association between drug prices and socioeconomic factors with regard to OTC drugs used by 15 -year-old adolescents from the German GINIplus/LISAplus birth cohorts.

\section{Methods}

The GINIplus/LISAplus studies are based on two German birth cohorts that started with 5,991 (GINIplus) and 3,097 (LISAplus) healthy full-term newborns who were recruited between September 1995 and January 1999 from obstetric clinics in the southern (Munich), eastern (Leipzig), and north-western (Bad Honnef and Wesel) parts of Germany.

For the 15-year follow-up, some 6,094 participants' parents/legal guardians were contacted between January 2011 and October 2014. Using a self-administered questionnaire on drug utilization within the past 4 weeks, the participants were asked to enter the drug names and the pharmaceutical identification numbers (PZNs) into five designated spaces. The PZN is used for almost all products sold by German pharmacies. It is printed on the drug package and precisely identifies the drugs with respect to package size, dosage, manufacturer, listed price, etc. Prices were tracked via PZNs using the official price list 'Lauer-Taxe' (August 2012) which provides data for all pharmaceuticals dispensed in German pharmacies. In the present analysis, only those drugs used were considered where the prices were clearly identifiable via the PZNs.

The reported drugs were subdivided into prescription drugs and OTC drugs (available without a physician's prescription) according to the German Ordinance on Prescription-Only medicinal products [4]. Parental education and household income were classified into three levels (low, middle, high) based on the completed years of schooling and the equivalent income, respectively. Further information on the methodology (e.g., inclusion criteria, definition of the drug categories, classification of socioeconomic variables, etc.) is available in detail in previous publications $[5,6]$. 
The GINIplus/LISAplus cohorts obtained approval from the respective ethics committees. Furthermore, written informed consent was given by the participants' parents/legal guardians and by participants.

\section{Results}

Questionnaires on drug use were returned for 4,677 adolescents (response rate: $76.8 \%$ ). Exactly 3,873 drugs had been used by the study participants within the past 4 weeks. The majority $(70 \%, n=2,694)$ were OTC drugs. For 1,499 OTC drugs that were eligible for the further analysis, listed prices were tracked by the reported PZN number. The mean price was €9.75 [95\% confidence interval (CI): €9.27-10.22; standard deviation (SD): 9.44], ranging from $€ 0.94$ to $€ 158.98$. Most $(74.6 \% ; n=1,118)$ of the drug packages had listed prices of less than $€ 10$, whereas 74 (4.9\%) packages were sold at more than $€ 25$ (Supplementary Figure S1). A high percentage (12.1\%) of OTC drugs cost between $€ 9.50$ and $€ 9.99$, the price segment just below $€ 10$ (only eight OTC drugs $(0.5 \%)$ were in the next, same-sized price segment between $€ 10.00$ and $€ 10.49)$.

There was a noticeable variation in the mean OTC drug prices in the different therapeutic categories. Whereas conventional drugs with chemical active ingredients (e.g., ibuprofen or paracetamol) cost €7.23 [95\% Cl: 6.78-7.68; SD: 6.97] on average (range: $€ 0.94-158.98$ ), homeopathic drugs were sold at €12.67 [95\% Cl: 11.41-13.94; SD: 9.55] on average (range: €3.70-116.69), and herbal drugs (range: €1.99-94.45) had a mean price of $€ 14.99$ [95\% Cl: 13.41-16.56; SD: 11.41].

The average price of OTC drugs (Figure 1 ) used by male adolescents ( $€ 10.14 ; 95 \%$ $\mathrm{Cl}$ : 9.27-11.01; SD: 11.39) was higher than the mean price of drugs used by female adolescents (€9.44; 95\% Cl: 8.92-9.95; SD: 7.57). OTC drugs that were purchased in Munich had the highest mean prices (€10.74; 95\% Cl: 9.97-11.52; SD: 10.80), about $€ 2$ above the price level of OTC drugs sold in Wesel (€8.65; 95\% Cl: 7.98-9.32; SD: 8.02), where the mean drug price was lowest.

Higher maternal or paternal education was correlated with higher mean prices for OTC drugs used (e.g., lowest paternal education level (€8.12; 95\% Cl: 7.41-8.83; SD: $5.56)$ vs. highest paternal education level (€10.17; 95\% Cl: 9.47-10.86; SD: 10.40)).

On average, adolescents from the lowest income group bought cheaper OTC drugs (€9.18; 95\% Cl: 7.92-10.44; SD: 9.15) than adolescents from the highest income group (€10.24; 95\% Cl: 9.34-11.14; SD: 11.08). This association of higher drug prices with higher educational or income levels was also shown within specific drug categories (conventional drugs, homeopathic drugs, herbal drugs) or even within the very narrowly defined category of drugs containing ibuprofen only (the most mentioned active ingredient), where children from the highest socioeconomic level used higher priced 
ibuprofen containing drugs (e.g. lowest income level (€4.82; 95\% Cl: 4.37-5.27; SD: 1.22 ) vs. highest income level (€5.94; 95\% Cl: 5.38-6.51; SD: 2.86$)$ ).

Generally, adolescent users of OTC drugs priced at $\geq € 10$ were significantly more likely (tested with $\left.\mathrm{Chi}^{2}\right)$ to reside in Munich $(\mathrm{p}=0.0060)$ and to have a father $(\mathrm{p}<0.0001)$ with the highest education level. However, general use of OTC drugs (regardless of the price) was also positively associated (tested with $\mathrm{Chi}^{2}$ ) with residing in Munich $(p=0.0459)$, paternal education level $(p=0.0002)$, or maternal education level $(p=0.0003)$.

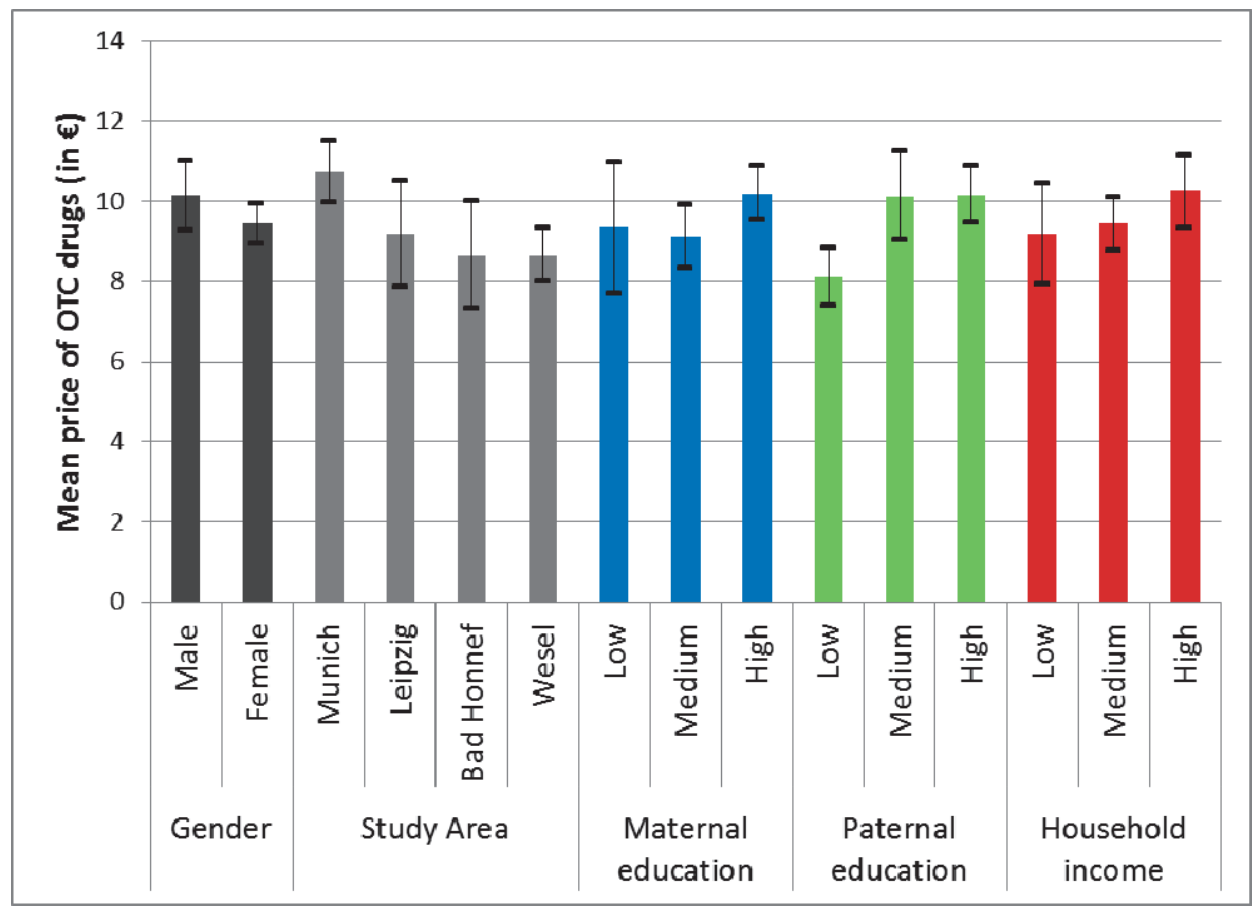

Figure 1. Stratified mean drug prices of over-the-counter drugs

\section{Discussion}

The results indicate that adolescents' use of higher priced OTC drugs may be associated with the geographical region and with parental (mainly paternal) education. There may also be an association with parental income, but further research is needed to confirm this on a significant basis. In Germany, only very few OTC drugs are included in the list of reimbursable OTC drugs [7]. However, the relatively moderate price of $€ 10$ for an OTC drug seems to be a psychological threshold that may discourage consumers from buying higher priced OTC drugs. This is not an issue as long as cheaper alternatives of 
comparable quality are available or OTC drugs are covered by health insurance. On the other hand, it should also be considered that higher priced but medically advisable OTC drugs are possibly not used if they have to be paid for out of pocket, especially in view of adolescents from the lowest socioeconomic level. The '10-euro-barrier' may also have implications with regard to the use of e.g. not reimbursable herbal drugs (mean price: $€ 14.99)$, which may be less attractive just because they cost more than $€ 10$ on average. But also with regard to other drug categories (e.g. emergency contraceptives, recently switched to OTC status and costing roughly €18 (levonorgestrel) in Germany), the price should not be the predominant factor that determines whether a drug is used or not. Nevertheless, a limiting factor of the above-mentioned results is that prices for all OTC drugs are freely calculable in Germany and only the listed prices were considered, which may vary from the actual prices paid in the pharmacies. Moreover, no information was available on how many of the included OTC drugs were actually paid out of pocket.

\section{Acknowledgments}

We thank the families for participation in the study, the obstetric units for allowing recruitment, the GINIplus and LISAplus study teams for excellent work, and several funding agencies listed herein.

The 15-year follow-up examination of the GINIplus and LISAplus studies was supported by the Commission of the European Communities, the $7^{\text {th }}$ Framework Programme: MeDALL project, and the 15-year follow-up examination of the GINIplus study as well by the companies Mead Johnson and Nestlé. This work was also supported by the German Competence Network Obesity ('Kompetenznetz Adipositas') funded by the German Federal Ministry of Education and Research (BMBF) as part of the 'Core Domain Health Economics' (Grant No. 01GI1127). This specific analysis on 'drug use among 15-year-old adolescents from the German GINIplus and LISAplus birth cohorts' was exclusively funded by the Helmholtz Zentrum Munich.

\section{Authors' contribution}

SI classified the reported drugs (therapeutic categories, ATC codes, prescription status, etc.), tracked the drug prices, analysed the data, interpreted the results, conceptualized the initial manuscript, and approved the final manuscript as submitted. SW and CT contributed to the data analysis and interpretation of the results. They critically revised the initial manuscript, and approved the final manuscript as submitted. IB, JH, DB, AB, IL, and MS were involved in data collection. They critically revised the initial manuscript, and approved the final manuscript as submitted. 


\section{Conflict of interest}

The authors declare that they have no conflict of interests.

KEY POINTS

- The mean price of OTC drugs used by adolescents in Germany is $€ 9.75$, and about $75 \%$ of all OTC drugs used cost less than $€ 10$.

- On average, adolescents from a higher socioeconomic background used higher priced OTC drugs.

- Higher prices could discourage especially adolescents from a lower socioeconomic background from taking medically advisable but not reimbursable OTC drugs. 


\section{References}

1. Martikainen J, Rajaniemi S. Drug reimbursement systems in EU Member states, Iceland and Norway. Helsinki: The Social Insurance Institution, Finland, Social security and health reports 54, 2002.

2. Italia S, Batscheider A, Heinrich J, Berdel D, von Berg A, Wolfenstetter SB. Utilization of self-medication and prescription drugs among 15-year-old adolescents from the German GINIplus birth cohort. Pharmacoepidemiol Drug Saf 2015;21:1133-1144.

3. Du Y, Knopf H. Self-medication among children and adolescents in Germany: results of the National Health Survey for Children and Adolescents (KiGGS). Br J Clin Pharmacol 2009;68:599-608.

4. Federal Ministry of Justice and Consumer Protection. Ordinance on prescription-only medicinal products. http://www.gesetze-im-internet.de/amvv/BJNR363210005.html (accessed 27 November 2015)

5. Italia S, Batscheider A, Heinrich J, et al. Utilization and costs of conventional and alternative pharmaceuticals in children: results from the German GINIplus and LISAplus birth cohort studies.

Pharmacoepidemiol Drug Saf 2012;21:1102-1111.

6. Italia S, Brüske I, Heinrich J, et al. A longitudinal comparison of drug use among 10-year-old children and 15-year-old adolescents from the German GINIplus and LISAplus birth cohorts. Eur J Clin Pharmacol 2016;72:301-310.

7. The Federal Joint Committee. Appendix I: Exemptions from the exclusion of OTC drugs from the statutory health insurance benefit package. https://www.g-ba.de/informationen/richtlinien/anlage/17/ (accessed 27 November 2015) 
Appendix

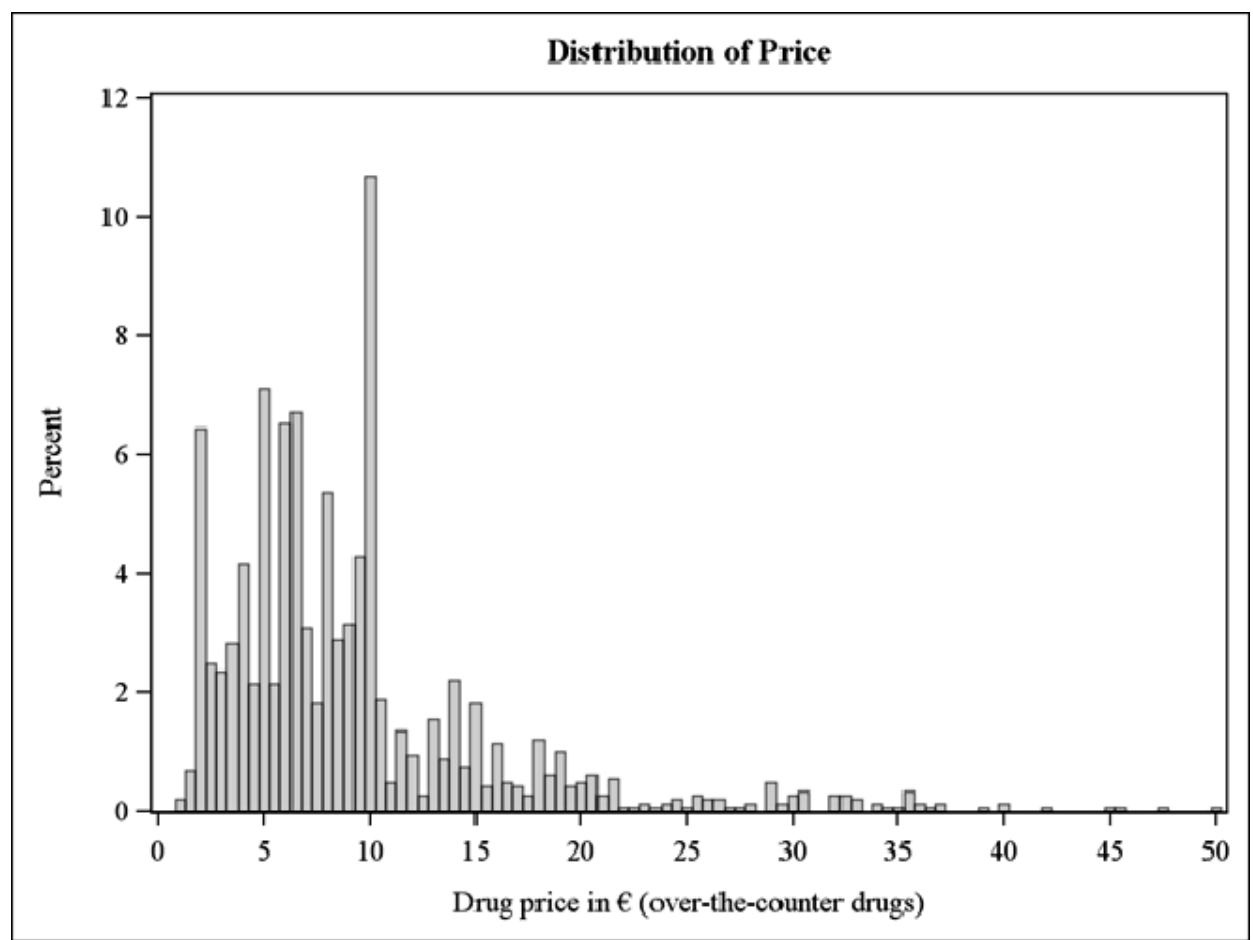

Supplementary Figure S1. Distribution of over-the-counter drugs by listed price (only drugs with prices $\leq € 50$ considered, reflecting $99.4 \%$ of all OTC drugs included in the analysis) 
Being a woman is a terribly difficult trade since it consists principally in dealings with men.

Joseph Conrad

Polish-British writer 


\section{CHAPTER 8}

Status of emergency contraceptives in Europe one year after the European Medicines Agency's recommendation to switch ulipristal acetate to non-prescription status

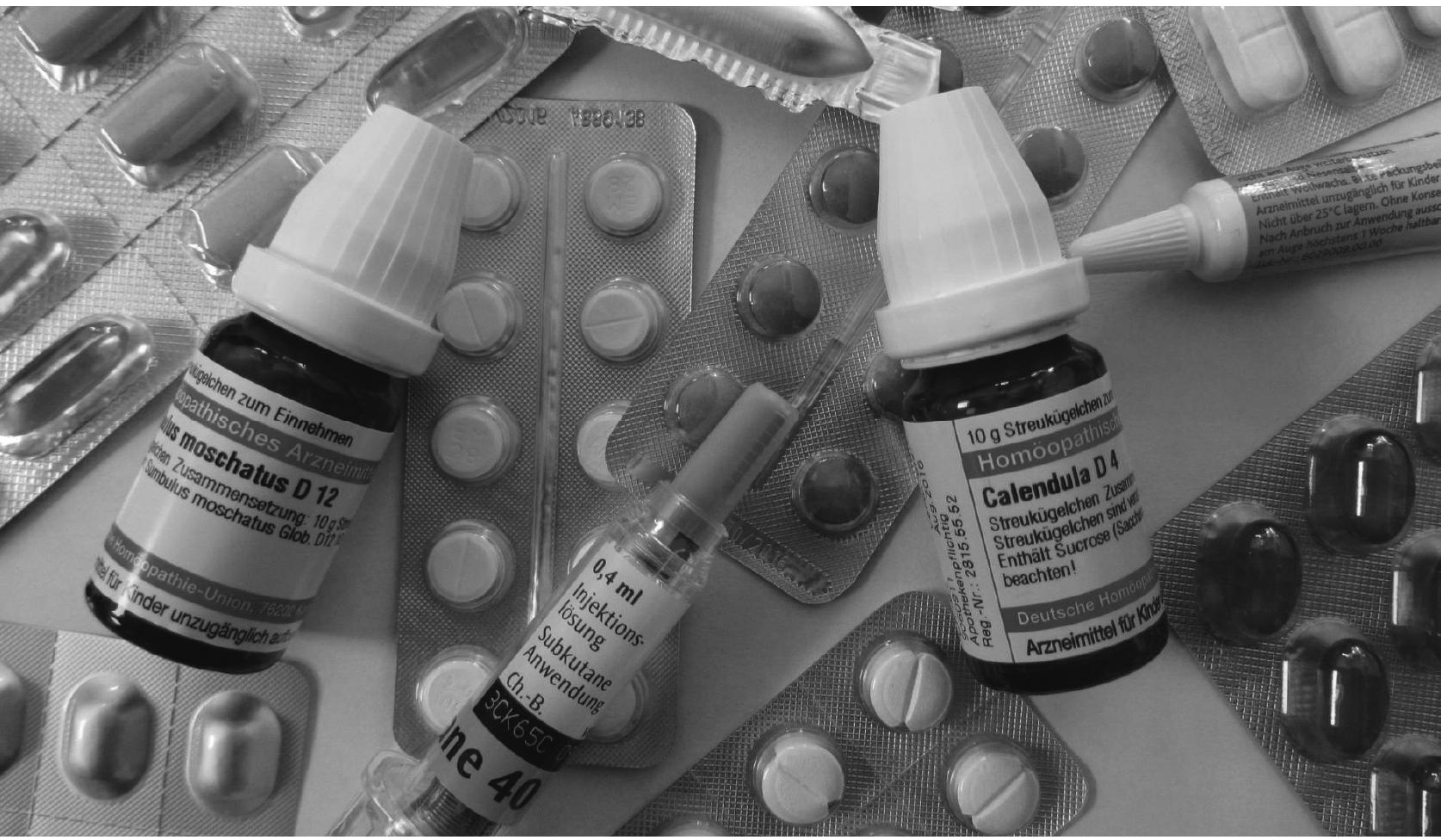

Salvatore Italia, Helmut Brand.

Status of emergency contraceptives in Europe one year after the European Medicines Agency's recommendation to switch ulipristal acetate to non-prescription status.

Public Health Genomics [published online 30 March 2016] 


\begin{abstract}
Background: In November 2014, the European Medicines Agency (EMA) recommended switching the emergency contraceptive (EMC) ulipristal acetate to non-prescription status. This study's objective was to assess the current legal status of the two EMCs ulipristal acetate and levonorgestrel in Europe and to report the development of sales figures for EMCs since they were made freely available.

Methods: Health authorities were contacted in autumn 2015 and asked about the current status of EMCs and whether the sales figures had changed after a switch to nonprescription status. Additionally, data on consumption were collected in 18 German community pharmacies.

Results: As of November 2015, most countries in the European Union have followed the EMA recommendation. Hungary kept the prescription-only status. In Malta, EMC drugs are not authorized. Germany and Croatia switched levonorgestrel to nonprescription status as well. Of the EU candidate and European free trade association countries, ulipristal acetate is available without prescription in Norway and Bosnia and Herzegovina only. Several countries reported an increase in EMCs sales since the switch.
\end{abstract}

Conclusions: An EMA recommendation can strongly contribute to the harmonization of a drug's legal status in the European Union. In most European countries, ulipristal acetate and/or levonorgestrel are now freely available.

\title{
Key words
}

Emergency contraceptives · Ulipristal acetate · Levonorgestrel · Europe ·

Prescription status · Availability 


\section{Introduction}

Unintentional pregnancy and terminations of pregnancy are relevant public health issues that, not least, affect adolescent girls [1,2] and are predicted by socioeconomic factors such as educational background or income [3-8]. In 2009, the active pharmaceutical ingredient 'ulipristal acetate' obtained marketing authorization through the centralized procedure of the European Medicines Agency (EMA) to be used for emergency contraception throughout the European Union (EU). Another active ingredient used for emergency contraception is levonorgestrel (1.5 $\mathrm{mg}$ as a single dose), which is authorized in most European countries on a national level.

An emergency contraceptive (EMC), also known as the 'morning-after pill', can prevent unintended conception in case of, e.g., failure of other contraceptive measures, if it is taken within 72 hours (levonorgestrel) or 120 hours (ulipristal acetate) after sexual intercourse. Effectiveness is increased by taking EMCs very quickly, preferably within 24 hours [9].

In November 2014, the EMA recommended switching the EMC drug ulipristal acetate (ellaOne ${ }^{\circledR}$ ) from prescription status to non-prescription status [10]. On 7 January 2015, the European Commission issued a legally binding decision valid (in principle) throughout the EU, which makes this EMC freely available as an over-the-counter (OTC) drug [11]. This decision was also based on the safety profile for ulipristal acetate, which is considered to be comparable with levonorgestrel [12], and was supposed to speed up women's access to emergency contraceptives. Prior to the EMA recommendation, ulipristal acetate (UPA) was available on prescription only in all European countries where it was marketed (with some exceptions in the United Kingdom (UK), where it was partly already available without a prescription on a trial basis). At the time of the EMA recommendation, levonorgestrel (LNG) was already available without a physician's prescription to be used for emergency contraception in most European countries.

This study has two main objectives:

First, to summarize the current legal and availability status of the two emergency contraceptive drugs UPA and LNG in Europe.

Second, to describe the impact of the switch of emergency contraceptive drugs to non-prescription status on EMC sales in Germany and other European countries where respective data were available. 


\section{Methods}

\section{Included countries}

For this study, all 28 member states of the EU and the four members of the European Free Trade Association (EFTA), Iceland, Liechtenstein, Norway, and Switzerland, were addressed. Additionally, EU candidate countries and potential candidates [13] were also considered for the assessment.

\section{Assessment of the prescription status}

To obtain information on the current legal status of EMCs and further data, the countries' national pharmacists' associations, as listed on the homepage of the Pharmaceutical Group of the European Union (PGEU) [14], were contacted by email between September 2015 and November 2015. A list was attached to the email with several questions on EMCs. In detail, the following issues were addressed:

- Current prescription status of UPA and LNG?

- If not yet switched to free availability, implementation process underway?

- Available in pharmacies only?

- Dispensed behind the counter only?

- Any restrictions when dispensing an EMC (e.g. for girls $>18$ years)?

- Can EMCs be advertised in the common media such as TV or print media?

- Are the prices of EMCs fixed by legislation or freely calculable?

- Any information available as to whether the EC sales figures changed markedly since the change to non-prescription status?

- Any information on drug shortages in relation to EMCs available?

If no response was obtained from the pharmaceutical associations, other health authorities (e.g. national medicines agencies, national health ministries, pharmacists' chambers, etc.) were contacted and/or the authorities' homepages as well as the website of the European consortium for emergency contraception [15] were screened for information with regard to the current legislation on EMCs. In addition, the market leader for EMCs in Europe (HRA Pharma) was also contacted and asked to supply market data on EMCs. 
Own data on EC sales figures were assessed in 18 community pharmacies from various German regions (Baden-Württemberg, Bavaria, Hesse, North Rhine-Westphalia, Saarland, Schleswig-Holstein) by directly contacting the pharmacy owners. Sales figures were collected for the period between January 2014 and October 2015.

\section{Results}

\section{EU member countries}

As of November 2015, nearly all EU countries followed the European Commission's decision and made UPA freely available. The decision was transposed to national legislation very quickly (by January 2015) in, e.g., Spain, Austria, Belgium, Lithuania, and the United Kingdom. UPA is registered but not yet available (expected by 2016) in Estonia. One country (Hungary) did not follow the recommendation and decided in January 2015 to classify all orally administered contraceptives (including UPA for emergency contraception) as prescription drugs. No EMCs containing UPA or LNG are licensed in Malta.

Normally, UPA is available in pharmacies behind the counter only. In the Netherlands and Sweden, UPA is also sold outside pharmacies. In Luxembourg, e.g., UPA is additionally distributed in family planning centres, whereas the UK also offers access through UK-based internet sites.

In the context of the UPA implementation process, Germany and Croatia (where LNG was subject to medical prescription before November 2014) switched LNG to nonprescription status as well. LNG remained a prescription drug in Hungary, Italy and Poland. In Cyprus, LNG has non-prescription status, but is not available on the market because of the financial crisis since 2013. LNG is also partly available outside pharmacies (Netherlands, Portugal, Sweden). In Luxembourg and Romania, e.g., UPA is additionally distributed in family planning centres, whereas the UK and France also offer access through government-based internet sites.

In the Principality of Monaco, formally not part of the EU, both UPA and LNG are freely available. No data were available for San Marino and Andorra, two further microstates closely related to the EU.

\section{EFTA countries}

UPA is available without prescription in Norway (switch by the end of December 2014), but still requires a prescription in Liechtenstein (according to Swiss law) and Switzer- 
land. UPA is not yet available in Iceland. LNG is available without prescription in all four EFTA countries. In Norway, both UPA an LNG are sold also outside pharmacies, whereas in Iceland, Liechtenstein and Switzerland, only pharmacies are allowed to sell UPA or LNG.

\section{EU candidate and potential candidate countries}

UPA is not marketed in Albania, the Former Yugoslav Republic of Macedonia, and Montenegro, but it is available as a prescription drug from pharmacies in Serbia. According to the information provided by the Istanbul Chamber of Pharmacists (Istanbul Ezcacl Odası), although subject to medical prescription, UPA may sometimes be sold without prescription in Turkish pharmacies. Bosnia and Herzegovina is the only candidate or potential candidate country (no data were available for Kosovo for UPA or LNG) where UPA can be bought without a physician's prescription.

LNG has prescription-only status in Albania and the Former Yugoslav Republic of Macedonia, whereas it needs no prescription in Montenegro and Serbia. LNG has nonprescription status in Turkey as well, but has not been available since 2014. LNG is also not available in Bosnia and Herzegovina.

\section{Development of sales figures}

Although only UPA was included in the EMA recommendation, the German administration switched both UPA (restricted to the brand product ellaOne ${ }^{\circledR}$ ) and LNG contemporaneously to non-prescription status by a respective modification of the ordinance on prescription-only medicinal products. The relevant decision was published in the Federal Law Gazette dated 13 March 2015. Dispensing a drug as an OTC product requires packages to be labelled accordingly. By the middle of March 2015, only ellaOne ${ }^{\circledR}$ was available in German pharmacies as an OTC-compatible product. Suitable LNG products were available about 1 month later by the middle of April 2015. Figure 1 shows the number of EMCs sold (data available for 18 community pharmacies) per month for the assessment period from January 2014 until October 2015. The 18 included pharmacies were distributed over six different federal states of Germany. Ten pharmacies were located in small cities (5,000-20,000 inhabitants) and five in mid-sized cities (20,000100,000 inhabitants). A further two pharmacies were in larger cities (>250,000 inhabitants). One pharmacy was located in a town with a rather rural character $(2,500$ inhabitants). 


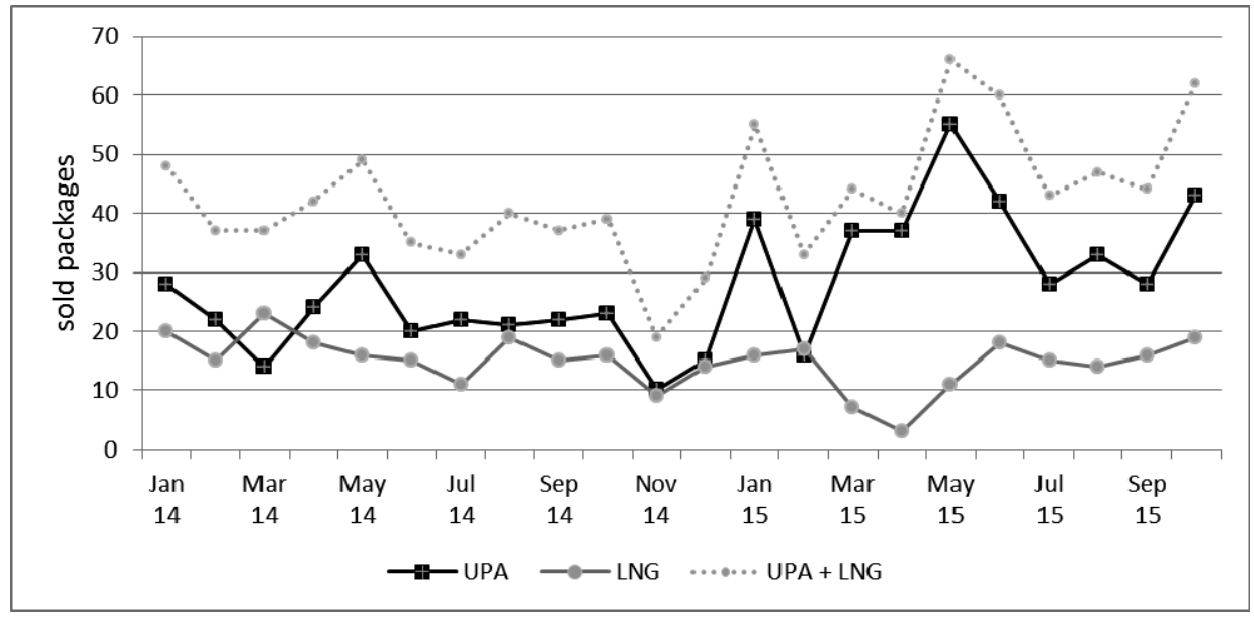

Figure 1. EMC packages sold in 18 German community pharmacies (all four EMC brands of levonorgestrel (LNG) and all reimported medicinal products of ulipristal acetate (UPA) currently available in Germany considered)

According to the cumulated data from the 18 participating pharmacies (Figure 2), the overall increase in EMC sales in 2015 (May-October) for both UPA and LNG together was $38 \%$ for all pharmacies together, compared with the same period in 2014 . However, the increase in consumption was visible for UPA only (+62\%), whereas the number of LNG packages used remained at an almost stable level (+1\%).

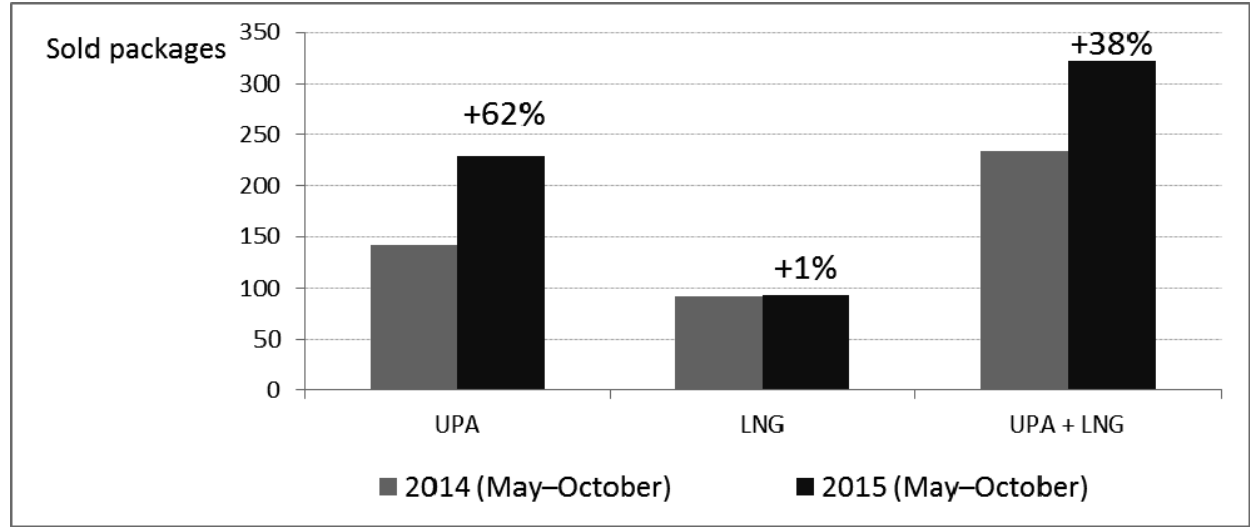

Figure 2. Consumption of ulipristal acetate (UPA) and levonorgestrel (LNG) containing emergency contraceptives since the switch to free availability, in comparison with the corresponding period in 2014 
In the 2 months before the change in prescription status, the consumption of EMCs was very similar to the corresponding months in 2014 (January and February 2015: $n=88$ EMCs sold vs. $n=85$ EMCs sold in January and February 2014). Since May 2015, exactly $74 \%$ of the EMCs sold were purchased without presenting a physician's prescription (based on dispensing data ( $n=99$ EMC packages sold) from two of the 18 included pharmacies only).

Further information on the impact of the switch on German sales of EMCs is integrated into Table 1, which also summarizes the development of EMC consumption in Europe for those countries with available studies or reports on consumption since the change in classification status.

Table 1. Development of EMC consumption since the change in classification status

\begin{tabular}{ll}
\hline Country & General description of the impact since EMCs were freely available \\
\hline Austria & An increase in LNG sales of $30 \%$ was reported for the Austrian federation state \\
& 'Vorarlberg' within only 2 months after the switch to OTC status in December \\
& 2009. For the rest of Austria, no such clear trend was reported. The increase espe- \\
& cially in Vorarlberg may be explained by the short distance from Germany, where \\
& LNG was available by prescription only in 2009, and Switzerland, where prices for \\
& LNG may be higher [16]. \\
Croatia & Some increase in UPA sales (not further quantified) after the switch to non- \\
& prescription status in April 2015 was reported for Croatia by the Croatian Pharma- \\
& ceutical Society (Hrvatsko Farmaceutsko Društvo). LNG was not yet switched at the \\
& time this information was provided, but was expected to gain non-prescription \\
status very soon. & Prior to the switch to availability without prescription in 2001, the use of LNG \\
Denmark & increased slightly from 23,000 DDD in 1996 to 29,000 DDD in 2000. After the \\
change in classification status in 2001, LNG use increased from 39,000 DDD (in \\
2001) to 103,000 DDD in 2008. Since then, the sales figures have remained almost \\
stable. For UPA, an increase in market share from 4\% before the switch in May \\
2015 to $10 \%$ in autumn 2015 was reported by the Association of Danish Pharma- \\
cies (Apothekerforeningen). \\
According to the 2015 yearbook of the Estonian agency of medicines (Ravimiamet), \\
the consumption of LNG was almost stable in the period 2010-2014 at levels be- \\
tween 0.06 and 0.07 DDD/1,000 inhabitants/day \\
Finland \\
In Finland, LNG has been available as an OTC drug since 2002. In 2002, EMC sales \\
increased by 62\% [17]. \\
LNG was switched to non-prescription status in 1999. The proportion of women \\
aged 15-24 years who had ever used EMCs rose from 14.6\% in 1999 to 31.7\% in \\
2004 [18]
\end{tabular}


Table 1 (continued)

Germany Based on data collected by a market research company (IMS Health), the consumption of emergency contraceptives increased by about $30 \%$ in the first 6 weeks after the change in classification status (compared with consumption in the corresponding period in 2014). Compared with the week prior to the change $(9,500$ packages), consumption increased by $42 \%$ in the week directly after the switch (13,500 packages) [19]. Similar data provided by the Federal Union of German Associations of Pharmacists (ABDA) based on results from another market research company (Insight Health) suggest an increase in EMC consumption from 37,330 packages in February 2015 to 49,298 packages (+32\%) in March 2015 and 60,152 (+61\%) packages in May 2015 (the mean consumption per month in 2013 and 2014 was about 38,000 packages).

Iceland LNG was switched to OTC status in 2001. A 2009 publication [20] stated that use of LNG has become more common since the switch (consumption roughly doubled).

Latvia No increase in emergency contraceptives use during the last year was reported for Latvia by the State Agency of Medicines (Zālu valsts aǵentūra).

Montenegro A stable consumption of 0.04 DDD/1,000 inhabitants/day of LNG between 2012 and 2014 was reported by the agency for medicines and medical devices of Montenegro (Calims - Agencija za ljekove i medicinska sredstva Crne Gore).

Poland According to a newspaper article in 'Die Welt', ellaOne ${ }^{\circledR}$ was sold out in Warsaw pharmacies shortly after the classification switch to non-prescription status, presumably because women feared that the decision regarding the switch might be reversed again [21].

Switzerland In Switzerland, LNG was made freely available in 2002. About 8,000 packages of the leading brand of EMCs were sold in the year of the switch. This figure increased to 78,500 packages in 2007 and 93,500 packages in 2008 (based on data from the Swiss Pharmaceutical Union 'pharmaSuisse'). Simultaneously, the use of condoms steadily decreased in the Swiss population [22].

United LNG has been available without prescription since January 2001 in the United Kingdom Kingdom. Compared with 2001, when 8.4\% of women aged 16-49 years used EMCs once, the proportion of women using EMCs did not change significantly in 2001 (7.9\%) and 2002 (7.2\%). However, in the youngest age group (16-19 years), there was a (not significant) rise from $15.3 \%$ in 2000 to $21.5 \%$ in 2001 , and a significant drop to $8.9 \%$ in 2002 of women using EMCs. At the same time, the proportion of women obtaining EMCs directly from a pharmacy increased from $0 \%$ in 2000 to $19.7 \%$ in 2001 and $32.6 \%$ in 2002 [23].

\footnotetext{
$D D D$, defined daily dose

$E M C$, emergency contraceptive

$L N G$, levonorgestrel

OTC, over-the-counter

UPA, ulipristal acetate
} 


\section{Discussion}

EMCs and the linked aspect of unintended pregnancy are relevant public health topics and important issues with relevance to women's self-determination and empowerment as well. However, the debate on EMC drugs, also in terms of their availability without a physician's prescription, is not free from emotions or ethical objections. Hence, it might have been assumed that harmonization of the legal status across the various European countries would be quite difficult. This study showed that a decision by the European Commission in relation to the legal status of an active pharmaceutical ingredient may be followed and transposed to national legislation by most of the EU members within a time period of approximately 1 year or less, despite existing possibilities for circumventing the Commission's decision (e.g. in the case of EMCs, by adopting Article $4 \S 4$ of the Directive 2001/83/EC [24]). Even in countries that used to have a negative attitude towards freely available EMCs (e.g. Germany, Italy, Poland) before the EMA recommendation, the national administrations decided to liberalize access to EMCs (at least for UPA). Evidently, in the context of the EMA recommendation for UPA, some countries such as Germany or Croatia generally reassessed their attitude towards EMCs and switched LNG to non-prescription status as well. Nevertheless, other EU countries (Italy, Poland) did not extend the EMA recommendation to LNG, but limited the change in classification status to UPA containing EMCs only.

As expected, the option of getting EMCs directly over the counter resulted in greater use of EMCs in most of the countries with available data on drug consumption. Apparently, women make use of this new possibility quickly. Additionally, most pharmacists may not refuse (for whatever reason, e.g. no need to use, ethical aspects [25], etc.) to dispense EMCs if requested without prescription. For instance, in Ireland, where LNG has been freely available since spring 2011 , only $3 \%$ of the consultations with a pharmacist resulted in no delivery of EMCs (based on data from the 2014 annual report of the Irish Pharmacy Union). Almost the same refusal rate of $2 \%$ of pharmacists (on account of moral or religious beliefs) was reported for pharmacies in Boston, Atlanta and Philadelphia (United States) [26]. The magnitude of the increase in EMC use may also depend on the local setting and may vary between urban and more rural regions $[18,19]$. It is also conceivable that women might prefer 'anonymous' urban pharmacies to a more rural pharmacy in their home town where everybody would know everybody, although in theory discretion at the counter should be given in all pharmacies. At the same time, women should bear in mind that the use of EMCs cannot prevent sexually transmitted diseases (in Switzerland, the use of condoms has decreased since the switch of LNG to OTC status [22]) and are also not appropriate for regular use as an ongoing contraceptive method [27]. However, in some countries, the change in prescription status has had only a weak impact on the use of EMCs (e.g. UK [23]). 
In the context of consumption figures, it should also be mentioned that the change in classification status touches different economic interests. Evidently, first and foremost, pharmaceutical manufacturers of EMCs will benefit economically from facilitated access to EMCs that may result in higher demand for those medicines [28]. Additionally, according to the data on EMC consumption in Germany, UPA sales may profit the most from the switch to OTC status. This may be explained in part by more intense promotion of the use of UPA, not simply because of possibly favourable pharmacological properties in comparison with LNG, but also because of the higher prices of UPA (e.g. listed prices in Germany are about 30 euros for UPA vs. 16-18 euros for LNG). Furthermore, without the need for a prescription, women are more likely to consult a pharmacist directly rather than a physician. In Germany, shortly after the change in classification status, about $78 \%$ of EMCs were sold without a physician's prescription [19]. Similar trends had been observed in the UK and in France [23,29]. As a consequence, physicians may consider the switch as an intrusion into their sphere of competence. However, they may also lose consultancy fees and may therefore try to impede a switch to non-prescription status, even if the physicians' organizations mainly use drug compliance and safety problems as arguments for their reluctant attitude [21,30,31] towards a change in classification status.

A further aspect of presumably growing importance in the context of approving new drugs or switching already approved drugs to free availability is the issue of personalized pharmacotherapy. LNG and UPA as well are mainly metabolized through the cytochrome P450 3A4/5 systems [32,33], which are known to be subject to genetic variability between individuals of the European population. Genetic polymorphism may influence the efficacy and the tolerance of emergency contraceptives. For instance, high LNG doses (1.5 mg) as administered for emergency contraception can cause nausea and vomiting, which in turn may result in an increased failure risk of emergency contraception (if no further LNG dose is applied). In theory, side effects such as nausea could occur even more among slow metabolizers, owing to increased LNG plasma concentrations. However, only little data is available on the influence of genetic polymorphism on UPA or LNG metabolism [32]. Hence, the aspect of pharmacogenetics may not have been investigated sufficiently yet with regard to emergency contraceptive drugs. Furthermore, also personal body parameters such as the body weight may influence efficacy of emergency contraceptives. Results from a 2012 publication [34] suggest, that effectiveness of 30 mg UPA for emergency contraception is lower among obese women. However, UPA is only available as tablet with a dose of $30 \mathrm{mg}$ so far.

In general, prescription-only status for EMCs might not appear very meaningful, if those products are available without a prescription in neighbouring countries. This may presumably lead to an increase in drug tourism in border regions, probably including communication problems between customers and dispensing pharmacists because of 
insufficient language skills which, in sum, are likely to have a negative effect on drug compliance. In particular, Maltese women may perceive their situation as rather unsatisfactory, as neither LNG nor UPA is available even on prescription in their country. This is a remarkable state of affairs, especially as the World Health Organization recommends levonorgestrel for EMC and included this active ingredient in the essential medicines list [35]. Nevertheless, Maltese women could adopt the Yuzpe method (by prescription only), which is however less effective and less well tolerated [36,37]. Of course, they may also undertake, e.g. a trip by speedboat to Sicily (which would be the nearest EU territory with freely available EMCs), but this would be rather strenuous, hypothetical and quite unreasonable. Presumably, women living in countries without freely available EMCs are also more likely to stock up with those products whenever they have the opportunity to do so (for instance when travelling to other European countries), which might be contrary to the original intention of the legislators.

Reimbursement policies vary across the European health care systems [15]. Some countries fully cover the costs of UPA or LNG if prescribed or procured in family planning clinics, whereas in other countries EMCs have to be paid out-of-pocket (in Germany, free for $<18$ years, 5 euros prescription charge for $<20$ years, not covered for $\geq 20$ years). This may also have socioeconomic implications, as mainly women from lower socioeconomic levels are known to be more affected by unintended pregnancy [3-5]. High prices may discourage especially women from a lower socioeconomic background from purchasing an emergency contraceptive [38]. If concerned, they may just be tempted to take nothing, resulting, of course, in a higher risk of unintended pregnancy. Results drawn from our own research on the use of OTC drugs among adolescents in Germany (study sample size $n=4,677$; data not yet published) imply that a price of 10 euros or more for an OTC drug may represent a psychological threshold beyond which (socioeconomically weaker) adolescents are likely not to buy an OTC drug (75\% of the OTC drugs utilized cost less than $€ 10)$. This may be relevant especially for those countries (e.g. Italy, Poland) where EMCs are not covered by the social system and UPA is the only emergency contraceptive drug available without prescription, as UPA normally has a much higher price than LNG and is usually marketed at prices roughly between 20 and 40 euros in the EU [15]. Presumably, potential socioeconomic disparities regarding access to EMCs would have been further reduced if the relevant national authorities had not limited the change in classification status to UPA, but had implemented free availability of LNG as well.

This study has some limitations. The sample consisting of 18 included pharmacies cannot be considered representative of Germany, although the results are roughly in line with findings (cumulated for UPA and LNG together) for the first 3 months after the switch reported by the Federal Union of German Associations of Pharmacists (ABDA). However, no other data source for the period under research was available that could 
provide sales figures specified by active ingredient (UPA, LNG). Additionally, for five EU countries, we had to refer to data from the European consortium for emergency contraception [15] only, as no response was obtained directly from the relevant national authorities.

\section{Conclusions}

Based on the results of this study, it may finally be concluded that Europe is able to harmonize the positions of the single European countries after an EMA recommendation or decision, even towards controversially discussed health topics such as the legal status of EMCs. At the same time, European countries can and do use their scope of action to adapt their positions regarding (current) political and societal circumstances and attitudes, e.g. by recommending checklists for pharmacists as a tool for dispensing EMCs (e.g. Austria, Croatia, Finland, Liechtenstein, Germany, Ireland, Spain, Switzerland), setting advertising restrictions or prohibitions (e.g. Croatia, Germany, Hungary, Lithuania), minimum age limits for customers (e.g. Bulgaria, Croatia, Italy, Latvia, Poland, Slovenia) or implementing a ban on internet sales (e.g. Germany, Italy). Nevertheless, there still remain (a very few) countries within the European community that persist in their own legitimately different position, which may change with time or might even be reduced to absurdity by the versatility of concerned women who will know where to procure EMCs when necessary.

\section{Acknowledgements}

We would like to thank all authorities and pharmacies who contributed detailed information to this study.

\section{Disclosure statement}

The authors declare that they have no conflict of interest. 


\section{References}

1. Gissler M, Fronteira I, Jahn A, Karro H, Moreau C, Oliveira da Silva M, Olsen J, Savona-Ventura C, Temmerman M, Hemminki E; REPROSTAT group: Terminations of pregnancy in the European Union. BJOG 2012;119:324-332. Doi:10.1111/j.1471-0528.2011.03189.x.

2. The European Society of Contraception and Reproductive Health (ESC) and the International Federation of Gynecology and Obstetrics (FIGO). The global epidemic of unintended pregnancies. www.figo.org/sites/default/files/uploads/generalresources/FIGO_ESC_Unwanted\%20Pregnancy\%20Slides.pdf. (accessed 10 September 2015)

3. Thomas A: Policy solutions for preventing unplanned pregnancy (2012). www.brookings.edu/research/reports/2012/03/unplanned-pregnancy-thomas. (accessed 16 November 2015)

4. Mallard SR, Houghton LA: Socio-demographic characteristics associated with unplanned pregnancy in New Zealand: implications for access to preconception healthcare. Aus NZJ Obstet Gynaecol 2013;53:498-501. Doi:10.1111/ajo.12074.

5. Yago Simón T, Tomás Aznar C: Variables sociodemográficas relacionadas con embarazos no planificados en jóvenes de 13 a 24 años [Sociodemographic and clinical data predicting unplanned pregnancy in young 13 to 24 years, Spain]. Rev Esp Salud Publica 2014;88:395-406. Doi: 10.4321/S113557272014000300009. Spanish

6. Daniels K, Jones J, Abma J: Use of emergency contraception among women aged 15-44: United States, 2006-2010. NCHS Data Brief 2013 Feb;(112):1-8.

7. Font-Ribera L, Pérez G, Salvador J, Borrell C: Socioeconomic inequalities in unintended pregnancy and abortion decision. J Urban Health 2008;85:125-135. DOI:10.1007/s11524-007-9233-z.

8. Kozinszky Z, Sikovanyecz J, Devosa I, Szabó D, Barabás K, Pál A, Arthur J: Determinants of emergency contraceptive use after unprotected intercourse: Who seeks emergency contraception and who seeks abortion? Acta Obstet Gynecol Scand 2012;91:959-964. DOI:10.1111/j.1600-0412.2012.01429.x.

9. Schmid R: The cost-effectiveness of emergency hormonal contraception with ulipristal acetate versus levonorgestrel for minors in France. Plos One 2015;10:e0138990. DOI:10.1371/journal.pone.0138990.

10. European Medicines Agency. EMA recommends availability of ellaOne ${ }^{\circledR}$ emergency contraceptive without prescription.

http://www.ema.europa.eu/ema/index.jsp?curl=pages/news_and_events/news/2014/11/news_detail_ 002223.jsp\&mid=WCOb01ac058004d5c1. (accessed 16 November 2015)

11. Spiegel-Online - Barmer BEK (7 January 2015). Notfallverhütung: EU-Kommission befreit Pille danach von der Rezeptpflicht. www.spiegel.de/gesundheit/sex/pille-danach-eu-kommission-gibt-ellaone-frei-a1011457.html. (accessed 16 November 2015)

12. European Medicines Agency. Assessment report EMA/73099/2015. www.ema.europa.eu/docs/en_GB/document_library/EPAR_-_Assessment_Report__Variation/human/001027/WC500181904.pdf. (accessed 15 November 2015)

13. European Commission. European Neighbourhood Policy and Enlargement Negotiations. ec.europa.eu/enlargement/countries/check-current-status/index_en.htm. (accessed 15 November 2015)

14. The Pharmaceutical Group of the European Union (PGEU). www.pgeu.eu. (accessed 15 November 2015)

15. European consortium for emergency contraception ECEC. www.ec-ec.org. (accessed 19 November)

16. DiePresse.com. "Pille danach": Größere Nachfrage nur in Vorarlberg. http://diepresse.com/home/panorama/oesterreich/541528/Pille-danach_Grossere-Nachfrage-nur-inVorarlberg-. (accessed 19 November 2015)

17. Falah-Hassani K, Kosunen E, Shiri R, Rimpelä A: Emergency contraception among Finnish adolescents: awareness, use and the effect of non-prescription status. BMC Public Health 2007;7:201 DOI:10.1186/1471-2458-7-201.

18. Moreau C, Trussell J, Bajos N: The determinants and circumstances of use of emergency contraceptive pills in France in the context of direct pharmacy access. Contraception 2006;74:476-482. DOI:10.1016/j.contraception.2006.07.008.

19. Schersch S: Pille danach - Absatz steigt regional unterschiedlich stark. Pharmazeutische Zeitung 160(24);14. German

20. Heiđarsdóttir ML, Almarsdóttir AB, Geirsson RT: Providing emergency contraceptive pills in pharmacies [Afgreiđsla á neyđargetnađarvörn í apótekum]. Icel Med J 2009;95:343-347. Icelandic 
21. Die Welt. Polen streitet über die Pille danach. www.welt.de/politik/ausland/article137044233/Polenstreitet-ueber-die-Pille-danach.html. (accessed 19 November 2015)

22. Neue Zürcher Zeitung NZZ. Abgabe der "Pille danach" stark gestiegen. http://www.nzz.ch/abgabe-derpille-danach-stark-gestiegen-1.2254737. (accessed 19 November 2015)

23. Marston C, Meltzer H, Majeed A: Impact on contraceptive practice of making emergency hormonal contraception available over the counter in Great Britain: repeated cross sectional surveys. BMJ 2005;331:271. DOI:10.1136/bmj.38519.440266.8F.

24. European Commission. Directive 2001/83/EC of the European Parliament and of the Council. ec.europa.eu/health/files/eudralex/vol-1/dir_2001_83_consol_2012/dir_2001_83_cons_2012_en.pdf. (accessed 15 November 2015)

25. Gallagher CT, Holton A, McDonald LJ, Gallagher PJ: The fox and the grapes: an Anglo-Irish perspective on conscientious objection to the supply of emergency hormonal contraception without prescription. J Med Ethics 2013;39:638-642. DOI:10.1136/medethics-2012-100975.

26. Gee RE, Shacter HE, Kaufman EJ, Long JA: Behind-the-counter status and availability of emergency contraception. Am J Obstet Gynecol 2008;199:478.e1-e5. DOI:10.1016/j.ajog.2008.04.032.

27. World Health Organisation. Emergency contraception. Fact sheet № 244. www.who.int/mediacentre/factsheets/fs244/en. (accessed 15 November 2015)

28. Rücker D: Switches sind ein Wachstumsmotor. Pharmazeutische Zeitung 2014; 159(45):6-8. German

29. Moreau C, Bajos N, Trussell J: The impact of pharmacy access to emergency contraceptive pills in France. Contraception 2006;73:602-608. DOI:10.1016/j.contraception.2006.01.012.

30. N24. „Pille danach“ - Ärzte-Präsident warnt vor Freigabe. www.n24.de/n24/Wissen/Gesundheit/d/4132766/aerzte-praesident-warnt-vor-freigabe-.html. (accessed 17 November)

31. Ärzteblatt. Bundesärztekammer: Verschreibungspflicht für „Pille danach“ beibehalten. www.aerzteblatt.de/nachrichten/57352/Bundesaerztekammer-Verschreibungspflicht-fuer-Pille-danachbeibehalten. (accessed 17 November 2015)

32. Moreno I, Quiñones L, Catalán J, Miranda C, Roco Á, Sasso J, Tamayo E, Cáceres D, Tchernitchin AN, Gaete L, Saavedra I: Infuence of CYP3A4/5 polymorphisms in the pharmacokinetics of levonorgestrel: a pilot study [Influencia de polimorfismos genéticos de CYP3A4/5 en la farmacocinética de levonorgestrel: studio piloto]. Biomedica 2012;32:570-577. DOI:10.7705/biomedica.v32i.789. Spanish

33. Kim A, Bridgeman MB: Ulipristal acetate (ella)-A selective progesterone receptor modulator for emergency contraception. PT 2011;36:325-326, 329-331.

34. Moreau C, Trussell J: Results from pooled phase III studies of ulipristal acetate for emergency contraception. Contraception 2012;86:673-670.

35. World Health Organisation. WHO Model List of Essential Medicines list. www.who.int/medicines/publications/essentialmedicines/en/. (accessed 15 November 2015)

36. Task Force on Postovulatory Methods of Fertility Regulation: Randomised controlled trial of levonorgestrel versus the Yuzpe regimen of combined oral contraceptives for emergency contraception. Lancet 1998;352:428-433.

37. Lee SM, Dunn S, Evans MF: Levonorgestrel versus the "Yuzpe" regimen. New choices in emergency contraception. Can Fam Physician 1999;45:629-631.

38. Cameron ST, Gordon R, Glasier A: The effect on use of making emergency contraception available free of charge. Contraception 86;2012:366-369. DOI:10.1016/j.contraception.2012.02.018. 
Eureka! - I have found it!

Archimedes

Greek mathematician and inventor, Syracuse (Sicily, Italy) 


\title{
CHAPTER 9
}

\author{
General discussion
}

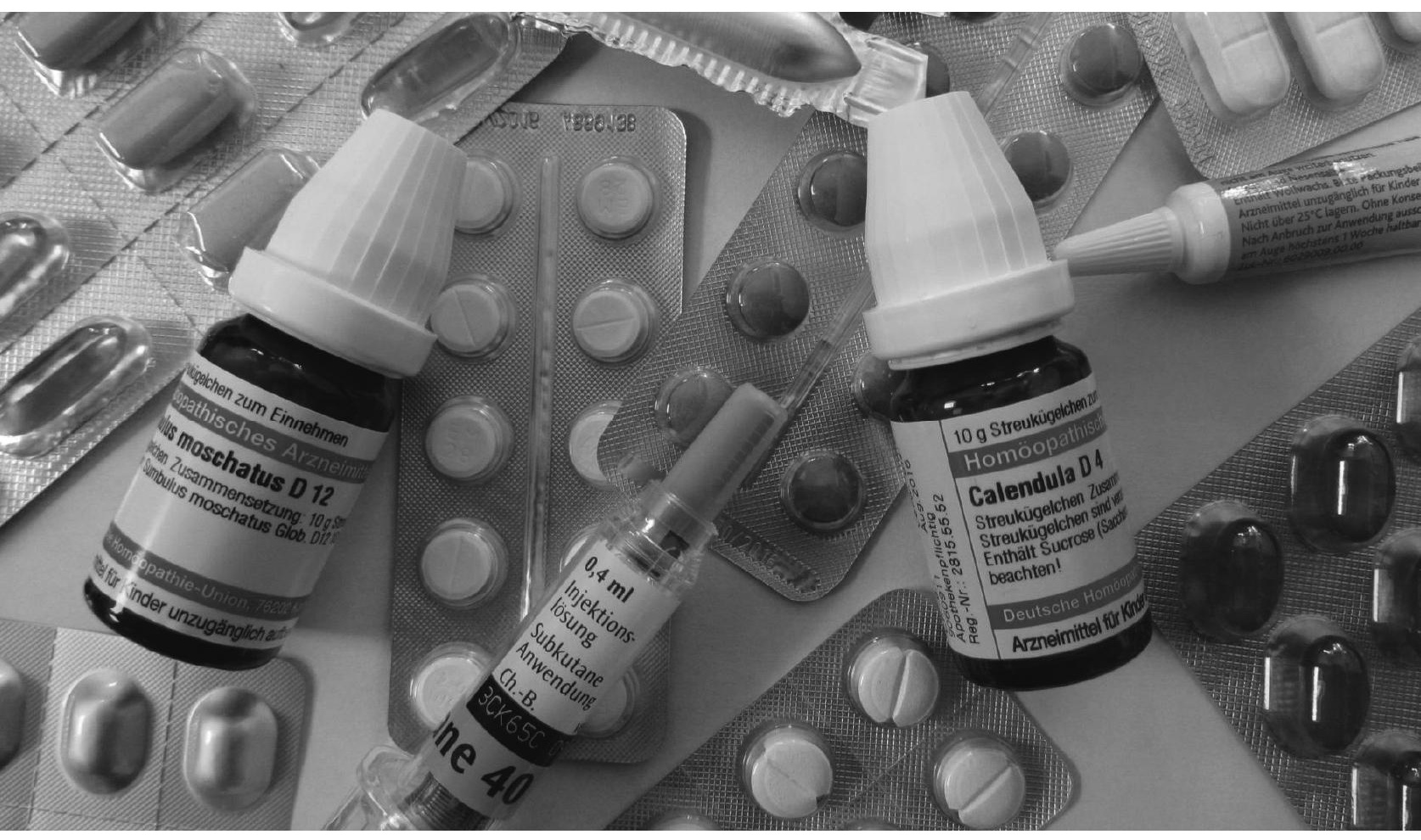




\section{Introduction}

The present dissertation deals with drug utilization among children and adolescents in Europe. From a public health point of view, various research questions with regard to paediatric drug use are of interest and relevance, such as pharmacoepidemiological issues, the promotion of the development of new drugs for orphan diseases that very often also affect children [1-3], the lack of availability of numerous (approved) drugs with dosages or forms of administration that are suitable for children [4-6], etc. However, it is in the nature of things that not all relevant issues may be addressed in a comprehensive way by one dissertation. Therefore, this disseration focuses on the pharmacoepidemiological and socioeconomic aspects of drug use among children and adolescents in Europe, with a particular emphasis on paediatric drug use in Germany. The first chapters concentrate on the use of medicinal products from the field of complementary and alternative medicine (CAM) such as homeopathic remedies or herbal drugs. The following chapters are dedicated to paediatric drug use in general and the longitudinal associations of drug use. Finally, the current issue of emergency contraception is addressed, as adolescents are also directly concerned with this topic.

\section{Main results}

Chapter 2 investigated patterns of paediatric CAM use in European countries and nonEuropean countries as well, with a focus on the use of homeopathic remedies and herbal drugs, two of the most commonly used CAM modalities [7]. A systematic review detected 58 eligible studies from 19 countries, mainly from Western Europe (43\%) and North America (41\%). No data were available for Eastern Europe (except Turkey) and Africa, emphasizing the need for research with regard to these regions. Based on the included studies, a meta-analysis was performed in order to estimate the prevalence rates of use in Europe, North America, and 'other' continents. Furthermore, the socioeconomic predictors of CAM use are summarized in a descriptive manner.

Overall, the prevalence of use of homeopathic products was relatively high among children in Europe, where, for example, the use within the past year was estimated at 8.98\% (95\% confidence interval: 5.07-15.43). It was highest in Germany, the Netherlands, and the United Kingdom. Compared with the estimates for North America, the prevalence of homeopathy use was about three times higher in Europe, regardless of the underlying recall period.

The 1-year prevalence rate of herbal drug use was estimated at $13.53 \%$ for Europe (95\% confidence interval: 2.30-50.96), which was almost on the same level as in North America. Very high prevalence rates of herbal drug use were reported from Germany, Turkey, and Brazil. 
With regard to the socioeconomic predictors of CAM use, most studies did not analyse predictors for specific CAM modalities, although it has been shown that predictors may vary between the single CAM categories [8]. Only four studies reported predictors for homeopathy use, and eight studies presented predictors for herbal drug use. In summary, mainly parental CAM use and parental education predicted their children's use of CAM. The findings may have implications insofar as paediatricians should, with concern for potential interactions, be aware of their patients' high CAM use when prescribing pharmaceuticals. Furthermore, health care managers should take note of the evidently existing wish of a noticeable part of the European population to integrate CAM into their medical treatment.

The main findings of chapter 3 are based on data from the German GINIplus and LISAplus birth cohorts and complement the research performed in chapter 2 . The results in chapter 3 show that the prevalence of complementary and alternative medicine use, compared with healthy adolescents, is usually higher among adolescents suffering from chronic conditions. This was particularly the case for adolescents suffering from allergies or 'any chronic condition' with respect to the use of homeopathic remedies and the consultation with CAM providers such as non-medical health providers ('Heilpraktiker') or osteopaths. These findings support the assumptions from chapter 2 that studies assessing the prevalence of CAM use among chronically ill children only should be excluded from a systematic review if the review's objective aims to estimate the prevalence of CAM use in the general paediatric population.

However, the prevalence of use does not reflect drug usage comprehensively, and higher prevalence rates of e.g. homeopathy or herbal drug use among chronically ill children do not necessarily mean that they unreasonably substitute treatment with conventional drugs for a non-conventional medicinal therapy approach with CAM. The findings of chapter 3 imply that, despite higher prevalence rates of CAM use, chronically ill adolescents and their parents/legal guardians rely more on conventional drugs and may use medicinal CAM products as an additional ('complementary') rather than 'alternative' treatment. This apparently contradictory result is explained by the fact that chronically ill adolescents used more drugs in general and, at the same time, the proportion of medicinal CAM products among all drugs used was lower among adolescents with chronic conditions than among healthy adolescents. Nevertheless, paediatricians should know about the presumably higher prevalence of CAM use among their patients with chronic conditions and should take into account that the risk of pharmacological interactions (e.g. between conventional drugs, but between conventional drugs and non-conventional drugs as well) may be higher among their chronically ill patients, as they generally use more medicinal products than apparently healthy children. 
Chapter 4 presents an updated view of paediatric CAM use in Germany based on findings from a large German birth cohort (GINIplus). The results show that about $26 \%$ of all drugs utilized are medicinal CAM products. Homeopathic remedies and herbal drugs, the two most mentioned CAM modalities, which accounted for about $85 \%$ of all reported medicinal CAM products, were used by $7.5 \%$ and $5.6 \%$, respectively, of the 15 year-old adolescents within the observation period of 4 weeks. Exactly $10.8 \%$ consulted CAM providers (non-medical health providers ('Heilpraktiker'), homeopaths, or osteopaths) within the preceding year. Compared with the findings from the 10-year followup of the same birth cohort, the prevalence of homeopathy use was practically halved $(-52 \%)$ and dropped substantially for herbal drug use $(-36 \%)$, whereas the prevalence of 'overall drug use' remained almost on the same level, as 15-year-old adolescents used only slightly fewer drugs in general $(-6 \%)$ than 10 -year-old children. All but one of the medicinal CAM products were over-the-counter drugs available without a physician's prescription. On average, homeopathic remedies cost $€ 10.14$, and the mean price for a herbal drug amounted to $€ 13.72$. The average price of conventional over-thecounter drugs containing chemical active ingredients such as ibuprofen was lower (€6.06) compared with medicinal CAM products. This may in part have contributed to the lower prevalence rates of CAM use among 15-year-old adolescents in comparison with 10-year-old children, as medicinal CAM are not normally reimbursed by statutory health insurance companies for children older than 12 years. Thus, higher prices of homeopathic and herbal drugs may lead to a preference for conventional over-thecounter drugs among adolescents if drugs have to be paid for out-of-pocket. However, the presence of other factors may also have led to lower prevalence rates of CAM use, for instance a lower acceptance of CAM among adolescents (compared with 10-yearold children).

Household income was not associated with the use of any CAM modality. Female gender and residing in Munich predicted the use of homeopathic remedies and consultation with CAM providers. Adolescents whose mothers had a higher educational background used more herbal drugs and consulted more with CAM providers. Very similar results with respect to the predicting factors had already been found at the 10-year follow-up of the GINIplus study. Overall, the results imply that the users' profile not only varies between users of conventional drugs and CAM users, but between users of the single CAM modalities as well.

In chapter 5, patterns of paediatric drug utilization are compared between prescription drugs available on a physician's prescription only and freely available over-the-counter drugs. Since the implementation of the 2004 German health act [9], OTC drugs are no longer reimbursed by German statutory health insurance companies for children older than 12 years. OTC drugs may still be prescribed or recommended by physicians, but 
are covered by statutory health insurance only in exceptional cases for children aged over 12 years and therefore have to be paid for out-of-pocket. The research in chapter 5 reveals that the 4-week prevalence of drug use among 15-year-old adolescents in the German GINIplus birth cohort was quite high (41.0\%). Furthermore, the majority (69\%) of the drugs utilized by adolescents were OTC drugs.

In sum, socioeconomic factors such as gender, study area, maternal education, or household income did not predict the use of prescription drugs in general. On the other hand, higher use of OTC drugs was significantly associated with female gender, residing in South Germany (Munich), and a higher maternal educational background. Looking at specific drug categories classified by the anatomical therapeutic chemical classification (ATC) system, socioeconomic factors predicted the use of various drug groups, e.g. antiinflammatory drugs, antiallergics, methylphenidate, or drugs for thyroid therapy. Health care managers should therefore take into account the impact of socioeconomic variables on paediatric drug use when deciding on the prescription status of drugs (with subsequent consequences for the reimbursability of those drugs) or the further liberalization of drug sales, as respective measures may lead to over- or undersupply with drugs in specific population strata.

In chapter 6, a longitudinal analysis of drug use is performed by comparing drug use among 15-year-old adolescents from two German birth cohorts (GINIplus and LISAplus) with drug use among 10-year-old children from the same cohorts at the 10-year followup. The overall prevalence of drug use was almost on the same level when comparing both age groups. Nevertheless, there were noticeable differences with regard to the use of specific drug categories. For instance, the prevalence of antiinflammatory drug use (mainly ibuprofen) more than doubled among 15-year-old adolescents compared with 10-year-old children. Of the 12 most mentioned active ingredients used by adolescents, four were antiinflammatory agents (ibuprofen and naproxen) or analgesics (paracetamol and acetylsalicylic acid). About $11 \%$ of the adolescents took at least one antiinflammatory drug within the (relatively short) observation period of 4 weeks, and almost $7 \%$ used at least one analgesic drug. A further remarkable finding from chapter 6 was that one of the strongest predictors for using a specific drug category or ATC group at the age of 15 years was previous use of the same drug category or ATC group at the age of 10 years. This might be interpreted such that drug use as a child may partly determine the kind of drugs that will be used in adolescence or adulthood.

The main result from chapter 7 is that higher prices for OTC drugs used by adolescents (and presumably bought predominantly without a physician's prescription or recommendation) may be directly associated with socioeconomic factors. For instance, adolescents residing in Munich or those having a father with a higher educational level 
used more higher priced OTC drugs on average, compared with adolescents residing in Wesel or adolescents with fathers from a lower educational stratum. In sum, the findings could have implications insofar as high prices of OTC drugs may discourage especially adolescents from a lower socioeconomic background from buying medically advisable but not reimbursable OTC drugs.

The final chapter 8 deals with the current issue of emergency contraception. In November 2014, the European Medicines Agency (EMA) recommended changing the classification status of ulipristal acetate from 'subject to medical prescription' to 'not subject to medical prescription'. As a result, most EU countries followed the recommendation, although it would have been possible to evade the EMA decision. The decision to make ulipristal acetate freely available also had an impact on the sales figures, which have increased noticeably since the switch (e.g. by about 38\% in Germany within a period of 6 months after the switch for ulipristal acetate- and levonorgestrel-containing emergency contraceptives together).

\section{Summarizing discussion}

According to the results from chapters 2-8, drug utilization is considerably prevalent among children and adolescents in Germany and other European countries as well. Furthermore, socioeconomic variables evidently have a significant impact on paediatric drug use. With regard to the overall use of prescription drugs, there were no big variations between the socioeconomic strata in Germany. Nevertheless, when viewed in detail, it seems that the use of prescription drugs from specific ATC categories varies between the higher and lower income and educational strata. For instance, children from the lowest income groups used more psychoanaleptics and antibiotics compared with those from the highest income group. If it is assumed that the higher use results from a higher prevalence of the underlying disorders (attention deficit and hyperactivity disorder, bacterial infections) in the lowest income groups, the question arises whether and how the prevalence of those disorders could be reduced in children from low income households by respective (public health) measures.

The picture changes when focusing on over-the-counter drugs, not normally covered by the German statutory health insurance companies for insured persons older than 12 years. In case of need, OTC drugs have to be purchased on the patient's (or the patient's parents') own initiative. This may require a certain level of health literacy, the ability to judge the child's health status correctly, and a critical attitude towards exaggerated advertising messages. At the same time, efficient OTC drugs that are necessary (or at least do no harm and have a subjectively perceived benefit for the patient) but are not covered by statutory health insurance must also be affordable for people from 
a lower socioeconomic background. The results based on the German GINIplus and LISAplus birth cohorts indicated that, in sum, the prevalence of OTC drug use was lowest in the children of mothers with the lowest educational level (paternal education had almost no impact on the prevalence of drug use, either OTC drug use or the use of prescription drugs) and from poor households ( $\leq 60 \%$ of $\mathrm{MEI}$ ). Also a closer look at single drug categories (e.g. herbal drugs, mainly available without prescription) or specific ATC categories that included mostly OTC drugs (e.g. antiinflammatory drugs, analgesics, antiallergics) showed that higher use of OTC drugs was associated with higher maternal education. In no instance of analysed 'OTC subgroups' was a higher use of the respective 'OTC subgroup' associated with lower maternal education or lower parental income.

Additionally, the mean prices of the OTC drugs used were highest in children with the highest maternal/paternal education background and household income. Hence, the decision to use (or not to use) higher priced OTC drugs may be directly associated with the child's socioeconomic background. Overall, this is a remarkable result for a country that is ranked quite highly in the list of countries with the best or most efficient health care systems [10-12].

Of course, Europe should set high standards for the population's supply with medicinal products. The availability, the quality, and the affordability of pharmaceutical products must also be ensured for the future. Social inequalities regarding access to drugs are not acceptable and must be reduced to a minimum. Nevertheless, these apparently self-evident points cannot be taken for granted in times of ageing populations, economic crisis, and austerity policies that are putting European health care systems under pressure [13]. Countries such as Greece, which have been particularly hard hit by the financial crisis, are currently experiencing severe problems with drug shortages [14-16], although this phenomenon is not limited to those countries and shortages have been reported for Germany as well, for example [17]. The pharmaceutical industry is important and has been defined as a strategic sector for the European economy [18], not only in terms of the development of new drugs. On the other hand, it has to be pointed out that the pharmaceutical market is not free from economic interests. Corruption among health professionals and counterfeit drugs are further challenges that need to be addressed. Initial steps in this direction have already been taken [19-21]. However, it is likely that less well-off people may face more problems in accessing necessary drugs, especially when it comes to exceptional circumstances. An extreme example is the case of the life-saving antiretrovirals for the treatment of HIV/AIDS that were not affordable because of disputes over property rights [22-24] for large sections of the adult and paediatric populations in the developing countries before the 2001 Doha declaration. 
The data from the GINIplus and LISAplus birth cohorts did not reveal extreme social disparities with regard to paediatric drug use in Germany, but they highlighted the importance of health literacy and showed significant tendencies towards lower OTC drug use among socially weaker children, which should be taken seriously. Against this background, the German decision to exclude OTC drugs from reimbursement for children older than 12 years should probably be reassessed. Financial resources should be spent prudently and health services and medicinal products should be priced adequately, but it should be kept in mind that the people's, and especially children's, health, must come first, not anyone's economic interests. Therefore, it would be desirable that all actors and stakeholders within the health systems should again judge pharmaceuticals more as valuable (and appropriately priced) products for the treatment of disorders rather than classifying them merely as a cost factor or, on the other side, having predominantly the potential of high profits in mind $[25,26]$. 


\section{References}

1. Rare diseases UK. About rare diseases. www.raredisease.org.uk/about-rare-diseases.htm (accessed 8 September 2015)

2. Heyn G. Meist sind Kinder betroffen. www.pharmazeutische-zeitung.de/index.php?id=25864 (accessed 21 September 2015)

3. Federal Ministry of Health. Seltene Erkrankungen.

www.bmg.bund.de/themen/praevention/gesundheitsgefahren/seltene-erkrankungen.html (accessed 8 September 2015)

4. Federal Institute for Drugs and Medical Devices.EU-regulation on medicinal products for children. www.bfarm.de/EN/Drugs/licensing/kam/eureg/_node.html;jsessionid=55C8A75F62026ECEF0A46003B5 9E018C.1_cid340 (accessed 8 September 2015)

5. European Commission. Better medicines for children-From concept to reality. Progress report on the paediatric regulation (EC) № 1901/2006.

http://ec.europa.eu/health/files/paediatrics/2013_com443/paediatric_report-com(2013)443_en.pdf (accessed 8 September 2015)

6. Sauer B. EU verordnet kindgerechte Arzneimittel. www.pharmazeutische-zeitung.de/index.php?id=7516 (accessed 8 September 2015)

7. Surette $S$, Vanderjagt L, Vohra S. Surveys of complementary and alternative medicine usage: a scoping study of the paediatric literature. Complement Ther Med. 2013;21 (Suppl 1):48-53. doi: 10.1016/ j.ctim.2011.08.006jk

8. Italia S, Batscheider A, Heinrich J, Wenig C, Bauer CP, Koletzko S, Lehmann I, Herbarth O, von Berg A, Berdel D, Hoffmann B, Schaaf B, Wolfenstetter SB. Utilization and costs of conventional and alternative pharmaceuticals in children: results from the German GINIplus and LISAplus birth cohort studies. Pharmacoepidemiol Drug Saf. 2012;21:1102-1111. doi: 10.1002/pds.3323

9. The 2004 German Health Act. GKV-Modernisierungsgesetz. http:///buzer.de/s1.htm?g=GMG\&f=1 (accessed 1 September 2015)

10. World Health Organisation WHO. Measuring overall health system performance for 191 countries. www.who.int/healthinfo/paper30.pdf (accessed 12 September 2015)

11. Bloomberg. Most efficient health care 2014. www.bloomberg.com/visual-data/best-and-worst/mostefficient-health-care-2014-countries. (accessed 12 September 2012)

12. Euro Health Consumer Index 2014. www.healthpowerhouse.com/index.php?Itemid=55 (accessed 12 September 2015)

13. European Forum on Forward Looking Activities - EFFLA. Policy Brief № 7. Health and demographic change and well-being. https://ec.europa.eu/research/innovation-union/pdf/expert-groups/efflareports/effla_pb7_-_health_and_demographic_change_and_well-being.pdf (accessed 21 September 2015)

14. Karamanoli E. Greece's financial crisis dries up drug supply. Lancet. 2012;28:302

15. Sukkar E. Greeks feel effects of drug shortages caused by austerity measures. BMJ. 2012;344:e3589. doi:1136/bmj.e3589

16. Klein L. Die Lage ist „katastrophal“. Deutsche Apotheker Zeitung. 2015;155(28):15

17. Hohle A. Lieferengpässe weltweit-Pro Generika will mehr Sicherheiten. Pharmazeutische Zeitung. 2015;160(13):14

18. European Commission. The pharmaceutical industry: a strategic sector for the European economy. http://ec.europa.eu/growth/sectors/healthcare/competitiveness/index_en.htm (accessed 23 September 2015)

19. Ziegler J. Antikorruptionsgesetz passiert Kabinett. www.deutsche-apotheker-zeitung.de/politik/ news/2015/07/29/antikorruptionsgesetz-passiert-kabinett/16361.html (accessed 24 September 2015) 
20. European Commssion. Falsified medicines. Directive 2011/62/EU. http://ec.europa.eu/health/humanuse/falsfied_medicines/index_en.htm (accessed 17 September 2015)

21. Securpharm - The German shield against falsified medicines. www.securpharm.de/index.html (accessed 17 September 2015)

22. 't Hoen EFM. Trips, pharmaceutical patents and access to essential medicines: Seattle, Doha and Beyond. http://www.who.int/intellectualproperty/topics/ip/tHoen.pdf (accessed 24 September 2015)

23. Wise J. Access to AIDS medicines stumbles on trade rules. Bull World Health Organ. 2006;84:342-344

24. World Health Organization. AIDS treatment for children. www.who.int/3by5/paediatric/en/ (accessed 24 September 2015)

25. Steinbrook R, Redberg RF. The high price of the new hepatitis C virus drugs. Jama Intern Med. 2014;174:1172 doi:10.1001/jamainternmed.2014.2135

26. Schiff L. Finding the truth in a world full of spin: myth-busting in the case of Sovaldi. Clin Ther. 2015;37:1092-1112. doi:10.1016/j.clinthera.2015.02.009 
Annex 


\section{Valorisation}

The results of this thesis can be valorised by the relevant implications they have on the following aspects of Public Health at a national or European level.

a. Saving financial resources by avoiding oversupply with pharmaceuticals

In general, it should be stated that both prescription drugs and OTC drugs should be used according to need and after a careful risk-benefit evaluation only. In light of the high prevalence rates of drug use among a supposedly quite healthy sample of children/adolescents in Germany, it may at first be critically questioned whether all drugs used by children/adolescents are really necessary from a medical perspective, not least in view of the fact that active pharmaceutical ingredients also have the potential to harm. Consumption of drugs is, of course, a consumption of private or public financial resources as well. The mean price of pharmaceuticals used by adolescents in Germany is around €9.75 for OTC drugs and €69.28 for prescription drugs. The results of this thesis suggest that, on average, an adolescent may use about 0.58 packages of OTC drugs and 0.24 packages of prescription drugs within an observation period of 4 weeks, creating monthly expenditures on drugs (OTC and prescription drugs together) of roughly $€ 24$ on average per adolescent. Furthermore, the findings of chapter 6 imply that the use of prescription drugs and OTC drugs also partly follows habitual patterns. Drug utilization during childhood may to a certain degree determine drug use during adolescence or adulthood and, hence, result in (probably avoidable) expenditures on pharmaceuticals in the future. Thus, detecting the 'necessity' of drug use already at an early stage in life and subsequent efforts to reduce drug utilization to the required amount could be a relevant contribution to keep the expenditures of statutory health insurance companies on pharmaceuticals under control. However, 'necessity' might be perceived differently by different individuals and needs to be defined accurately.

b. Value of self-medication and over-the-counter drugs to society

According to evidence based on studies conducted in the United States, Australia, and Brazil [1-3], self-medication with OTC drugs helps to relieve social security systems. Depending on the source, every dollar/Brazilian real spent on self-medication saves 4-7 dollars/Brazilian reals for the health care systems. Savings can be derived from reduced costs for prescription drugs, avoided costs for physician visits, and maintenance of the population's working productivity. A prerequisite for exploiting the potential benefits of OTC drugs is that they are used in time as 'early intervention' to prevent, e.g. sick leave or consultation with a physician, which additionally would be likely to result in using 
cost-intensive prescription drugs (in Germany, prescription drugs are about six times more expensive than OTC drugs). However, as shown in chapter 5, lower social background may predict lower use of OTC drugs among adolescents. Furthermore, according to the results from chapter 7 , adolescents from a higher social background may be more likely to use higher priced OTC drugs. Thus, higher prices could generally discourage particularly people from a lower socioeconomic background from taking medically advisable but not reimbursable OTC drugs. Against this background, reimbursement of at least some defined categories of OTC drugs by social security could also make sense economically in relation to public health expenses to avoid higher costs caused by delayed treatment. Of course, all OTC drugs (as well as prescription drugs) should be used properly. This highlights the importance of further fostering of personal health literacy and good medical and pharmaceutical advice that is ideally not influenced by conflicting economic interests.

Additionally, it could be worth reflecting on whether and how the role of pharmacists could be strengthened with regard to the reimbursability of OTC drugs when bought without a medical prescription. For instance, in Germany, in the meantime, an increasing number of statutory health insurance companies reimburse expenditures on OTC drugs again, but coverage normally still requires a physician's prescription (causing consultancy fees) on an OTC prescription form, which can be presented for reimbursement after having purchased the OTC drug at the pharmacy.

\section{c. Pharmaceuticals as an economic factor}

The pharmaceutical industry is one of Europe's key markets. As mentioned in chapter 1, it generates a yearly turnover of about 190 billion euros in Europe and provides jobs for roughly 690,000 employees (figures for 2012 and 2013). Additionally, a substantial number of people are working in the public health care sector (e.g. some 150,000 people as pharmaceutical personnel alone in German community pharmacies [4]). Where pharmaceuticals promote health in any way, expenditures on pharmaceutical products appear to be justified. A proper use of, e.g. OTC drugs, may not only save costs for health insurance companies but also supports the health economy. However, according to the results in chapter 5 , there might be an undersupply of OTC drugs especially in the socioeconomically lowest stratum of the (paediatric) population. Closing this supply gap could bring further revenues to the health economy and at the same time a health benefit to those who are presumably using fewer drugs than actually needed or at least recommended. However, market mechanisms have to make sure that OTC drugs as well as generic or innovative prescription drugs also remain affordable in the future, if necessary regulated by political measures. 
Health and access to healthcare services such as treatment with medicinal products are high values that should not be limited by national borders and, undoubtedly, a healthy population is also an important pillar of a productive and prosperous society.

The European Union promotes freedom of movement for goods, workers, services, and capital. Not least against the background of the new EU directive on patients' rights in cross-border health care, it may not appear very meaningful if different rules apply for the same medicinal products across the various EU member countries, e.g. with regard to the classification of drugs into freely available, presciption only status, or narcotics, but also with regard to the coverage of medicinal products by social security. The case of emergency contraceptives (chapter 8) suggests that a centralized recommendation by the European Medicines Agency (EMA) can strongly contribute to harmonization of, e.g., the legal status of a medicinal product across the EU member countries. Therefore, centralized drug supply standards may help to reduce disparities between EU countries with regard to access to medicinal products (which, in a certain sense, also represents a social inequality) and might contribute to further promote European integration.

\section{References}

1. Booz\&Co. The value of OTC medicines to the United States. http://www.yourhealthathand.org/images/uploads/The_Value_of_OTC_Medicine_to_the_United_ States_BoozCo.pdf (accessed 18 January 2016)

2. Macquarie university. The value of OTC medicines in Australia. http://www.wsmi.org/wp-content/ data/pdf/FINALWEBCOPYASMI_ValueStudy.pdf (accessed 18 January 2016)

3. Ferreira CN, Santana CF, Rufino CS. The value of OTC medicines in Brazilian public health systems (SUS). Pfizer Brasil, Sao Paulo, Brazil (elsevier). http://www.valueinhealthjournal.com/article/S10983015\%2815\%2900569-0/pdf (accessed 18 January 2016)

4. Federal Union of German Associations of Pharmacists (ABDA). Zahlen Daten Fakten. http://www.abda.de/service/publikationen/zdf/ (accessed 7 March 2016) 


\section{Summary}

The main objective of the research in this thesis was the analysis of paediatric drug use, in view of both the prevalence of use and the socioeconomic predictors of drug utilization. The focus was placed on drug use among children/adolescents in Germany, as new data from the 15-year follow-up of two ongoing German birth cohorts were available. The analysis was not limited to conventional drugs, but included alternative medicinal products such as homeopathic or herbal remedies as well. Furthermore, the use of prescribed drugs and self-medicated drugs was assessed.

The starting point of the research was a systematic review on complementary and alternative medicine (CAM) use among children in Europe, in comparison with CAM use in North America and other regions. Out of 58 included studies, 49 studies were conducted in Europe or North America, whereas only nine studies analysed CAM use in Australia/New Zealand or South America. One main result was that the estimate for the prevalence of homeopathy use in Europe (1-year prevalence: $8.98 \%$ ) is about three times the prevalence in North America (1-year prevalence: 3.08\%), whereas for herbal drug use, there is only a small difference between the two regions (1-year prevalence: 13.53\% for Europe vs. $12.05 \%$ for North America). Studies conducted with chronically ill children were excluded from the review because of a hypothesized bias towards higher prevalence rates of CAM use, which was demonstrated to be true in a following, separately conducted study in this thesis.

A detailed view on CAM use in Germany yielded quite high prevalence rates (use within the last 4 weeks) of homeopathy use (7.5\%) and herbal drug use (5.6\%) among adolescents. A higher use of homeopathy was significantly predicted by female gender and by residing in Munich (compared with Wesel in Northwest Germany), whereas herbal drug use was positively predicted by higher maternal education. However, compared with the results from the follow-up of the same birth cohort study at the age of 10 years, the use of homeopathy was more than halved and herbal drug use dropped by more than a third among 15 -year-old adolescents. This may be explained in part by the fact that medicinal CAM products are normally reimbursed by German health insurance for children younger than 12 years only.

The subsequent investigation focused on the comparison of prescription drugs with over-the-counter (OTC) drugs used by 15 -year-old adolescents in Germany, including all kinds of medicinal products (conventional and alternative ones). The results showed that the use of OTC drugs (accounting for roughly $69 \%$ of all drugs used and not normally reimbursed by statutory health insurance) was significantly predicted by socioeconomic factors such as maternal educational background, whereas there was almost no difference between the socioeconomic strata in relation to the use of prescription 
drugs. At the same time, the use of drugs from specific anatomical therapeutic chemical (ATC) categories seems also to depend on the adolescents' socioeconomic background.

A longitudinal analysis of drug use revealed that the strongest predictor of 15-yearold adolescents' use of a defined drug category (conventional drugs, homeopathic drugs, herbal drugs) or ATC group was the previous use of the same drug category (conventional drugs, homeopathic drugs, herbal drugs ) or ATC group at the age of 10 years. Evidently, drugs may not only be utilized according to need but might also follow habitual patterns. It may be concluded that drug use as a child partly determines what kind of drugs they use during adolescence or adulthood.

Socioeconomic factors were also associated with prices of OTC drugs. On average, the prices for OTC drugs used were highest among adolescents residing in Munich or among those with parents from the highest education and income levels. The results were significant for the area of residence and paternal education. Generally, prices of $€ 10$ or more for an OTC drug seem to be a psychological threshold, as about $75 \%$ of all OTC drugs cost less than $€ 10$. In this context, it should be taken into account by health care managers that non-reimbursable but medically advisable OTC drugs could be used less, especially by those children from the socioeconomically weaker levels.

The research was completed by consideration of the current European issue of emergency contraceptives. In November 2014, the European Medicines Agency (EMA) recommended switching the emergency contraceptive ulipristal acetate from prescription status to non-prescription status and, thus, making freely available without a physician's prescription. Although retaining the possibility of circumventing the EMA decision, most EU member countries implemented the recommendation and transposed it into national legislation within a period of 1 year. Since the switch, the use of emergency contraceptives has increased substantially in Germany and other European countries.

In summary, it may be concluded that paediatric use of medicinal products, especially those available without a physician's prescription (which account for a substantial part of the drugs used), is significantly predicted by socioeconomic background. This may have implications insofar as children and adolescents from the socioeconomically weaker levels might use fewer (medically advisable) drugs if they have to be paid for out-of-pocket, not least because the higher prices of the OTC drugs used are presumably associated with higher socioeconomic status. Against this background, the list of reimbursable drugs may need to be reassessed in those countries where OTC drugs are not normally covered by statutory health insurance. However, medicinal products, both prescription drugs and OTC drugs as well, should keep their status as special products. Therefore, decisions on exclusion from reimbursement ought to be evaluated carefully, as well as decisions on the liberalization of drug sales that would make them available outside pharmacies without the possibility of medical or pharmaceutical advice. 


\section{Samenvatting}

Het voornaamste doel van het onderzoek in deze dissertatie was de analyse van het geneesmiddelengebruik bij kinderen, zowel met betrekking tot prevalentie van het gebruik alsook met betrekking tot de sociaal-economische indicatoren bij het gebruik van geneesmiddelen. De nadruk lag op geneesmiddelengebruik bij kinderen en jongeren in Duitsland, aangezien actuele gegevens beschikbaar waren over een periode van 15 jaar van twee nog lopende onderzoeken van Duitse geboortegroepen. Deze analyse werd niet beperkt tot conventionele geneesmiddelen maar omvatte ook alternatieve geneesmiddelen zoals homeopathische en plantaardige middelen. Verder werden zowel gebruik van voorgeschreven medicijnen alsook zelfmedicatie in de analyse meegenomen.

Het uitgangspunt van het onderzoek was een systematische review van het gebruik van complementaire en alternatieve geneesmiddelen (CAM) door kinderen in Europa, in vergelijking met CAM-gebruik in Noord-Amerika en andere regio's. Van 58 meegenomen studies waren 49 studies in Europa of Noord-Amerika gedaan, terwijl slechts 9 studies het CAM-gebruik in Australië/Nieuw-Zeeland of Zuid-Amerika onderzochten. Een wezenlijk resultaat was dat de inschatting voor de prevalentie voor homeopathiegebruik in Europa (1 jaar-prevalentie 8,98\%) ongeveer driemaal over de waarde voor Noord-Amerika (1 jaar-prevalentie 3,08\%) ligt, terwijl voor het gebruik van plantaardige middelen slechts een gering verschil tussen beide regio's laat zien (1 jaar-prevalentie: $13,53 \%$ voor Europa en 12,05\% voor Noord-Amerika). Studies met uitsluitend chronisch zieke kinderen werden buiten beschouwing gelaten in de review aangezien dit vermoedelijk een vertekend beeld met betrekking tot een hoger CAM-gebruik zou weergeven. Dit vermoedelijke vertekend beeld kon ook door een verder, separaat doorgevoerd, onderzoek bewezen worden.

Een gedetailleerde blik op het CAM-gebruik in Duitsland liet nogal hoge prevalentiepercentages zien (gebruik gedurende de laatste 4 weken) van homeopathica (7,5\%) en plantaardige middelen $(5,6)$ bij jongeren. Een hoger gebruik van homeopathica was significant bij het vrouwelijke geslacht en in de plaats München (in vergelijking tot de plaats Wesel in noordwest Duitsland) terwijl het gebruik van plantaardige middelen op positieve wijze door de hogere scholingsgraad van de moeder werd bepaald. In vergelijking met de resultaten van het onderzoek van dezelfde groep in de leeftijd van 10 jaar, halveerde het gebruik van homeopathica door 15-jarigen en het gebruik van plantaardige middelen verminderde met meer dan eenderde. Voor een deel berust dit op het feit dat complementaire en alternatieve geneesmiddelen in de regel slechts tot de leeftijd van 12 door de ziektekostenverzekeringen in Duitsland worden vergoed.

Het aansluitend onderzoek legde het zwaartepunt op het vergelijken van medicijnen die alleen op recept verkrijgbaar zijn en vrij verkrijgbare medicijnen (OTC- 
geneesmiddelen), die door 15-jarigen gebruikt werden, met inachtneming van welk geneesmiddelen dan ook (zowel conventionele als alternatieve middelen). De resultaten toonden dat het gebruik van OTC-geneesmiddelen (die ongeveer 69\% vormden van alle gebruikte middelen en die in de regel niet van de ziektekostenverzekering vergoed werden) afhing van sociaal-economische factoren, zoals bijv. de opleiding van de moeder, waarbij geen verschil vast te stellen was tussen de afzonderlijke sociale bevolkingsgroepen met betrekking tot het gebruik van middelen die alleen op recept verkrijgbaar zijn.

De longitudinale analyse van medicijngebruik liet zien dat de sterkste indicator van het gebruik van een gedefinieerde geneesmiddelencategorie (conventioneel, homeopathisch of plantaardig middel) of ATC-groep bij 15-jarigen het gebruik van dezelfde geneesmiddelencategorie of ATC-groep bij 10-jarige leeftijd was. Klaarblijkelijk richt zich het geneesmiddelen gebruik niet alleen op noodzaak, maar zou het ook op geijkte patronen kunnen wijzen. Een voor de hand liggende conclusie is dat het medicijngebruik door kinderen, voor een deel, al bepaalt welk soort geneesmiddel ze als jongere of volwassene zullen gebruiken.

Sociaal-economische factoren werden ook geassocieerd met de prijzen van OTCgeneesmiddelen. Gemiddeld genomen was de prijs van OTC-geneesmiddelen bij jongeren uit München en jongeren met ouders uit de hoogste categorie van opleiding en inkomen, het hoogst. De resultaten waren voor woonplaats en opleiding van de vader significant. Over het algemeen lijkt het alsof het bedrag van 10 euro voor een geneesmiddel een psychologische grens aangeeft, aangezien $75 \%$ van alle OTCgeneesmiddelen minder dan 10 euro kosten. In dit verband zou van leidinggevende functionarissen in het gezondheidssysteem in acht genomen moeten worden, dat nietvergoede doch medisch gezien zinvolle OTC-geneesmiddelen mogelijk juist door kinderen uit sociaal-economisch zwakke lagen minder gebruikt worden.

Het onderzoek werd door het actuele Europese Thema van noodcontraceptiva gecompleteerd. In november 2014 gaf de Europese geneesmiddelenautoriteit EMA de aanbeveling om de status voor het contraceptivum Ulipristalacetaat zodanig te wijzigen dat er geen recept van de arts meer voor nodig is. Ondanks het feit dat de mogelijkheid bestaat het besluit van de EMA te omzeilen, is in de meeste EU-landen de aanbeveling opgevolgd en heeft men binnen een jaar na het besluit in de nationale regelgeving vastgelegd. Sinds deze verandering is het gebruik van noodcontraceptiva in Duitsland en andere Europese landen aanmerkelijk toegenomen.

Samenvattend mag geconcludeerd worden dat het geneesmiddelengebruik bij kinderen, met name de geneesmiddelen die zonder recept verkrijgbaar zijn (en die een aanzienlijk deel van alle genomen middelen vormen), significant afhangt van de sociaaleconomische achtergrond. Dit zou implicaties kunnen hebben in zoverre, dat kinderen en jongeren uit sociaal-economisch zwakkere lagen mogelijkerwijs minder (medisch 
aanbevolen) geneesmiddelen nemen als ze uit eigen zak betaald moeten worden, niet in het minst ook omdat hogere prijzen van OTC-geneesmiddelen kennelijk met een hogere sociaal-economische status geassocieerd zijn. Tegen deze achtergrond zou de lijst van vergoede medicatie aangepast moeten worden in die landen waar OTCgeneesmiddelen normaalgesproken niet door de ziektekostenverzekering worden vergoed. Hoe dan ook, geneesmiddelen, zowel op recept als vrij verkrijgbaar, zouden hun status als bijzonder product moeten behouden. Derhalve zouden beslissingen over de vergoedingsmogelijkheden van geneesmiddelen zorgvuldig afgewogen moeten worden, evenals besluiten inzake liberalisering van de verkoop van geneesmiddelen, die geneesmiddelen buiten apotheken toegankelijk maken zouden, zonder mogelijkheid van medisch of farmaceutisch advies. 


\section{Zusammenfassung}

Das Hauptziel der Untersuchungen dieser Dissertation war die Analyse des Arzneimittelgebrauchs bei Kindern, sowohl hinsichtlich der Prävalenz des Gebrauchs als auch in Bezug auf die sozioökonomischen Prädiktoren der Arzneimittelanwendung. Der Schwerpunkt wurde auf den Arzneimittelgebrauch bei Kindern und Jugendlichen in Deutschland gelegt, da aktuelle Daten aus der 15-Jahres-Untersuchung zweier fortlaufender deutscher Geburtskohorten verfügbar waren. Die Analyse wurde nicht auf konventionelle Arzneimittel begrenzt, sondern schloss auch alternative Arzneimittel wie z.B. homöopathische oder pflanzliche Mittel mit ein. Ferner wurde sowohl der Gebrauch verschriebener Arzneimittel als auch die Selbstmedikation erfasst.

Der Ausgangspunkt der Forschungsarbeit war ein systematischer Review zum Gebrauch komplementärer und alternativer Arzneimittel (CAM) durch Kinder in Europa, im Vergleich zum CAM Gebrauch in Nordamerika und anderen Regionen. Von 58 eingeschlossenen Studien wurden 49 Studien in Europa oder Nordamerika durchgeführt, während lediglich 9 Studien den CAM Gebrauch in Australien/Neuseeland oder Südamerika untersuchten. Ein wesentliches Ergebnis war, dass der Schätzer für die Prävalenz des Homöopathiegebrauchs in Europa (1-Jahres-Prävalenz: 8,98\%) etwa dreimal über dem Wert für Nordamerika (1-Jahres-Prävalenz: 3,08\%) liegt, während für den Gebrauch pflanzlicher Mittel nur ein geringer Unterschied zwischen beiden Regionen zu sehen ist (1-Jahres-Prävalenz: 13,53\% für Europa und 12,05\% für Nord Amerika). Studien mit ausschließlich chronisch kranken Kindern wurden aus dem Review wegen einer vermuteten Verfälschung in Richtung eines höheren CAM Gebrauchs ausgeschlossen. Diese vermutete Verzerrung konnte auch durch eine weitere, separat durchgeführte Untersuchung nachgewiesen werden.

Ein detaillierter Blick auf den CAM Gebrauch in Deutschland zeigte recht hohe Prävalenzraten (Gebrauch während der letzten 4 Wochen) von Homöopathika (7,5\%) und pflanzlichen Mitteln (5,6\%) bei Jugendlichen. Ein vermehrter Gebrauch von Homöopathika wird signifikant vom weiblichen Geschlecht und dem Wohnort „München“ (im Vergleich zum Wohnort "Wesel“ in Nordwestdeutschland) bestimmt, wohingegen der Gebrauch pflanzlicher Mittel in positiver Weise vom höheren Bildungsgrad der Mutter bestimmt wurde. Im Vergleich zu den Ergebnissen der Untersuchung derselben Kohorte im Alter von 10 Jahren halbierte sich der Gebrauch von Homöopathika durch 15-jährige Jugendliche, und der Gebrauch pflanzlicher Mittel ging um mehr als ein Drittel zurück. Dies mag zum Teil auf der Tatsache beruhen, dass komplementäre und alternative Arzneimittel im Regelfall nur bis zu einem Alter von 12 Jahren durch die gesetzlichen Krankenkassen in Deutschland übernommen werden.

Die anschließende Untersuchung setzte ihren Schwerpunkt auf den Vergleich von verschreibungspflichtigen mit nicht verschreibungspflichtigen Arzneimitteln (OTC- 
Arzneimittel), die von 15-jährigen Jugendlichen verwendet wurden, unter Berücksichtigung jeglicher Arzneimittel (sowohl konventionelle als auch alternative Mittel). Die Resultate zeigten, dass der Gebrauch von OTC-Arzneimittel (die etwa 69\% aller verwendeten Mittel ausmachten und die im Regelfall nicht von den gesetzlichen Krankenkassen übernommen werden) von sozioökonomischen Faktoren wie z.B. mütterlicher Bildung abhing, wohingegen kein Unterschied zwischen den einzelnen sozioökonomischen Schichten bezüglich des Gebrauchs verschreibungspflichtiger Mittel festzustellen war.

Die longitudinale Analyse des Arzneimittelgebrauchs ergab, dass der stärkste Prädiktor des Gebrauchs einer definierten Arzneimittelkategorie (konventionelle, homöopathische oder pflanzliche Mittel) oder ATC-Gruppe durch 15-jährige Jugendliche der Gebrauch der gleichen Arzneimittelkategorie oder ATC-Gruppe im Alter von 10 Jahren war. Offenbar orientiert sich der Arzneimittelgebrauch nicht nur an der Notwendigkeit, sondern könnte auch gewohnheitsmäßige Muster aufweisen. Dies legt den Schluss nahe, dass der Arzneimittelgebrauch durch Kinder zum Teil schon mit bestimmt, welche Art Arzneimittel sie als Jugendliche oder Erwachsene verwenden werden.

Sozioökonomische Faktoren waren auch mit den Preisen von OTC-Arzneimitteln assoziiert. Im Durchschnitt war der Preis der OTC-Arzneimittel bei Jugendlichen aus München und Jugendlichen mit Eltern aus der obersten Bildungsstufe am höchsten. Die Ergebnisse waren für Wohnsitz und väterliche Bildung signifikant. Generell scheint es, als ob der Preis von 10 Euro für ein OTC-Arzneimittel eine psychologische Barriere darstellt, da 75\% aller OTC-Arzneimittel weniger als 10 Euro kosteten. In diesem Zusammenhang sollte von Führungskräften im Gesundheitssystem berücksichtigt werden, dass nicht erstattungsfähige aber medizinisch sinnvolle OTC-Arzneimittel möglicherweise gerade von Kindern aus sozioökonomisch schwächeren Schichten weniger genutzt werden.

Die Untersuchungen wurden durch das aktuelle europäische Thema der Notfallkontrazeptiva vervollständigt. Im November 2014 sprach die europäische Arzneimittelbehörde EMA die Empfehlung aus, den Status für das Notfallkontrazeptivum Ulipristalacetat von „verschreibungspflichtig“ auf „nicht verschreibungspflichtig“ zu ändern und es somit ohne Erfordernis einer ärztlichen Verordnung frei zugänglich zu machen. Obwohl die Möglichkeit gegeben ist, den Beschluss der EMA zu umgehen, sind die meisten EU-Länder der Empfehlung gefolgt und haben den Beschluss innerhalb eines Jahres in nationales Recht umgesetzt. Seit der Umstellung hat der Gebrauch von Notfallkontrazeptiva in Deutschland und anderen europäischen Ländern spürbar zugenommen.

Zusammenfassend mag der Schluss gezogen werden, dass der Arzneimittelgebrauch bei Kindern, vor allem solcher Arzneimittel, die ohne ärztliche Verschreibung erhältlich sind (und die einen beträchtlichen Teil aller genommenen Mittel ausmachen), signifikant vom sozioökonomischen Hintergrund abhängt. Dies könnte Implikationen 
haben in soweit, als dass Kinder und Jugendliche aus sozioökonomisch schwächeren Verhältnissen möglicherweise weniger (medizinisch ratsame) Arzneimittel nehmen, wenn sie aus eigener Tasche bezahlt werden müssen, nicht zuletzt auch weil höhere Preise der OTC-Arzneimittel offensichtlich mit einem höheren sozioökonomischen Status assoziiert sind. Vor diesem Hintergrund könnte die Liste der erstattungsfähigen Arzneimittel in den Ländern überdacht werden, in denen OTC-Arzneimittel üblicherweise nicht von den gesetzlichen Krankenkassen übernommen werden. Wie auch immer, Arzneimittel, sowohl verschreibungspflichtige als auch nicht verschreibungspflichtige, sollten ihren Status als besondere Produkte beibehalten. Daher sollten Entscheidungen über die Erstattungsfähigkeit von Arzneimitteln sorgfältig abgewägt werden, ebenso wie auch Beschlüsse zwecks Liberalisierung des Arzneimittelverkaufs, die Arzneimittel außerhalb von Apotheken zugänglich machen würden, ohne Möglichkeit einer medizinischen oder pharmazeutischen Beratung. 


\section{Riassunto}

L'obiettivo principale della ricerca di questa tesi è stato l'analisi dell'uso pediatrico di medicinali, sia per quanto riguarda la prevalenza sia per i predittori socioeconomici dell'uso dei farmaci. L'accento è stato posto sull'uso di farmaci tra bambini ed adolescenti residenti in Germania, visto che erano disponibili dati attuali dall'indagine di una coorte di nascita eseguita all'età di 15 anni. L'analisi non è stata limitata a medicinali convenzionali ma ha considerato anche medicinali alternativi come rimedi omeopatici o fitoterapici. Inoltre, è stato rilevato sia l'uso di medicinali soggetti a prescrizione medica sia quelli di auto-medicazione.

Il punto di partenza della ricerca è stata la revisione sistematica sull'uso della medicina complementare e alternativa (CAM) riguardante i bambini in Europa, rispetto all'uso di CAM nell'America settentrionale ed altre regioni. Di 58 studi inclusi 49 in totale sono stati condotti in Europa e nell'America del Nord, mentre solo 9 studi hanno analizzato I'uso di CAM in Australia/Nuova Zelanda o nell'America del Sud. Tra i risultati più importanti c'è stato che lo stimatore per l'uso dell'omeopatia in Europa (prevalenza annuale: $8,98 \%$ ) è stato superiore all'incirca tre volte del valore in America settentrionale (prevalenza annuale: $3,08 \%$ ), mentre per l'uso dei farmaci fitoterapici è stata rilevata solo una lieve differenza tra le due regioni (prevalenza annuale: 13,53\% in Europa e $12,05 \%$ per L'America dell'Nord). Studi condotti esclusivamente con bambini ammalati di disturbi cronici sono stati eliminati dalla revisione sistematica con motivazione di una possibile falsificazione a raggione di un uso più elevato di CAM. Questa distorsione ipotizzata è stata possibile di verificarla tramite un'altra indagine condotta separatamente.

Un esame più dettagliato dell'uso di CAM in Germania ci mostra rate di prevalenza d'uso abbastanza elevate da parte degli adolescenti (uso durante le 4 settimane precedenti) per l'omeopatia $(7,5 \%)$ e la fitoterapia $(5,6 \%)$. II sesso femminile e la ripartizazione geografica "Monaco di Baviera" (rispetto al luogo di residenza "Wesel" nel nordovest della Germania) sono predittori significativi dell'uso di rimedi omeopatici, mentre adolescenti con madri di un livello di istruzione più alto hanno mostrato un maggiore ricorso alla fitoterapia. In confronto ai risultati dell 'indagine sulla stessa coorte all'età di 10 anni, l'uso di omeopatia a parte di adolescenti quindicenni si dimezza e il ricorso a medicinali fitoterapici si è ridotto di più di un terzo. Ciò può essere in parte dovuto al fatto che medicinali complementari e alternativi vengono rimborsati dalla sanità pubblica tedesca normalmente solo fino all'età di 12 anni.

L'indagine successiva ha posto l'accento sul confronto dell'uso a parte di adolescenti quindicenni di medicine soggette a prescrizione medica con farmaci da banco ( $\mathrm{FdB}$ ), considerando tutte le medicine usate (sia convenzionali sia alternative). I risultati hanno mostrato che l'uso dei farmaci da banco (che costituiscono all'incirca il 69\% di 
tutti i farmaci usati e che normalmente non sono coperti dalla sanità pubblica) dipende da fattori socioeconomici quali ad esempio il livello di istruzione della madre, mentre non sono state visibili differenze notevoli tra le classi socioeconomiche relative all'uso di farmaci con obbligo di prescrizione.

L'analisi longitudinale dell'uso di farmaci ha mostrato, che il predittore più potente dell'uso di una specifica categoria di medicinali (convenzionali, omeopatici o fitoterapici) o di una classe definita secondo la classificazione anatomica, terapeutica e chimica (ATC) a parte di adolescenti quindicenni è stato l'uso della stessa categoria di medicinali o classe ATC all'età di 10 anni. Evidentemente, I'uso dei farmaci non dipende solo dalla necessità, ma presenta anche caratteristiche abituali. Questi dati suggeriscono la conclusione che l'uso di farmaci da parte di bambini già determina parzialmente il tipo di medicinale che userà da adolescente o adulto.

Fattori socioeconomici erano anche associati ai prezzi dei farmaci da banco. In media, i prezzi più elevati pagati per un farmaco da banco si registrano tra adolescenti residenti a Monaco e adolescenti con genitori dal livello di istruzione superiore. I risultati erano significativi per il luogo di residenza e per il livello di istruzione del padre. In linea generale, sembra che il prezzo di 10 Euro per un farmaco da banco potrebbe costituire una barriera psicologica, visto che il $75 \%$ dei farmaci da banco hanno prezzi inferiore a 10 Euro. A tale riguardo, i quadri dirigenti nel settore della sanità pubblica dovrebbero considerare che bambini provenienti da famiglie con un livello socioeconomico più basso fanno possibilmente meno uso di farmaci da banco non rimborsabili ma medicalmente sensati.

La ricerca è stata completata dall'argomento attuale europeo dei contraccettivi di emergenza. Nel novembre 2014 l'agenzia del farmaco europea (EMA) ha raccomandato di modificare lo stato legale del contraccettivo di emergenza "ulipristal acetato" da soggetto a prescrizione medica a non soggetto a prescrizione medica e quindi da renderlo accessibile senza necessità di una ricetta medica. Nonostante la possibilità di eludere la decisione dell'EMA, la maggior parte degli stati membri dell'Unione Europea hanno seguito la raccomandazione e hanno trasformato entro un anno il suggerimento in legge nazionale. A partire dalla conversione l'uso di contraccettivi di emergenza è aumentato notevolmente in Germania e altri paesi europei.

In sintesi si può concludere, che l'uso dei farmaci da parte di bambini, in prima linea farmaci non soggetti a prescrizione medica (quali costituiscono una parte considerevole di tutti I farmaci usati) dipende significativamente dal sottofondo socioeconomico. Ciò potrebbe implicare che bambini e adolescenti provenienti da contesti socioeconomici svantaggiati probabilmente fanno meno ricorso a farmaci (medicalmente consigliabili) se devono essere pagati di tasca propria, non ultimo anche perché prezzi più elevati per farmaci da banco potrebbero essere associati a uno status socioeconomico più alto. Su tale base, la lista di farmaci non rimborsabili potrebbe essere riesami- 
nata nei paesi dove farmaci da banco normalmente non sono coperti dalla sanità pubblica. Ad ogni modo, farmaci, soggetti o non soggetti a prescrizione medica, dovrebbero mantenere il loro stato di prodotto speciale. Perciò decisioni sulla rimborsabilità dovrebbero essere valutate attentamente, come anche deliberazioni allo scopo di liberalizzare la vendita di farmaci che potrebbero essere reperiti all'infuori delle farmacie senza possibilità di consultazione medica o farmaceutica. 


\section{Contributing authors}

Following authors contributed to this thesis:

$\begin{array}{ll}\text { AB } & \text { Andrea von Berg } \\ \text { CT } & \text { Christina Maria Teuner } \\ \text { DB } & \text { Dietrich Berdel } \\ \text { HB } & \text { Helmut Brand } \\ \text { IB } & \text { Irene Brüske } \\ \text { IL } & \text { Irina Lehmann } \\ \text { JH } & \text { Joachim Heinrich } \\ \text { MS } & \text { Marie Standl } \\ \text { SI } & \text { Salvatore Italia } \\ \text { SW } & \text { Silke Britta Wolfenstetter }\end{array}$

The authors' contributions to the publications are stated in the respective chapters as published in the journals. In chapters 2 and 8, the authors' contributions were not published by the journal and are therefore stated as follows:

Chapter 2 (Patterns of Complementary and Alternative Medicine (CAM) use in children: a systematic review)

SI performed the literature search, screened all included studies, extracted the relevant figures on CAM use, contacted the corresponding authors, and performed the quality assessment. Furthermore, he initialized the first draft of the manuscript and approved the final manuscript as submitted. SI and CT were involved in the meta-analysis that was finalized by two further statistical experts as stated in the acknowledgement section of chapter 2 . SW and CT critically revised the initial manuscript and approved the final manuscript as submitted.

Chapter 8 (Status of emergency contraceptives in Europe one year after the European Medicines Agency's recommendation to switch ulipristal acetate to non-prescription status)

SI designed the study and contacted all authorities and pharmaceutical organizations. He conceptualized the initial manuscript and approved the final manuscript as submitted. HB critically revised the initial manuscript and approved the final manuscript as submitted. 


\section{Annotations}

The questionnaires for the 15-year follow-up were collected until September 2013 for the GINIplus study, whereas the data collection for the LISAplus study was only completed in October 2014. Therefore, chapters 4 and 5, which were among the first chapters by chronological order, considered data from the GINIplus study only. In the process of the PhD trajectory, data for the LISAplus cohort were also available and, hence, were used for chapters 3,6 , and 7 .

Chapters 2-8 correspond to the manuscripts as published by the journals or to the versions submitted to the journals in case they were still under review at the time of submitting the dissertation to the assessment committee. Owing to the journals' different editing and requirements, the format is not uniform across the dissertation's chapters, e.g., with regard to spelling (American English or British English), reference style, or the use of thousand separators. Furthermore, the orthography of medical terms may vary between the articles' published version and the dissertation, for instance 'antiinflammatory' (journal's version) vs. 'antiinflammatory' (as partly used in the dissertation, based on the WHO collaborating centre for drug statistics methodology). Because of limited margins, some tables were modified slightly (e.g. by using abbreviations that were not used in the original publications). 


\section{Abbreviations}

ATC

CAM

$\mathrm{Cl}$

DDD

EFTA

EMA

EMC

EU

GINIplus

LISAplus

LNG

MEI

OECD

$\mathrm{OR}$

OTC (drug)

PZN

$\mathrm{Rx}$ (drug)

UPA

WHO
Anatomical therapeutic chemical classification

Complementary and alternative medicine

Confidence interval

Defined daily dose

European Free Trade Association

European Medicines Agency

Emergency contraceptive

European Union

German infant study on the influence of nutrition intervention plus environmental and genetic influences on allergy development

Influence of lifestyle factors on the immune system and allergies in East and West Germany plus the influence of traffic emissions and genetics

Levonorgestrel

Median equivalent income

Organisation for Economic Co-operation and Development

Odds ratio

Over-the-counter (drug)

Pharmazentralnummer (pharmaceutical identification number)

Prescription (drug)

Ulipristal acetate

World Health Organisation 


\section{Acknowledgements}

I would like to thank Professor Dr Helmut Brand for supervising this thesis and for his confidence that the Public Health aspects of drug utilization could open a new field of activity within the Department of International Health at Maastricht University.

I also want to thank my co-supervisor Dr Silke Wolfenstetter for support as well as Maastricht University for allowing me the possibility to carry out my PhD project. Furthermore, I want to thank all contributing coauthors and the Helmholtz Zentrum Munich for their help and advice. A warm 'Thank you' to Heather Hynd for the linguistic revision of the manuscripts in English, to Michele Finelli for the linguistic revision of the Italian summary, to Anita Creusen for the Dutch translation of the summary, and to my sister Nadia, who had a final editing view on the thesis as a proof-reader.

I would like to dedicate this dissertation to my family and my friends who always showed great interest and confidence in my work. 


\section{Curriculum vitae}

Salvatore Italia, son of Italian parents who emigrated from Sicily to Germany in the early 1960s, was born in Ulm (Germany) on 7 July 1967 and grew up in Southern Germany. He attended primary school at the 'Grundschule Wullenstetten' and received the general German qualification for university entrance ('Abitur') at the 'NikolausKopernikus-Gymnasium' in Weißenhorn (Bavaria) in 1986. Afterwards, he started his academic career at the University of Applied Sciences in Ulm, where he enrolled for electrical engineering. During the first 6 months, he did an internship at Mannesmann Tally, a computer printer producing company. In 1987, he decided to change to the life science sector and began his studies of pharmacy at the Eberhard Karls Universität Tübingen, motivated not least by the fact that pharmacy contained both aspects of natural sciences with a strong chemical emphasis and medicine as well. The study included 6 months of internship at a community pharmacy and a further 6 months at the hospital pharmacy of the university hospital Ulm. After 5 years of study, he gained his degree in December 1992. On completion of his studies, he spent some time abroad in Australia and Italy before starting work as a pharmacist at a community pharmacy in Aalen in November 1993. In 2008, Salvatore accepted a new professional challenge and joined JRS Pharma, a leading company of the pharmaceutical excipients branch, where he worked as an Area Manager for Germany until 2010, which included both commercial and technical assistance for customers in Germany. Simultaneously, he started his postgraduate studies in Public Health at the Ludwig-Maximilians-Universität Munich in October 2009. He completed his Master's thesis at the Helmholtz Zentrum Munich (German Research Center for Environmental Health) and received the Master of Public Health in October 2011. In 2012, he took up a position as head of a branch pharmacy at the medical centre in Biberach (Germany). The working conditions were adjusted in accordance with the pharmacy owner to ensure that Salvatore could also start his external PhD trajectory with the Department of International Health at Maastricht University. His private interests include earth and marine sciences, cycling, and hiking. 


\section{International workshops/conferences/presentations}

Tirana, Albania, 24/25 April 2012

International PhD workshop

Glasgow, Scotland, United Kingdom, 19-22 November 2014

European Public Health Conference 2014

Poster presentation ('Patterns of Complementary and Alternative Medicine (CAM) use in children: a systematic review')

Munich, Germany, 24/25 November 2014

GINI study group meeting

Oral presentation ('GINIplus Studie: 15-Jahres Follow-up-Erste Ergebnisse zur Arzneimittelinanspruchnahme')

Maastricht, The Netherlands, 25-27 June 2015

European Congress of Epidemiology 2015

Poster presentation ('Drug utilization among 10-year-old children and 15-year-old adolescents from the German GINIplus and LISAplus birth cohorts')

Munich, Germany, 2-5 September 2015

$111^{\text {th }}$ Annual Meeting of the German Society for children's and adolescents' health Oral presentation ('Arzneimittelgebrauch 15jähriger Jugendlicher: Ergebnisse der GINIplus- und LISAplus-Geburtskohortenstudien')

Milan, Italy, 14-17 October 2015

European Public Health Conference 2015

Poster presentation ('Use of prescribed and self-medicated drugs among adolescents from the GINIplus/LISAplus birth cohorts') 


\section{Public Health related publications}

Italia S, Batscheider A, Heinrich J, Wenig C, Bauer CP, Koletzko S, Lehmann I, Herbarth O, von Berg A, Berdel D, Hoffmann B, Schaaf B, Wolfenstetter SB. Utilization and costs of conventional and alternative pharmaceuticals in children: results from the German GINIplus and LISAplus birth cohort studies. Pharmacoepidemiol Drug Saf. 2012; 21:1102-1111. DOI:10.1002/pds.3323

Italia S, Wolfenstetter SB, Teuner CM. Patterns of Complementary and Alternative Medicine (CAM) use in children: a systematic review. Eur J Pediatr. 2014;173:1413-1428. DOI:10.1007/s00431-014-2300-z

Italia S, Brand H, Heinrich J, Berdel D, von Berg A, Wolfenstetter SB. Utilization of complementary and alternative medicine (CAM) among children from a German birth cohort (GINIplus). BMC Complement Altern Med. 2015;15:49. DOI:10.1186/s12906-0150569-8

Italia S, Brand H, Heinrich J, Berdel D, von Berg A, Wolfenstetter SB. Utilization of selfmedication and prescription drugs among 15-year-old children from the German GINIplus birth cohort. Pharmacoepidemiol Drug Saf. 2015;24:1133-1143. DOI:10.1002/pds.3829

Italia S, Brüske I, Heinrich J, Berdel D, von Berg A, Lehmann I, Standl M, Wolfenstetter SB. A longitudinal comparison of drug use among 10-year-old children and 15-year-old adolescents from the German GINIplus and LISAplus birth cohorts. Eur J Clin Pharmacol. 2016;72:301-310. DOI:10.1007/s00228-015-1977-x

Italia S, Brand $\mathrm{H}$. Status of emergency contraceptives in Europe one year after the European Medicines Agency's recommendation to switch ulipristal acetate to nonprescription status. Public Health Genomics. 2016. DOI:10.1159/000444686 [in press]

Italia S, Brüske I, Heinrich J, Berdel D, von Berg A, Lehmann I, Standl M, Wolfenstetter SB. Complementary and alternative medicine (CAM) use among chronically ill adolescents from two German birth cohorts. Forsch Komplementmed. 2016 [in press] 
ISBN: 9789461595935 